\title{
Factors affecting the competitive position of the poultry industry in West Virginia and in other regions
}

H. C. Kriesel

Follow this and additional works at: https://researchrepository.wvu.edu/ wv_agricultural_and_forestry_experiment_station_bulletins

\section{Digital Commons Citation}

Kriesel, H. C., "Factors affecting the competitive position of the poultry industry in West Virginia and in other regions" (1966). West Virginia Agricultural and Forestry Experiment Station Bulletins. 529.

https://researchrepository.wvu.edu/wv_agricultural_and_forestry_experiment_station_bulletins/485 @ WVU. It has been accepted for inclusion in West Virginia Agricultural and Forestry Experiment Station Bulletins by an authorized administrator of The Research Repository @ WVU. For more information, please contact ian.harmon@mail.wvu.edu. 
West Virginia University Libraries (1)

(1)

308021009521334 


\section{Digitized by the Internet Archive in 2010 with funding from \\ Lyrasis Members and Sloan Foundation}




\section{Factors Affecting the Competitive}

\section{Position of the Poultry Industry in}

\section{West Virginia and in Other Regions}

$$
\begin{aligned}
& \text { AG-ENG LIBRARY } \\
& \text { WEST VIRGINIA } \\
& \text { UNIVERSITY }
\end{aligned}
$$

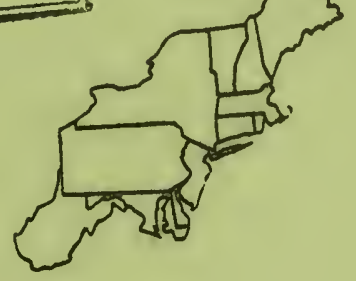

West Virginia University

Agriculfural Experiment Station 
THE AUTHOR

H. C. Kriesel, at the time of this study, was a Research Associate in Agricultural Economics.

This bulletin is published as a contribution to a Northeast Regional Marketing Research Project (NEM-2l), "Adjustments Needed to Enhance the Competitive Position of West Virginia in Marketing Broiler Products." Research basic to the data included was supported by both State and regional research funds.

West Virginia University Agricultural Experiment Station College of Apriculture and Forestry

A. H. Vantandingham, Director Morgantown 


\section{PREFACE}

The preponderence of low personal incomes in West V1rginia and 3 ec tions of surrcunding states has been in the national spotligit for egrytral years. Not only are the people of thls area falling to share filiy lu the forward surge in the natlonal economy, but prevaling condirions are ytewad as a deterrent to even more Eavorable progress. Henca, thare is an urguny that the nature and causes of the phenomenon be identifled ard, there possible, the causal influences measured. This calls for increass atsturton by economists, with appropriate particlparton by other swelai scientst3.

The broiler industry began to make significant contriburlons ro the net agricultural income in West Virginfa about three decades ago. A healthy condition prevailed through the $1940^{\circ} \mathrm{s}$, and inco the car $1 \mathrm{y} 1950^{\circ} \mathrm{s}^{\circ}$

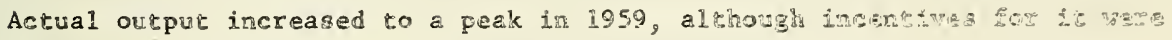

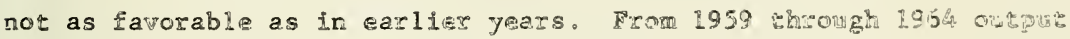
dropped about 40 per cent and, in addition, the not incone realized per bird has been smaller than in earlier years. Hotereny there are Lre.

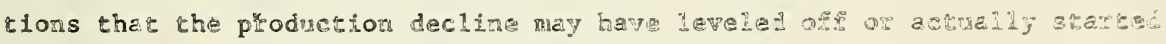
back up In 1965. While production figures are aot yer araliable for logs, placements vere up from $17,635,000$ birdz in 1964 to $18,260,000$ B.

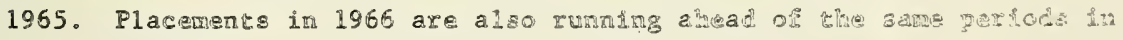
1965.

The egg industry of West Pirgind has bsen on a downtert sor a wht longer perlod than broilers, although swbsantial interral Geanges for

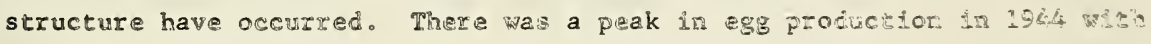
561 million eggs and a minor peak in 1960 with 384 millon eggs. Slace 
1960, the trend has again been downward bort ats a diminishing rate. Egg production appears to be leveling off with 327 million eggs in 1964 and $318 \mathrm{million}$ eggs in 1965.

The research reported herefn was undertaken for the purpose of (1) identifying the factors which have contributed to the observed declines in West virginfa broller and egg industries, and (2) explaining some of the underlying reasons for the emergence of these factors. The purpose was not to prescribe spectife solutions to problems of the poultry industry of West Virginia, although some of the opportunitien and obstacles for doing this are indicated by the analyses. This information is intended to be helpful to decision-makers of the pirwate and cooperative firms in making long-term plans to ope whth the rapidly changing com petitive condtions.

Because of the heavy rellance op the West Virginia broller lndugry on out-of-state inputs and on out-of-8tate markets for the product, sew eral facets of the study will be of interest to those concerned with firms or industries of the non-farm economy of Weste Wirgtur. Moreover, the analyses themselves suggesi a number of researchable areas of re gional nature relating to the total economis depelopment problem in Appalachia.

The research reported herein was condweted as a pate of the Northeastern Regional Research Project, NER-21. Assistance on the projest was provided by Mrs. Mary Templeton and her staff in the Statstical Laboram tory of this Department and by Graduate Assistanes Arthur Leonard and John Thorn.

Homer C. Evans Assiatant Director Agrieultural Experiment Station 
Introduction.

Some Over-All Developments in the Poultry Industry..............

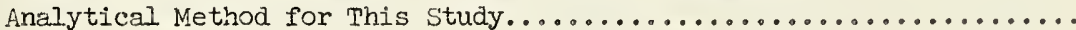

Part I

Some Physical Characteristics of West Virginia and Developments

in Transportation which Affect the Relative Position of the state....

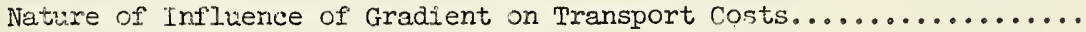

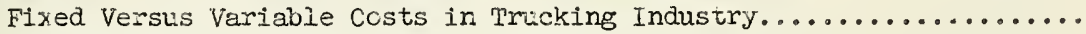

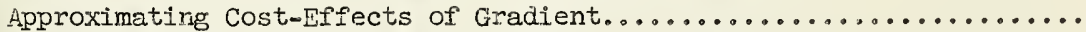

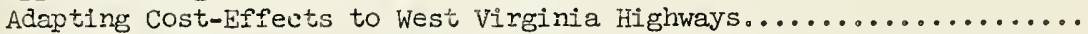

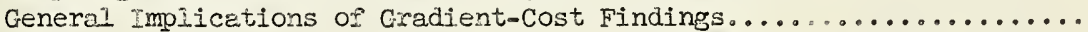

Effects of Terrain on Broiler Production and Marketing Costs.

Technologicai and Institutional Changes in Transportation Contribute

to some Realignments among Regions in Delivered costs of Poultry Feed.

Changes in Indistry Structure Probably had Differential Effects

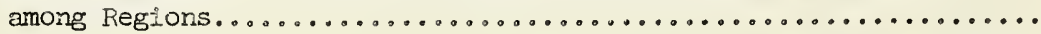

Advances in Production Technology can heve Differential Eifects among

Regions.

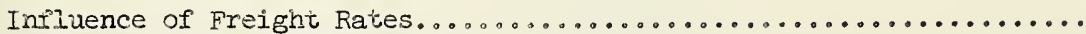

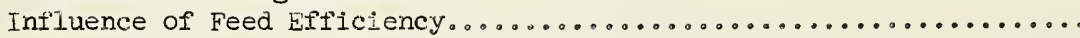

Sources and Nature of Technological Progress....................

\section{Part II}

Important Changes in Relationskips among states.................

Increases in Total Agricultural cutput vary ainong states........... Changes in Broiler Production by Regions and vtates..............

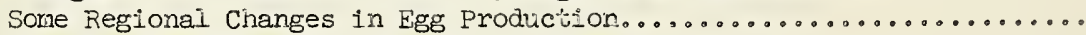
Structure of Farm Producing Units Changing Rapidly............... Changes in West Virginia Vary Considerabiy Among Counties..........

Relative Changes in Factor Prices as Motivations for Regional

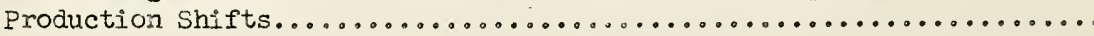

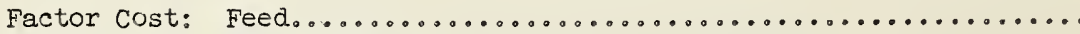

Indications of Shifts in Factor Costs for Broilers Among Regions

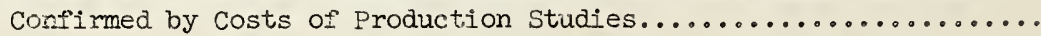


Motivations for Increasing Broller Production ...................... 95

Ablilty of Broller Growers to Accumulate Capitsl.................... 100 Characteristics of Broiler Growers............................... 101 Estimated Value of ChIcken Mamure............................. I03

Part. III

Comparizon of Some Internal Characteristics of Certain States

Producing Brollers and Eggs.................................. 107

Fopulation.............................................112

Employment. ............................................. 113

Velue Added by Manufacture.................................. 114

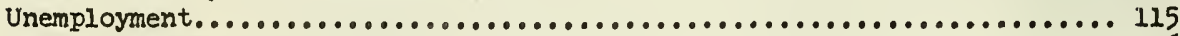

Mediun. Income.............................................. 116

rroportion of Land in Farms................................... 117

Froportion of People in Furming................................. II8

Size of F'arm Enterprise..................................... 1E0

Non-F'arm Employment and Incomes of Farmers...................... leI

Age of Furmers.......................................... 122

Cormunity Efficlency in Broller Production........................ 122

Density of Broller Production.................................. I25

Value of Brollers Solu......................................... les

Relationahip of Beef Cattle to Broller Production................... 128

Appendix A

Background on Institutional and Structural Changes in Transportation

Influencing Locntion of the Poultry Industry in the United States......... 131

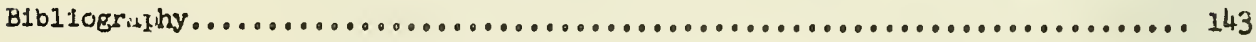

Appundix 'tublet............................................ 147 


\section{SUMMARY}

Production of broilers rose phenomenally in West Virginia, as in many other sections of the United States, from the mid-1930's through most of the 1950's. While national output has continued to rise, the geographical location of production has become quite fluid in the last decade. Currently, broiler production is reported for 42 states, and approximately three-fourths of these have produced a greater number of birds at some time in the recent past than at present. Through 1964, West Virginia ${ }^{\circ}$ s output declined about 40 per cent from the 1959 peak of 27 million birds. The decrease was of greater consequence to West Virginia than to most other states because it was part of an absolute decline of one-fourth in total agricultural physical output (during the last decade), and non-farming alternatives within the State are extremely limited.

For the nation as a whole there appears to have been little, if any, increase in per capita demand for all chicken since World War II. Broilers have been substituted to an increasing extent for the decrease in supplies of chicken emanating from production and maintenance of egg-laying flocks. Aside from this, the large increase in broiler consumption is the result of giant strides in the development and general adoption of new technology. These technological innovations were supply increasing and made necessary successively lower prices to equate supply flows with demand.

The technological innovations may be divided into two categories: (1) Those operating, in effect, within the broiler house, consisting mainly of genetic and nutritional advances; and, (2) the range of developments external to the grow-out phase encompassing those in interregional transport of both inputs and products, the whole gamut of functions at the production 
end such as distribution of feed, assembly and processing of birds, as well as important innovations in retail distribution of finished birds.

Genetic and nutritional advances apparently have been quite uniformly applied in all production areas. Any geographical deviations have been small compared with effects of regional differences in the second category of developments. It is to be recognized, however, that even uniform advances in technology can have differential effects among regions since transport rates per unit of weight are greatly different for inputs (feed) than for the products. Rapid growth of broiler and egg production in the Southeast and South has occurred partly because there was a willingness to accept less remuneration for human inputs than in orher areas. Moreover, capital, to an increasing extent, has been allocated by regional or national integrators and was readily forthcoming once the basic conditions for growth became apparent. Finally, delivered costs of feed to producers declined relative to other areas during the past 10 to 15 years. The latter stemmed initially from introduction of water transport of grain on the Tennessee River, accompanied and, laker, superceded by the growing role of motor truck transport and, most recently, by introduction of a new rail freight service which slightly under-cut the truck rates. As a resurt, in less than 15 years the chick and feed component of the brolier production cost has declined nearly three cents per pound more in Georgia than in Delaware, two areas with apparently equal progress in adoption of efficiencies of conducting business within their respective areas. Prices received have not adjusted commensurately.

The relative disadvantage may have been even more pronounced in West Virginia than in Delawaxe because of the inability to implement as many ex- 
ternal economies due to roughness of terrain. This has made for sparseness of broiler production and greater costs of providing transport and other services. Terrain-related factors apparently add about a half-cent per pound live weight to West Virginia's broller production and marketing costs as compared with Delaware. The half-cent is quite significant because of the narrow margins which prevail in the broiler industry. The rough terrain adds substantially to a wide range of costs of doing business in Appalachia and constitutes a very serious obstacle to any kind of economic development.

As a result of these two sets of conditions - interregional and intraregional - any former comparative advantage enjoyed by West Virginia in broiler production has been eroding away in recent years. Margins between costs of broiler production and farmers' selling prices have narrowed so drastically in many areas that gross receipts per bird in recent years have been less than the net per bird in earlier years. In some other areas, so long as the return was positive, the reduction in margin per bird has been at least partly offset by increasing size of enterprise. Unfortunately, as so often happens in developments of this nature, introduction of a disadvantage from whatever source tends to beget further relative disadvantage, just as a newly found advantage tends to bring further relative advantage. In West Virginia it appears that the disadvantage has progressed to the point that an increasing number of broiler growers have found the sum of variable costs exceeding the price received. The exodus of growers has been both steady and pronounced.

The new rail freight service launched in recent years (early 1963 to the Southeast, late summer 1963 to West Virginia and parts of Maryland and southern Pennsylvania, and mid-1964 to New England) in effect, sharply reducing rail 
rates, was a manifestation of a new national transportation policy in pricing transport services. The implications of it are broad and long-term, although the immediate effect was primarily a shift in mode of grain transport, particularly from trucks, and to some extent from barge to rail. Also, a grain movement has been altered, by-passing some terminal and warehousing facilities resulting in less complete utilization of such facilities. The effects on delivered costs of grain to eastern and southern areas have been rather mild, particularly in comparison with regional readjustments in delivered costs to farmers during the preceding decade or so.

To West Virginia and points eastward through Maryland and to Delaware, the new rates apparently lowered delivered costs about three cents or less, per bushel. This amounted to a little over $\$ 1.00$ per ton of corn but considerably less than $\$ 1.00$ for the mixed broiler feed. New England received little grain by motor trucks in the past. Except for consideration of the value of the "in-transit" privilege, direct comparison therefore can be made between the rates for non-transit (new) service with the conventional kind. On this basis, reduction from central Ohio to upper New England would be on the order of ten cents per 100 pounds, $\$ 2.00$ per ton for whole grain, or a minimum of $\$ 1.25$ per ton of complete broiler ration.

This means less than 2 per cent in terms of costs to producers for the complete ration. On the same basis of comparison, points in lower New England and parts of the Middle Atlantic States would have experienced larger reductions. However, direct comparisons, even in the absence of the trucking factor, have limitations because of the rise in demand for grain near rail terminals in surplus grain areas stemming from increased rail shipments to other areas and other short term factors. On balance, it appears that the 
reduction in delivered costs to New England points has been larger than to points in the mideast, including West Virginia. Further south, the reductions ranged from negligible, near barge terminal points, to several cents per bushel of corn at inland points. On the average, it appears that reductions to the southeast may have been somewhere between those to West Virginia and DelMarVa on the one hand, and those to New England. The price structure for the whole area was lowered slightly, of course, relative to the midwest. To all areas, the reduction in cost has been less for laying rations than for broiler feed since corn makes up a smaller portion in the former.

Although production of both eggs and broilers is shifting to the southeast and south, there are serious questions regarding long-term prospects in these areas. Particularly noteworthy is the disparity in net returns to broiler growers as between Georgia and DelMarVa. Using data on "typical" farms supplied by the Economic Research Service and assuming growers borrow and pay interest on one-third of their assets, attributing for this purpose the return on the other two-thirds to labor, the hourly returns in 1963 were \$1.59 for Maine, \$2.15 for DelMarVa, and $\$ .34$ for Georgia. Conditions within Georgia probably are far from equilibrium, extending to and including investments in education. Over two decades or so, as educational levels are raised and non-farm industry expands more rapidly, higher returns to human factors will be needed if the broiler industry is to be maintained.

The industry is more self-contained in DelMarVa than in most areas, with broilers providing the main market for corn and soybeans. Some relative adversity for that area can be absorbed, therefore, in land values, as well as in returns attributed to labor, thereby possibly making DelMarVa one of the most stable in the eastern United States. 
Egg production also is undergoing major relocational changes with growth in the south and a noticeable dimunution in traditionally important midwestern states. West Virginia's egg output has declined 25 per cent in the past decade and the State now produces just a little over half her consumption. Some of the same obstacles discussed above with respect to broilers exist for egg production and marketing. In general, however, egg production is more likely to be maintained at a significant level because there is little, if any, off-farm processing required and no offal disposal or utilization problems comparable to those encountered in broiler production and marketing.

\section{INTRODUCTION}

The purpose of this project is to identify and, where feasible, to measure the influence of factors which are bringing about changes among regions in relative economic positions for producing broilers and eggs. This was done in the belief that the best way to cope with difficult economic problems, such as those faced by West Virginia, is to courageously analyze the problem as objectively as possible in total and in appropriate sub-parts. The results, together with an understanding of their underlying causes, then should permit a determination of which aspects lend themselves to corrective measures either by individual farmers (or firms), by the industry-at-large, or by society as a whole. Where appropriate, solutions can be devised.

This project initially was addressed only to the comercial broiler industry; the egg industry was added in the latter part of the study period. There was a three-fold reason for the initial choice of broilers: (1) production and marketing functionaries of West Virginia, such as growers, hatcherymen, feed suppliers, and processors, were facing difficult problems 
with the periodic cyclical broiler price movements, occasional heavy out-ofpocket cash losses, and general long-term downward trend in broiler prices and in margins between costs and selling prices, (2) administrators of State agencies such as the Agricultural Experiment Station, Cooperative Extension Service, and the State Department of Agriculture were interested in knowing more about underlying economic developments within this industry; and (3) since broiler production uses relatively more off-broiler-farm and out-ofstate inputs than any other livestock product, some of the principles, methodologies, and conclusions could be applied to the broader economic development problems of the state and area.

Production of broilers was started earlier in West Virginia than in a number of other states which now are relatively much more important. This enterprise contributed importantly to net income of many farm people up to about the middle $1950^{\prime} \mathrm{s}$, although the State's total output at no time exceeded three per cent of total United States production. The number produced reached a peak of 27 million in 1959 , but by 1964 had dropped 40 per cent from that number. However, declines in broiler production have been by no means unique with West Virginia; of 42 states for which broiler production is reported, two-thirds (28) are now producing fewer birds than in their relatively recent past. Fifteen states showed a greater decline from 1958 to 1963 than West Virginia. Persistent increases have occurred in only a portion of these.

Egg production also has been trending downward in West Virginia and apparently little more than half the State ${ }^{p} s$ consumption requirements are now met from within-state production.

Indications are that margins between producers' costs and selling prices have continued to decline. In some years production costs for producing 
either broilers or eggs may exceed gross receipts. It is difficult, therefore, to assess the economic importance of the industry to agriculture or to the economy of the State. From 1953 through 1959 cash receipts from broilers in West Virginia were equivalent to $14-15$ per cent of total cash receipts from farming. In view of the relatively heavier off-farm purchases to produce broilers and the violent fluctuations in the fortunes of the enterprise, the real contributions to agriculture undoubtedly have been quite different amounts. Where contracts provide for a fixed cash payment per unit of output, the contribution could be more readily measured. Where this practice is employed the rate of compensation usually is upwards of $\$ 50.00$ per thousand birds, out of which the farmer frequently furnishes shelter, fuel, litter, and labor. The average sales per farm, annually, in West Virginia in 1959 were 18,000 birds, but was substantially higher in other states.

\section{Some Over-All Developments in The Poultry Industry}

As background for studying trends in relationships among regions and seeking possible explanations underlying them, it is helpful to have some perspective concerning certain aspects of developments in the industries for the country-at-large. For a given commodity, this means becoming aware of certain trends in aggregates and averages which, of course, represent the composite of all producing, distributing, and consuming units. Also, it is necessary to be cognizant of changes relative to some other commodities.

The commercial broiler industry was founded rather recently but has developed rapidly. It started with a backlog of technical knowledge concerning production generated to assist less specialized producers of eggs and chickens. Adequate resources then were forthcoming to solve additional researchable problems as they arose. Simultaneously, vast changes unfolded in 
business-organization aspects of broiler production and distribution. The composite effect was a willingness to produce increasing quantities of broilers at given or declining prices. At the same time there apparently was, in economic terms, at least a maintenance of demand. Production increased rapidly -- six-fold in 15 years -- and prices gradually worked to lower levels to strike successive balances between supply and demand.

Some of the results: per capita consumption of broilers has increased five-fold since World War II and now accounts for more than four-fifths of chicken consumption (Figure 1); retail prices for poultry and eggs have declined sharply relative to all foods (Figure 2); and gross cash receipts to producers from broilers have been relatively stable in recent years despite sizable further increases in production and marketings (Figure 3).

Technology for producing eggs in the United States also has been improved in recent years. As a result, in this case too, producers have been willing to supply increased quantities at a given price. However, even with declining egg prices, both absolutely and relative to other foods, consumers have steadily been reducing egg consumption (Figures 1 and 2). For egg producers in many areas, the results have been narrowing margins and very serious economic conditions. In all regions the producing units are being increased substantially in order to apply improved technologies and to take advantage of more effective business arrangements.

Among the associated or competitive elements affecting the broiler industry, the rising consumer demand for beef undoubtedly has been important (Figure 4). Without this rise, given the increase in consumer incomes that took place, the demand for broilers may have increased noticeably. The rise in beef demand has indirectly affected the egg industry also. It has re- 
sulted in a bidding away of resources for egg production in the midwest, or has provided employment for those resources. At the consumer level, eggs have suffered by two major developments: the practice of eating lighter or no breakfasts, and use of more finally prepared foods. Other developments may also have contributed to the long-term and substantial decline in egg demand, helping to account for decline in cash receipts, despite increased total sales (Figure 5).

The highlights of the related tables and charts using data for the United States are summarized in Table 1.

\section{Analytical Method for This Study}

The procedure for any economic study must be chosen according to the nature of the problem to be analyzed. The narrow objective of this project was to appraise the prospects for West Virginia's producers to maintain and, if possible, to enhance their position in the production and sale of commercial broilers and eggs. The commerclal broiler industry, in turn, was chosen partly because it was symptomatic of the much larger economic development problem facing West Virginia, in particular, and much of Appalachia, in general. The specific study here undertaken falls into the general category of studies entitled "Inquiries into Interregional Competition." But this particular analytical method, as the problem itself, is part of a larger "whole."

Invariably, when the economic welfare of West Virginia is discussed by West Virginians or others concerned with West Virginia, comparison is made between West Virginia and the other states as to levels or trends. This appears to be true in all aspects of economic and social life. In a rapidly developing economy the economic calculus on which hopes for, or expectations of, equality of returns are based is that epitomy of fortunate economic cir- 


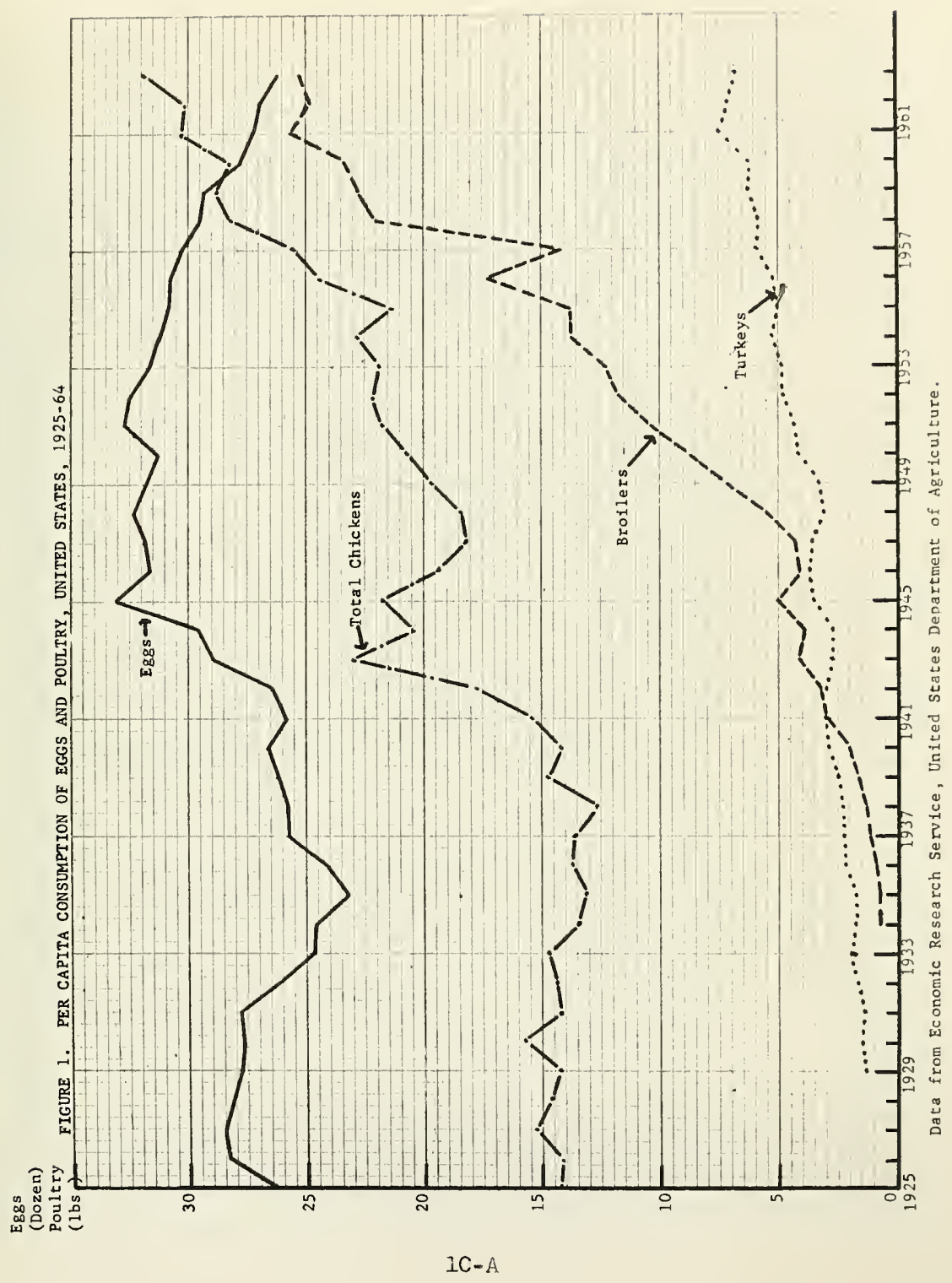




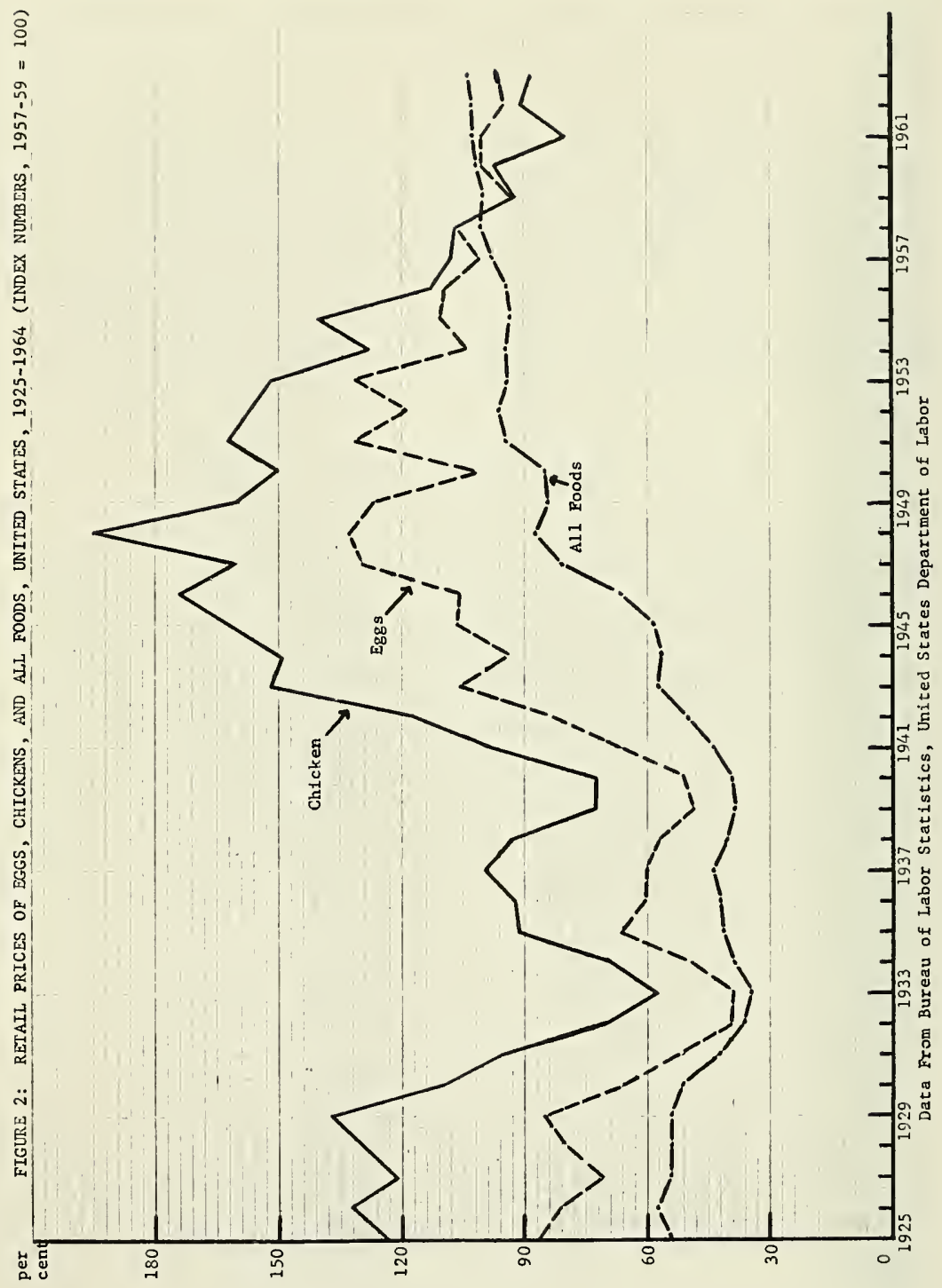



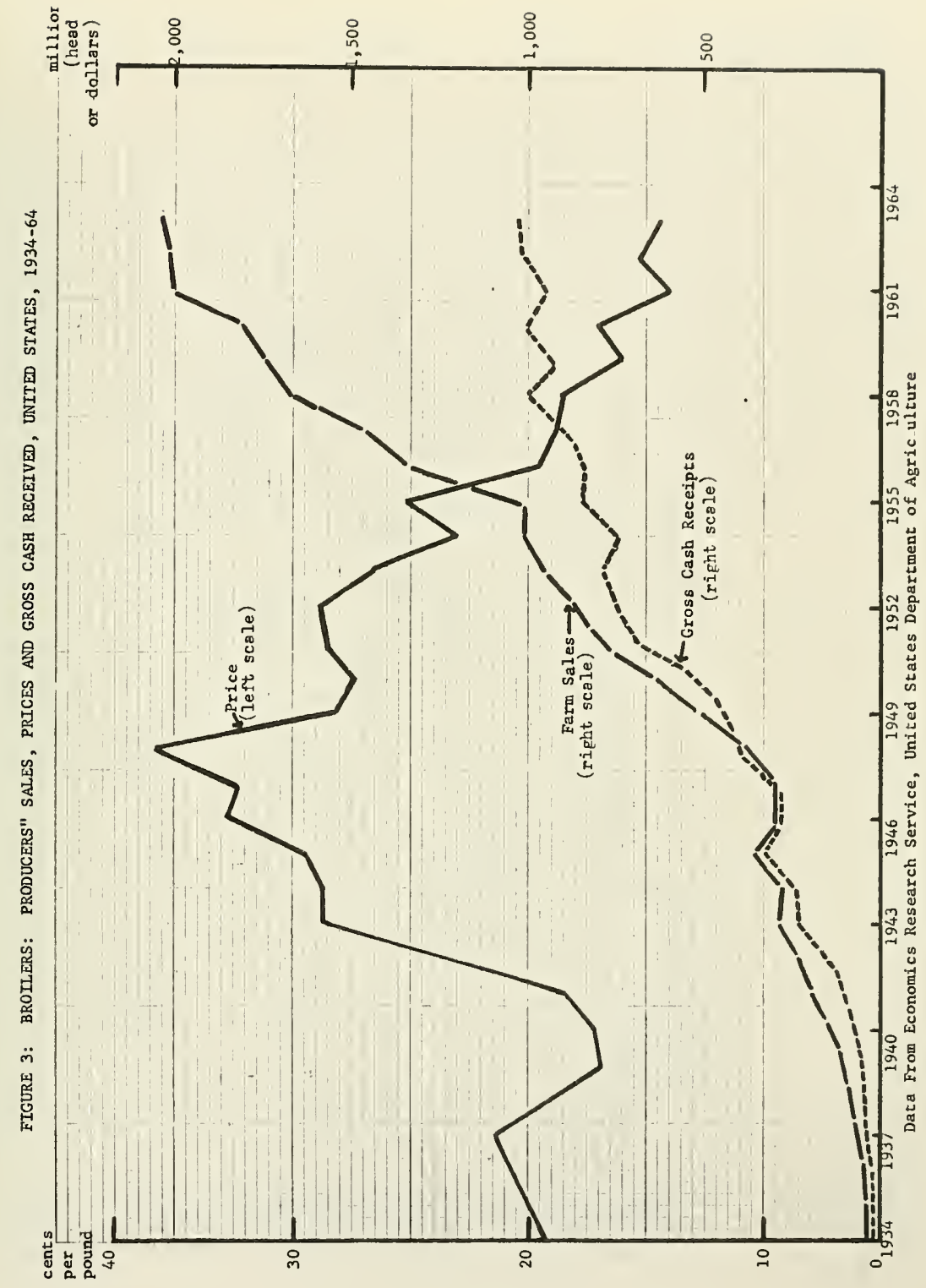


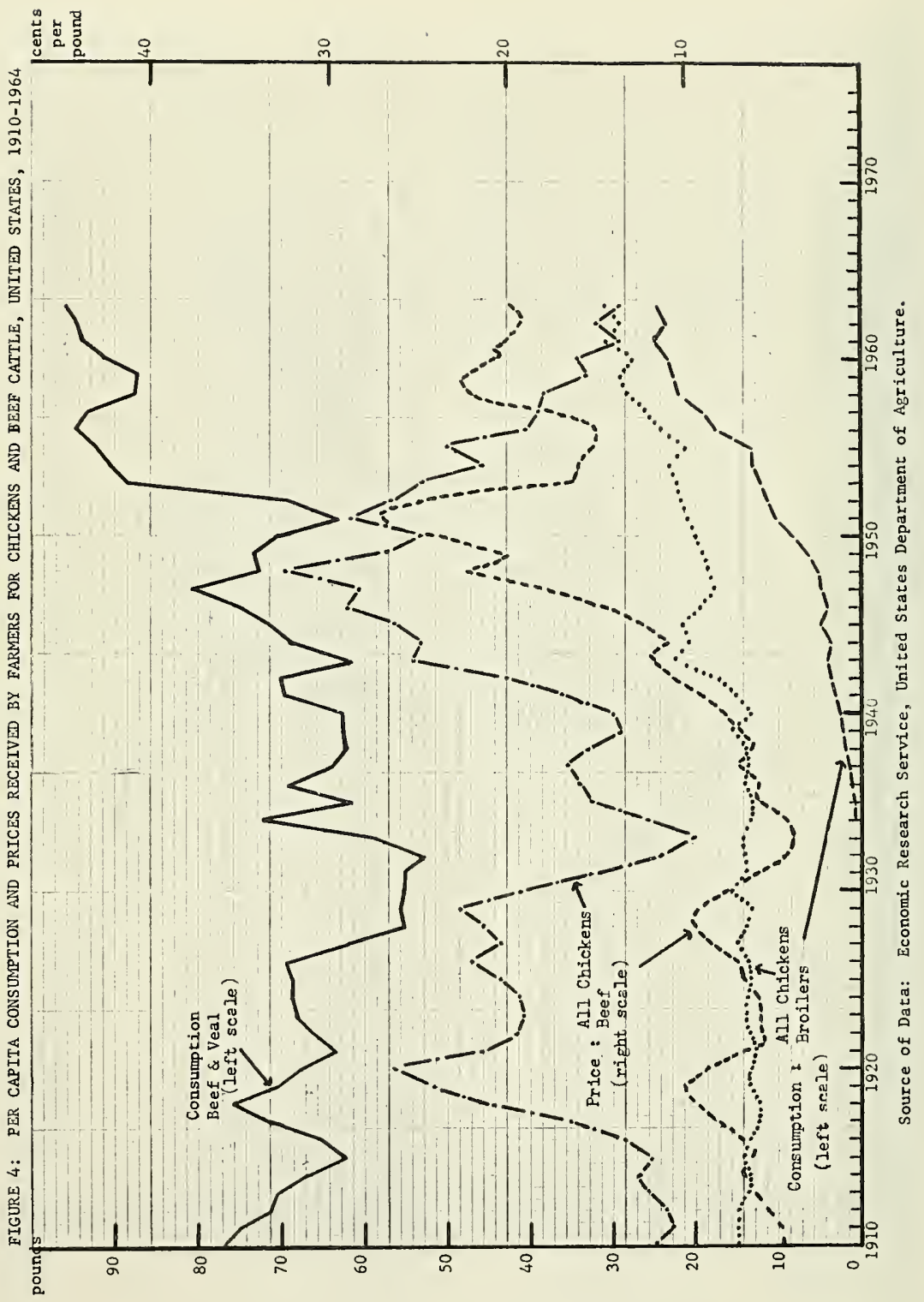




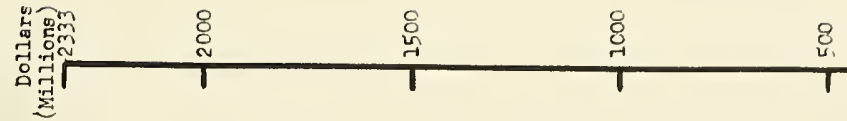

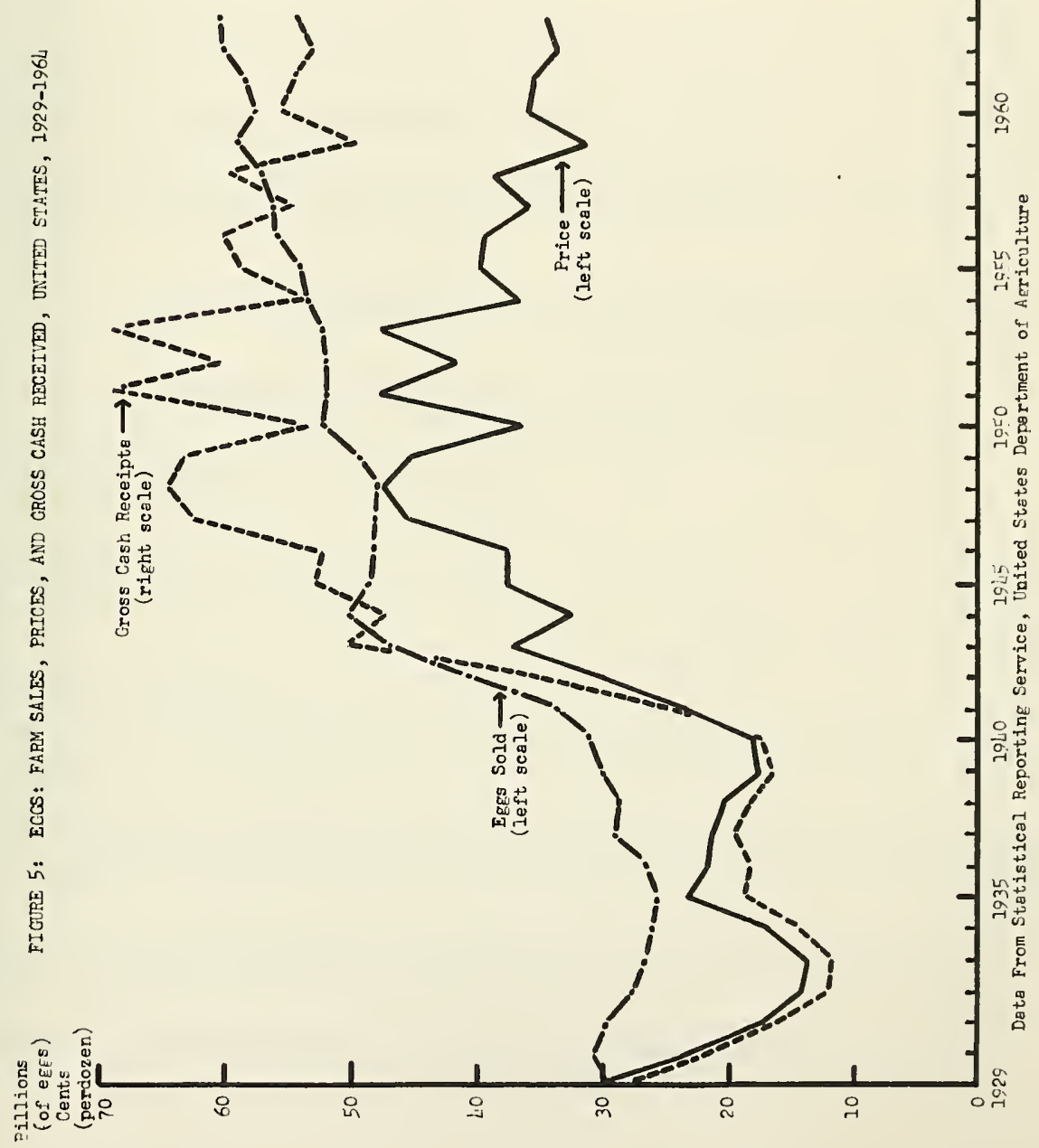




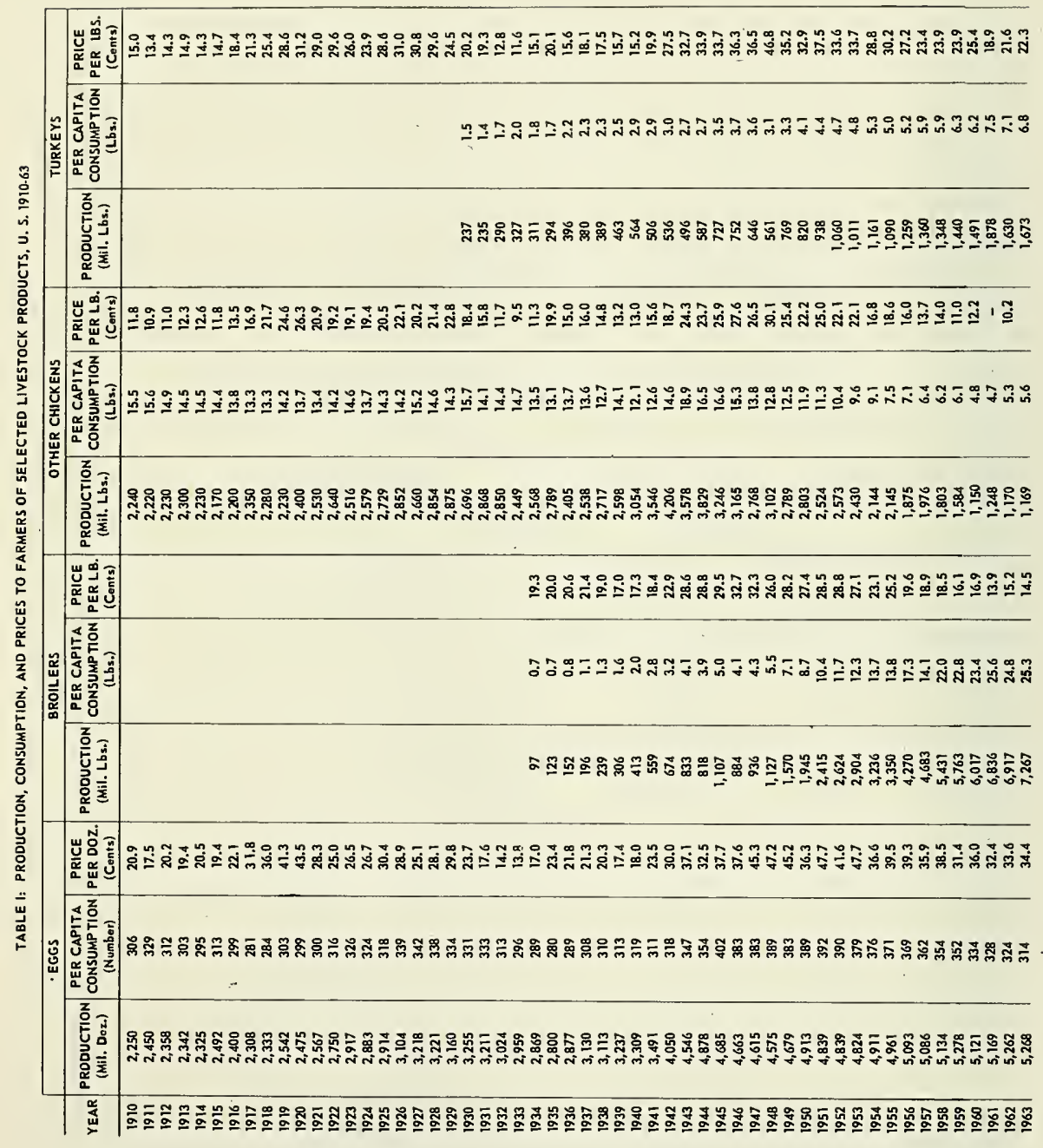




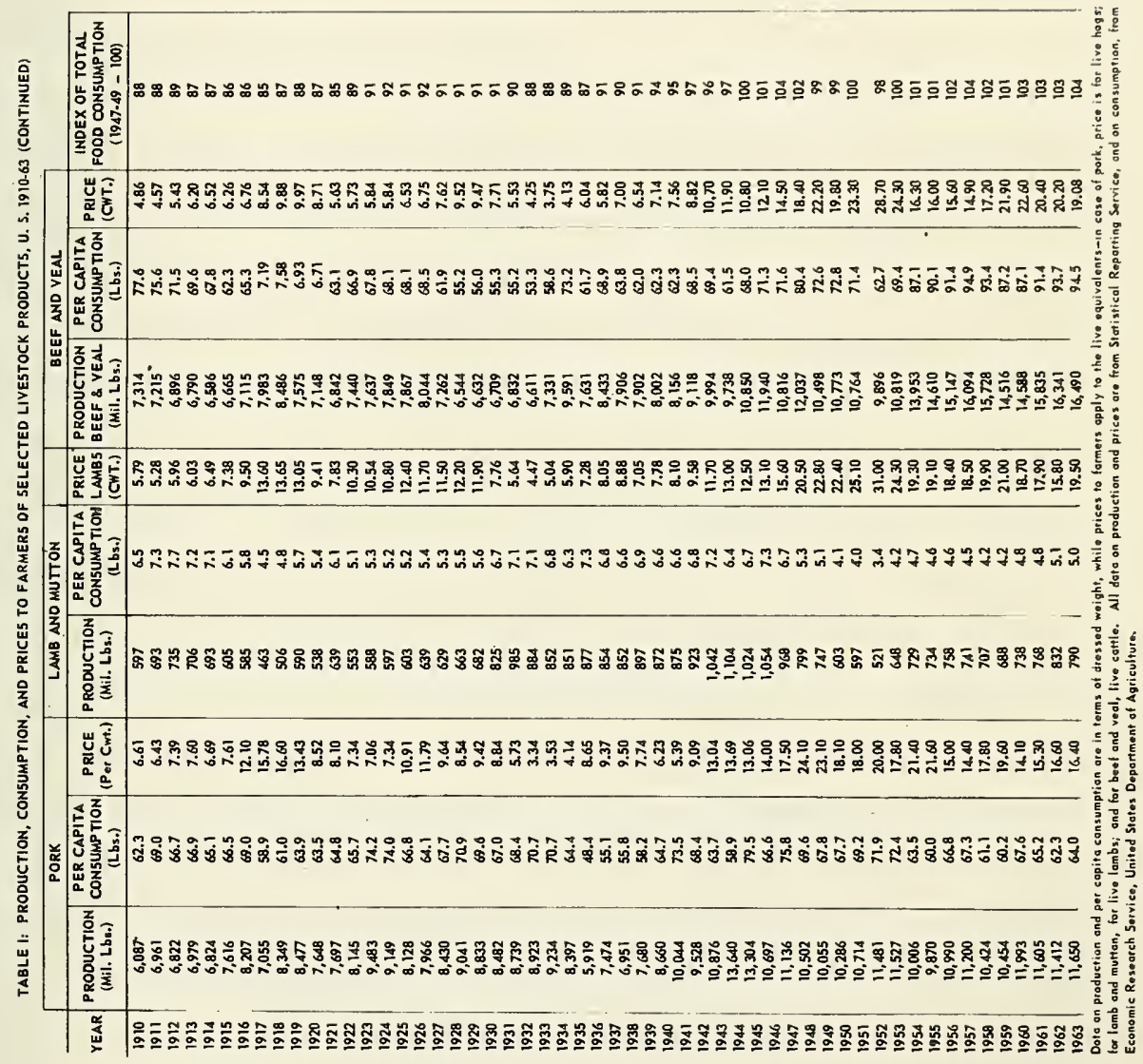



cumstances, described as "General Economic Equilibrium."

Given complete mobility of labor, capital, and management and stable demand, general economic equilibrium is said to prevail when no shifting of these resources among or within areas will yield a larger total product or a larger return to the units so shifted.

As a practical matter, such a state of general equilibrium is never attained in a rapidly developing society. The most that can be hoped for is reasonably rapid adjustments toward it. This movement toward equilibrium is called the process of "economic dynamics."

Dis-equilibrium can prevall for many reasons -- institutional barriers to movement of factors or products, inadequate transportation, communications, education or information. Dis-equilibrium means employment of productive resources in a less than an optimum manner. As a result, owners of some productive assets (physical or mental) are underpaid when compared with their yields under different deployment. One of the tasks of economics is to identify the instances of such mis-allocations, measure the degree of disparity from optimal use, and to suggest measures to promote more nearly equal returns for given qualities of resources. In the final analysis, unequal marginal returns to assets means unequal returns to people, although returns to some assets are reflected in the value of the assets concerned. The benefit to people may be long delayed, frequently for more than a generation. Meanwhile owners of such assets may find it necessary to make large financial sacrifices, ranging from income foregone to carrying costs of the assets .

Given reasonably competitive conditions, the smaller the geographic area the more likely that general equilibrium will prevail with respect to the use 
of resources within it. Any real differences in returns to 1 and or other immobile physical assets tend to show up in differences in capitalized values of such assets. So long as labor is mobile, as between two locations, returns to labor can be equal even though returns to physical assets are unequal and result in different valuations (potential sales values) of such assets. As a practical matter, of course, laborers are not completely mobile and returns to labor can differ considerably between two areas and for extended periods of time. Frequently, this leads to a bidding up of prices of physical assets, and, in effect, attributes income to such assets the owners of the assets might otherwise attribute to their labor. An example of this is the bidding up of farm land prices in eastcentral West Virginia to levels 50 per cent or more above prices of the best corn land in the midwest despite much lower returns to the labor-management component in West Virginia. (1) 1

Whether or not equilibrium in employment of resources exists, or is approached, between two producing areas within a nation (or in different nations), the general tendency in modern economies is to specialize by areas, firms, and people. Trade tends to take place between specializing sectors in such a way that the respective producing areas are better off than if each tried to produce all items demanded by consumers within its borders. This specialization through the functioning of a reasonably free price system is the result of a rather important economic doctrine known as "The Principle of Comparative Advantage." One formulation of this principle is the following:

$1_{\text {Throughout the text the numbers in parentheses refer to literature citations }}$ at end of report. 


\begin{abstract}
"each area tends to produce those products for which its ratio of advantage is greatest as compared with other areas, or its ratio of disadvantage is least, up to the point where the land may be needed by some products less advantaged in the area in order to meet the demand for them at such prices as will come to prevail under such circumstances." (2)
\end{abstract}

It is significant to observe that the forging of this principle by economic theorists extended over nearly a century and was formulated with primary reference to agriculture. That it was made with orientation to agriculture, specifically stipulating "land," does not by itself detract from its application to non-agricultural affairs. In focusing primarily on non-modern agriculture two significant implications are made: (1) one important factor, land, is immobile and (2) in the total cost structure, the fixed component is large relative to the variable group. In a broad sense these two points may be considered as identical but their analytical consequences are distinguishable. Many phases of modern agriculture have taken on aspects of non-agricultural firms in that land is relatively unimportant in the total cost structure and (partly for that reason), variable costs are a very high proportion of total costs. As will be pointed out later, the broiler industry is a good example of firms with variable costs that account for a high proportion of total costs, apparently exceeding 90 per cent in many instances.

One possibly surprising result of the operation of this "comparative" principle, given the free price system and mobility of resources within areas, is that we have no assurance that the area of lowest production "cost" for any given commodity actually will be imporcant in the production of that commodity. To illustrate, we could have two separate areas with some differing abilities to produce only the same two commodities. The "cost" of producing both items may be higher in area A than in area B. Nevertheless, there will be a tendency for all of one item to be produced in area $A$ and all 
of the other in area B. Through trade between the areas, the economic position for both will be enhanced over what it would be if each produced both items as demanded within their respective boundaries.

For the comparative principle to be meaningful in all circumstances, there must be some kind of equalizer in the form of a "residual claimant." Within agriculture, the factor most often functioning in this capacity is land as illustrated explicitly in the above formulation. For two distinct areas we may find that costs are equal for all non-land items. Moreover, within each area we might find that each factor, including land, is realizing a higher return than could be achieved through any alternative employment. This is known as the "opportunity cost" principle in economics and gives us an all-inclusive measure of cost for producing any given item at a particular place.

Returns to land may differ considerably between two locations due to special circumstances. In each area, the cost of the land factor for producing any item is what could be realized by using it to produce the next most remunerative alternative item. In addition to the pair of items being considered, for example, we might have a third item which could return to 1 and much more in area $A$ than in area $B$. The value of this differential in productivity is called "residual rent" or "differential rent" and accounts, in part, for observed differences in land values. Through time, this differential advantage is capitalized, giving differences in land prices. In this manner it trends to equalize apparent total current costs per unit among areas.

Economic dynamics, as indicated above, is the process by which, in a highly competitive system, changes in uses of resources are made in the 
direction of permitting the marginal components of each resource to produce more than, or at least as much as, they could under any alternative pattern of uses. The nearer this objective (general equilibrium) is accomplished, as stated earlier, the greater the total national product and the greater the income to resources (including human resources) involved. The rearrangement of resources in accordance with the principle of comparative advantage determines the location of production for given items and other kinds of specialization in resource use within the economy. To abstract from all the inter-relationships among resources and among products, attention usually is focused on just one, or a few, products. An equally important reason for such narrowing of attention is that some pressing economic problems usually are presented in terms of one, or a few, products. "The term 'interregional competition' is more often given the more specific meaning of competition between two or more regions producing the same or closely related products for a common market. The common market may be regarded loosely as the total national market......." (3)

Singling out just one, or a few, commodity(ies) from many products and resources that may be concerned in any considerations involving general equilibrium or comparative advantage, on the surface, may seem to abstract from so many relevant relationships as to raise real questions as to whether studies in "interregional competition" are worthwhile. As a practical matter such analyses are justifiable for some important reasons. Since questions most often arise in terms of specific products, it is incumbent upon analysts to make what abstractions are necessary to develop meaningful answers to problems concerning the particular products. The individual producer in a given locality involved with a "problem" product usually doesn"t have to be 
told "what" is happening -- the most common symptom is downward price tendencies for the finished product relative to its cost of production, and the producer is aware of this. However, he wants to know, as fully as possible, "why" as guidance for his future investment policies and/or occupation plans. He can observe his neighbors and make adjustments to keep in competitive pace with them. Moreover, he usually does not have knowledge concerning developments in distant producing areas or about institutional or other changes causing shifts in relationships among areas. An analyst in interregional competition can identify these changes, probably can quantify their effects, and may be able to make projections as to the duration and extent of such changes for the future.

Probably, most often the questions come from producers experiencing an economic "squeeze" of some kind. To the extent that trends giving rise to the problem may be persistent, the objective of the economist will be to ascertain the basic changes in relationships which underlie them. Even then his role may be construed as that of the dismal scientist, particularly if alternatives are few and much less remunerative. On the otherhand, interregional competition studies also are made to locate new producing or processing areas, particularly in opening new agricultural areas, introducing a new product, or inaugurating new producing or processing techniques.

The broiler industry of the United States is not a monolithic economic organism, although there is great similarity among some of its sub-parts, and the steady growth in total output may give an impression of a certain oneness. Recently, more states have decreased in broiler output than have increased. The production of this item, perhaps more than any other that is still labeled an agricultural product, makes extensive use of inputs from off the farms pro- 
ducing it. On the other hand, there are important exceptions - broiler growers also produce relatively large amounts of corn and/or soybeans which are fed to chickens in the immediate area. The broiler section most generally approximating an indigenous basis or self-contained industry is DelMarVa, although in several southern areas production of both crops is rising substantially. In general, however, broilers are produced by people who produce little, if any, such crops.

At the grow-out (farm) level, variable costs constitute a relatively high proportion of total costs. In this and in other ways broiler production units, particularly the highly integrated ones, more nearly resemble non-farm producing entities than farms in the traditional sense. The labor for the growing-out activities and the managerial element to handle the on-the-scene decision-making is viewed by prospective integrating firms much like the potential labor supply for any industrial or manufacturing concern. One main difference is that the labor for the growing-out phase is located at varying distances from the processing plant and there is need for field-man supervision at some distances from headquarters. Secondly, the growers provide shelter facilities and some other items of equipment and supplies.

The supply of labor and the potential supply of broiler houses is available over rather wide sections of the United States. Within these broad sections, the particular localities which have been chosen for broiler production have been in large part the result of an accident in Jocation of an enterprising individual. Building on small beginnings invariably has meant, where conditions were suitable, an expansion to sizeable total operations and otherwise a decrease or demise of such production.

Accidental location, such as alluded to above, has become much less prevalent with the growing importance of regional and some national integrators. 
In view of a national orientation to production and marketing, a systematic choice of a production area is made in an attempt to ascertain a combination of delivered costs of feed and other inputs, grower compensation, processing costs, and transfer of the finished product to market that will be the least among possible alternatives. Some important difficulties, however, are inherent in this approach. First, there are frequently unmeasurable, possibly unknown, or unidentifiable, elements that make for differences in costs among regions. Secondly, even for the identifiable factors which can be measured, there is the difficulty of selecting or describing a representative firm or group of firms since each area will have a family of cost curves (or structures) within it.

Thirdly, at any given time, deviations from equilibrium may differ greatly among areas. These departures may have deep roots in the economy of the area encompassing not only the mere matching of resources in appropriate proportions by individual firms, but extending through a series of economic decisions of different importance and orders of complexity, including the allocation of capital by governmental units for social overhead, particularly elementary and secondary education. Substancial under-investment in education (private and public) in area "A" will tend to equip each succeeding year's youth with less earning power as compared with those in area "B" where relatively heavier investments in education may be made. Under-investment in education is closely associated with labor immobility; both can contribute to prolonged differences in returns to labor among areas producing the same product. Undoubtedly, this is involved in accounting for the apparent very low returns attributable to labor on Georgia broiler farms as contrasted with DelMarVa. (In 1963, as discussed in Part II, the calculated return to the typical Georgia grower was $-\$ .11$ per hour compared with $\$ 1.33$ in DelMarVa, in 
both cases after deducting interest at current rates on all assets, borrowed or owned, supplied by the grower). With increased emphasis on education and other measures to equalize opportunities, these returns will tend to converge. Thus, to construct either an elaborate and possibly high cost analytical framework on a firm premise of such continued disparities or to make heavy, "permanent" investments on the same basis is to build on something considerably less than a firm foundation. In the real world, of course, investment decisions must be made. If allowance is made for those elements which are particularly transitory in nature, investment decisions may be more enlightened and will be reflected in type or permanency of construction, depreciation schedules, etc., all of which will contribute to a lessening of subsequent costs in coping with change.

Finally, possibly the most likely insurmountable difficulty of all is that most of such analyses, to abstract from the numerous complexities, are essentially static in nature. This gives rise to a two-fold problem: the "cross-sectional, still-picture" of the economy will depict varying degrees of departures from equilibrium under prevailing technology. Any further adjustments toward equilibrium immediately after the cross-sectional picture is finished, will provide an entirely new set of relationships and render the static picture obsolete. (2) Introduction of each new institutional or technological change produces a potentially new equilibrium situation and the need for an entirely new complex of dynamic adjustments if progress toward the successively new equilibria is to be realized.

Technological and institutional changes have been coming to the broiler industry with such rapidity that when superimposed on (1) above, the results of many analyses are virtually obsolete by the time they appear in print, even if the very latest computers are employed. No doubt for reasons such 
as these, Bressler recently observed that "the demand and supply curves that we use in our models (of interregional competition) are simply the 'fingernails and toenails' of a highly complex organism about which very little is said." (4) The inability to cope analytically with the dynamic adjustments toward a given equilibrium, and lack of control of, or inability to predict introduction of innovations which generate successive equilibrium situations, apparently also prompted Bressler to make the following very cogent remark: "Logical (theoretical) tests may be better measures of a good model than is $r^{2} . "$ The central question posed by Bressler was "How can we help society plan and move most effectively toward the normative solution?" In the context of the study herein, this means that attention should be focused on analyses designed to suggest ways to minimize, for example, disparities between returns to the labor component, as between Georgia and DelMarVa, rather than to appraise the existing balance (in some sense) or measure changes in some less relevant relationships as between the two areas.

Some studies in "Interregional Competition" have as their objective merely the determination of an "ideal" geographic distribution of given production among markets over a stated (short) period. For an item produced and marketed under highly competitive conditions, such as commercial broilers, this "ideal" consists of equalizing "net" prices from all available markets, thereby maximizing returns within the highly competitive framework. 1

${ }^{1}$ In a highly competitive situation, only one or a few producers can maximize net income by selling in the highest priced market, thereby tending to equalize prices among markets. For an industry as a whole to maximize returns, control of supply and marketings must be centralized (in a private or public decision-maker) and, taking account of specific demand functions in each market, the supplies so channeled as to equalize marginal net returns among markets. Almost invariably this means unequal net (average) prices among markets for given uses and discriminatory (unequal) pricing among uses. For further discussion of these differences, with examples, see Waugh's excellent recent bulletin. (5) 
The actual distribution can be compared with this "ideal" to ascertain whether the desired equalization of net prices was achieved or whether any particular producing area properly distributed its output among markets. Such an inquiry will not be undertaken in the study here presented; it will be assumed, simply, that available supplies in successive periods are made sufficiently mobile. The salesmen and brokers are agile and resourceful enough that allocation in the real world practically approximates the "ideal." (This is almost invariably the conclusion of such analyses; one such analyst reported to this author that any departure usually directs questions and skepticism to the analytical method rather than to the real world).

In the poultry industry, not unlike other industries, the one certainty is that the future is uncertain. Uncertainties arise mainly from the unpredictable nature of technological and institutional (e.g. freight rate) innovations. These factors make it incumbent upon the decision-maker, with freedom to choose among alternative locations, to emphasize probable future, rather than existing, relationships of production and transfer costs. The first twelve months of operations hopefully will be only a small fraction of the total productive life of an installation. Some specific factors bearing on the future relative advantages of any particular producing area are the following: (1) changes in technology of transportation and changes in pricing policies for transportation services; (2) changes in technology of broiler production, especially the change in relationship between feed inputs and product outputs, including disease control; (3) innovations in the integrated business organizations; (4) economic growth prospects for an area as a whole with particular consideration to the long-term alternative opportunities for labor in the grow-out, as well as the processing phases; and (5) population shifts and other factors which may contribute to a relative shift in source of demand for one particular producing area. 
The central and comparatively limited objective of this project, as indicated above, was to identify and, where possible, measure some of the major changes which have occurred to affect the economic environment for producing commercial broilers and eggs in West Virginia. The immediate purpose was to attempt to establish reasons for the downturn in output of both products, to provide some basis for appraising prospects for the future and, if possible, in the normal course of the analysis, make manifest any feasible remedial actions that could be taken by firms acting singly or in concert.

The analysis was conducted against the background as to requirements for general equilibrium and comparative advantage referred to above but employing the relatively simple technique known as "The Trends Method" for analyzing and expressing the changes in the more influential factors. (3) Attention was focused on the following elements: production of the product; price received for the product; price paid for feed and for broller-type baby chicks. In all cases other than production, emphasis was directed to changes in relationships among states rather than to absolute levels. The "Trends" approach was employed recognizing that given trends in past years are not necessarily helpful in forecasting the future since the so-called trends can abruptly change. (Twenty-eight states now produçe fewer broilers than they did in the fairly recent past). However, by unearthing the probable reasons for certain trends or changes in them a better insight can be obtained for forecasting the future if this is all that is desired. But more important, even where the analysis itself does not permit direct forecasts, the identifying of relevant factors for decision makers will enable them to develop better informed judgments for guiding their activities, as time passes. It was not the purpose of this project to make internal analyses of firms and to make comparisons thereof among regions. Unquestionably, the 
changes in the particular elements chosen for rather close analysis have been reflected in widely different "pocket book" effects among individual producers. Individual farmers and operators of non-farm entities associated with the broiler grow-out and producing units will know best what their performance is currently and how this compares with given points in past periods.

Individual private operators in West Virginia then can become aware of the influence of these external factors on their firms" performance. At all times, of course, determined efforts must be made by such operators to keep up-to-date in application of new developments in production, management, and marketing if they are to keep pace with producers in other areas.

While no specific long-term projections are made, it is inescapable that many of the trends, several of which are adverse to West Virginia farming, generally will continue in present directions. A further deterioration in the broiler and egg industries and other important segments of the State's agriculture raises questions as to the ultimate solutions to a problem which seriously concerns the future of so large a portion of the population. This suggests the compelling need for research over a much broader spectrum than just the economics of one phase of agriculture or even of West Virginia agriculture as a sectorial study.

Feasible alternatives for poultrymen as well as for many other components of the West Virginia population, are difficult to prescribe because of prolonged under-investments in social over-head, particularly in educational services at primary and secondary levels. ${ }^{1}$ As a result the populace of the

${ }^{1}$ Pavlic has suggested a 4-point program for enhancing incomes of employable farm operators in Applachia and preventing perpetuation of low-income conditions into succeeding generations: (1) forest improvement projects; (2) labor retraining and out-migration; (3) increased welfare for the disabled and retired; and (4) an improved educational system for school-age youth; "...an improved educational system is conceived to be the most important long-run solution to the low-income problem." (6) 
State has many disadvantages and few inherent advantages as compared with their counterparts elsewhere in the nation. Moreover, the rough terrain constitutes a formidable negative influence to many non-farm activities as well as to agriculture. 


\section{SOME PHYSICAL CHARACTERISTICS OF WEST VIRGINIA AND DEVELOPMENTS IN TRANSPORTATION WHICH AFFECT THE RELATIVE POSITION OF THE STATE}

There is ample justification for calling West Virginia the Mountain State. Some western states undoubtedly have as large a portion of their areas in mountains, but generally the steepness of slope is not as great. In West Virginia relatively few elevations exceed 3,000 feet. But the difficulties of employing the land for any of a number of uses is indicated by the following classification of the surface by slope: ${ }^{1}$

Proportion of total acreage with

\begin{tabular}{cr} 
Slope & slope indicated \\
\hline Percentage & \\
& Percen \\
$0-11$ & 16 \\
$12-24$ & 18 \\
$25-39$ & 38 \\
40 and over & 28
\end{tabular}

About two-thirds of the State $^{\prime} \mathrm{s}$ area slopes in excess of 25 per cent, but some counties range much higher. In fact, for seven counties 90 per cent or more of their area has slopes in excess of 25 per cent.

Rugged terrain, such as described above, is a serious obstacle to agricultural enterprises as well as to efficient transportation for non-farm as well as for farm uses.

${ }^{1}$ Actually, since the area measurement presumed a flat surface, the official total figures for the state are understated with probable consequent overstatement of proportions of surface in lower slopes and substantial understatement of proportions with steeper slopes. 
Attention in this study will be focused on the transportation problems presented by the gradient characteristic. It will only be observed that the rather rapid diminution of West Virginia land in farming presumably attests to the infeasibility of using modern equipment and otherwise improved farming methods on such rough terrain.

\section{Nature of Influence of Gradient on Transport Costs}

The rugged terrain of the State results in greater cost of constructing or improving highways. (8) As a result, most other states are making greater improvements which help to lessen the transportation costs of conducting business. (9) Because of these differential rates of improvement, it appeared essential to attempt to quantify in meaningful economic terms the significance of the terrain of West Virginia as reflected in gradients of highways and the influence of this, in turn, upon transportation costs.

Only brief reference will be made in this report to construction aspects of the highway problem. Attention will be focused on the highways as they now exist and the contribution of the existing gradients to cost of transport over and above what the cost would be on nearly level conditions . The effect of terrain on transportation is really two-fold: (1) distance is added in order to get between two given points because highways are constructed to take some advantage of the contour of mountains and, in addition, there is the up and down movement which further detracts from the straight line approach between two points, and (2) power has to be exerted to provide vertical lift to cargo as well as forward movement. These two aspects of the problem are mentioned only to indicate the separate principles of physics involved. The approach will be to use the standard gradient measures and appraise the influence of these on transport cost. 
So far, at least, it has not been possible to obtain data from transport agencies that would permit the derivation of differential costs among gradients. For railroads, cost data are developed by zones or divisions. But, invariably, such areas encompass level as well as rough terrain, and it is not possible to obtain data that are directly useable for the purpose at hand. Even fewer data have been assembled in regard to truck transport and these also have been averages of widely differing types of terrain.

In general, the railroads were constructed so as to take greater advantage of existing river beds and more tunnels were employed than has been the case for highways. It is economically more compelling to provide minimum gradients for railroads than for auto vehicles because railroads incur a greater cost, it appears, in going down, as well as up, steep grades. In the case of highway vehicles the downgrade is in some respects an offset to the cost of negotiating steep upgrades.

The task of ascertaining the cost of operating motor trucks is complex even on level terrain because of the many factors involved. Some of the variable factors are: (1) the gross weight of vehicles, (2) wage bases for drivers, (3) speed at which vehicles operate, which of course reflects the traffic congestion, as well as other road conditions, and (4) over a period of time, of course, additional factors come into play, such as original cost of equipment, depreciation, interest on investment, taxes, and the general overhead cost of doing business. To ascertain the separate influence of terrain we shall focus on only those costs that vary because of the terrain factor. A dual basis for choosing the items which vary with gradient was employed: (1) items which logically vary by gradient of the highway, and (2) items for which data are available. These happen to be fuel consumption 
and travel time. Other factors exist which also vary with the gradient but these two items appear to be the major factors. According to one recent study, these items account for 20 and 22 per cent, respectively, (fuel and time of travel) of the total cost of operating motor vehicles. (10)

\section{Fixed Versus Variable Costs in Trucking Industry}

There is a wide range of concepts as to what constitutes fixed and variable costs, respectively, in the trucking industry. This industry is vastly different from railroads in the sense that there is no road bed to be maintained as direct costs by truck lines. A recent study by the Interstate Commerce Commission with regard to costs in the Rocky Mountain States suggests that the variable costs may range upward from 85 per cent of the total cost of truck operation. (11) For that particular study the 90 per cent level was arbitrarily chosen. This study applied to eleven Class I and Class II common carriers in the Rocky Mountain region having a gross annual revenue of over $\$ 500,000$ with 75 per cent, or more, of such revenues being derived from general commodities. These are the only carriers that are required by the Interstate Commerce Commission to keep the supplemental statistics needed to determine rate-making costs. This study concluded, incidentally, that the total line-haul cost per vehicle mile (based on the vehicles traveling an average of 37.3 miles per hour) was 34.350 cents. The weight of cargo on which this cost was premised was not indicated and presumably it was implicitly assumed that the cost per vehicle mile was independent of the load carried. Although this study was based on data for the Rocky Mountain region, it is not clear as to the influence of terrain. In the vast majority of cases the gradients of highways in that part of the United States are much less than they are in West Virginia. Although the 
mountains reach greater heights, the surfaces are relatively smoother, and much of the travel may take place along the contour to lessen the influence of gradient. Nevertheless, the fact that a figure of 34 cents per mile is reported suggests that there was substantial gradient involved.

In Apri1, 1963, the Economic Research Service of the United States Department of Agriculture released what is described as a Pilot Study of Exempt Motor Carriers operating in Delaware, Maryland, and Virginia. (10) In all, this study covered 28 trucking firms concentrated in the eastern shores of Delaware and Maryland, and in the Shenandoah Valley of Virginia. No minimum was specified as to the size of firm in the survey, and, as a result, much smaller firms were included than was the case in the study by the Interstate Commerce Commission. The average load haul, according to this study, was 15 tons per trip, but there was no specification made as to the speed of travel for the vehicles. This study also made no specification as to the gradient involved in the travel routes for the vehicles. Those trucks operating on the eastern shore of Maryland and Delaware probably had virtually a zero gradient. But those operating from a central headquarters in the Shenandoah Valley of Virginia inevitably would have encountered a gradient in some phases of their operation. However, as a rough approximation of a point of departure for the analysis herein it seemed safe to assume that the 28.8 cents per mile applied to a gradient not significantly different from zero. This will be sufficient, particularly if it is recognized that the true figure probably is a little lower than the 28.8 cents, and as this figure is lowered the relative disadvantage of a mountainous area such as that of West Virginia would be larger.

It will become evident as the following analysis progresses that in studies of the cost of operating motor vehicles, it is necessary to specify 
the numerous influential factors in addition to the speed of vehicle and/or the amount of cargo carried. It is helpful, at least as an indicated first approximation, to specify a breakdown of costs of operating a motor vehicle on a mileage basis in the manner described in the publication by the Economic Research Service. This breakdown, both relative and absolute, is shown in Table 2 .

\section{Approximating Cost-Effects of Gradient}

The basic data for the present study on the relationship of travel time and fuel consumption to profile of the highway and weight of trucks were obtained from a study conducted by the Bureau of Public Roads In 1948. (12) In the phraseology of the highway engineer, that study was designed to solve the "problem of size and weight of commercial vehicles." More specifically, it may be described as a performance study designed to produce two segments of direct operating costs, fuel and time, for commercial vehicles of various types, powers, and gross weights as related to the profile of the highway.

This performance test was conducted over two routes in Pennsylvania that differed radically in gradient. One was a major portion of the Pennsylvania Turnpike between the Carlisle and New Stanton interchanges, a distance of 148.7 miles. This was a four-lane divided highway with a maximum gradient of three per cent. The other highway was part of U.S. 11 from Carlisle to Chambersburg and a section of U.S. 30 from Chambersburg to Greensburg, a total length of 149.4 miles. The latter had gradients of up to 12 per cent and many continuous long climbs of six to eight per cent. The Turnpike sector was divided into 16 different sections while the other highway was marked off into 20 separate sections. 
Table 2: Distribution of Trucking Costs Among Specific Variable and Non-Variable It ems

\author{
Per Cent \\ of Sub-Total \\ Costs
}

\author{
Per Cent \\ of Total \\ Costs
}

\author{
Estimated \\ Actual Costs \\ Per Mile
}

(Cents)

Variable Cost Items

$\begin{array}{lr}\text { Fuel and oil } & 30.8 \\ \text { Fuel use taxes } & 1.1 \\ \text { Icing charges } & .9 \\ \text { Tolls } & 6.3 \\ \text { Loading and Unloading charges } & 1.3 \\ \text { Phone calls } & .3 \\ \text { Brokerage } & 1.7 \\ \text { Repair and Maintenance: } & 16.5 \\ \quad \text { Parts and labor } & 4.8 \\ \quad \text { Tires } & 34.9 \\ \text { Wages to drivers and helpers } & 1.4 \\ \text { Other costs } & 100.0\end{array}$

21.7

.8

.6

4.4

.9

.2

1.2

11.6

3.4

24.6

$\frac{1.0}{70.4}$

6.25

.22

.18

1.28

.26

.06

.35

3.35

.97

7.08

$\frac{.28}{20.28}$

Non-Variable Costs

Equipment depreciation

other depreciation

Insurance

$44 \cdot 5$

13.2

3.79

.2

.05

21.2

6.4

Interest

9.8

Vehicle property taxes

.6

other fixed costs

.7

Indirect Costs

Sub-Total

$\frac{16.2}{100.0}$

6.2

1.9

2.9

1.80

.55

.83

.2

.2

.05

.06

$\frac{4.8}{29.6}$

$\frac{1.38}{8.51}$

Grand Total

$\overline{28.79}$

Adapted from "Cost of Operating Exempt-for-Hire Motor Carriers of. Agricultural Commodities", U. 6. Department of Agriculture, ERS 109 (Washington,
1963). 

Seven different vehicles were employed in the study with a range in the type and size of the trucks and in the load. The weight of cargo varied from 20,000 pounds to 139,500 pounds. Each vehicle made three trips on each stretch of roadway with three different load weights. Thus, each vehicle traveled a minimum of 5,400 miles making approximately 40,000 miles total travel for the seven vehicles in the period from July 19, 1948, through October 7, 1948. The trucks operated five days a week, day and night, regardless of weather conditions.

Numerous data were collected in the course of that study. As far as the present study is concerned the important data were those on gas consumption and time of travel for each of the 37 sections for the 21 different gross weights involved. Following the field phase of the Pennsylvania road study, the authors applied statistical procedures (least-squares) to determine the average relationships which existed between gradient and gasoline consumption for the different gross weights of the vehicles and, secondly, the travel time and the gradient of highway for the various weight-to-power ratios which existed for the different vehicles. The following two formulas were adopted to describe the relationships involved:

(1) $\mathrm{GPM}=\mathrm{aw}$

where: $\mathrm{GPM}=\mathrm{Gallons}$ per mile, and $\mathbf{w}=$ Gross weight in thousands of pounds

(2) $M P M=a+b R$

$$
\begin{aligned}
& \text { where MPM = minutes per mile, and } \\
& \mathbf{R}=\text { weight-power ratio in pounds per net horsepower. }
\end{aligned}
$$

As indicated by the formulas, for given gradient of highways, the relationship from which gasoline consumption is derived is curvilinear, while the one depicting relationship of travel time to weight-power ratio is 
linear. However, after allowing the gradients to vary, as in Figures 6 and 7 , both relationships take on a curvilinear appearance.

Using the first formula above, composite data (that is, both directions) on gasoline consumption were determined for the full range of gross vehicle weights for the different gradients. For situations in which declines about equaled the inclines for the full span of travel, a family of curves resulted as shown in Figure 6 . Using the second formula, data on the composite travel time for vehicles of various weight-power ratios were ascertained (as shown in Figure 7) on those sections also for which the gross rise about equaled the gross fall. In other words, in both cases rolling territory was assumed so that the height above sea level at the end of the run was not significantly different from that at the beginning. Many other sets of curves were derived covering situations where there were predominately inciines or predominately declines as well as for separate directions of travel in contrast to the composite. However, for the study herein only the composite charts 11 be employed and for those situations in which the gross rise about equals the gross fall. This is the practical situation that one encouncers as he crosses West Virginia and as broller contractor's service vehieles traverse to and from grower locations.

The statistical analysis of data from the Pennsylvania field survey indicated that for identical vehicles traveling on different sections of highway the gasoline consumption permile or the minvtes of travel per mile were the same as long as the rise and fall were the same on the different sections, regardless of pavement surface, alignment of highway, or length of the sections involved. This was a very significant finding because it means that the results from the study may be used on any highway at any place so long as the altitude generally is less than $3,000 \mathrm{feec}$. It is to be empha- 
FIGURE 6. CONSUMPTION OF GASOLINE PER MILE BY MOTOR FREIGHT VEHICLES OF CERTAIN GROSS WEIGHTS AS INFLUENCED BY HIGHWAY GRADIENT

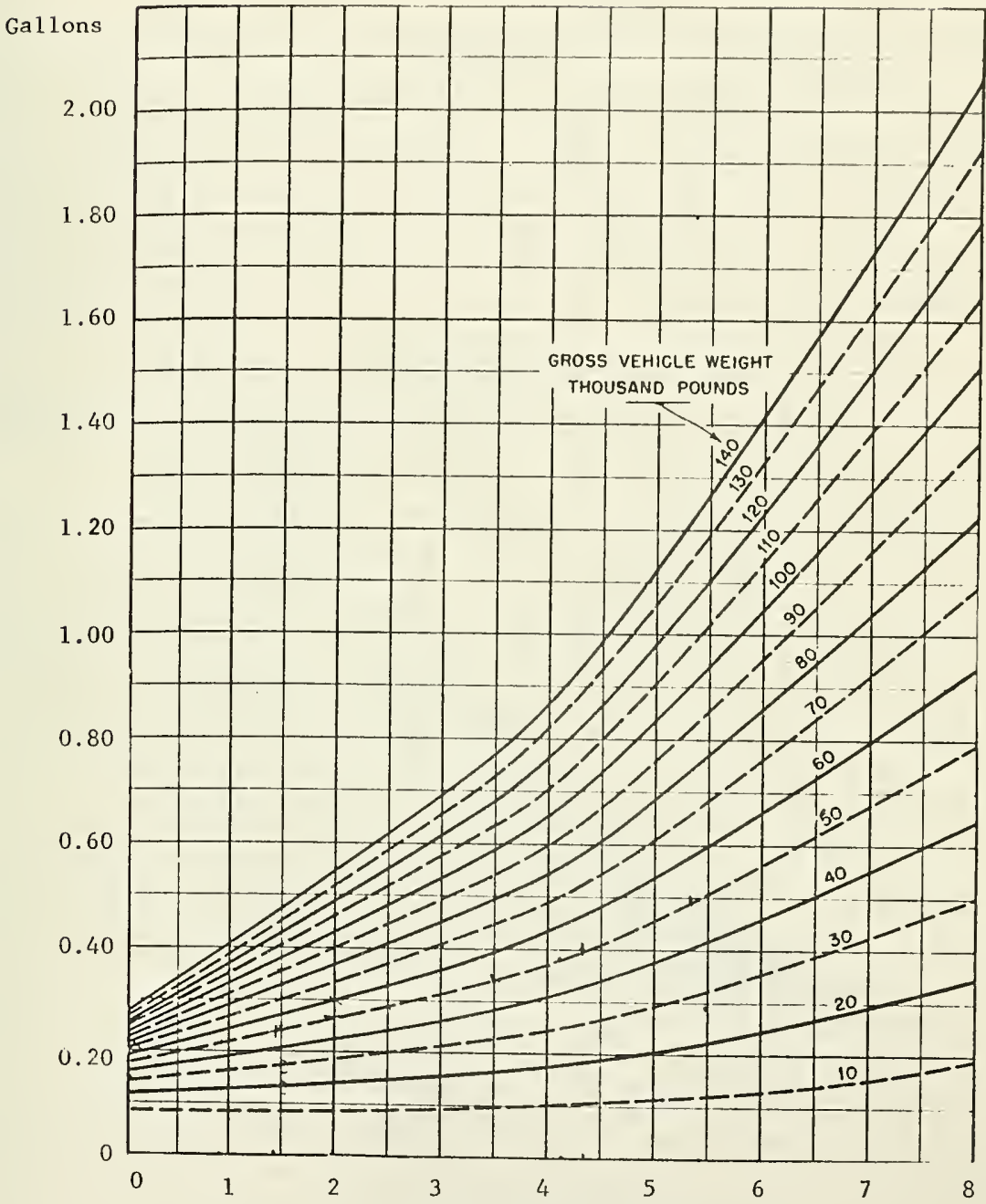

Rate of Rise and Fall

(Feet per 100 feet where the rise is 45-54 percent of the total rise and

Estimates based on data from Bureau of Public Department of Commerce (12) 
FIGURE 7. ELAPSE OF TIME PER MILE BY MOTOR FREIGHT VEHICLES OF CERTAIN WEIGHT-TO-POWER RATIOS AS INFLUENCED BY HIGHWAY GRADIENT

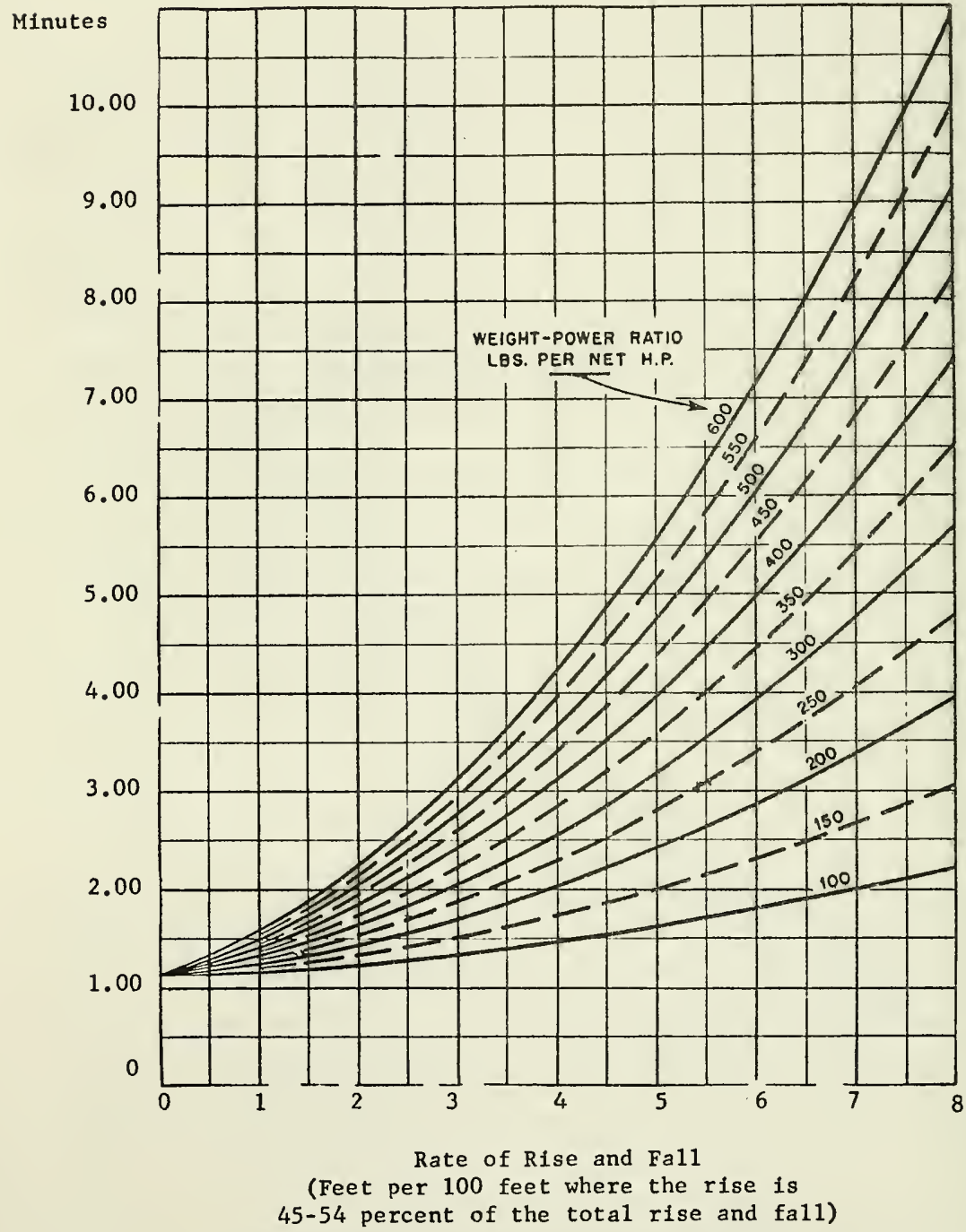

Estimates based on data from Bureau of Public Roads, U.S. Department of Commerce (12) 
sized, of course, that the term, "statistically applicable," is to be employed since the results were determined by statistical procedures and, therefore, they may not be as exact as accounting or engineering data might be if used in the same context. Thus, the data can be applied to any section of highway as long as the average gradient is known for the particular section of highway involved and the amount of incline, as compared with the total incline, plus decline involved. Obviously, vastly different results would be obtained as between a situation where the inclines about equal the declines as compared with long continuous inclines or long continuous declines.

\section{Adapting Cost-Effects to West Virginia Highways}

The highways of West Virginia with which we were initially concerned are those servicing the South Branch Valley broiler area. Accordingly, profile highway maps were obtained from the State Road Commission covering the highways starting from the center of Moorefield, going eastward on Route 55 to Wardensville, and then northeastward on Route 259 to the West Virginia Virginia border, a total distance of 43 miles. From these maps a tabulation was made showing the linear distance and gradient for every section of the highway that had an uninterrupted gradient. In all, there were in excess of 800 sections so tabulated, ranging in length from 50 feet to more than 5,000 feet each. These sections were classified in accordance with the observed gradient rounded off to the nearest whole number as shown in Table 3 . Actua11y in this stretch of highway, 44 per cent of the linear distance had a gradient of 5 per cent or more. About 20 per cent of the mileage had gradients of 7 and 8 per cent; 9 per cent had a gradient of 9 per cent or more. The average gradient for the entire distance was approximately 3.5 per cent. 
In total, the gross decline was so nearly equal to the gross incline that the charts referred to earlier showing the composite calculations for time and fuel consumed, respectively, for the situation where the rise was between 45 and 54 per cent of the total rise and fall, were applicable to this set of data.

The percentage distribution of this particular segment of road among the different observed gradients is shown graphically in Figure 8 . In the same chart, curves are shown which represent the total cost of operating two different tractor-trailer combinations of given descriptions for the first eight categories of gradients. (The Pennsylvania study did not contain data for more than 8 per cent gradient so the lines cannot be extrapolated to higher gradients.) As indicated by the chart, the total cost of operating the 50,000 pound vehicle ( 250 pounds gross weight per net horsepower) ranged from around 27 cents per vehicle mile where the roadway was practically level up to approximately 65 cents for the 8 per cent gradient. At the 3.5 per cent gradient, the approximate average for the total distance, the total operating cost was about 37 cents per mile, around 37 per cent above the cost under near-level conditions. The upper curve in the chart, representing the 72,000-pound vehicle, ${ }^{1}$ rises even more rapidly with increases in steepness of grade. At the 3.5 per cent average gradient the cost for this vehicle was around 45 cents per mile, somewhat over 60 per cent above costs based on level conditions.

${ }^{1}$ Data for a 72,000 pound vehicle ( 400 pounds gross weight per net horsepower) are shown (graphically but not in tabular form) despite the fact that the load limit in $\mathrm{W}$. Va. for a 4-axle vehicle is approximately 68,000 pounds; the 72,000-pound limit prevails in most other states. 


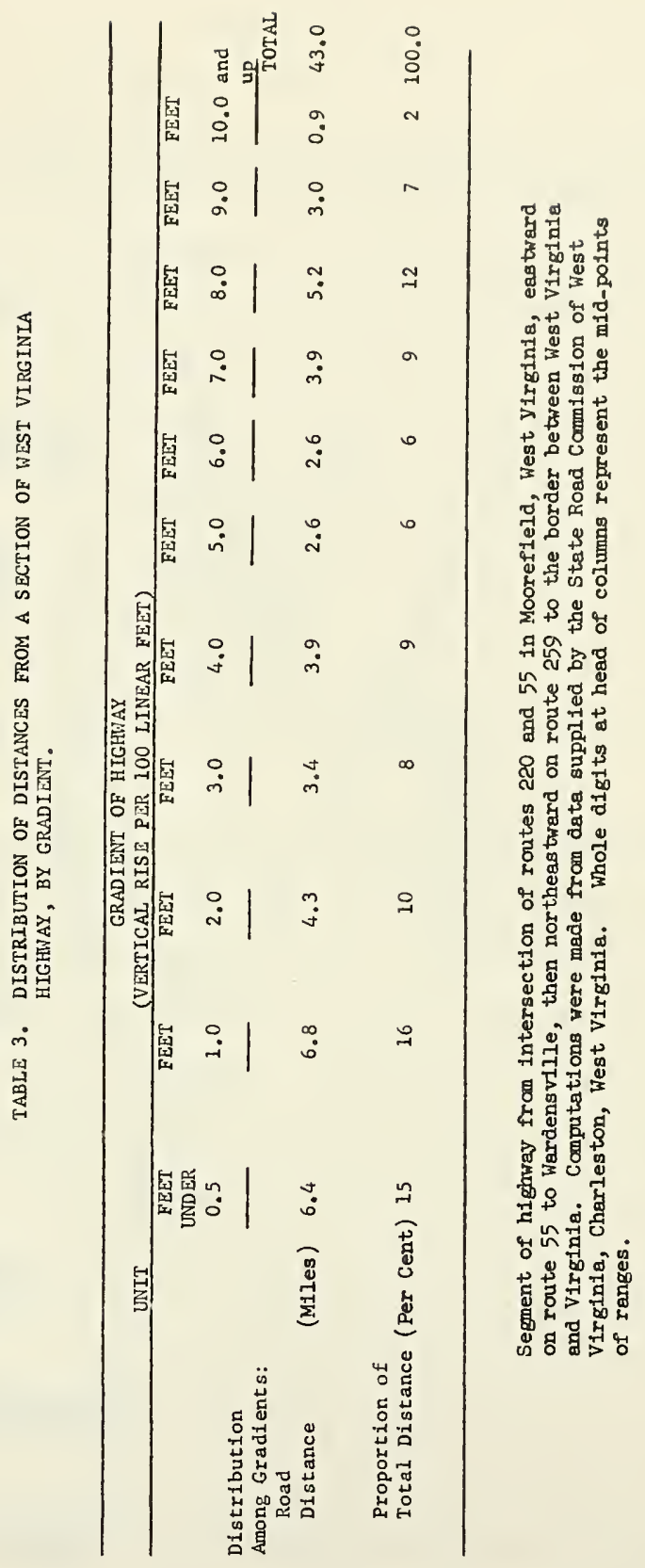




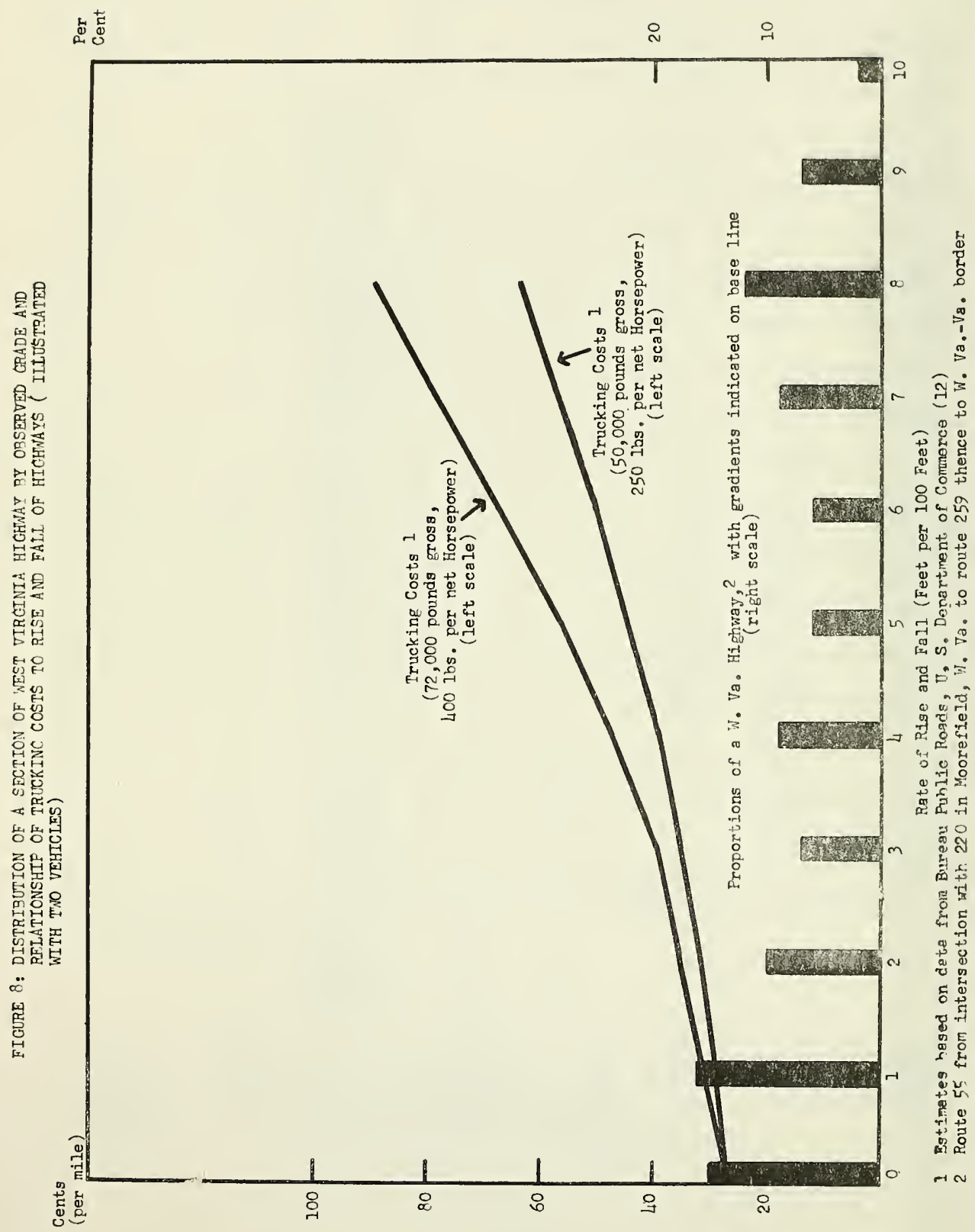


In Table 4 are the supporting data for the 50,000 pound vehicle shown in the chart, along with the components of the total operating cost data and the method for combining the results from the Pennsylvania Survey with the data applicable to the West Virginia highways. (Similar data are not included for the larger vehicle.) It will be noted that fuel and time contribute about equally to the increased costs of operating the 50,000 pound vehicle under the specified conditions, up to the 3 per cent level. Beyond that point, the time involved caused the expenditure for that component to increase more rapidly than the cost of gasoline. At the zero grade, or level condition, time and gasoline required the expenditure of 5.8 and 4.9 cents per mile, respectively. At the 4 per cent grade the fuel expenditure was about 10 cents per mile, while that for time was 11.5 cents. At the 8 per cent gradient fuel cost was 21.3 cents, while the cost for time was 24 cents per mile.

It was possible to make one field test of these observations on part of the section of road referred to above. This was done by having the Rockingham Poultry Marketing Cooperative record the gross weight of the vehicle and supply the data on the power unit and then to make the run from Moorefield to Baker, a distance of 23 miles. They were not asked to record the amount of gasoline consumption; only to keep a record of the time involved in making that particular run. Meanwhile, based on the data as to gross weight and power unit, a calculation was made in advance using the formulas from the Pennsylvania study as to the probable time that would be required. Upon subsequent checking, it was found that the advance calculation was within less than 5 per cent of the average of three such runs. 
The significance of the above data as shown in the table and the chart can be indicated in a broader manner by using a larger section of state highway. For this purpose, a11 of U.S. Route 50 was used as it extends from the eastern to the western border, including the small segment of western Maryland, a total distance of 216 miles. It was assumed for this purpose that the 43-mile section of highway, involving Routes 55 and 259 , was representative of the entire section of Route 50 which crosses West Virginia. Using the gradient of 3.5 per cent, as derived for the orher section of highway, which gave a figure of 42 cents per mile as an estimated total cost of operating the 72,000 pound vehicle, the cost of traversing the 216 miles would be $\$ 90.72$. Now, the distance between the same two points, if they were located in Delaware, or in parts of Indiana, Illinois, or Iowa would be in the neighborhood of 163 miles. The cost per vehicle mile, in that instance, having practically a level gradient, would be approximately 29 cents. The 163 miles multiplied by the 29 cents per mile gives $\$ 47.27$. This, it will be noted, is about half the cost that would actually be experienced under present road conditions of West Virginia. This assumes, incidentally, that less than one-half of the costs are truly variable.

Actually, with the slower speeds involved in making the run under the present road conditions, as compared with the speed that could be obtained under a practically level situation, about twice the fleet of trucks would be required to provide a given amount of service. So, it may not be unreasonable to conclude that, at the 3.5 per cent grade, the cost per vehicle mile would be nearly double what would prevail if the terrain were practically flat. Adding to this the fact that one-third more miles must be traveled under the present conditions than if flat terrain prevailed, it seems safe to conclude that the costs of operating the larger trucks in the mountainous parts of West 
Virginia are fully double what they would be if the terrain were practically level. This undoubtedly constitutes a major obstacle to economic development in general, although probably not to the full extent indicated by the relative disadvantage calculated above. The reason for this is that many truck lines serving West Virginia currently also service more nearly level terrain of surrounding states. In all likelihood there is a tendency among truck lines, as among railroads, to average out thẹ per mile cost so that the disadvantage experienced by firms in West Virginia is not as pronounced as indicated by the above figures. But as the time element itself in truck operation becomes more important and the technique for cost accounting improves, there will be a tendency for an increased amount of point-to-point pricing in supplying transportation services. This could lead eventually to more exacting allocation of costs in accordance with the travel conditions actually encountered.

The main broiler area of West Virginia is not as mountainous as indicated by the sample of West Virginia highways studied above. Thus, the cost per mile traveled is not at as much of a disadvantage as would be indicated by the above data. However, the circuity of the routes involved is a major factor in increasing the distance traveled so that the cost of servicing flocks of chickens or servicing farms producing other products is substantially above what it would be with more neaxly level terrain. Moreover, the dressed poultry or eggs must be trucked out of the State and must negotiate in many cases the same 43-mile stretch of highway for which the data were obtained and used in the above calculations.

While the physical characteristic of rugged cerrain constitutes an internal problem to West Virginia, the factor has important interstate implications for such a study as is undertaken here. This arises because trans- 
portation systems can more readily be improved in most other states, thereby tending to enhance community efficiencies for conducting business.

\section{Effects of Terrain on Broiler Production and Marketing Costs}

Based on budgeted cost approximations typical of 1959 conditions in the southeastern United States, Chappe11, et al., concluded that "each mile added to the average one-way length of haul between broiler farms and the central servicing and processing facility increased total costs of chick delivery, feed delivery, fieldman service, and live hauling by the equivalent of about 1.4 cents per 100 pounds of live birds." (13) These budgeted costs apparently were developed based on operations in the Robbins, North Carolina, area, a relatively level portion of that state. Hence, the supporting coefficients for this statistic can be employed, without modification, to estimate the separate influence of distances in West Virginia as contrasted with some comparative standard. The different coefficients associated with each of the several service factors involved, secondly, can be modified to reflect influence of gradient, as generally derived in an earlier section of this report but with specific application to the appropriate size of the vehicle employed. The comparative standard used in this analysis is DelMarVa which is virtually level (zero gradient) and has a distance, as reported by Chappel1, of 23.5 miles, which is assumed to apply to all service factors in that state.

Terrain affects costs of broiler production and marketing through its influence on density of production as well as directly on transport costs, per se. Density of production varies considerably among major areas as indicated in Table 5, ranging in 1959 from a little over 5,000 birds per square mile, per year, in Maine, to 65,000 for DelMarVa; West Virginia averaged 
TABLE 4: ILLUSTRATION OF INFLUENCE OF TERRAIN ON COST OF OPERATING MOTOR FREIGHT VEIICLES (BASED ON 50,000 POUNDS GROSS WEIGHT OF VEHICLE AND WEIGHT-PONER RATIO OF 250)

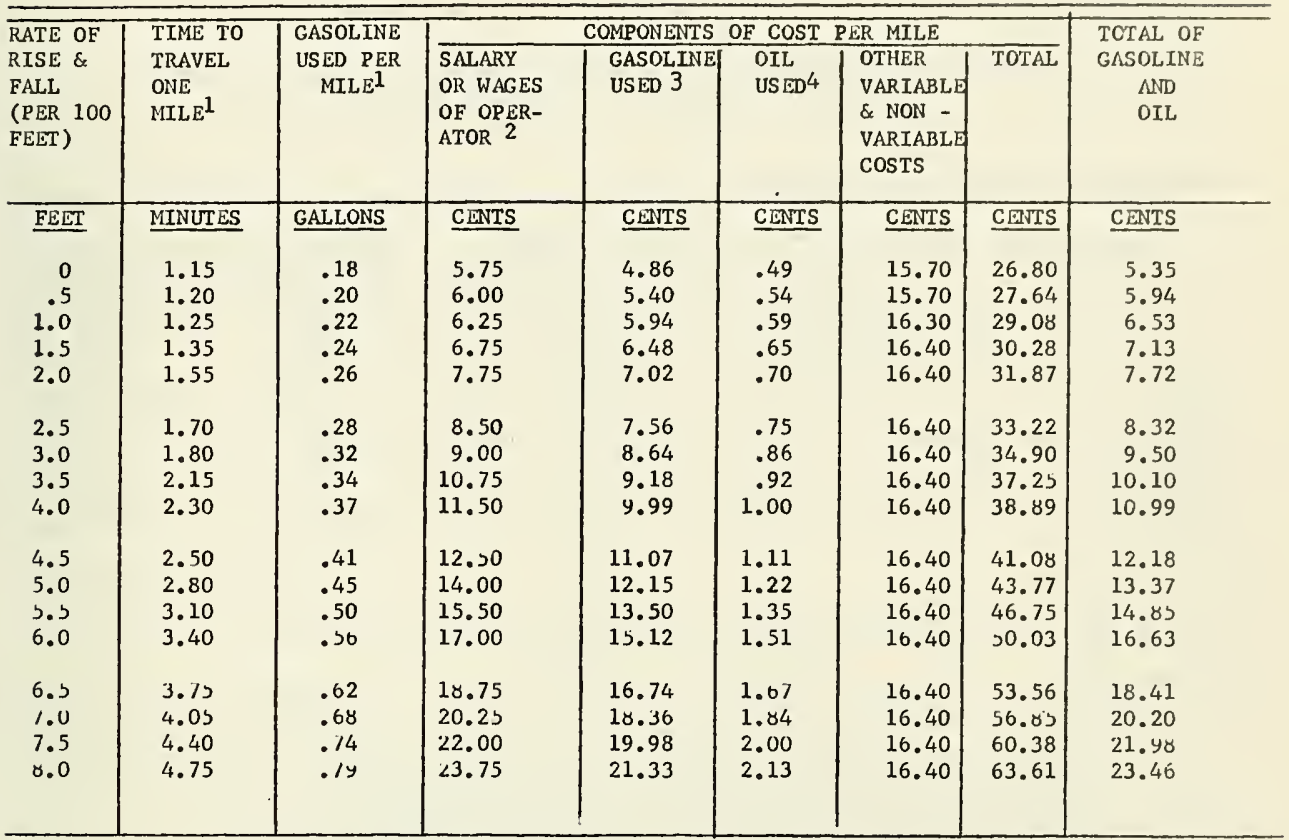

1 Lased on data from "Time and Gusoline Consumption as Affected by the Weight and Power of Vehicles and the Rise and Fall of Highways," Highway Research Report No. 9-A, Highway Research Board, Washington, February, 1950.

2 Based on assumed hourly rate of $\$ 3.00$.

3 Based on price of 27 cents per gallon.

4 Assumed to be 10 per cent of fuel cost. 
TABLE 5. DENSITIES OF BROILER PRODUCTION AND LENGTH OF LIVE HAUL TO PROCESSING PLANTS, SELECTED AREAS, ARRIL, 1959

\begin{tabular}{l|c|c|cc}
\hline \multicolumn{1}{|c|}{ Region } & $\begin{array}{c}\text { Plants } \\
\text { Providing } \\
\text { Data }\end{array}$ & $\begin{array}{c}\text { Average Length } \\
\text { of Live Haul } \\
\text { Mean for Region }\end{array}$ & $\begin{array}{c}\text { Estimated Annual Sales of } \\
\text { Broilers Per Square Mi.le }\end{array}$ \\
\hline Maine & $\frac{\text { Number }}{4}$ & $\underline{\text { Miles }}$ & $\frac{\text { Number }}{1959}$ \\
Delmarva & 5 & 27.5 & 2,749 & 5,229 \\
Central N. C. & 12 & 23.5 & 50,030 & 64,593 \\
North Georgia & 4 & 47.2 & 3,936 & 11,230 \\
N. W. Arkansas & 5 & 28.8 & 12,559 & 22,858 \\
West Virginia & 1 & 77.4 & 7,873 & 16,899 \\
\hline
\end{tabular}

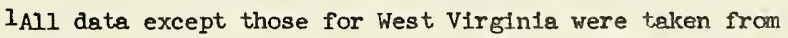
"Broller Production Density, Plant Size, Alternative Operating Plans and Total Unit Costs," Tech. Bull. 144, North Carolina Agr. Exp. Sta., June, 1960, which reported data for April, 1959. The West Virginia figure is a composite of data covering about two-thirds of the State's production for a recent 9 to 12 month period; as shown in Table 6, distances for other service-factors in West Virginia are much less.

${ }^{2}$ Calculated from county data published by Bureau of Census and represent those counties in each state which produced two-thirds or more of the State's total in 1959. 
6,400 birds in the countles which produced two-thirds of the output. Distances from central servicing points to growers were not closely correlated with densities, as here calculated, possibly reflecting differences in size and distribution of processing plants. Thus, as shown in column 2 of Table 5, Maine with the lowest density had next to lowest mileage - a little lower even than either Georgia or Arkansas where density was several times as great. It is to be noted that the mileage data for all areas shown in Table 5 apply to April 1959, except for West Virginia. It is probable that the mileage data shown for non-West Virginia areas are more uniformly representative of the actual distances for the different servicing factors than is the case for West Virginia. Hence, the distances for transporting the live birds, as reported by Chappe11, were applied to the different servicing factors for the DelMarVa volumes (Table 6).

Since the broller industry organization is substantally different for West Virginia than in most, if not all, other areas, separate mileages were obtained for each servicing factor. The data on distances were obtained for a 9- to 12-month period of 1963-64 in such form that the mileage data obrained from each firm, by runction, could be weighted by the number of birds involved. The resulting weighted averages for each function, shown in column 2 or Table 6, range from under 20 miles for serwicemen to nearly 80 miles for hauling the finished live birds.

The calculations presented (Table 6) were designed to ascertain the approximate separate contributions of distance and gradient to the greater total costs for West Virginia, as contrasted with DelMarVa. The data for the latter, column 3, are premised on level cerrain (approsimately zero-gradient) and the single mileage figure (23.5 miles) for each function. In coivm 4 are the costs per pound for providing each service, for West virginia distances in 
column 2, assuming the same gradients as for DelMarVa. The differences between costs for DelMarVa and West Virginia (column 3 and 4 respectively), shown in column 6 , are attributed entirely to differences in distance. The calculations in column 5 reflect the costs incident to the gradient factor as well as distance, although not recognizing explicitly that terrain tends to influence distance as well as gradient. The difference between columns 4 and 5 represent the separate effects of terrain (via gradient) on costs of each item. As shown in column 8, the combined costs for providing these different services is higher in West Virginia than in DelMarVa by approximately one-half cent per pound, live weight, of which 46 per cent may be roughly attributed to increased distance and 54 per cent to the more pronounced gradient. Such an attempt of pro-rating basic contributing causes, of course, is quite superficial since, as indicated above, the topography tends to influence the density of production and, therefore, indirectly, the distances involved. It is to be noted that the half-cent figure probably is a minimum approximation of the adverse influence of topography for two reasons: (I) a separate evaluation has not been made as to influences of terrain on comparative costs of transporting the dressed birds from processing plants to consumer markets; (2) no allowance has been made for the influence of rough topography of West Virginia toward increasing costs of doing business in general, and eventually increasing the cost of living, through the various ways these influences may penetrate, ranging from increased costs of transporting goods, to costs of providing the various community services, including water, sewer, streets, etc. 1

${ }^{1}$ These considerations can rapidly compound the problem and tend to lend economic support to an impression expressed to the author by an economist with a national feed distributor, to the effect that West Virginia conveys an image of a high-wage state. No doubt this image is buttressed by memories of rapidly escalating miners' wages in years past as well as the present wage structure for those actually employed. 
The reason for the greater distance that West Virginia live broilers must traverse to reach dressing plants, in part, is an outgrowth of traditionally heavier marketing of live birds in distant metropolitan areas, such as Pittsburgh. This traditional out-of-state bidding for birds seems to have been more pronounced than in other important broiler areas, and contributed to difficulties of building an efficient processing phase of the industry in the State. The decline in production in West Virginia since 1959 was accompanied by closing of most of the (then) existing processing plants within the state.

More distant plants as far away as Ohio are experiencing declining broiler production in their areas, a factor making for more aggressive bidding from out-of-state for live birds in more recent years. Apparently in an effort to operate nearer an optimum level of capacity, those buyers are willing to pay premium prices for live birds. In some instances up to 2 cents per pound is paid as compensation for this extra discance. To haul the dressed weight equivalent of a live bird this distance costs only about one-half cent per pound. So, obviously, with both competing for the same retail markets and using essentially the same dressing plant techniques, these practices cannot reflect a long-run equilibrium position. That such is the case, is confirmed by periodic financial difficulties among buyers of live birds from the distant points. In a larger sense, however, this manifests below-optimum operations for dressing plants in all states named above, including West Virginia. (The lone West Virginia plant assembles some birds from North Carolina). The result is higher assembling and marketing costs on the average for the group as a whole. This can be reflected over the long-run only in lower returns to producers than would be the case if the processing function could be conducted on a more efficient basis. 
TECHNOLOGICAL AND INSTITUTIONAL CHANGES IN TRANSPORTATION CONTRIBUTE TO SOME REALIGNMENTS AMONG REGIONS IN DELIVERED COSTS OF POULTRY FEED

Since variable costs (purchased inputs) constitute such a large proportion of the total costs of producing broilers and eggs, and feed accounts for a relatively large portion of such variable costs, it is appropriate, as a basis to help make informed judgments about future interregional feed price relationships, to consider some of the contributing, underlying developments which have helped account for the realignment in recent years. In brief, some of the important developments have been the following:

1. Improvement of navigable waterways connecting the mid-west surplus feed area with the southeast;

2. Improvement in highways and in motor vehicles for over-the-road interregional transport of feed and other items;

3. Some improvement in ral1 fac1lities for hauling feed;

4. A substantial change in the approach by carriers (particularly the railroads) to the development of proposals for rate changes;

5. Almost concurrently, partly voluntarily and partly as a result of cont orders, both related in some degree to the shift in national transFortation policy) a substantial change by the Interstate Commerce Commission in emphasis to factors used in evaluating proposals by railroads for rate changes. (Both 4 and 5 mere in the direction of more competitive pricing of transport services).

These several facets are discussed in some detail in Appendix A. Another highly relevant factor, in many instances overshadowing the effects of relative changes in freight rates, has been the difference among regions in rates of advances in economies for processing and distributing feed; this is treated to some extent in the next section. 
Expansion of waterways necessarily occurred in steps, while improvement in the over-the-highway potential took place gradually. In 1945, railroads transported by far the largest proportion of the feed grain destined for the southeast, as shown in Figure 9. Their absolute volume increased steadily to the early $1960^{\prime}$ s and the total movement by the various rail-barge-truck combinations increased from less than a half-million tons in 1945 to about a million tons in the mid-1950's and to nearly three million tons in the early 1960 's, substantially exceeding the rail volume. Long distance hauling of grain by truck was practically nonexistent in the mid-1940's, but by the mid-1950's, the volume exceeded that by either rail or barge, and by the early 1960's substantially exceeded the combined total of barge and railroads. Due largely to seasonal closings of water transport and the in-transit rates by rail, the rail volume was larger than might have been expected solely on the basis of the comparison of the gross rates. Most of the truck volume was on a back-haul basis and rates for such transport are not quoted in the same way as are the rail and barge rates. Clearly, however, the rate advantage for some time must have been decidedly in favor of trucks; this in fact was confirmed by hearings before the Interstate Commerce Commission on the Southern Railway's proposal. In the early 1960's trucks apparently had a rate advantage nearly everywhere in the East (outside of New England) and in the South except near the barge terminal points and to those areas which could utilize the "in-transit" rates offered by the railroads.

The Southern Railway System made the initial step to provide lower cost rail transport by filing its proposal to become effective August 10, 1961. other railroads servicing the southeast area soon joined with Southern in this proposal. However, by suspensions issued by the Interstate Commerce Commission and a series of court actions including a temporary restraining 
order by the United States Supreme Court, the rates proposed in August of 1961 did not become effective until April 15, 1963. The rates apply to the "Big-John," 100-ton capacity, covered aluminum cars, providing no "in-transit" privileges and requiring quick turn-around of equipment, and were more than 60 per cent below rates for normal service which, incidentally, are still in effect.

The first railroads to offer a lower rate in the area to the north of the Southern's territory was the Baltimore and Ohio line. Effective August 1, 1963, this railroad announced temporary rates nearly 50 per cent below its regular scales to points of West Virginia and some points in Maryland, using standard box cars. This line serves areas of West Virginia not far removed from Harrisonburg, Virginia, which is served by the Southern as well as, of course, the adjoining states of Maryland and Pennsylvania. The August 1 , 1963, rates of the Baltimore and Ohio line have been extended twice, and for practical purposes are permanent. In mid-Desember, 1963, the Fennsylvania line announced approximately comparable, lower rates to DelMarVa, southeastern Pennsylvania and southern New Jersey.

Rates for the new rail service (at the abruptly lower rates), to New England and northern portions of Pennsylvania and New Jersey were implemented as of July 15, 1964. These reductions, however, were far from uniform ranging initially from 10 per cent (for example, Columbus, Ohio to Augusta, Maine) to 35-44 per cent from Columbus to Pennsylvania and New Jersey points. The greater reductions, proportionately and in absolute amounts, were in the southern parts of the area. Terminal points in Maine, because of long distance from feed sources and limited back-haul opportunities for trucks, have traditionally relied largely on rail as the mode of feed transport. As a result, the reduction in rail rate (for the new service compared with the old) 


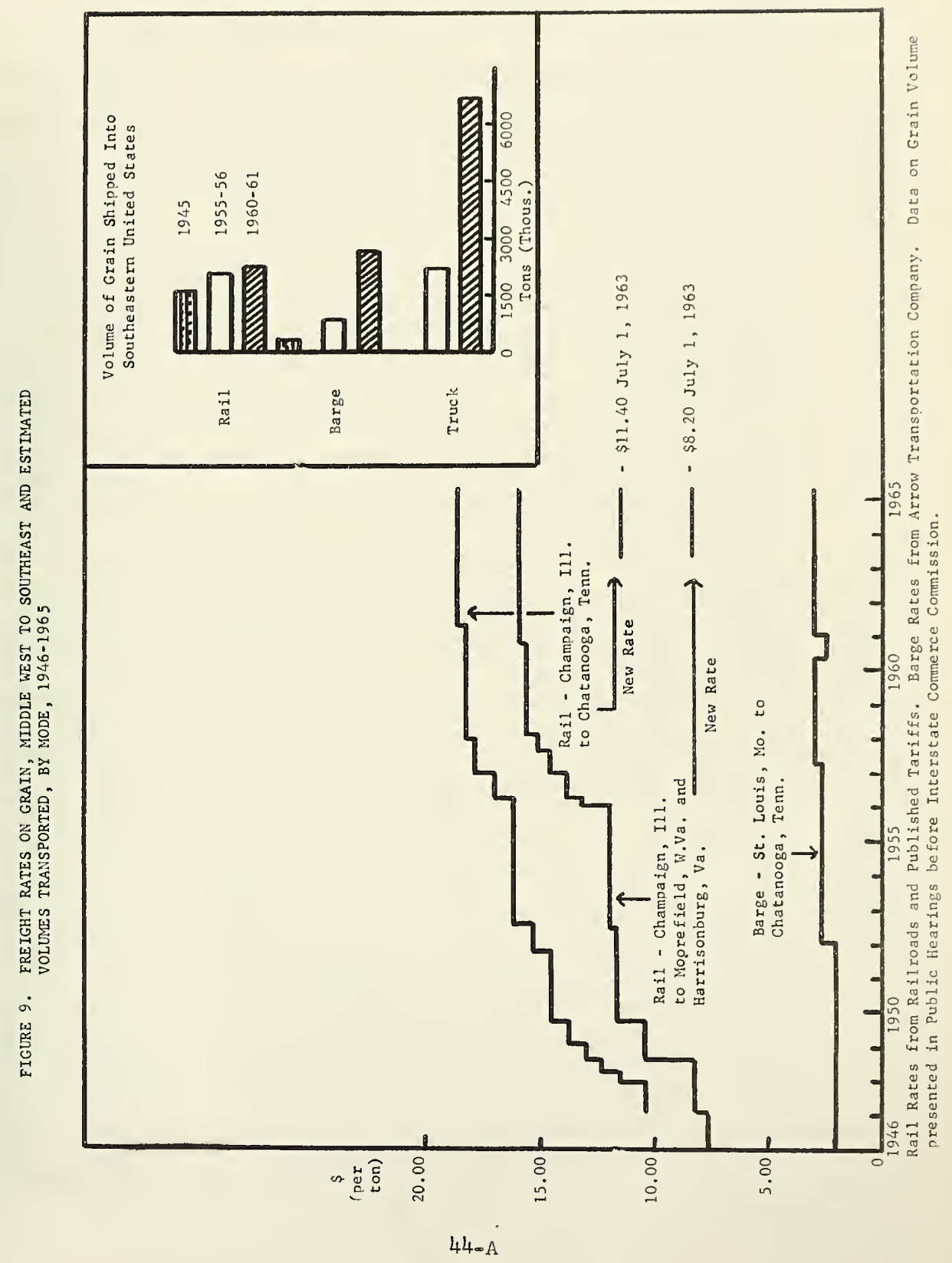




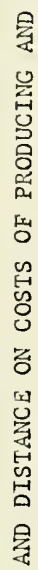

䆓完

零

空

乩

里

四骂

19

$\leftrightarrow$ 四

旬

舁象

을

定

泉尊

留娄

䍃

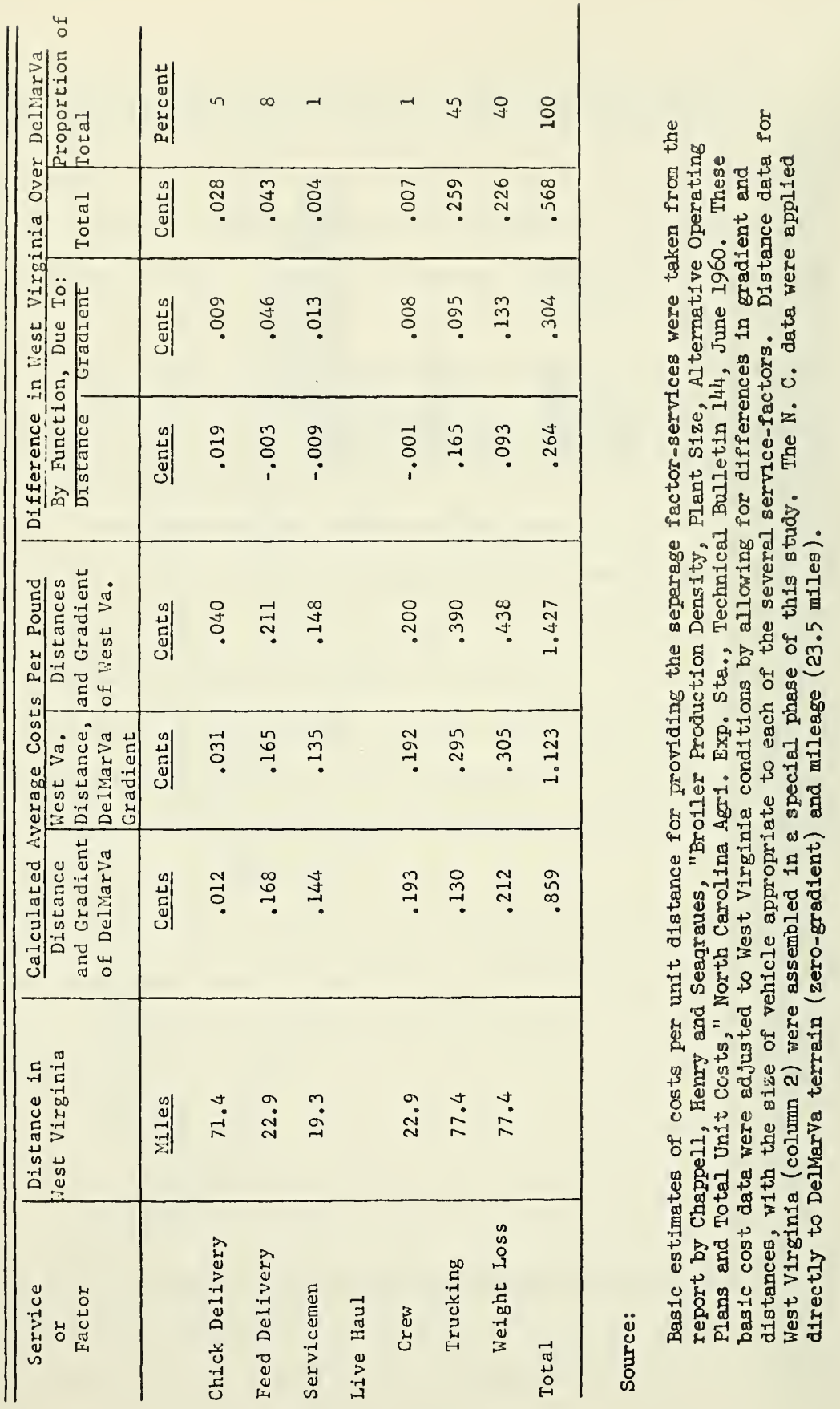


to Maine probably is a reasonably close approximation to the realized reductions in rates per se, aside from the value of in-transit service. In December 1964, a modification of the New England rate structure became effective which limited the upper New England area to the midwest-Boston rate, plus 2 cents per 100 pounds. By this action the total reduction from Ohio to Maine points was on the order of 12 cents per 100 pounds, about 7 cents per bushel, or approximately 20 per cent.

An important reason for the reduction in all cases was to cope with the unregulated truck competition and in the interest of trying to maintain a broiler industry within the respective service regions, thereby maintain a demand for the feed-hauling service. A new appreciation for the elasticity of demand for freight service no doubt greatly influenced actions of all rail lines servicing the entire eastern and southern areas.

The task of evaluating the effect of the rates for the new kind of rail service on the delivery costs of feed in the different broiler and egg producing areas along the East Coast and in the South is complicated by several considerations. First, it is to be noted that the rates for the new service apply to corn and other whole grains but not to grain products nor to soybean meal which is the second most important ingredient of poultry mash. Second, relatively little non-transit corn was carried by rail to the East Coast and South; much was carried by trucks and barges, except to New England. The truck rates have never been commonly quoted, but based on available information they apparently were just a few cents per 100 pounds above the rates for the new type of rail service in the area previously served by trucks. Moreover, some truck rates were lowered following introduction of the new rail service. 
Even if complete information were available on the mode of transport, it would not be possible to exactly ascertain the separate effects of the rate changes on delivered costs of feed because the shift to rail transport has generated modifications in geographical pattern of demand and prices for grain in the surplus grain area. Finally, some changes have been in effect too short a period to be appraised and it is to be recognized that the rate relacionships are still far from finally determined, even for whole corn. In addition, currently under consideration by railroad rate committees are proposals to extend the new lower-rate service to grain products and soybean meal which could generate further regional realignments, particularly as between the surplus feed area and important poultry areas along the East Coast and in the South.

In view of the foregoing, any assessments as to the net effects of the change in rail service and associated rates must necessarily be preliminary and tentative. Based on spot checks for the purpose of this study it was found that the delivered costs of whole corn to West Virginia destinations were reduced by 3 to 4 cents per bushel, as compared with the previous rail rate structure and relatively heavy movement by truck. Approximately the same reductions apparently took place in the Central Eastern area, i.e., southern Pennsylvania, Maryland, and Delaware. Specific data were not obtained that would permit a judgment for New England and upper portions of the middle Atlantic states, but since these areas are beyond the usual trucking distance, the actual reductions probably more nearly paralleled the rail rate reductions and may have been scmewhat greater than in DelMarVa and West Virginia. In the Southeast the reductions were far from uniform, ranging from very small near the barge terminal points to as much as 10 cents per 100 pounds at inland points. Partly offsetting the reductions to the 
Southeast has been the reported tendency for decidedly lower short-haul rail rates to minimize within-area seasonal corn price declines at harvest time. To the extent that different farmers are involved, this tends to improve the income position for those selling corn and to raise costs for locally produced corn used by poultrymen. On balance, therefore, it is difficult to ascertain an exact estimate of the average reduction in the Southeast, although it may have been slightly greater than in West Virginia and points to the east and slightly to the north. Since corn makes up no more than twothirds of a ton of broiler mash, the reduction in cost of the finished broiler feed, stemming solely from the change in mode and rate of freight transport, probably was no more than $\$ 1.25$ per ton to West Virginia and DelMarVa. In terms of live broiler, this would mean a little over one-tenth cent per pound. The average equivalent reduction for the Southeast and New England probably was slightly greater. In all areas, the reduction in terms of cost equivalents would have been less for eggs than broilers because corn and other grains (shipped in whole form) make up a smaller proportion of the completed ration.

Introduction of the new rail freight service and associated rates generated substantial geographical shifts in demand for grain in the surplus areas. To abstract from these influences for the purpose of evaluating the over-all effects of the new freight service on delivered costs of feed to farmers, a comparison may be made of surplus-deficit area differentials before and after initiation of the new service. Calculations of changes in differentials for broiler mash and egg mash, respectively, are given in Tables 7 and 8 .

In interpreting the comparisons it is to be recognized that the initial data have some limitations, as explained earlier, due to the fact that they 
apply only to transactions entailing a change in title to the feed. In addition, the state averages are reported only to the nearest figure (per hundredweight) divisible by five, and certain non-transport factors are generating shifts in relationships among states. However, confining the comparisons to a short period following the sate changes (as compared with a year earlier) the influence of these as well as the usual seasonal factors can be minimized.

In Section I of both tables, the differentials of prices paid in each of the indicated states over the average price in the east north central region are shown. The regional average was used here (as opposed to an average for a single state) as a base of comparison in order to avoid distortions steming from geographical shifts in demand within the surplus grain area which followed the major shift in mode of transport. All areas of the East and most areas of the Sowth report drawing grain from the east norti central region. (In recent years the annual average price of laying mash in the east north central states has been uniformly above the west north central states by $\$ .05$ per 100 pounds. However, the broiler mash differential has been successively $\$ .23, \$ .30$ and $\$ .36$ in 1962 through 1964 , compared to $\$ .24$ in 1960 and 1961.$)$

In Section II of each table the calculated differentials of each state over the east north central states are shown for the 6 months imnediately after the change in freight rate structure, along with the comparable differentials for a year earlier. Shown in Section IrI are the changes in the differentials expressed in Section II. While there was some increase in differential for the east north central states over the west north central group in the last 2 years, similar comparisons for the 6-month periods using 
TABLE 7: PRICES PAID BY FARMERS PER HUNDREDWEIGHT FOR BROILER HASH IN SULECTED STATLS LESS PRICES PAID IN EAST NORTII CLNTRAL STATES, 1953-64, WITH COMPARISONS FOJ, OIIING INTRODUCT ION OF NLT FREIGIT RATE STRUCTURES IN 1963-64.

I Prices paid in folling states minus prices in East North Central States (in dollars per 100 pounds):

Maine Conn. Del. Va. H.Va. N.C. Ga. Ala.

$\begin{array}{lllllllll}1953 & -.02 & .01 & .04 & .18 & .20 & .35 & .53 & .54 \\ 1954 & .02 & .02 & .01 & .16 & .17 & .28 & .51 & .38 \\ 1955 & -.03 & -.02 & .06 & .21 & .31 & .36 & .49 & .42 \\ 1956 & .19 & .22 & .22 & .32 & .43 & .34 & .50 & .39 \\ 1957 & .21 & .17 & .07 & .34 & .36 & .35 & .44 & .33 \\ 1958 & .12 & .28 & .25 & .42 & .42 & .42 & .38 & .68 \\ 1959 & .30 & .30 & .18 & .37 & .42 & .31 & .23 & .24 \\ 1960 & .16 & .16 & .05 & .25 & .19 & .18 & .06 & .18 \\ 1961 & .18 & .14 & .07 & .31 & .17 & .11 & .05 & .09 \\ 1962 & .17 & .11 & .18 & .32 & .10 & .11 & .02 & .05 \\ 1963 & .16 & .08 & .20 & .28 & .16 & .08 & .01 & .15 \\ 1964 & .17 & .17 & .25 & .28 & .16 & .06 & .06 & .05\end{array}$

II Differential calculated as in I for first 6 months following change in freight rate structure compared with year earlier (in dollars per 100 pounds):

Differential:

$\begin{array}{llllllll}\text { Post-Change (1) } .14 & -.02 & .18 & .26 & .14 & .06 & .03 & .14 \\ \text { Year Earlier (2).21 } & .09 & .17 & .31 & .12 & .14 & .03 & .05\end{array}$

III Reduction in differential, post-change compared with year earlier (in dollars per 100 pounds):

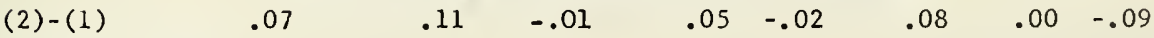
Effective date of adoption of rail rate $7 / 15 / 64 \quad 7 / 15 / 6412 / 18 / 634 / 15 / 63 \quad 8 / 1 / 634 / 15634 / 15 / 63 \quad 4 / 15 / 63$

Data on prices compiled from "Agricultural Prices," monthly release of Statistical Reporting Service, U. S. Dept. of Agriculture. Information on effective dates of freight rates obtained from Rallroads and/or Interstate Commerce Cormission. 
TABLE 8: PRICES PAID BY FARMERS PER HUNDREDWEIGHT FOR LAYING MASH IN SELECTED STATES LESS PRICE PAID IN EAST NORTH CENTRAL STATES, 1953-64, WITH COMPARISONS FOLLOVING INTRODUCTIONS OF NEW FREIGHT RATE STRUCTURES IN 1963-64.

I Prices paid in following states minus prices in East North Central States (in dollars per 100 pounds):

$\begin{array}{lllllll}1953 & -.04 & -.09 & .16 & .17 & .46 & .60 \\ 1954 & -.01 & .08 & .19 & .13 & .35 & .46 \\ 1955 & -.05 & -.03 & .8 & .25 & .46 & .52 \\ 1956 & .03 & .04 & .24 & .30 & .37 & .44 \\ 1957 & -.02 & -.01 & .26 & .24 & .39 & .43 \\ 1958 & .01 & .10 & .31 & .25 & .44 & .41 \\ 1959 & -.04 & .06 & .25 & .25 & .37 & .33 \\ 1960 & -.08 & .03 & .20 & .21 & .32 & .31 \\ 1961 & -.08 & .02 & .22 & .26 & .26 & .26 \\ 1962 & -.06 & -.01 & .30 & .31 & .32 & .23 \\ 1963 & -.40 & -.47 & .26 & .25 & .21 & .26 \\ 1964 & -.48 & -.65 & .23 & .26 & .21 & .23\end{array}$

II Differentials calculated as in I for first 6 months following change in freight rate structure compared with year earlier (in dollars per 100 pounds):

Differential:

$\begin{array}{lllllll}\text { Post-Change (1) } & -.25 & -.67 & .25 & .21 & .20 & .20 \\ \text { Year Ear1ler (2) } & -. .44 & -.61 & .28 & .28 & .33 & .22\end{array}$

II Reduction in differential, post-change compared with year earlier (in dollars per 100 pounds):
(2) $-(1)$
$-.19$
$.07 \quad .03 \quad .07$
.13
.02

Effective date

of adoption of rall

rate

$7 / 15 / 64$

$7 / 15 / 64 \quad 4 / 15 / 63 \quad 8 / 1 / 63 \quad 4 / 15 / 63 \quad 4 / 15 / 63$

Data on Prices compiled from "Agricultural Prices," monthly release of Statistical Reporting Service, U. S. Dept. of Agriculture. Information on effective dates of freight rates obtained from Railroads and/or the Interstate Commerce Commission. 
the west north central group as a base of comparison yielded no greater, but less uniform differentials, for the several states.

Assuming that the changes noted are both accurate and statistically significant, in general they confirm the indications above, based on delivered costs of corn, to the effect that the economic consequences of the revolutionary changes in rafl service and rates have been comparatively mild. The greater reduction for New England adduced above from rail rate data are confirmed by these comparisons for broiler mash (The laying mash series for New England since February 1963 has been non-comparable in level as contrasted to earlier years, so perhaps should not be seriously considered in the present context). ${ }^{1}$ The larger change for North Carolina than Georgia is noteworthy; it appears to lend support to the conclusion that the nearer to barge terminal points, the smaller the change in delivered costs of either feed as a result of the new rates. These data suggest that West Virginia showed more improvement than a number of other localities for egg mash but on broiler mash showed a slight negative change (i.e., a slight increase relative to prices in east north central states). Slight negative changes also are shown for Alabama on broiler mash as well as for egg mash $(\$ .02$, not shown in table).

Narrowing of differentials over the midwest in magnitudes such as $\$ .07$, $\$ .08$ and $\$ .11$ for Maine, North Carolina, and Connecticut, of course, is not unimportant, particularly in view of little, or possibly slightly negative,

\footnotetext{
1 Beginning in February 1963 the Statistical Reporting Service began to collect data on laying mash in a manner to more accurately reflect the large quantity, lower priced transactions. This resulted in a substantially reduced general level of average prices. Instability from the change may help account for the unusual figure for Maine in Section III of Table 8. (15)
} 
changes for some other states. However, even the largest decreases in differentials (over midwest) are small relative to the difference in rates for the new rail service compared with the standard (involving in-transit, of course, etc.). Moreover, the shifts stemming from rail rate changes are very small in comparison with observed changes among states over the past decade or longer.

While the effect of the recent rail rate changes have been comparatively limited in terms of economic effects among producing areas, they have generated momentous shifts in mode of transporting grain to some areas and in geographical patterns of demand for grain, warehousing, and handling services. As a result of the shift to rail, particularly with emphasis on through-shipments, many terminals in both origin and destination areas have become out of position.

Changes in Industry Structure Probably Had Differential Effects Among Regions

The broiler industry of the United States probably is characterized by more extensive changes in industry structure and methods of conducting business than any other livestock enterprise. One important incentive for entering into farm-non-farm entity agreements, or arrangements for financing broiler production, grew out of efforts by the feed suppliers to achieve greater feed volume. Phillips (14) reports the following several sources of added income to feed manufacturers under financing and contractual programs:

A. Charges on the Feed:

1. Interest on the feed financed.

2. Per ton services on the feed finances.

3. Savings on cash discounts available on cash sales.

B. Charges on Production Items:

1. Interest charges on production supplies financed.

2. Margins on supplies tied in with the programs.

3. Margins on feeder and breeder stock tied in with the programs.

4. Miscellaneous sources of income. 
C. Cost Savings in Feed Production and Distribution: scheduling.

2. Savings on delivery costs because of larger orders.

3. Savings in production costs because of larger volume.

It is clear that Phillips was referring to the mid-west kind of livestock industry, but, except for terminology, the same principles apply to poultry and egg production anywhere in the United States.

Many differences among regions exist in the types or details of contracts employed but the general effect has been for the non-farm entities to cooperate with the farm venture in financing and in the sharing of price, disease, and other uncertainties involved in the broiler grow-out operation. In return the supplier of the feed and, in many cases, the baby chicks, is given some share in return over what a strictly cash sale would have been, either explicit sharing, or a higher price for the feed and/or chicks. With the rapid introduction of technological advances during the $1950^{\prime}$ s it is entirely likely that the opportunity for financial gain in the contest for supremacy in the technological aspects of poultry production also served as an impetus to the contracting arrangements. The opportunities for benefiting from this were especially prevalent for the regional or national concerns since experiences gained in one part of the country could be quickly applied to all other areas in which the particular firm operated. The introduction of technology ahead of competitors, in effect, gave a temporary advantage that helped to increase returns to capital for the particular enterpriser making such introductions. It also helped to assure a larger feed volume, or a larger source of chickens for processing in case it was a processing firm, which financed the grow-out operation.

For the country as a whole, it is now believed that in excess of 90 per cent of the broiler volume is produced under some type of contractural 
arrangement between a non-farm entity (a supplier of feed, or chicks, or a purchaser and processor of the finished product) and the broiler grow-out operator at the farm level. A high degree of such integration is in existence in every major broiler producing area of the country. However, there is a substantial difference among areas in the degree of participation by national or regional distributors. This may have implications for rates of adoption of new techniques and margins in feed handling.

Currently, West Virginia broiler producers rely almost entirely on intra-state distributors of feed. The relatively few non-farm supplyingfirms operating in West Virginia apparently are well liked by the growers, and the operators of the firms apparently also are tolerably satisfied with the existing state of affairs. 1 It is noteworthy, nevertheless, that production of broilers in the State has declined about 40 per cent in the last five years. One possible difference for West Virginia, as compared with other areas, in the 1 ight of the relatively few non-farm entities involved, is that the supply of capital available to the broiler industry of the State may be more ilmited as compared with some other sections of the United States. 2 A second difference may be that the introduction of technology, particularly in the last five or eight years may have come at a slower rate

${ }^{1}$ As a method of maintaining good-will of its customers, a major firm in the State in two recent years made payments to growers for each pound of live broiler delivered as a result of the contract, amounting to one cent per pound in the first year and one-half cent the second year.

${ }^{2}$ Inter-state comparisons with regard to capital were not made in the course of this study but the absence of regional or national integrators in West Virginia suggests the likelihood that one or both of these conditions prevail. 
within the State and thereby added to the relatively adverse conditions stemming from the shift in other relationships to be discussed in Part II. Capital requirements for the non-farm entities involved in the broiler grow-out operation increase very rapidly with the scale of business. In the past few years, a number of such firms in the South and in the Southwest have made arrangements to sell stock to the public. This has permitted them to obtain additional equity capital in the national securities markets.

ADVANCES IN PRODUCTION TECHNOLOGY CAN

HAVE DIFFERENTIAL EFFECTS AMONG REGIONS

Although technological innovations for producing a given item may be adopted rather uniformly in all areas within the United States, this adoption likely will have differential effects among regions. In judging the effects of such changes, it is necessary to note that: (1) the relationship of feed input to product output for both broilers and eggs, while declining, still is greater than one to one, (2) the cost of feed accounts for the bulk of cost of production of both eggs and broilers, and (3) the transport rates per unit of weight are much lower on grain than on eggs and broilers.

The above conditions and their possible potential importance in tending to relocate the poultry industry can be shown by the use of an arithmetic, partially hypothetical example, such as shown in Table 9. This table is designed to compare the influence of: (1) a change in freight rates on feed 
similar to that announced by some railroads in $1963-64^{1}$, and (2) the difference in efficiency of producing broilers and eggs as between 1945 and 1963. The relative importance of these changes is illustrated by comparing changes in the costs of shipping eggs and broilers with the cost of shipping their feed equivalent from central Illinois to the eastern shore of Maryland.

\section{Influence of Freight Rates}

The difference between columns 1 and 2 for 1 ines 1 and 2 reflect the reduction between 1945 and 1963 in the amounts of feed required to produce the two products - 29 per cent for eggs and 42 per cent for broilers. While the data may be somewhat less exact for 1945 than for 1963, any inaccuracies are not believed to interfere with the general conclusions.

Focusing first the columns (2) and (4), with respect to eggs, the reduction in freight rate on feed from $\$ 0.75$ to $\$ 0.40$ per 100 pounds, lessened the cost for shipping the feed equivalent (in 1963) to 100 lbs of eggs from $\$ 2.50$ to $\$ 1.33$, a reduction of $\$ 1.17$, or 47 per cent. Given a shipping rate on eggs of $\$ 2.00$ per cwt, the reduction in freight rate on feed, by itself, transformed the situation from one in which it cost 25 per cent more to ship

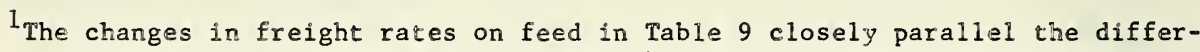
ences between rail rates for the (former) standard service and the rates for the new, non-transit, quick turn-around service which was put into effect during 1963 and 1964 by several railroads serving the east and southeast. Nevertheless, the data are partly hypothetical for the following reasons, at 1east: (1) the actual new, lower rates apply to whole grain and not to other ingredients of poultry rations; (2) the reduction in delivered cost to producers just for whole corn has been less than the difference between the standard service rates and the "new" rail rates since truck rates were considerably below the standard rail rates, and (3) the "new" rates do not yet apply all the way from Peoria, Illinois. These deviations from reality merely result in some exaggeration of consequences but do not interfere with illustration of the principle. Application of the "new" rate structure to soybean meal and possibly other ingredients would introduce still more realism. 
the feed than the eggs (Col. 2), (\$2.50-\$2.00 $\$ 2.00) \times 100)$ to a situation where it costs 33 per cent less, (Col. 4), (\$2.00-\$1.33 \$2.00) $x$ 100). Comparable calculations based on 1945 feed-to-product ratios i.e. columns 1 and 3 , would have entailed shifts from where the cost of transporting the feed was 75 per cent greater than transporting the egg equivalent, to one in which it cost 6 per cent less to transport the feed. But, as indicated, this would not seem the appropriate approach since the change in freight rates occurred under conditions more nearly representing 1963 poultry production technology.

Focusing now on the data pertaining to broilers in columns 2 and 4: The effect of the freight rate reduction was to lessen the cost of shipping the feed equivalent (in 1963) to 100 pounds of broilers from $\$ 2.47$ to $\$ 1.32$, 53 per cent. In contrast to eggs, even after the freight rate reduction, the cost of shipping the feed equivalent to the product exceeded the cost for shipping the product itself. But the margin was reduced substantially, from $\$ 1.20$ more, 94 per cent, (Co1. 2), (\$2.47-\$1.27) $\$ 1.27) \times 100)$ to only $\$ 0.05$ more, 4 per cent, (Col. 4), (\$1.32-\$1.27) $\div 1.27) \times 100)$. Similar comparisons could be made using the 1945 feed-to-product conversion rates, i.e. comparing columns 1 and 3 but, as for eggs, this seems inappropriate.

\section{Influence of Feed Efficiency}

The increase in efficiency of feed conversion has occurred over a period of years, although the period has been relatively brief considering the progress accomplished. Relocational effects of this factor must be judged in terms of "what would have been" if such advance had not taken place. If there had been no improvements in efficiency of feed use whatsoever between 1945 and 1963, it would have been necessary to have only two columns in the 
table, columns 1 and 3 .

The influence of the improvement in feed efficiency on regional locational tendencies is indicated by the comparison of columns 1 and 2 or 3 with 4. The influence, expressed in monetary terins, obviously will be

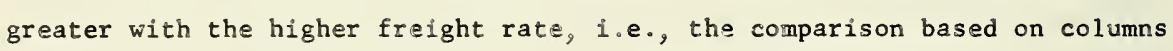
1 and 2. For the present illustration, the lower freight rates will be assumed for both levels of technology. For eggs, these data (cols. 3 and 4) indicate it would have been more economic to ship the feed than the product under both levels of technology. However, it would have cost 33 per cent less to ship the feed equivalent under 1963 technology, in comparison with 6 per cent with 1945 technology. Fo: broiler'; the reverse would have prevailed - it would have cost $h$ i per cent less to ship the product than the feed equival $t$ under 1945 technology and 4 per cent 1 ess under 1963 technology.

Clearly, changes in both freight rates and in technology can exert pronounced (although not necessarily controlling) tendencies on re-location of such industries. In this rather crude, though reasonably realistic, example it is not possible to exactly ascertain the separate contributions. However, upper and lower lirits can be derived. Of the cotal reduction of $\$ 2.17$ in cost of shipping feed equivalent to 100 pounds of eggs, freight rate reduction would account for between 54 per cent and 75 per cent with, of course, the other 46 per cent to 25 per cent attributed to technology of egg production. For broilers, each factor apparently accounted for one-third to two-thirds.

It is to be emphasized that as large as are these magnitudes, their influence may be offset or overshadowed by changes among producing areas in opportunities for producing other 1tems as well as shifts in demand among regions. 
Technology of production has increased more for broilers in the United States than for any other 1 ivestock product. Necessarily, this has taken place in all areas since World War II. There could be no standing still. Progress or perish was the dictum of the competitive process. And so all areas did progress, more or less.

In our modern society, technological progress has come to be looked upon as the result of a conscious investment in research to devise and apply new methods, although, in the process, accidental discoveries frequently flow from such major efforts. Practically every land-grant college in the United States has a substantial poultry department conducting research on methods of production, processing, distribution, etc. In addition, many non-farm entities have major research departments, including experimental farms, in order to test the feeds or drugs that may be produced for the purpose of aiding in the poultry production and marketing process. Once an innovation is devised, indfvidual growers have no choice but to adopt such innovations lest they fall completely off the "tread mill of progress." Progress in production and marketing of broilers is a result of some major advancements and many minor ones.

Trying to enumerate the many specific reasons for the progress in the broiler industry is not unlike the task of trying to identify specific reasons for economic progress as a whole. On the latter, Frofessor George Stigler of the University of Chicago has stated very concisely some observations highly relevant to the present matter, as follows: 
Although the sources of rising efficiency of our economic system are very imperfectly known, I believe that the dramatic invention and the large research projects containing the panoply of modern seiencists have been given entirely too much credit. The accumulating effects of a thousand minor improvements in a thousand enterprises each day, many of these improvements deriving much more from pragmatic business skills than from formal seience, have played a very large role in our progress. It is quite possible that the supermarket has meant more for economic progress to date than atomic energy.

This passage is relevant even to the point of mentioning the supermarket. This relatively new institution has made immeasurable contributions to the development of the broiler industry in this country by its broiler sales efforts. It is sometimes maintained that the special pricing practices of grocery stores with respect to broilers actually result in a lower average price to producers than would prevail of they maintained a steady price at a higher level. In all likelihood the decision to merchandise poulery in this manner is not one made out of thin air. Rather it probably is based on experimental evidence as far as the supermarket is concerned recognizing the elastic nature of demand for chicken, that a larger quantity of its services can be sold in this manner than if the prices are maintained at a steady level at some higher figure, and that larger total revenue will be realized by the store's sales of such services. By the same token, given the nature of demand at the farm level for chickens and with the prevailing level of technology in the industry, it is likely that if the supermarkets kept for themselves a larger portion of the consumer's dollar, the returns to farmers would be lessened considerably from those prevailing. In other words, to have maintained gross cash receipts from live broilers at the one billion dollar figure since 1958 would have required a U. S. production increase of more than the one-third. 
Stigler goes on to say,

Three facts suggest the importance of small, frequent, and diverse improvements. First, our rate of economic progress per capita was at least as large before 1914, when science played a less prominent role in economic life than today, as it has been since then. Second, for the nation as a whole the rate of economic progress has been remarkably stable, whereas the "great invention" theory would lead us to expect great surges and lapses in the pace of progress. Third, technological progress has been taking place over a wide range of industries and not concentrated in a few industries at any one time.

Certainly it is no exaggeration to say that the broiler industry owes its rapid development to numerous small advances as well as to some major ones. With respect to the latter, incidentally, the Agricultural Research Service of the United States Department of Agriculture, in 1954 and 1955, conducted a two-trial experiment designed to measure the contribution of two separate advances in technology: (1) improvements in strains of birds and (2) efficiency of feed. (17) With respect to the term "feed," it is to be recognized that more non-nutritive components are included than formerly, some of which have medicinal and/or growth-stimulating properties.

In this experiment three strains of birds were used (1) an improved, pre-war Rhode Island Red, (2) an unimproved meat-type New Hampshire, and (3) a New Hampshire-Silver Cornish cross. These birds were representative of birds used in 1930, 1945, and 1954, respectively.

The 1945 ration had certain shortcomings owing to wartime shortages of ingredients, which prevented full application of known technology and gave inferior results. (Apparently a comparable experiment has not been run based on technologies known or in existence at that time.) The experiments were run twice.

Over the 24-year period, the combined effects of improvements in feed and genetics were reductions of about 17 per cent in time to reach a given 
weight and 30 per cent in feed. Increased efficiencies for both time and feed were attributed about equally to advances in genetics and in nutrition, although the latter is popularly given major credit because feed efficiency is a measurable phenomenon. Presumably the management techniques and other conditions were unfform among all trials and were of reasonably (then) current vintage.

For more recent years, a number of agencies have conducted tests as to performance of chicks and feed employing up-to-date techniques generally. While the data from such tests do not permit allocation as between feed and chicks, they do permit a rather precise comprehensive measure. Using data, for example, from the Maine Department of Agriculture (18) it is possible to illustrate over-al1 improvement for the past 15 years. This improvement is implicitly represented, of course, by increased feed efficiency, for whatever reason, and reduction in time required to grow out a brood of broilers. These data are shown in Figure 10. Roughly, over the time span 1949-63, the time required for broilers to reach 3.3 pounds, as indicated by that test, was reduced from 83 days to 49 days, a decline of about 40 per cent. The quantity of feed required per unit of terminal live weight was reduced from 3.4 pounds to 1.9 pounds 1 , a decline of 45 per cent. These two developments account for much of the explanation for the rapid increase in broiler production despite the rather pronounced steady decline in "real" price received by growers for live broilers (Figure 10). (This real price is the United States annual average price received by growers for live broilers divided by

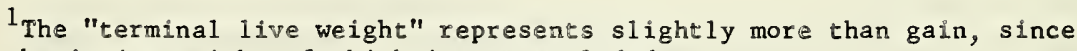
beginning weight of chick is not excluded. 
Table 9. Costs of Shipping Broilers and Eggs Compared with

Feed Equivalent Thereof Under Two Sets of Freight Rates and Production Technologies, Central Illinois to DelMarVa. 1

(1)

(2)

(3)

(4)

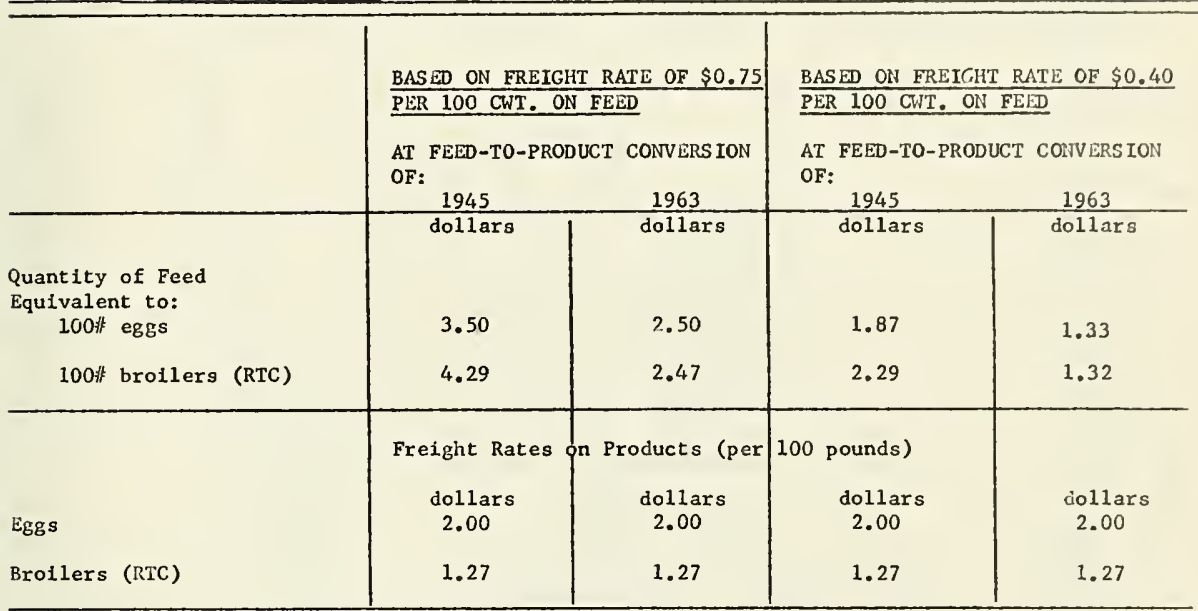

1 Frelght rates on feed closely approximate changes which became effective in $1963-64$. Rates on products approximate recent rates and were assumed not to have changed much from mid$1940^{\prime}$ s considering shift in mode of transport and in transport technology. The following feed-to-product conversion rates were used: brollers (live) 4.0 pounds in 1945 and 2.3 pounds in 1963; eggs ( $24 \mathrm{oz}$. size) 7.0 pounds per dozen in 1945 and 5.0 pounds in 1963. For both years, assumed ready-to-cook poultry equaled 70 per cent of l1veweight. The shift fram shipping New York dressed poultry to eviscerated birds, other things being equal, would favor heavier concentration of production in the midwest. However, as observed, a shift out of the midwest is taking place. (For supplementary interpretation, see footnote 1, page 54). 


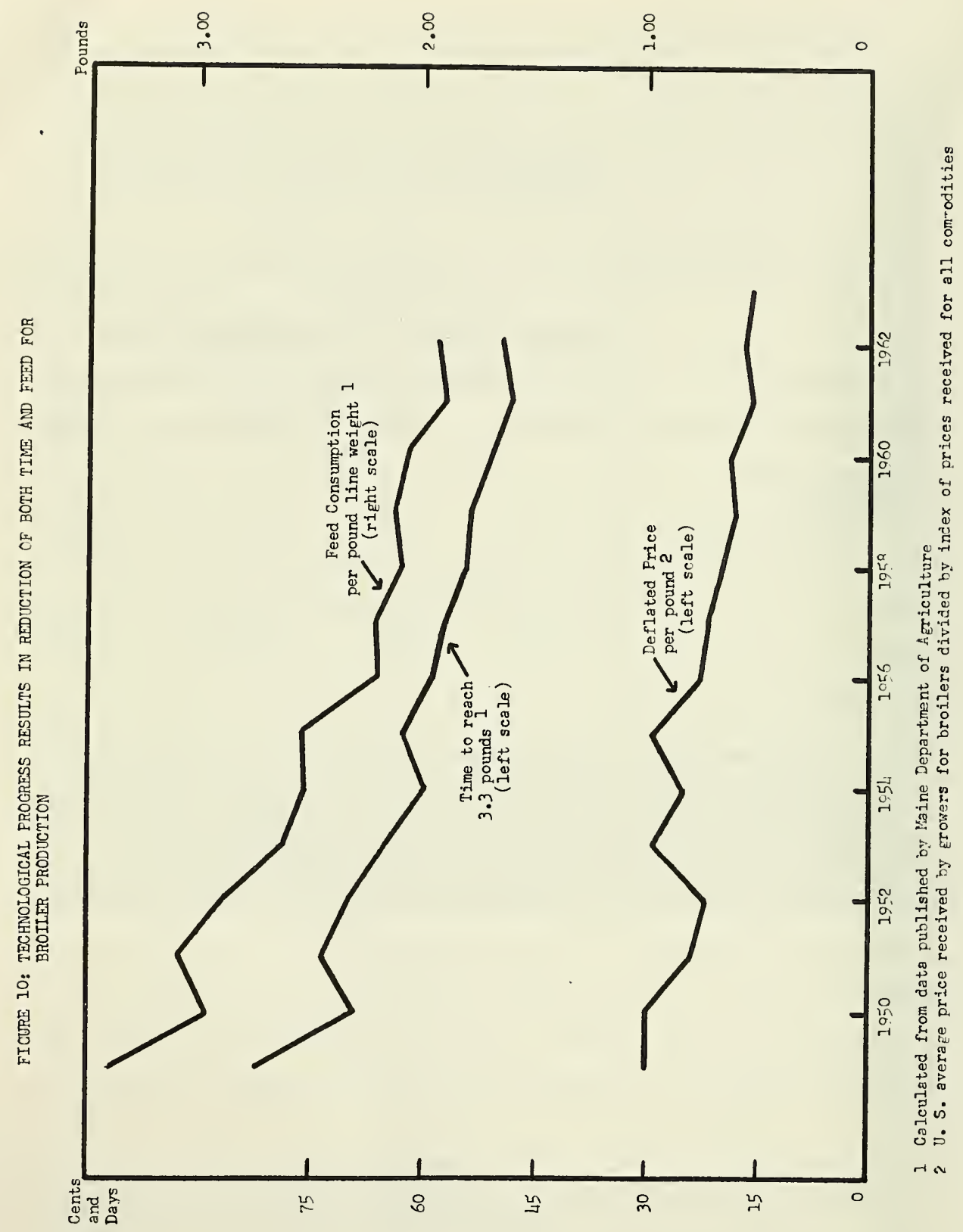


the index of prices received by farmers for all farm products, 1947-49=100).

The increase in the growth promoting quality of feed has been accomplished apparently without increasing the price as compared with pre-war levels. The cost of the modern ration with all of its additives, (and superlatives) is no greater than the pre-World War II ration.

No further attempt will be made here to identify and measure the contribution of the separate innovations to the over-all improvement in poultry production. It is rather clear, however, from a cursory examination of available data that unless care is exercised in the interpretation of such data, the sum of the parts would exceed the whole? Whatever the nature of the production advances, many of the effects are shown in the feed consumption rate or conversion ratio and others in the time required. This reflects improvements in feed, disease control, improvements in genetic quality of the bird, as well as management in its entirety. Besides these major advances we have Stigler's "one thousand minor improvements" - from "pragmatic business skills" to allow for in explaining the total improvement.

The impact on West Virginia of the expansion in broiler production has been two-fold. Producers elsewhere have simultaneously applied improved technology, and many have increased production, resulting in declines in prices because of the larger supplies on the national market. In addition, some of the lower cost areas probably would have come into the production picture even if there had been no changes in technological status, especially the newer areas. This also would have been to the relative disadvantage of West Virginia by increasing the supply on the national market.

West Virginia engaged in broiler production along with Delaware, Maryland, Virginia, and a few other areas, rather early in the history of that industry in the United States. Many people in West Virginia previously ex- 
perienced a greater net per bird than they have received gross per bird in some recent years. It is alleged by some West Virginians that this has been detrimental to the motivational attitude among the growers and potential growers of the State. Incentives of people in the newer areas have not been "handicapped" by such memories, it is claimed, and they are experiencing expanding production with no more net return than West Virginians experienced, and some of them, posibly, not as much.

It is not fully plausible that the high returns of past years uniform1y dampens the incentives of West Virginians to the extent attributed by some observers. It is not likely that West Virginians are so much different from people in other states such as Delaware, Maryland, and Arkansas, where production also started as early, or earlier, but where production has recently shown further substantial increases. Some of the internal characteristics to be discussed in Part II, and contrasted with changes for other states, will give some additional insights into this phenomenon. 


\section{IMPORTANT CHANGES IN RELATIONSHIPS AMONG STATES}

The developments and changes in circumstances discussed in the preceeding part will now be interpreted and appralsed in a manner to illustrate some of their effects on changes among states in production of broilers and eggs. To do this, a few important series will be employed which are both relevant to the purpose as described in the Introduction under "methodology" and meaningful to those engaged in, or associated with, the poultry industry. These series will be presented so as to portray any shifts among areas in the comparative positions relating to production and marketing of broilers and eggs. As indicated also in the Introduction, this is a form of economic analysis within the general category labeled "Studies in Interregional Competition," $(3,19,20,21)$ although an effort will be made to focus primarily on the dynamic aspects.

Some of the trends to be observed will reflect the composite results of efforts by private firms to adjust as the rest of the economy progresses and grows. Due to various factors, the free price system apparently does not function to the same degree of effectiveness in all geographic sectors. Partly for this reason, individual farmers or entrepreneurs located in the different regions probably do not achieve the same degree of performance, reacting to the prevailing economic stimuli, in combining the use of resources at their command so as to optimize returns from them.

It is granted that those areas which may be moving into a disadvantaged situation are more likely to call the foregoing phenomena a "competitive" one than merely a "process of adjustment." In this context the free enter- 
prise system at times can appear brutal and result in very real personal sacrifices and financial hardship. But this is the pattern which has been followed to give the most highly developed economy of the world. The first step to sclving difficult economic problems resulting from such adjustment processes is to interpret recent history, courageously evaluate the present position, and then try to develop a prognosis for the near-term or longterm future.

The central puxpose of this part is to develop meaningeul information with respect to the first two points. Information can be power. With the information on the first two points, decision makers should be able to appraise the future more clearly and thereby nake sounder plans. An analysis of the first two points, moreover, fill permit readers to take account of technological and institutional developments as they transpire and as information about then becores generally available.

\section{Increases in Total Agricultural Output Vary Anong States}

It is not, of cowrse, the central purpose of this study to analyze reasons for changes in total agricultural output for any state involved. To provide a setting, however, for analysis of changes in the production of individual products, in this case broilers and eggs, it is helpful to have a general impression as to the trends in output of the agricultural industry as a whole. Among the reasons for this is that the production of some agricultural products complement the production of others. For example, a thriving livestock industry, to the extent concentrates are used, could mean a strong demand for mixed feeds and thereby help to support the overhead necessary'in supplying poultry feeds. Likewise, at the farm level, some of the overhead costs can be allocated to items other than poultry. 
For the United States as a whole the United States Department of Agriculture has developed and published a series representing total agricultural output. This series has been developed by using prices received by farmers in a representative base period as weights and applying these prices to quantities of individual items produced annually (with allowances for those such as feed grains used in the production of other agricultural items). An index of total agricultural output is obtained then by dividing the aggregate annual values by the average aggregate values for the base years. A similar procedure has been employed by the State Agricultural Statistician for Wisconsin and a production index has been developed back to 1910. For New York state a comparable index is available back to 1950 and for the state of Kansas such a series is available for about two decades. At the University of California, a series was developed in the mid-1950's but apparently has not been kept current.

With the exception of New York none of the states along the Atlantic Seaboard has developed such a series. Accordingly, for this brief reference purpose, series for the individual states were developed by dividing the annual values of farm products sold, plus values of home-produced items consumed in farm households, by the annual index of prices received by farmers for agricultural products in those states, with 1947-49 as base period. The 1947-49 average for each series, so deflated, was divided into the deflated figure for each other year in the period giving what might be termed "a derived index of physical output." For the United States series and for the individual states mentioned above a detailed comparison was made between the published indexes of physical output and the series for those states derived in the above manner. In all cases the average deviations were negligible. The only individual years which showed sharp de- 
partures were those involving either drought or sharp price changes occasioned by war time conditions. It seems reasonable to conclude, therefore, that, assuming that the price indexes for the individual states have been developed with equal precision, the resulting indices are roughly indicative of the relative charges in agricultural output among the states concerned. 1 However, the validity of the series will be less for those states with a greater transformation of their agriculture in recent years.

Data on chysical procuction are reported in Table 10 for the several states surrounding West Virginia and others for which data are avallable and are relevant in considering the changes in relationships among states in the production of broflers and eggs. (See Figure 11 for comparison of West Virginia with total for United States.)

In terms of production of poultxy products and total agrieultural products, individual states may be classified into four categories:

I. Production of poultry froducts increasing and total agrieultural output increasing. The states in this category of those shown in the accompanying table are Tennessee, Mississippi, Arkansas, Alabama, North Carolina, Georgia, and Maryland.

II. Poultry production decreasing, total agricultural output increasing. The states in this category are Pennsylvania and Orio.

It is to be noted that the deflated data on which these index numbers are based are not additive among states. To illustrate the reason for this we have, for example, the case of Illinois selling large quantities reflecting in that state ${ }^{\circ}$ index of production, and a large proportion of such sales moving to Georgia and used in the production of broilers. The method employed will show the production in Georgia to include the corn used in the process of producing the broilers. To this extent it is duplication of the production reported for Illinois and thereby makes it impossible to add data for the several states. 


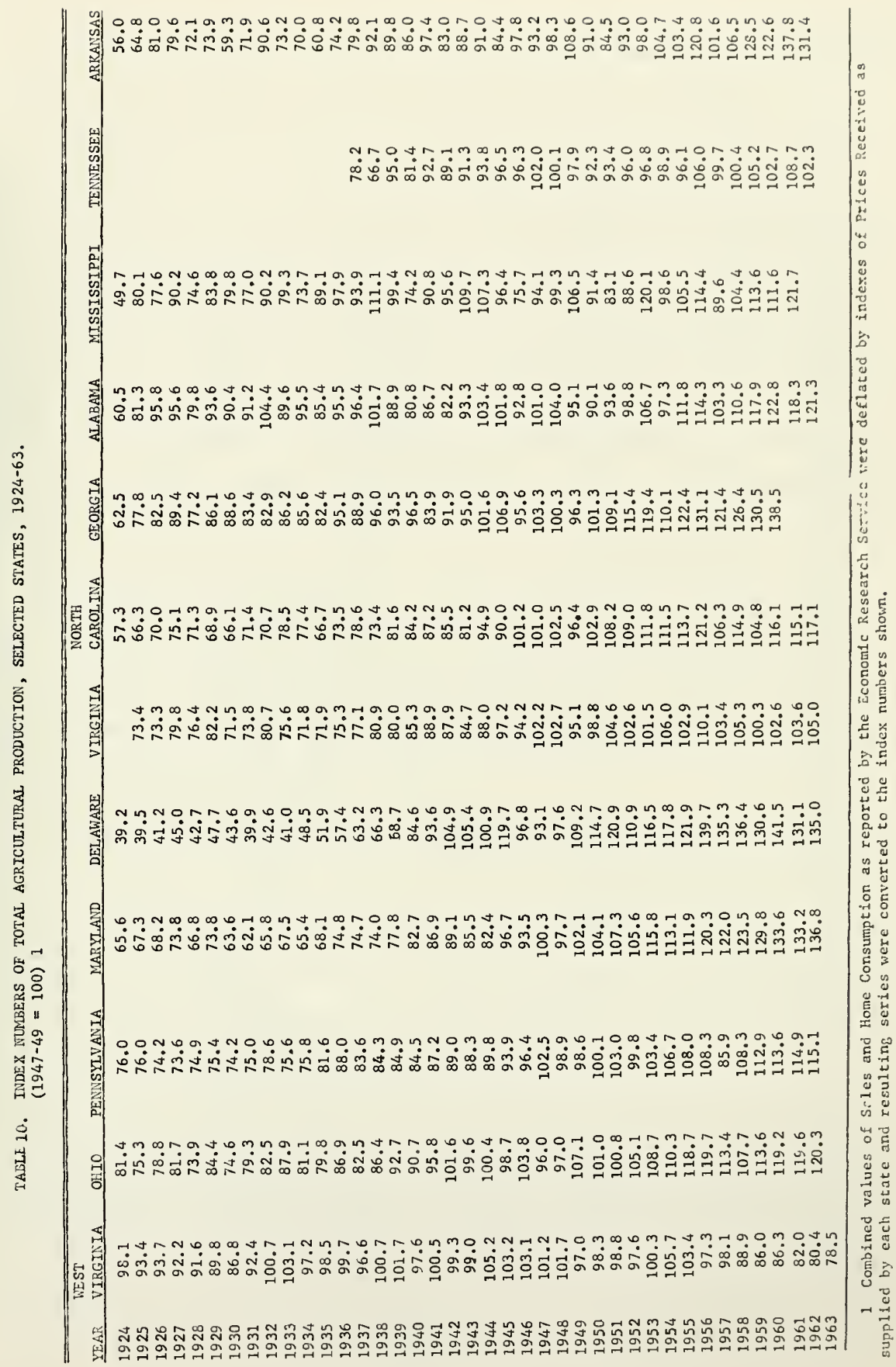




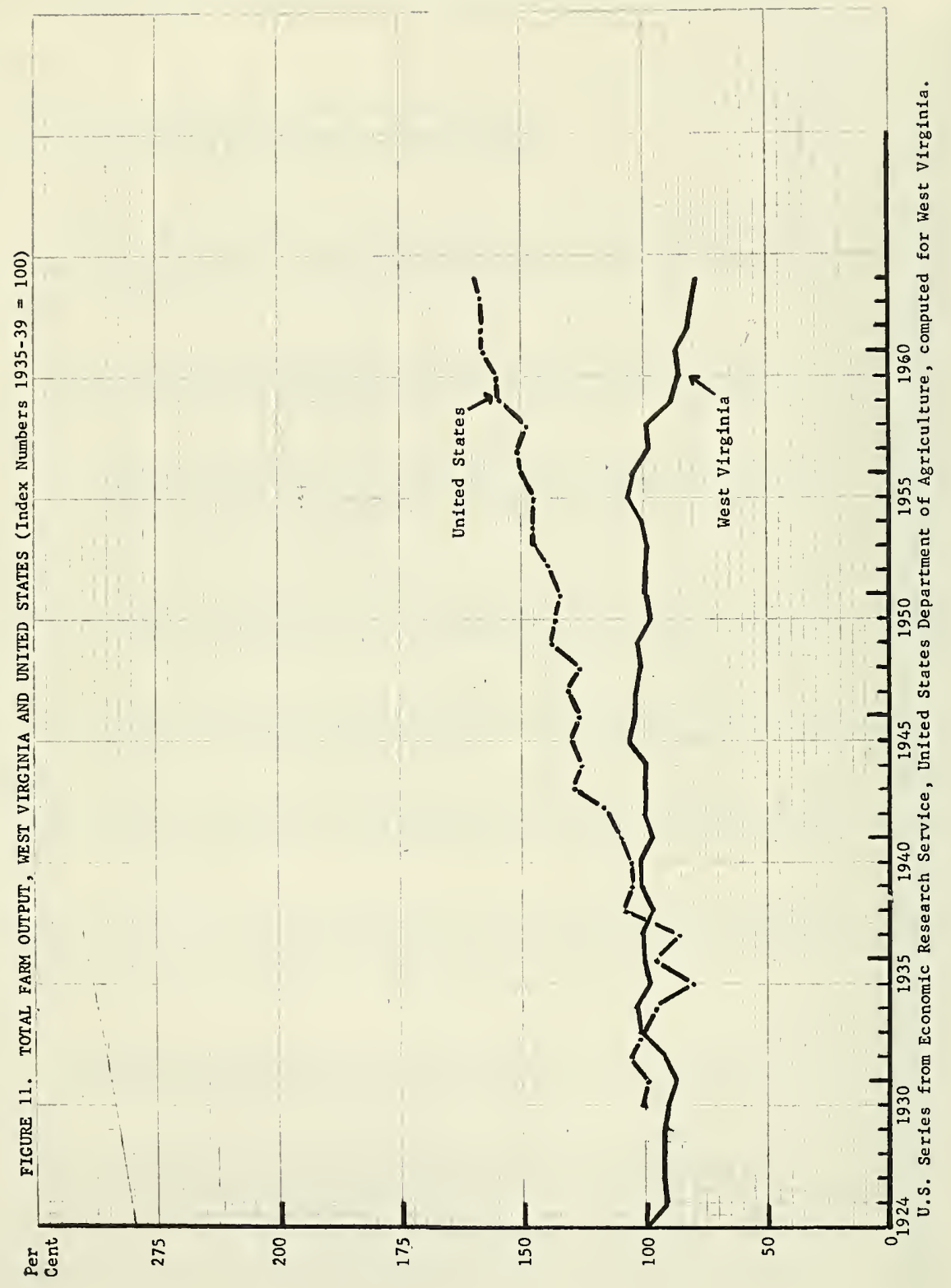


III. Poultry production decreasing, total agricultural output decreasing. The states in this category are West Virginia and possibly Virginia. Virginia is listed only as a possibility because the total agricultural production of that state has fluctuated up and down with slight variation for a number of years and the most recent data, those for 1962, have been exceeded on three previous occasions.

IV. Poultry production increasing, total agricultural output decreasing. In this category is the state of Delaware. Apparently the increase in poultry products, consisting wholly of broilers, has been insufficient to offset the decrease in some other poultry products and in the output in a number of field vegetables.

The significance of situation $I$ is that so long as the output of both poultry and total agriculture is increasing it may be assumed that the increase in demand for resources utilized in farming also is increasing, although a lack of demand for such services in the non-agricultural sector may explain the increased agricultural output.

In situation II, it may be observed that so long as the non-poultry farm output is increasing the resources that were previously employed in poultry production should have reasonably remunerative alternatives. However, with the progress in technology, resources used in poultry do not lend themselves as well to other farming purposes as in past periods. In fact, much poultry is produced in totally non-agricultural settings.

In situation III, it would be indicated that a decrease in demand for all services used in agriculture was taking place. However, such resources could be taken up in non-agricultural pursuits and offser the effects on the total economy. It happens, however, that in West Virginia, the only state of those enumerated above that clearly falls into this category, there has been 
a decrease also in non-agricultural employment.

In category IV it appears that a clear relative advantage has developed for broilers as compared with other facets of agriculture, although the broiler industry is closely linked to the corn-soybean industry of the Eastern Shore. Since increased broiler production is the element giving rise to the increase in the poultry sector this means that substantial off-farm employment is generated also in the servicing involved for providing and processing both raw materials and the finished product.

\section{Changes in Broiler Production by Regions and States}

Before considering some of the motivational elements which have been important in bringing about changes among states and regions in production of broilers and eggs, the magnitude of change within certain areas or regions and the interrelationship of these changes among areas will be considered. This will only be summarized at this point (see Figures $12 \mathrm{~A}$ and $12 \mathrm{~B}$ ). For further detail and intensive study the reader is referred to the appropriate tables.

For the United States as a whole, production of broilers has increased each year since 1934 with two exceptions - 1944 and 1946. (Appendix Table I). Total output exceeded two billion birds for the first time in 1962, having passed the one billion level in 1954.

The rather steady growth in U.S. total broiler production conceals some rather pronounced adjustments among states and regions. Of the 42 states for which broiler production is now reported, 28 are now producing fewer birds than at some time in their relatively recent past. In 15 of these states the declines from 1958 to 1963 exceeded the 30 per cent for West Virginia, with some exceeding a 70 per cent drop. For the 28 states as a group, 


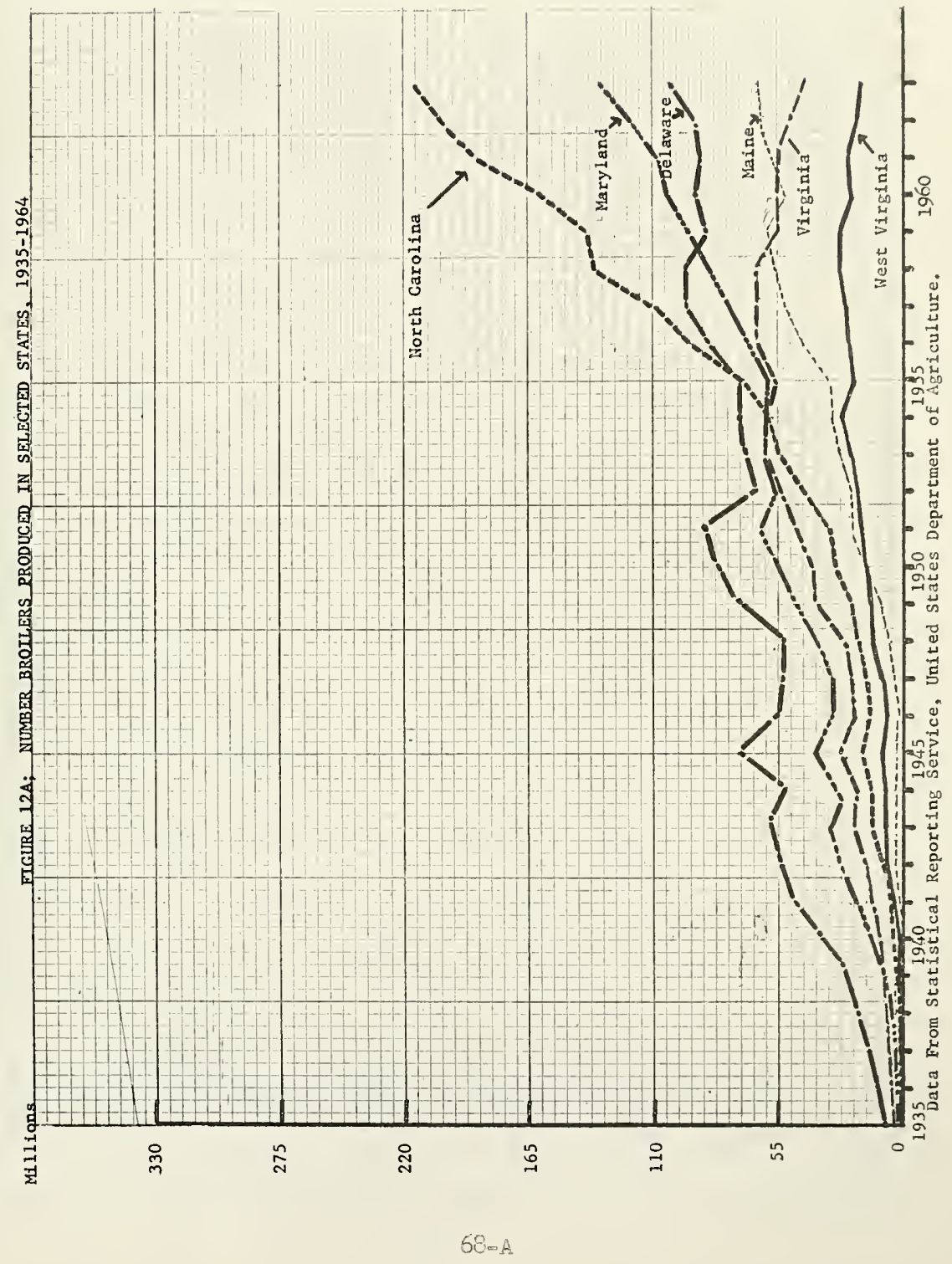




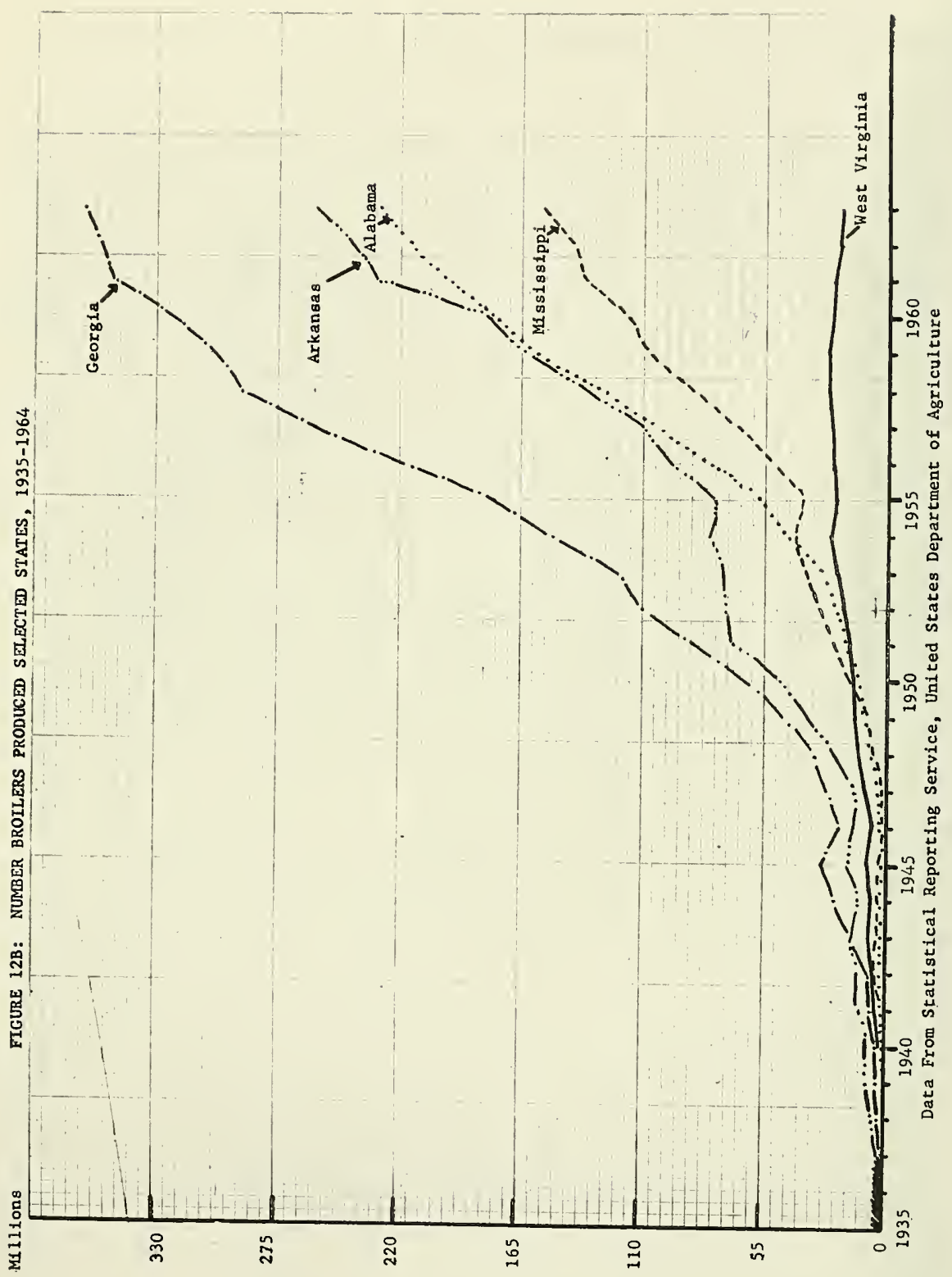


output in 1963 was down 31 per cent from their combined records and 22 per cent from the 1958 combined output.

Through 1963 only 14 states had shown a persistent increase so that the level of output that year was record high. In the 5 years, 1958-63, these states showed a combined increase of 45.2 per cent. Four other states showed an aggregate increase over 1958 of 30 per cent, although each was still below the previous record high. For the 18 states combined, the increase was 44.2 per cent in 1963 over 1958. (Preliminary data indicate that four of the forementioned 14 states turned downward slightly for the first time in 1964).

Concentration of broiler production within a relatively few states is occurring rather rapidly. Of the 18 states which showed increases from 1958 to 1963, five accounted for nearly four-fifths of the 567 million head increase. These, with their proportionate contributions (in per cent) were: Arkansas, (now the second largest producer) 22; Alabama, 17; North Carolina, 14; Mississipp1, 13; and Georgia (st111 the leading producer, 359 million to 259 for Arkansas) 12 .

The scale of enterprise has been increasing for broilers as it has for most agricultural producing units. Not in all states, however, has the number of broiler-producing farms been declining. Alabama, for example, increased from 1,900 farms in 1954 to more than 3,700 in 1959 (Table 11). Between the same two years the average number of birds sold annually per farm increased from 22,000 to 37,000 . States which have shown large increases in total broiler production also had increases in numbers of farms. Beside Alabama, Maine increased from less than 900 farms to 1, 100, North Carolina from 2,900 to 3,400 and Mississippi from 1,200 to nearly 1,500. The two leading states, Arkansas and Georgia, showed small change between 1954 and 
1959 in the total number of farms engaged in broiler production; Arkansas showed an increase of less than one per cent and Georgia less than two per cent. In both instances, however, the output per farm at least doubled. of the states shown in Table 11, only Virginia, West Virginia, and Delaware showed declines in the number of farms. West Virginia, in 1959, had 1,199 farms which reported the production of broilers compared with 1,849 in 1954. Output per farm in West Virginia rose from 9,000 birds to 19,000. For Virginia the number of farms declined from 2,852 in 1954 to 1,634 in 1959 . In this case the output per farm rose from 12,000 to 25,000 birds. For both Virginia and West Virginia there apparently has been a sizeable reduction in the number of farms engaged in broiler production since 1959, inasmuch as the aggregate output has dropped so substantially in both states.

For the purpose of intensive study of the internal circumstances involving broiler production, a number of counties where chosen in each state in the eastern part of the country. Such counties have a total output equivalent to about two-thirds of the output for each state involved. For West Virginia, four counties, accounting for 67 per cent of output in 1959, were chosen. Details pertaining to each county are 11sted in Appendix Table XXII. For the particular counties in West Virginia (Hardy, Pendleton, Grant, and Prestion), the number of farms dropped from 1, 342 in 1954 to 871 in 1959. The number of birds per farm moved up from 8,800 in 1954 to 17,700 in 1959. For Delaware, only one county was involved, Sussex, and accounted for 95 per cent of the output of that state in 1959. For Virginia, a total of seven counties were involved - one county on the eastern shore and the others in the central and western part of the state. 
Some Regional Changes in Egg Production.

Production of eggs in the United States, reflecting a decline in per capita demand, has been increasing at a slower pace In recent years than when the per capita consumption rate was constant or rising. In five out of the seven years, 1956-62, tocal egg production in the United States was between 61 and 63 billions.

However, the comparatively stable total production for the country is a composite of some sharp changes among regions. From 1952 to 1962 three regions of the country showed decreases as follows: the North Atlantic states 10 per cent and the North Centrai states 11 per cent. On the other hand the three remaining regions showed increases as follows: South Atlantic 80 per cent, South Central 22 per cent, and Western about 50 per cent. (Appendix Table XVI). The momentum of these changes appears to have increased in recent years and there is 11tule reason to expect their termination in the near future. Here again, however, a word of aution is in order because of uncertahties about further changes in relative economic positions of the severa? regions.

The divergent changes in egg production by regions has brought about a substantial geographic redistribution of egg production as indicated by the following tabulation:

Proportion of Total U. S。 Egg Production

Region

N. Atlantic

E. N. Central

W. N. Contral

S. Atlantic

S. Central

Western

United States
1952

Sercent

18.3

19.7

27.6

8.8

14.3

11.3

100.0
1962

Percent

15.1

16.4

22.5

14.1

16.1

15.8

100.0 
An area-redistribution of egg production is indicated somewhat more effectively by using data for individual states rather than for the usual regions, inasmuch as within regions there have been offsetting trends. In 1962 five states accounted for approximately one-third of the total U. S. egg production. These were California, Iowa, Minnesota, Pennsylvania, and Georgia. Data for these states, along with those for Virginia, West Virginia, and North Carolina are shown in Appendix Table XIV. It is significant that in Pennsylvania, Minnesota, and Iowa substantial reductions in egg output have occurred since the mid-1950's - 21 per cent in Minnesota, 12 per cent for Pennsylvania, and 10 per cent for Iowa. On the other hand, in the same period it more than doubled in Georgia, increased by over 50 per cent for California, and by more than one-third for North Carolina (Figure 13A). North Carolina, incidentally, has noved up from sixteenth place in the volure of eggs produced in 1955 to eighth place in 1962 (Appendix Table XIII). Output in Virginia appears to have leveled off in recent years; it is still somewhat above the mid-1950's although below the level of the late $1940^{\circ} \mathrm{s}$. In West Virginia, on the other hand, egg production has been on a downtrend since about 1950, and in 1962 was eight per cent below the 1955-57 average. Incidentally, the five leading states in egg production listed above accounted for the following proportions of total U.S. egg output in 1963: California, 11.7 per cent; Iowa, 6.3 per cent; Pennsylvania, 4.9 per cent; Georgia, 4.8 per cent; and Minnesota, 4.6 per cent.

The several states enumeraced above are not the only ones, however, to have shown significant changes within the past decade. This is illustrated in Appendix Table IX which contains data on per capita egg production at intervals beginning with 1925. It is to be noted that the vast majority of states show a decline in per capita output within the past five to ten years. 
Significant and persistent increases in per capita egg production have occurred in only nine states: Maine, North Carolina, South Carolina, Georgia, Florida, Alabama, Mississippi, Arkansas, and California. A tenth state, Connecticut, has shown some increase in the last few years, but in 1962 was still substantially below the level of the mid-1950's; more time is needed to judge the permanence of this trend. It is noteworthy that probably all these states except South Dakota showed little net increase during the $1950^{\prime} \mathrm{s}$, but in the past two or three years have shown more substantial increases.

In West Virginia, egg production has declined to a record low. Even with some out-migration of people in the past decade, per capita production of eggs also has dropped to a record low of only 185 in 1963 compared with 208 in both 1955 and 1960. Of the years shown in Appendix Table IX, the high point for West Virginia was in 1945 at 284 eggs per person.

\section{Structure of Farm Producing Units Changing Rapidly}

Egg producers in the different states have reacted with wide differences to the changing price relationships and advances in technology. With few exceptions the states enumerated above which showed the largest increases in per capita egg production within the past decade are states in which the average volume sold per farm increased more than four times from 1949 to 1959, according to Census data (Appendix Table X). The exceptions, moreover, are states which have had some substantial increases in population. In Maine, for example, the average volume of eggs sold by farmers in 1949 was 3,369 dozens and by 1959 this had increased to 16,289, a five-fold gain. Far larger increases occurred, however, in southeastern states.

Georgia showed the largest increase in the scale of operations, rising from 
334 dozens sold in 1949 to 8,954 dozens in 1959, an increase of 27 times. Among the other states 1isted, sales in 1959 had shown the following unit increases over 1949: North Carolina, 9 times; South Carolina, 16; Florida, 14; Alabama, 21: Mississippi, 19; Arkansas, 13. Among the states with the smallest gain in volume sold per farm were two of the leading states, Minnesota and Iowa. In each case sales in 1959 were about 1.7 times those of 1949. It is true, of course, that the sales volume by a number of the southeastern states was very low in 1949. Nevertheless it is noteworthy that by 1959 sales of eggs per farm in Georgia at 334 dozens per farm were around one-fifth to one-sixth of the volume sold per farm in Iowa and Minnesota. The 1949 volumes were even substantially lower for other states of the southeast. Mississippi, for example, had an average in that year of only 160 dozens. But by 1959 even the Mississippi average exceeded that in Iowa and practically equaled the figure for Minnesota.

The state with the highest average sales per farm in 1959 was California with 40,351 dozens. The next highest was New Jersey with approximately 30,000 dozens. Connecticut had 21,000 dozens, and several states averaged 15,000-16,000 dozens - Maine, New Hampshire, Massachusetts, Rhode Island, Florida, and Axizona. The average for West Virginia in 1959 was 968 dozens, a little less than three times the 387 dozens sold per farm in 1949.

The internal changes which permitted the wide differences in accomplishment as between, for example, Georgia on the one hand, and Minnesota and Iowa on the other, are illustrated by comparison of numbers of farms in the different size-groupings as to annual sales (Appendix Table X). First, it is to be noted, however, that the decline in number of farms in a relative sense was much greater for Georgia than for the two mid-western states. Likewise, the reductions in all states were heaviest in the less than 2,000 dozens 
annual sales volume. A sharp difference exists, however, as between Georgia on the one hand, and the mid-west states on the other in the number of farms in the larger volume category. In Georgia during 1959 there were 2,377 farms which sold 5,000 dozens or more, compared with 596 farms in 1949, nearly a four-fold increase. In Iowa, the increase was less than threefold, and for Minnesota the increase in this category was less than twice.

\section{Changes in West Virginia Vary Considerably Among Counties}

Among West Virginia counties there were wide variations in the extent of change, with some actually showing a smaller volume sold per farm in 1959 than in 1949. Greenbrier County showed the largest increase in volume per farm, rising to 2,565 dozens in 1959 , compared with 370 in 1949 . It so happens that this county also had reported the largest total sales of eggs from farms in 1959. The second largest total volume for a county was Upshur with 568,000 dozens sold in 1959. In this county the increase in sales per farm from 1949 to 1959 was more than five-fold. In both of these counties, as well as in all other counties in the state, there was a reduction in number of farms selling eggs between 1949 and 1959 (Appendix Table XI).

\section{RELATIVE CAANGES IN FACTOR PRICES AS MOTIVATIONS FOR REGIONAL PRODUCTION SHIFTS}

In attempting to identify reasons for the various substantial changes in production among areas, described in Appendix Tables XII and XIII for broilers and eggs, both product and factor prices will be utilized. In the main, however, it will become evident that shifts in spatial relationships among product prices have been of less importance than changes in relarionships among factor prices; mainly, feed and chick prices. 
Unquestionably, regional shifts in population have occurred in the post-war period and this has given rise to changes in demand relationships among producing areas. But probably even larger shifts in such demand have resulted from improvements in transportation of the products, a development which has had the same effect as if the markets had been relocated physically with constant transportation rates. For the most part, however, increases in demands, where they have occurred, have been manifested only in the taking of increased quantities. Prices, with appropriate geographic differences, reflect interaction of national supplies and demands.

Throughout this study it will be assumed that both the products and factors moving through trade channels (for example, chicks and feed) are distributed efficiently. That is, no significant quantity can be sold at any given time at other points for any higher price. While this condition may not actually prevail at all times, any departures are short-1ived, reflecting mobility of most products and effective communications.

The factors to which attention will be focused in the "Trends" approach are only two - feed and baby chicks. To some observers, labor as a factor will appear conspicuous by its absence. But, as indicated in the section on methodology in the Introduction, labor, in effect, is the "residual claimant" since it terds to be quite immobile, and 1 and is now so relatively unimportant in broiler and egg production. By focusing on changes in feed and chicks, the bulk of variable costs are considered which influence the fortunes of these industries in any given area and therefore help determine changes in income available to the self-employed labor component, as well as indirectly influencing the amount that can be paid the hired segment. On some large-scale producing units hired labor is a sizable item of variable costs, but this prevails more elsewhere than in West Virginia. On 
the "typical broiler farms" reported by the Economic Research Service (27) hired labor accounted for the following proportions of total labor utilized in 1963: Maine, 17 per cent; DelMarVa, 10 per cent; and Georgia, 9 per cent.

\section{Factor Cost: Feed}

Feed accounts for well over half the total cash cost of producing both eggs and broilers although husbandry practices for poultry production have been altered considerably in the last generation. Mixing of poultry feeds has become such an art that it is not always feasible to make use of homegrown grains even when they are available.

It might be expected, in general, that the prices paid by farmers for feeds of any kind, including broiler and laying mashes, would be lowest in the surplus feed area of the nation and then be graduated above that level as the distance from the surplus area increased. For any given level in a particular kind of marketing channel, this pattern of price relationships may prevail. However, significant differences have come to exist in the nature of marketing procedures among areas. In supplying poultry feeds, particularly, there have been growing differences among areas in scale of operations for individual plants coupled with diversity in competition among non-farm firms for farmers with whom to contract. As a result, based on data comparisons for a number of national distributors, quoted feed prices in areas distant from the corn belt frequently are lower for identical feeds than in the heart of the surplus feed area. This is to say that differences among areas from economies of scale apparently are offsetting any differentials due to location of freight rates. The above developments demonstrate why a growing area might achieve declining prices relative to areas of less rapid growth merely because of the factor of growth itself, 
i.e., introduction of external economies. In other words, a relative advantage for any area may beget growth and growth in turn may beget further relative advantage. Likewise, the area which, for some reason, falls into a disadvantaged situation will tend to beget contraction and contraction in turn beget further relative disadvantage.

In 1957, W. R. Henry assembled data on prices charged by feed distributors in major broiler areas along the East Coast, in the Southeast, and in Arkansas and Texas. (22) The pattern obtained suggested that a graduated freight rate schedule above the Midwest probably prevailed. He found that the highest prices were in Maine and Connecticut followed by Virginia, and the price in Georgia was below that for both Arkansas and Texas, as well as all states along the East Coast. Ralph L. Baker, also giving some attention to feed prices, in this case the prices of laying mash in 1957, stated: "Prices of laying mash now do not appear to be closely related to whether the area is surplus or deficit in feed." (23) Baker was not explicit as to the basis for his observations. However, it appears from some other aspects of his work, that he was referring to prices published by the Statistical Reporting Service concerning prices paid by farmers for laying mash. The findings indicated in the second paragraph above suggest that indications observable to a degree in 1957 probably have become more pronounced.

The United States Department of Agriculture through the Statistical Reporting Service publishes prices paid by farmers for a number of feeds and ingredients of feeds, including laying mash, scratch grain, chick starter, broiler grower, and turkey grower. (24) These data now are published each month of the year for every state. The starting dates for publishing the different series are not uniform, however. The series on 


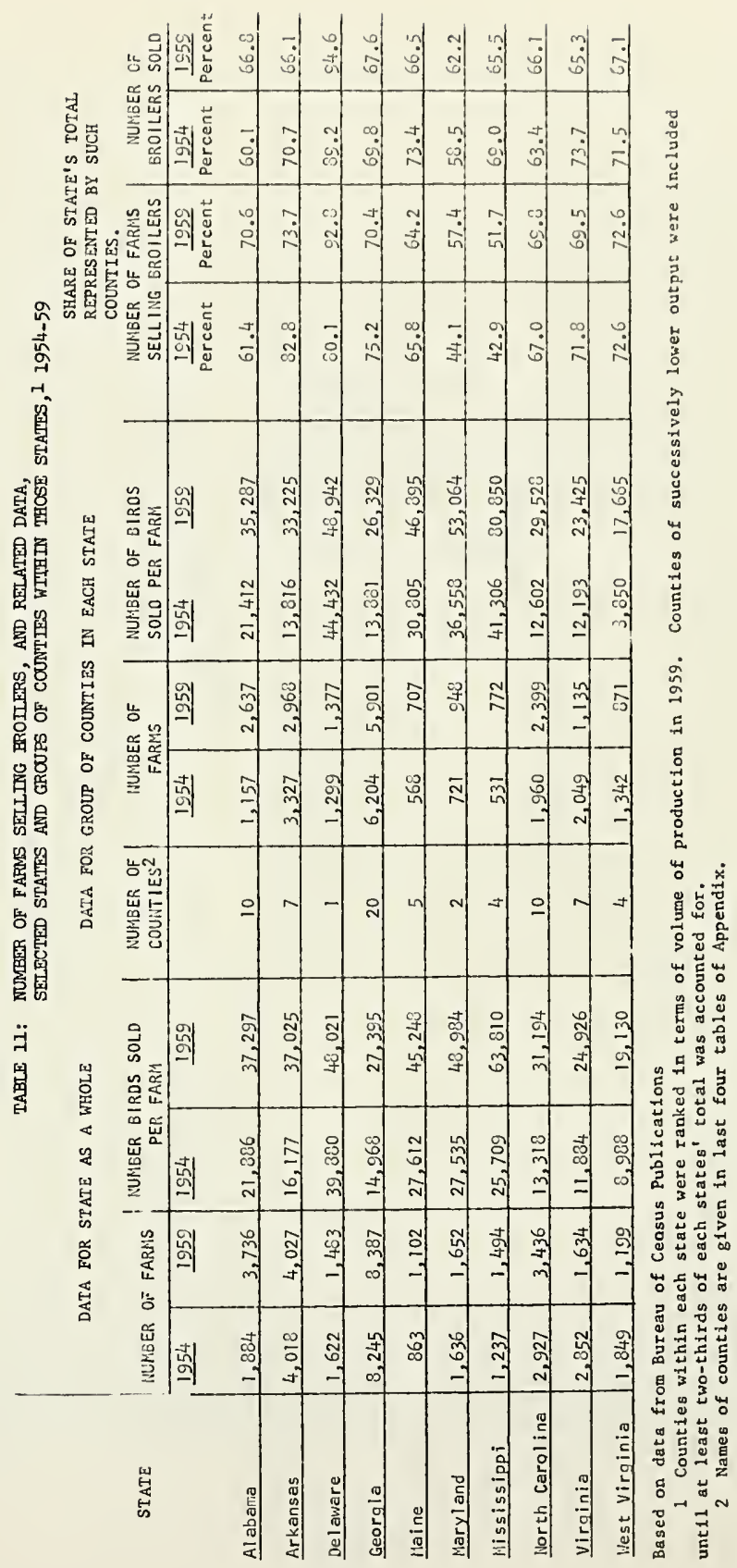




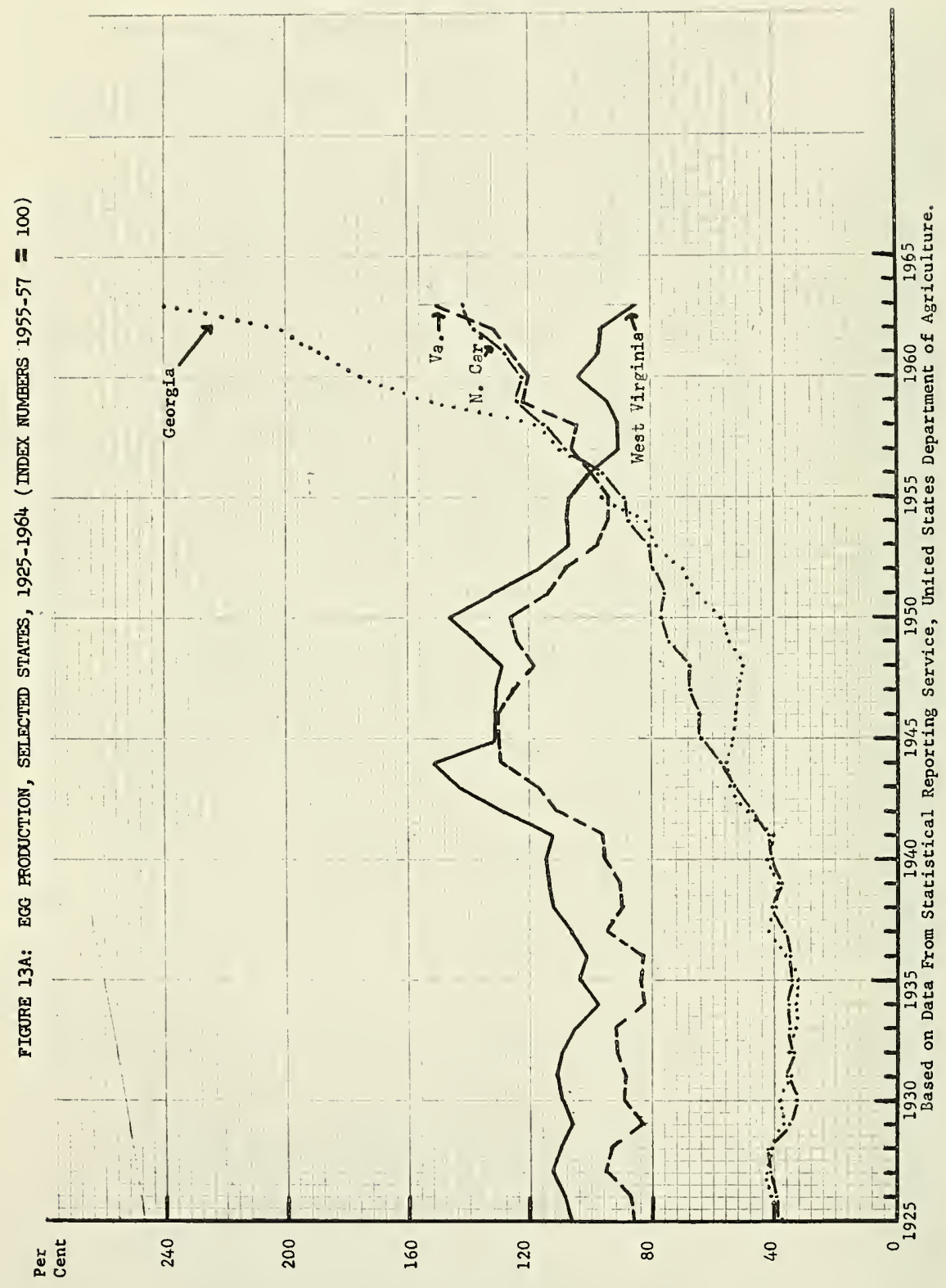




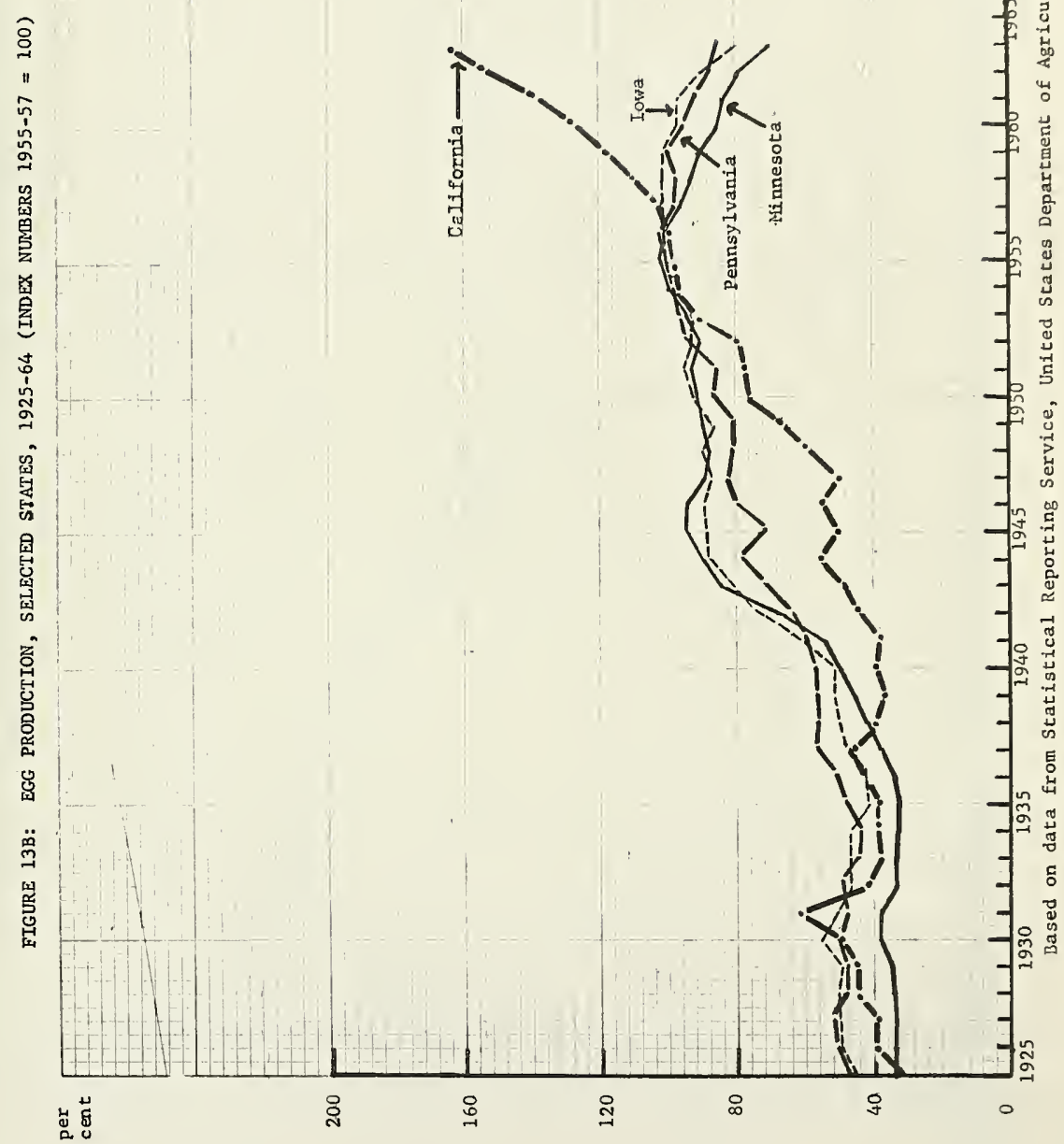




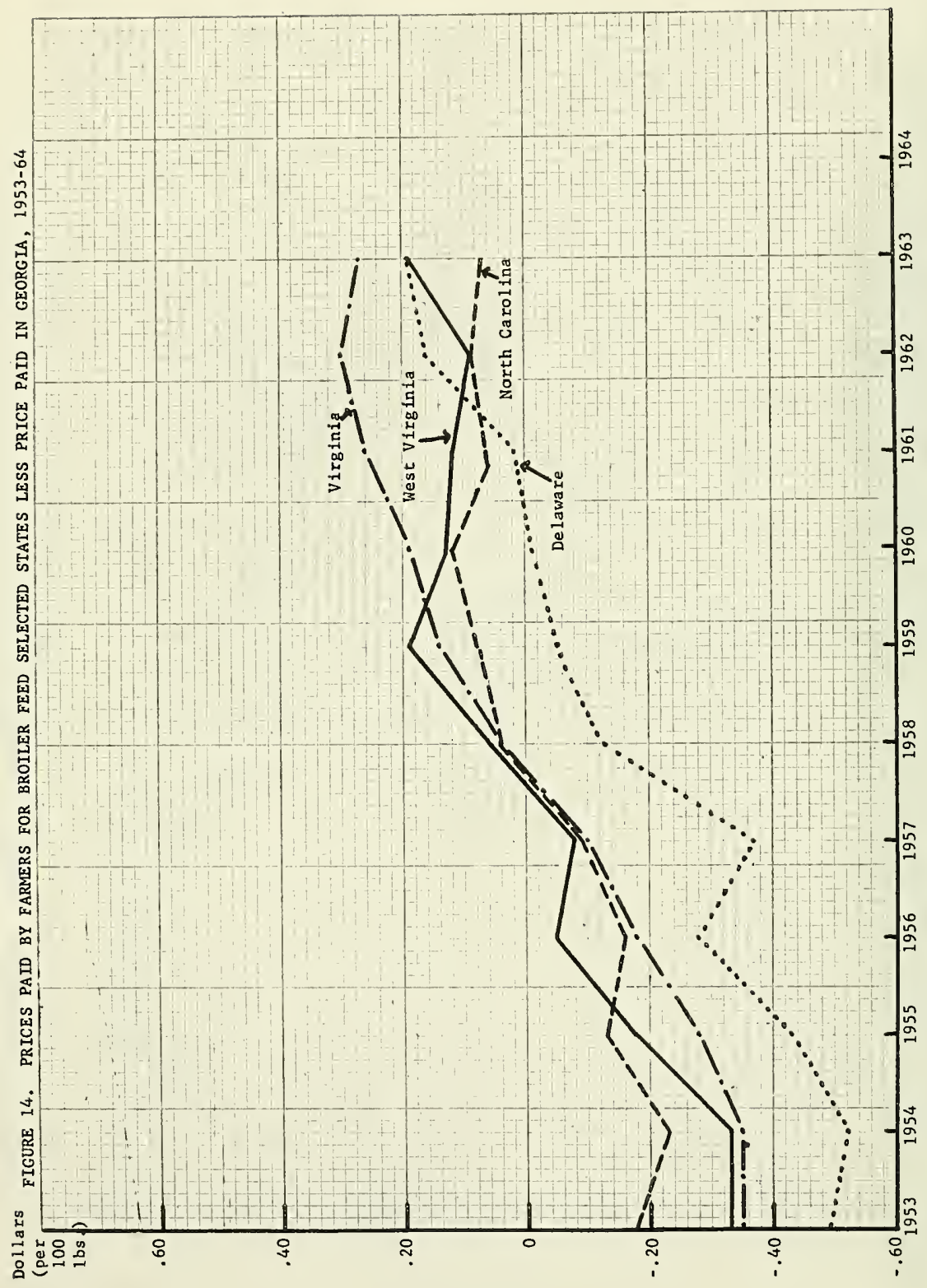


laying mash began in 1935, while the one on broiler grower began in 1953. The procedure for collecting these prices is designed to cover only those transactions involving changes in title to the commodity. Clearly, with the high degree of vertical integration and other contracting, the reported prices relate to a rather small proportion of total feed used in broiler production. There is also the problem of comparability anong states as to the weights used in obtaining stace-wide averages, particularly as to volumes associated with prices that differ because of variations in services provided with the feed. For these and possibly other reasons, wide differences show up between (even adjacent) states for readily identifiable items of uniform quality and content. The combined effect of these factors were of such order as to make use of absolute data for states infeasible. However, in general, there appeared to be considerably greater comparability within states through time than among states at any given time.

Changes in feed price relationships among some of the states used in this analysis have been rather erratic. West Virginia is one of these states. As indicaced in Figure 14 (and Table 12) the differential over Georgia in the price paid by farmers for broiler mash in west Virginia showed a departure from Virginia and Delaware during 1960-62. (The series for North Carolina also showed some departure but no inquiry was made into its inherent nature and causal reasons. For West Virginia, the aberration appears to have been associated with modification of the contractual arrangements as between suppliers and growers. Prior to the autumn of 1959 , among the contracts generally employed in West Virginia was the one providing for dividing gross receipts, above feed and chick costs, 90 per cent to growers and 10 per cent to suppliers (of feed and chicks). 
Introduced in the autumn of 1959 was the formula which divided "proceeds above costs" 38 per cent to growers, 25 per cent to associazed hatcherymen, and 37 per cent to feed suppliers. A gentlemen's agreement undergirded the contracts by which the hatcheryman was to supply chicks at cost, even excluding incubation costs, and the feed supplier was to provide feed at ingredient costs. This meant, in the case of feed, a reduction in the "price" at which the feed was "charged" to the enterprise of around $\$ 15.00$ to $\$ 20.00$ per ton. The timing of the departure from previous relationships to other states, such as observed in Figure 14, suggests that some portion of these lower prices found their way into the sample of prices used by the FederalState Statistical Reporting Service in deriving its state-wide averages of prices paid by farmers for broiler mash. A limited verification of this hypothesis consisted of a comparison by months of the reported state average prices with prices obtained from individual substantial suppliers of broiler mash of given, constant, non-contractual terms of sale. In mid-1963, however, the State Agricultural Statistician reported an inability to detect a trace of any such downward biasing influences that would help explain the departure.

In 1963 the West Virginia-Georgia differential increased to \$.15 per 100 pounds, compared to $\$ .07$ in 1962, and was the largest on record except for the $\$ .19$ in 1959. The five-cent decline from 1963 to 1964 matched the change in differential for Delaware and Virginia.

\section{Factor Cost: Baby Chicks}

The second single most important item in production of broilers is the cost of chicks, although it is estimated for recent years that this component represents only about one-fifth the cost of feed and one-seventh of the 
total cost of producing a finished three-pound broiler. Nevertheless, the change in relationships among states in prices for broiler chicks has been of a magnitude to result in as great a contribution to the shift in total cost of production of broilers as has been the shift in prices paid for feed. Unfortunately, the price received by commercial hatcheries for broiler-type chicks has become available only in the past ten years so that a long-term comparative analysis is not possible.

It is known that the original source of chicks for broiler production was in the New England area, particularly New Hamphire and Connecticut. Subsequently, as the industry grew rapidly on the eastern shore of Maryland and Delaware, hatcheries were established in that locality to supply local and other outlets. At that time, most of the chicks for production of broilers in Georgia, and other sections of the Southeast, were supplied either indirectly by eggs from New England or directly by chicks therefrom. Later the function of producing broiler chicks shifted toward the Southeast and currently, to illustrate the magnitude of this shift, Delaware is obtaining a substantial portion of its broller chicks from North Carolina.

It is noteworthy that the shift in favor of Georgia in the chick price (Table 13) indirectly reflects the shift observed in the price paid for laying mash as compared with other states. Added to this is the growing volume of chicks and the expanding broiler industry complex in Georgia and surrounding states as contrasted with states to the north. There may be some further change toward Georgia but any future change is not likely to be as pronounced as that of the last six to ten years.

Combining Changes in Geographical Factor Price Differentials

Because of the limitations of the data discussed above in measuring ab- 
solute levels of feed prices in the several states, differentials among state average prices were employed in this study. This was done not only because greater comparability was presumed to exist within states through time than among states at any given time, but also because changes in such inter-state relationships would be prime reasons to expect geographical shifts in production, other things remaining unchanged. The same method was employed with regard to chick prices to facilitate the subsequent combining of the two series of factor prices, although there was less reason to expect incomparability among states in the chick price series.

In observing changes in the inter-state relationships on feed prices, it is well to bear in mind that such changes can be the result of: changes in the relationships of freight rates from the central source of feed to the respective areas, (2) changes among areas in the scale of individual feed plants or methods of business operations, and (3) changes in feed output-demand balances or relationships among areas.

Differentials in factor costs were determined as between states on which attention is focused (for example, West Virginia) and those which are showing large increases in production. For broilers, in the case of both feed and baby chicks, Georgia has been used as the base of reference. Prices for brollers in Georgia, in recent years, have been the lowest in the country or nearly so, and production exceeds that of any other state. Increases in production are still occurring and there apparently is a potential for some further increases for the near-term future, at least. The results are shown in certain accompanying tables and charts. In chart form the data are largely self-explanatory, including the manner in which production is influenced. But some of the highlights may be summarized for emphasis. 
TABLE 12: PRICES PAID BY FARMERS FOR BROTLER MASII, SELECTED STATES, LESS PRICE PATD IN GEORGIA, PLR 100 POINNDS, 1953-64.1

\begin{tabular}{|c|c|c|c|c|c|c|c|c|}
\hline YEAR & DELAIVARE & VIRGINIA & W.VA. & NORTH CAROLLNA & ARKANSAS & MAINE & ALABNAA & IIISSISSIPPI \\
\hline . & DOLLARS & DOLLARS & DOLLARS & DOLLARS & DOLLARS & DOLLARS & DOLLARS & DOLIARS \\
\hline 1953 & -.49 & -.35 & -.33 & -.18 & -.53 & -.55 & .01 & .10 \\
\hline 1954 & -.52 & -.35 & -.42 & -.23 & -.75 & -.49 & -.13 & -.02 \\
\hline 1955 &.- .43 & -.28 & -.18 & -.13 & -.46 & -.52 & -.07 & .08 \\
\hline 1956 & -.28 & -.18 & -.07 & -.16 & -.49 & -.31 & -.11 & .04 \\
\hline 1957 & -.37 & -.10 & -.08 & -.09 & -.34 & -.23 & -.11 & -.06 \\
\hline 1958 & -.13 & .04 & .04 & .04 & -.43 & -.10 & .30 & -.05 \\
\hline 1959 & -.05 & .14 & .19 & .08 & -.18 & .07 & .01 & .11 \\
\hline 1960 & -.01 & .19 & .13 & .12 & -.14 & .10 & .12 & .20 \\
\hline 1961 & .02 & .26 & .11 & .06 & -.29 & .13 & .04 & .13 \\
\hline 1962 & .16 & .30 & .07 & .09 & -.28 & .15 & .03 & .11 \\
\hline 1963 & .19 & .27 & .15 & .07 & -.40 & .15 & .14 & .05 \\
\hline 1964 &. .14 & .22 & .10 & .00 & -.49 & 11. & .04 & .01 \\
\hline
\end{tabular}

1 Based on data from, "Agricultural Prices," published monthly by Statist1ce? Reporting Service, U. S. Depertment of Agriculture. 
TABLE 13: STRAIGHT RUN BROILER TYPE CHICKS: ANNUAL AVERAGE PRICE PER 100 GHICKS PAID TO COMMERCIAL HATCIIERIES, SELECTED STATES, LESS PRICE PAID IN GIORGIA, 1953-64.

\begin{tabular}{|c|c|c|c|c|c|c|c|c|c|}
\hline YEAR & MAINE & DELAWARE & MARYLAND & VIRG INIA & W. VA. & N.CAROLINA & ALABAMA & MISS. & ARKANSAS \\
\hline & Dollar & Dollar & Dollar & Dollax & Dollar & Dollax & Dollax & Dollax & Dollar \\
\hline 1953 & .90 & -2.40 & -2.20 & -1.00 & -1.30 & -1.60 & -1.80 & -1.00 & -1.30 \\
\hline 1954 & 1.70 & -2.10 & -2.20 & .20 & -.30 & -.70 & -.40 & -.40 & -.90 \\
\hline 1955 & -1.70 & -1.40 & -1.60 & -1.10 & -1.50 & -1.30 & -.90 & -.80 & -1.10 \\
\hline 1956 & .30 & .10 & 0 & .60 & .90 & -.90 & -.30 & .10 & .30 \\
\hline 1957 & .20 & .40 & .30 & .40 & .80 & .40 & .30 & .50 & 1.50 \\
\hline 1958 & .10 & .40 & .50 & -.10 & -.20 & .20 & .10 & .30 & .40 \\
\hline 1959 & 2.40 & 1.60 & 1.60 & 1.40 & 1.50 & .50 & 0 & .40 & 1.20 \\
\hline 1960 & 1.00 & .90 & .90 & .50 & .70 & .50 & -.10 & -.50 & -.90 \\
\hline 1961 & 2.00 & 1.20 & 1.20 & .50 & 1.10 & .10 & .10 & -.10 & -.10 \\
\hline 1962 & 1.50 & 1.20 & 1.20 & .50 & .50 & 0 & -.20 & -.30 & -.10 \\
\hline 1963 & 1.80 & 1.50 & 1.30 & .60 & 1.10 & -.20 & -.40 & -.80 & -.50 \\
\hline 1964 & 1.50 & 1.68 & 1.74 & .77 & 1.13 & -.21 & -.38 & -.46 & .18 \\
\hline
\end{tabular}

Based on date complled fram "Agricultural Prices," published monthly by Statistical Reporting Service of the United States Department of Agriculture. 
First, notice Figure 14. (and Table 12) for the simple differences between the prices paid by farmers for broilermash in Virginia, West Virginia, North Carolina, and Delaware as compared with Georgia. In 1953 the price in the first four states, on the average, was between 40 and 45 cents per hundred pounds ( $\$ 8$ to $\$ 9$ per ton) below the price paid in Georgia. By 1962 the average for the four states was approximately 20 cents per hundredweight, or $\$ 4$ per ton, above the price paid in Georgla. This is a net change of $\$ 12$ to $\$ 13$ per ton in one decade. In terms of present prices this is in excess of a 10 per cent change in the relative cost of feed, to the advantage of Georgia or disadvantage of the other states. Net changes from 1962 to 1964 were negligible for West Virginia and Delaware, while slight decreases occurred for North Carolina and Virginia.

A similar shift in relationships among states has occurred for the price of broiler chicks, as shown in Table 13 but not charted separately. For example, in 1953 the price received by hatcheries for broiler chicks in Georgia was 2.4 cents per head more than the price received by hatcheries in Delaware. A gradual shift has occurred to the point that in the last three years the price received in Georgla has been less than in Delaware by between one and two cents per head. Thus, there has been a net shift in favor of Georgia of between three and four cents per bird. For a threepound broiler this means by itself, without any allowance for feed price change, at least one cent per pound, live weight. In terms of contribution to total cost per pound of broiler, this is equivalent to the effect of a change in feed cost of $\$ 10$ and $\$ 12$ per ton.

In appraising the price motivations for shifts in the location of broiler production, the unit costs for factors (such as feed and chicks) have some limitations. These arise from the fact that the intensity in the 
use of the two inputs varies in two ways: (1) for feed there is variation over time, although probably with a rather high degree of uniformity among states, and (2) for baby chicks the equivalent cost per pound of finished product differs among states in both level and trends due to differences and changes in average weight of broilers sold. To provide a more meaningful basis for comparison, the feed and chick costs were combined to show their composite influence on differentials per pound of live broilers sold. The net shift in the West Virginia-Georgia differential has been somewhat over 2 cents per bird. It is to be noted, however, that West Virginia has produced a rapidly declining proportion of the chicks used in the State for broiler production. As a result, the data pertaining to West Virginia in Table 13 may under-state the true shift relative to Georgia.

The contribution of the chick cost (section I of Table 14) was obtained by dividing the price paid for baby chicks per head by the average weight of broilers sold for each state. The resulting series, which represent costs of baby chicks per pound of live bird sold, have shown approximately uniform declines for Maine, Delaware, Virginia, and West Virginia. Compared ro these four states, declines shown for North Carolina and Georgia have been much more pronounced.

The quantity of feed used per pound of live broiler sold was estimated on an annual average basis from the broller tests made by the Department of Agriculture in Maine. (18) To do this, it was arbitrarily assumed that under average conditions in the field, a quarter-pound more of feed was used than in the official Trials.

So, the procedure involved determination of the trend line in the data from the Department of Agriculture in Maine and arbitrarily adding the quarter-pound to the trend value. The annual feed-to-product conversion 
ratios were uniformly employed in all states. The composite figures so generated and expressed in feed and chick costs per pound of live broller sold are shown in Table 14 and Figures $15 \mathrm{~A}-\mathrm{E}$, all as differences over the comparable figures for Georgia. Two significant changes stand out in these relationships: (1) the combined cost of feed and chicks in the five states (Maine, Delaware, Virginia, West Virginia, and North Carolina) shown in the charts depict a significant increase relative to the cost in Georgia, and (2) these indicators of cost changes show an increase relative to the differentials over Georgia in the prices received by farmers for broilers, except for Maine where increases in prices approximated increases in costs.

The import of the above calculations and changes in relationships may be illustrated further by using a pair of states. In 1953, the price paid by farmers for broiler mash in Delaware was below the price in Georgia by the equivalent of 1.4 cents per pound of live broiler. In 1963, on the other hand, the Delaware figure on feed was higher than in Georgia by the equivalent of 0.4 cent per pound. This is a net change of 1.8 cents per pound of finished broiler. During the same period the cost of baby chicks in equivalent per pound of live broiler showed a 1.1 cent smaller decline in Delaware than in Georgia. Thus, during the decade, the cost of producing broilers in Delaware as gauged by feed and chick costs decreased 2.9 cents per pound less in Delaware than in Georgia. For West Virginia the combined cost dropped 2.4 cents less (per pound of live weight equivalent) than it did for Georgia. Again, however, it should be noted that the series on chick prices as well as feed may be less representative for West Virginia. For both components, any error probably would be in the direction of enlarging the change in cost relative to Georgia. 
It is apparent from the several sections of Table 15 that there has been a rather pronounced correlation for some states between changes in relationship between costs (as there expressed) and prices received, on the one hand, and changes in production on the other. But the degree of association varies considerably even among this small group of states. In West Virginia and Virginia differentials over costs of feed and chicks in Georgia have increased relative to prices received for broilers, and production has turned downward in recent years. For Maine and Delaware, movements in costs have approximately paralleled prices received, as differentials over Georgia, and gradual further expansion has continued in both states. In the case of North Carolina (again in terms of differentials), costs have shown some increase relative to prices received as compared with the mid-1950's, although in recent years they have moved in parallel. Moreover, from 1957 to date, both series for North Carolina have shown less deviation from Georgia than any other state in the chart. Nevertheless, North Carolina production showed substantial increases each year through 1963; preliminary indications point to an abrupt let-up, if not a decline in 1964. A net shift of 2.9 cents per pound in the cost of production, such as indicated above for broilers in Delaware, normally would be expected to have pronounced interregional consequences. Partially tempering a judgment on this, however, is the fact that during the period under study, 1953-64, the United States average price of broilers declined from the high $20^{\prime} \mathrm{s}$, in cents per pound, to 14-15 cents in recent years. Furthermore, the differences between average costs of production per pound and prices received probably vary among states at any given time, as well as change over time for given states. The consistency of costs as between variable and fixed components also is of considerable importance. Clearly, if the margin be- 
TABLE 14. DERIVATION OF DIFFERENTIALS OVER GEORGIA IN COMEINED COSTS OF FEED AND CHICKS IN BROILER PRODUCTION, SELECTED STATES, 1953-63.

\begin{tabular}{cccccc}
\hline IEAR MAINE & DELAWARE & VIRGINIA & WEST VIRGINIA & NORTH CAROLINA & GEORGIA \\
\hline Cents & Cents & Cents & Cents & Cents & Cents
\end{tabular}

I - CALCULATED COSTS OF BABY CHICKS PER POUND OP FINISHED LIVE WEIGHT PER BIRD

$\begin{array}{lllllll}1953 & 4.6 & 4.6 & 5.0 & 4.8 & 5.2 & 5.7 \\ 1954 & 4.5 & 4.0 & 4.7 & 4.4 & 4.8 & 4.8 \\ 1955 & 3.7 & 4.4 & 4.5 & 4.2 & 4.6 & 5.2 \\ 1956 & 3.9 & 4.6 & 4.5 & 4.4 & 4.1 & 4.4 \\ 1957 & 3.7 & 3.4 & 3.7 & 3.6 & 3.7 & 3.5 \\ 1958 & 3.4 & 3.7 & 4.1 & 3.8 & 2.7 & 4.0 \\ 1959 & 2.9 & 2.9 & 3.2 & 2.9 & 3.6 & 2.6 \\ 1960 & 3.2 & 3.4 & 3.9 & 3.7 & 2.8 & 2.8 \\ 1961 & 2.9 & 2.9 & 3.2 & 3.1 & 2.7 & 2.8 \\ 1962 & 2.8 & 2.8 & 3.3 & 2.9 & 2.8 & 2.9 \\ 1963 & 2.9 & 2.9 & 3.4 & 3.2 & & \end{array}$

II - FEED COST PER FOUND OF LIVE BROTLER SOLD

$\begin{array}{lllllll}1953 & 14.8 & 15.1 & 15.4 & 15.5 & 15.9 & 16.5 \\ 1954 & 14.7 & 14.6 & 15.1 & 15.1 & 15.4 & 16.1 \\ 1955 & 12.8 & 13.0 & 13.4 & 13.8 & 13.8 & 14.2 \\ 1956 & 12.6 & 12.7 & 12.9 & 13.3 & 13.0 & 13.4 \\ 1957 & 12.0 & 11.7 & 12.4 & 12.4 & 12.4 & 12.6 \\ 1958 & 12.0 & 11.9 & 12.3 & 12.2 & 12.2 & 12.2 \\ 1959 & 11.3 & 11.0 & 11.4 & 11.5 & 11.5 & 11.1 \\ 1960 & 10.5 & 10.2 & 10.7 & 10.6 & 10.6 & 10.3 \\ 1961 & 10.4 & 10.0 & 10.7 & 10.3 & 10.1 & 0.1 \\ 1962 & 10.3 & 10.3 & 10.6 & 10.1 & 9.9 & 9.3 \\ 1963 & 10.5 & 10.1 & 10.3 & 9.9 & \end{array}$

III - COMBINED COST OF FEED AND CHICKS PER POUND OF LIVE BIRD SOLD

$\begin{array}{lllllll}1953 & 19.4 & 19.7 & 20.4 & 20.3 & 21.1 & 22.2 \\ 1954 & 19.2 & 18.6 & 19.8 & 19.5 & 20.2 & 20.9 \\ 1955 & 16.5 & 17.4 & 17.9 & 18.0 & 17.4 & 19.4 \\ 1956 & 16.5 & 17.3 & 17.4 & 17.7 & 16.1 & 17.8 \\ 1957 & 15.7 & 15.1 & 16.1 & 16.0 & 16.1 & 16.2 \\ 1958 & 15.4 & 15.3 & 16.4 & 16.0 & 14.2 & 13.7 \\ 1959 & 14.2 & 13.6 & 14.6 & 14.4 & 14.2 & 13.8 \\ 1960 & 13.7 & 13.6 & 14.6 & 14.3 & 13.1 & 12.9 \\ 1961 & 13.3 & 12.9 & 13.9 & 13.4 & 12.8 & 12.7 \\ 1962 & 13.1 & 13.1 & 13.9 & 13.0 & 12.8 & 12.6 \\ 1963 & 13.4 & 13.0 & 13.7 & 13.1 & \end{array}$

IV - COMBINED COSTS (SEC. III) LESS COSTS IN GEORGIA

$\begin{array}{rrrrrr}1953 & -2.8 & -2.5 & -1.8 & -1.9 & -1.1 \\ 1954 & -1.7 & -2.3 & -1.1 & -1.4 & -0.7 \\ 1955 & -2.9 & -2.0 & -1.5 & -1.4 & -1.0 \\ 1956 & -1.3 & -0.5 & -0.4 & -0.1 & -0.7 \\ 1957 & -.4 & -1.0 & 0.0 & -0.1 & 0.0 \\ 1958 & -.8 & -0.9 & 0.2 & -0.2 & -0.1 \\ 1959 & .5 & -0.1 & 0.9 & 0.7 & 0.5 \\ 1960 & .1 & -0.2 & 0.8 & 0.5 & 0.4 \\ 1961 & 0.4 & 0.0 & 1.0 & 0.5 & 0.2 \\ 1962 & 0.4 & 0.4 & 1.2 & 0.3 & 0.1 \\ 1963 & 0.8 & 0.4 & 1.1 & 0.5 & \end{array}$

Methodology described in text. Data on prices (of chicks and feed) and weight per bird from Statistical Reporting Service of United States Department of Agriculture. Data on feed conversion ratios based on results from State of Maine Official Broiler Tests. 


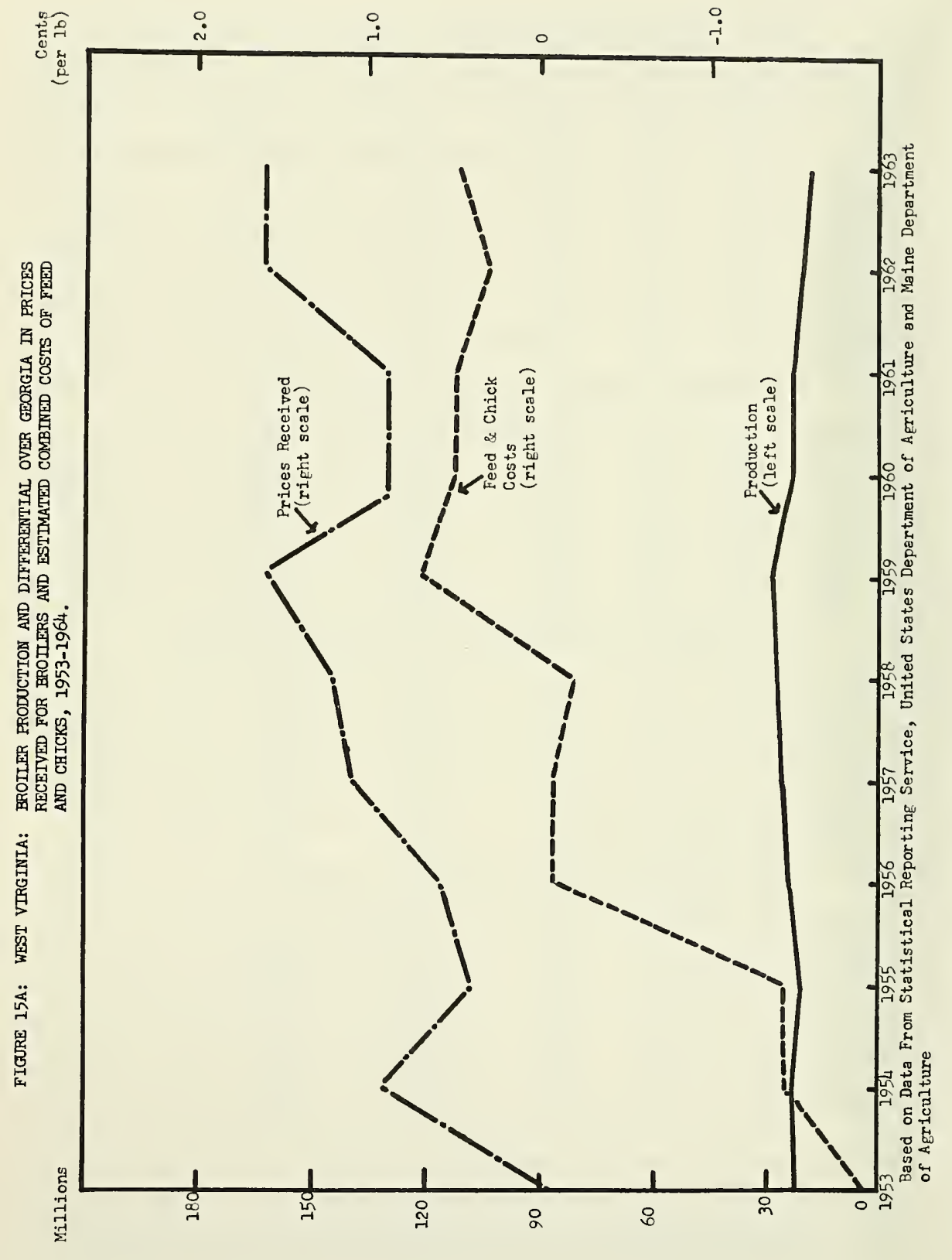

$86 \ldots$ B 


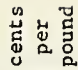

$\stackrel{\circ}{i}$

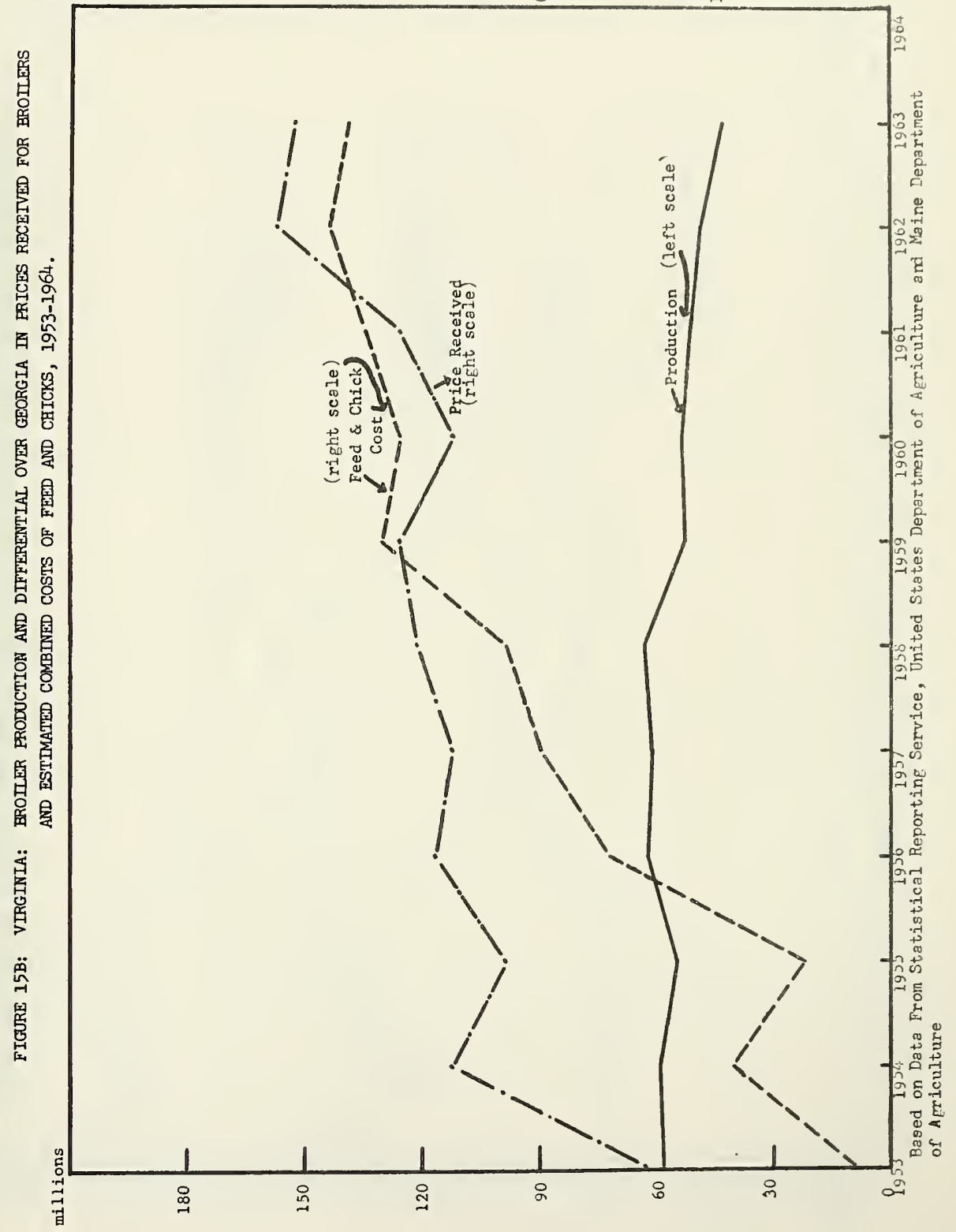




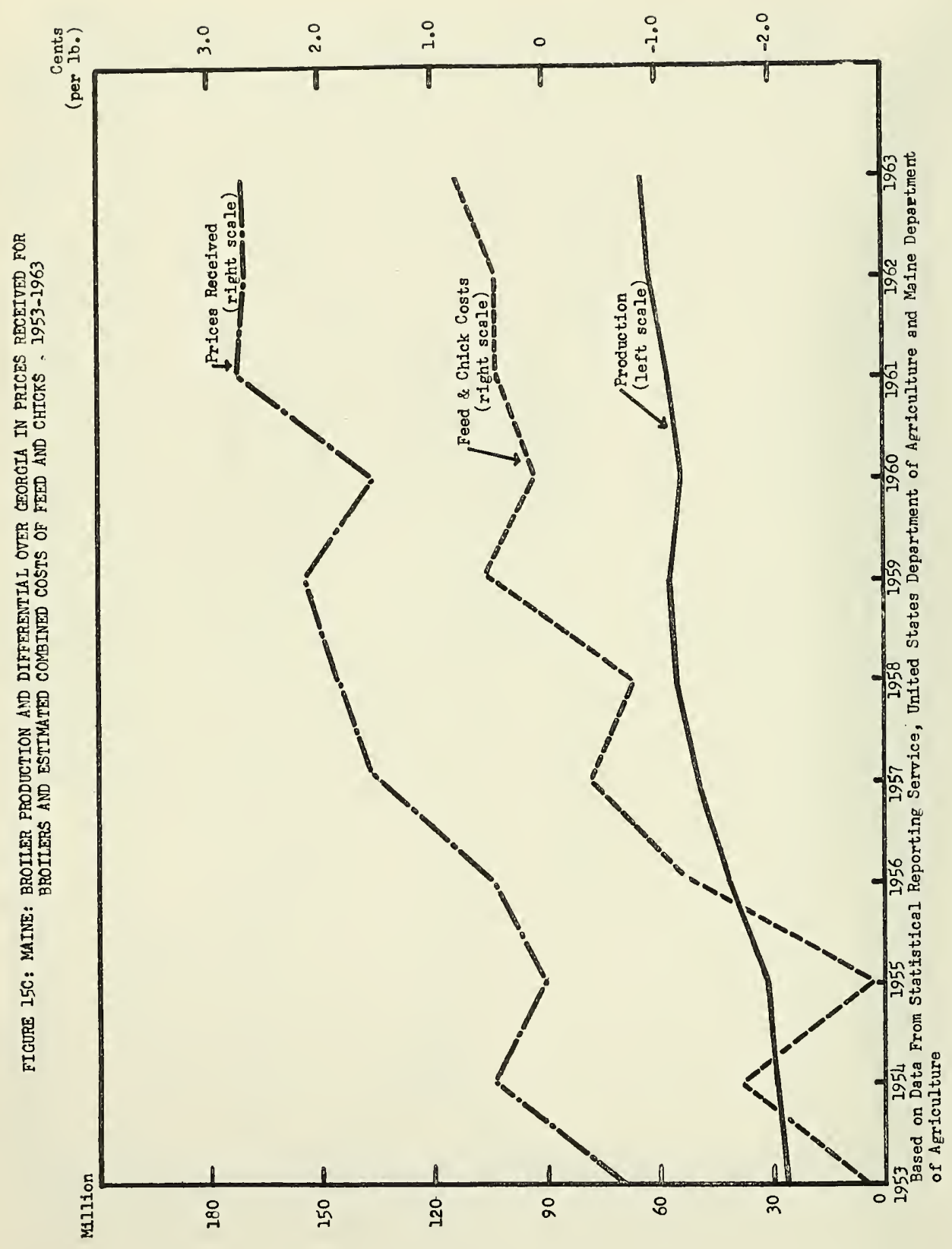




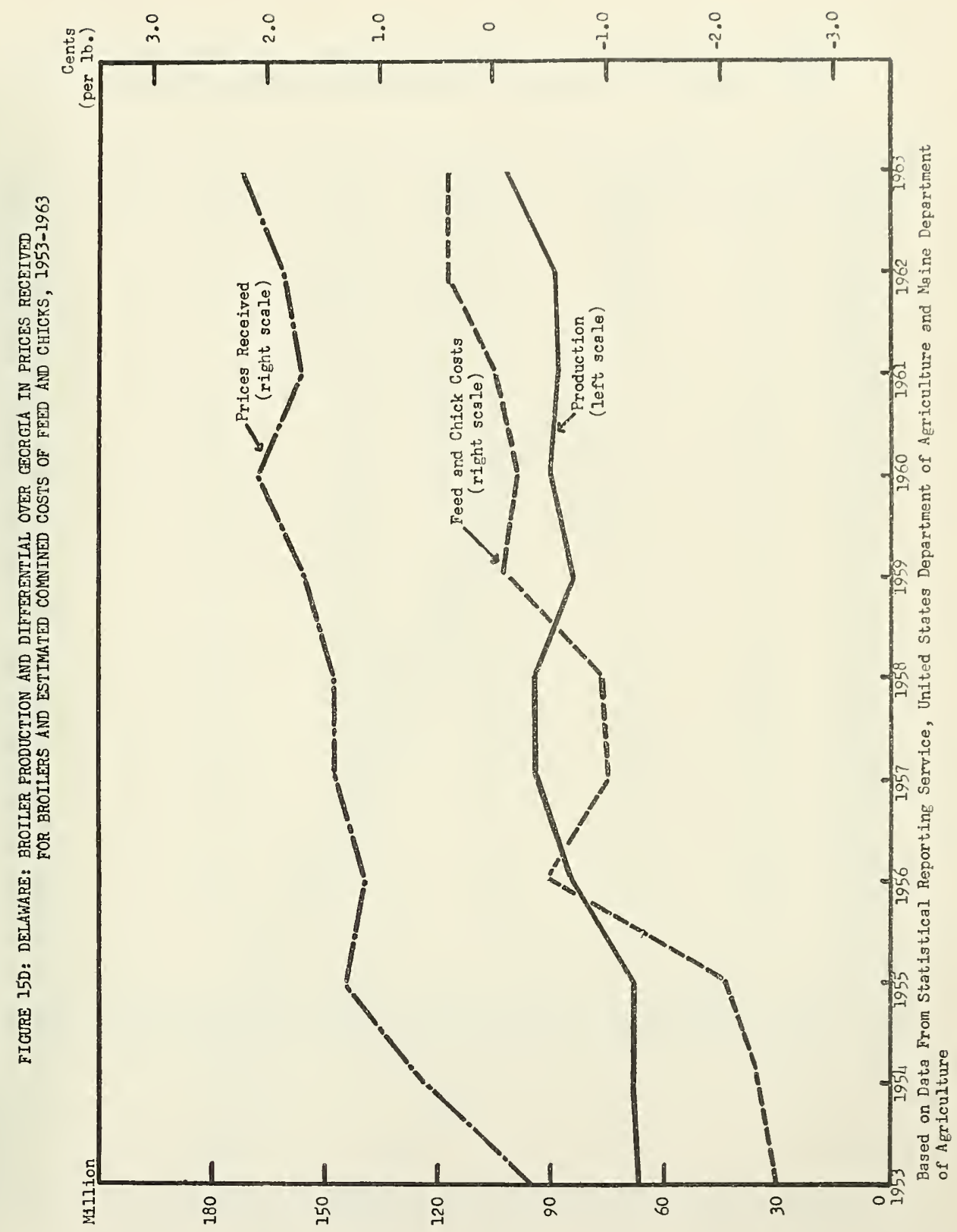




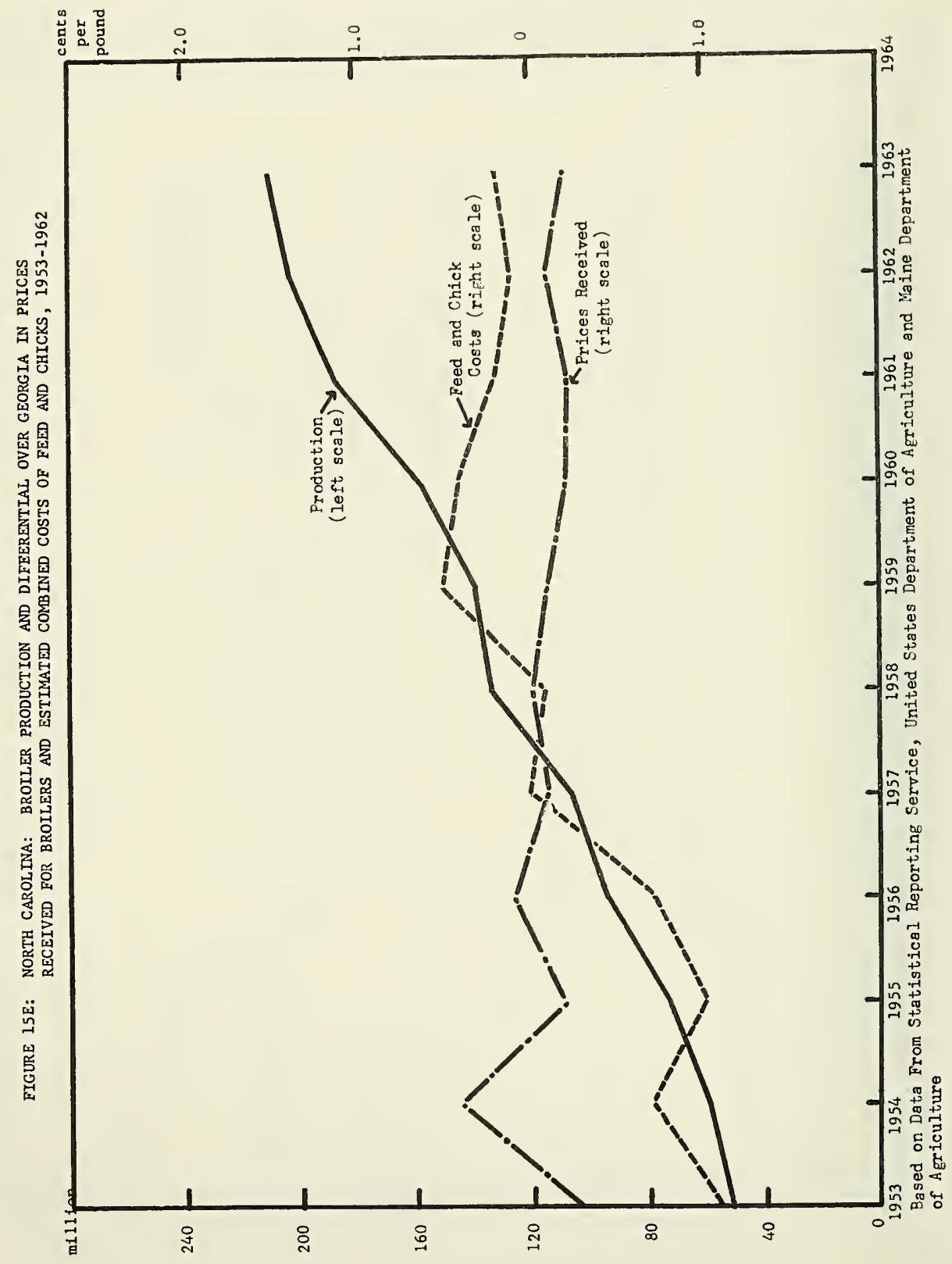


TABLE 15: PRICE RECETVED BY FARMERS FOR BROILERS, LLSS PRICE RECEIVED IN OEORGIA, PER POUND, SELECTED STATES, 1935-63.

\begin{tabular}{|c|c|c|c|c|c|c|c|}
\hline & YEAR & MAINE & DELAWARE & VIRGINIA & WEST VIRGINIA & N.C. & $\begin{array}{c}\text { GEORGIA, LESS } \\
\text { ARKAINSAS }\end{array}$ \\
\hline & & CENTS & CENTS & CENTS & CENTS & CENTS & CENTS \\
\hline 1935 & & 2.3 & 2.0 & 3.0 & 1.9 & -0.5 & -0.2 \\
\hline 1936 & & 1.2 & 1.9 & 3.0 & 1.5 & 0.0 & -2.0 \\
\hline 1937 & & 3.5 & 3.1 & 4.7 & 2.8 & -0.8 & -1.1 \\
\hline 1938 & & 0.1 & 1.0 & 2.0 & 0.8 & 0.5 & -1.3 \\
\hline 1939 & & -1.1 & -1.5 & 0.6 & -0.8 & 0.4 & 1.2 \\
\hline 1940 & & -0.7 & -1.7 & 0.2 & -0.4 & $-0 B$ & $-0,2$ \\
\hline 1941 & & 0.4 & -0.9 & 1.0 & 0.5 & -0.5 & 0.7 \\
\hline 1942 & & -1.6 & -0.4 & 0.1 & 1.1 & -1.4 & 0.4 \\
\hline 1943 & & -0.6 & -0.4 & 0.3 & -0.4 & -0.4 & 0.1 \\
\hline 1944 & & -1.4 & -1.9 & 0.0 & -1.1 & -1.3 & -0.5 \\
\hline 1945 & & -0.6 & -0.8 & 0.9 & -1.8 & 0.1 & 1.6 \\
\hline 1946 & & 0.2 & -3.0 & 0.2 & -1.8 & -1.0 & 1.3 \\
\hline 1947 & & -2.2 & -0.9 & -0.7 & 0.8 & 1.7 & -0.6 \\
\hline 1948 & & 1.1 & 1.2 & 1.5 & 1.1 & 0.8 & -1.6 \\
\hline 1949 & & 0.5 & 0.4 & 0.1 & 1.0 & 0.1 & -0.7 \\
\hline 1950 & & 1.7 & 0.2 & 0.0 & 0.8 & 0.5 & -1.0 \\
\hline 1951 & & 0.0 & -0.5 & -0.3 & 1.1 & 0.3 & 0 \\
\hline 1952 & & -1.1 & 0.1 & -0.1 & 0.4 & -0.3 & -0.1 \\
\hline 1953 & & -0.7 & -0.3 & -0.6 & -0.1 & -0.3 & 0.3 \\
\hline 1954 & & 0.5 & 0.6 & 0.5 & 0.9 & 0.4 & 0 \\
\hline 1955 & & 0.0 & 1.3 & 0.2 & 0.4 & -0.2 & 0 \\
\hline 1956 & & 0.5 & 1.1 & 0.6 & 0.6 & 0.1 & 0.2 \\
\hline 1957 & & 1.5 & 1.4 & 0.5 & 1.1 & -0.1 & -0.2 \\
\hline 1958 & & 1.8 & 1.4 & 0.7 & 1.2 & 0 & 0 \\
\hline 1959 & & 2.1 & 1.7 & 0.8 & 1.6 & -0.1 & 0.3 \\
\hline 1960 & & 1.5 & 1.4 & 0.5 & 0.9 & -0.2 & -0.1 \\
\hline 1961 & & 2.7 & 1.7 & 0.8 & 0.9 & -0.2 & 0.3 \\
\hline 1962 & & 2.6 & 1.9 & 1.5 & 1.6 & -0.1 & -0.1 \\
\hline 1963 & & 2.7 & 1.6 & 1.4 & 1.6 & -0.2 & 0.1 \\
\hline
\end{tabular}

Differences of welghted annual averages as complled from "Chickens and Eggs: Farm Production, Disposition, Cash Recelpts and Gross Income," Issued annually (and revised periodicaliy) by Statistical Reporting Service, U. S. Department of Agriculture. 

tween variable cost and price is narrow in a given state, a shift, such as occurred for Delaware, will have different consequences than if the margin is relatively wide, initially. If the variable cost-price margin is relatively narrow, a relative increase in the feed and chick component of costs can be sufficient to generate a downward adjustment in production. This very well could have been the situation for Virginia and West Virginia; hence the recent down-turn in production. In situations of a wider cost-price margin, a shift in feed and chick component in one state relative to others may not be sufficient to generate a change in broiler production. In addition, there could be cases where a change in the feed-chick cost component would be neither sufficient nor necessary. Thus, in North Carolina, large increases in production have occurred despite moderate increases in costs relative to prices.

There is no assurance, however, that production in North Carolina will continue to increase even if both prices received and feed-and-chick costs remain unchanged relative to Georgia. The increase of recent years may be the result of a series of separate, unrelated events, none of which is identifiable or measurable. If so, a termination of these would bring the production increase to a halt or cause a decline in output. In the final analysis, the availability of alternative uses for capital and labor (including managerial component) will influence the level of broiler production in North Carolina as well as in other states. If alternative opportunities for both factors should become exceptionally remunerative, broiler production in a state such as North Carolina, which has experienced several years of uninterrupted increases, probably would show a sharp down-turn even if margins between broiler prices and "costs" were relatively wide. 
All of the foregoing is by way of emphasis that production in the future in any area cannot be projected from past relationships. This is particularly applicable to states which have long histories of production increases, inasmuch as about three-fourths of the states now producing broilers have produced a greater number at some time in their recent past. On the other hand, no state which has shown a decrease as large and as persistantly as Virginia and West Virginia has reversed the trend.

There is some reason to expect that broiler production has a more stable future in those non-corn belt areas which, nevertheless, have a potential for substantial local production of corn and soybeans, particularly if such crops are produced on the same farms as the broilers. The data on DelMarVa broiler farms, discussed on page 95, would appear to lend strong support to this hypothesis. This indigenous quality coupled with long-established, local research facilities, and the venturesomeness and productivity of local entrepreneurs apparently goes a long way in accounting for the rather steady growth in output and relatively favorable returns to the total labor component on broiler type farms of DelMarVa.

Indications of Shifts in Factor Costs for Broilers Anong Regions Confirmed by Costs of Froduction Studies

As indicated earlier, the amount of land involved in broiler production is minor so that the problem of allowing for returns to land is not as significant in "cost-of-production" studies on broilers as it would be on many other agricultural products. It is illuminating at this point to compare results of some "cost-of-production" studies which have been made on broilers at intervals with the indications of change which were obtained above. 
In these comparisons no allowance will be made for labor "costs" in the actual grow-out operation; costs will be ascertained only for those factors purchased from non-farm sources.

First, in a study reported in 1951 by Rice of the Delaware Experiment Station, it was concluded that the cost of producing broilers in DelMarVa was one cent per pound below the cost in Georgia. (25) His calculations were synthetic in the sense that he made certain assumptions as to conversion rates, prices for feed, and chicks, as well as the other items used in production. The main assumption that is open to some question is that the wholesale price of chicks was the same in all areas of the country. At that time no data were available, so it was necessary to make an assumption. As indicated above, for the more recent years, there have been not only differences among states but substantial shifts over time anong states in the relationship of broiler chick prices.

A study was made for 1957 by W. R. Henry of North Carolina State College. (22) He reported that the cost of feed, baby chicks, and fuel all were higher for DelMarVa than in Georgia. In terms of price per pound Henry concluded that the cost in DelMarVa was approximately 1.1 cents above that for Georgia. In other words, in this six-year interval there was a net shift in favor of Georgia to the extent of about two cents per pound.

The next study was reported by the University of Delaware and applied to July, 1961. (26) This tabulation of costs was based on a survey of producers in the DelMarVa area and a report from a "knowledgeable source" in the southeastern area. This report concluded that the cost, as of July, 1961, was higher in DelMarVa than in Georgia by approximately two and one-half cents per pound. Thus, from 1951 to 1961 there was a net shift in favor of Georgia over the DelMarVa area of about 3.5 cents per pound. The shift in disadvan- 
tage for West Virginia as contrasted with that for Georgia probably is fully as great as that for DelMarVa, if not greater, because of the lessened volume of baby chicks produced and available in the state and the decline in total production of broilers which set in a year or two earlier. These indications of changes in relationships among the states in cost of production of broilers lend strong confirmation to conclusions based on the trends in relationships for feed and chick costs discussed above.

\section{Changes in Factor and Product Prices Useful also in Explaining Regional} Shifts in Production of Eggs

Cash outlays for feed also constitute a significant part of total costs of producing eggs. Moreover, prices are available by states covering the laying mash purchased by farmers for producing eggs. Cash outlays for replacement birds also constitute an important production item in an egg enterprise. In this part of egg production, however, significant changes have occurred in the past decade, from purchasing baby chicks for raising pullets, to purchasing started pullets from specialized producers. Unfortunately, no data are available on prices paid by producers for the started pullets in the same sense that they were on baby chicks. For this part of the analysis, therefore, only feed prices are used as a factor in the cost of producing eggs. Here again, attention is focused on a few states, mostly in the eastern part of the country; however, prices paid by farmers for laying mash are expressed as differentials over prices paid in Minnesota.

Minnesota was chosen for this purpose because the output of that state was among the greatest of any state in the country; the prices received by farmers for eggs and the prices paid for laying mash were among the lowest, of all states. 
In many states with rapidly growing egg output, prices paid by farmers for laying mash have been declining relative to prices in Minnesota. However, the declines in these differentials have been smaller than those discussed above for broiler mash. It is to be observed that egg production now is declining in Minnesota while in Georgia, production of broilers (and eggs) still is increasing rapidly。

As shown in Figure 16 and Table 16, the West Virginia price of laying mash (expressed as differential) was below the other states from mid-1940's through 1957; during this period the differential widened relative to Minnesota. But in the following 6 years prices in all other states dropped below West Virginia prices although the latter declined relative to Minnesota dropped $\$ 10.80$ per ton, from 1953 to 1963 , while the West Virginia series increased, net, by $\$ 2.00$ per ton. California also has shown a remarkable decline ${ }^{1}$ in laying mash price relative to other states, although the reported prices are still above those in Minnesota. In 1936-37, California mash prices actually were below the Minnesota prices, reflecting the severe Midwest drought of 1936.

It is to be noted, based on Figures 17 (a-f), that declines in laying mash prices apparently are not the sole motivations for increases in egg production in the expanding states. In some states, (e.g. North Carolina, California, and Georgia) substantial increases to successively new record levels occurred in advance of any decline in feed price relative to Minnesota. In California and Georgia the rate of production increase accelerated

1The trend in differentials pertaining to California may be influenced somewhat by the effect within that state to increase the statistical weighting of volume feed purchases in calculating state-wide price averages. 
following the relative drop in feed price. But it is questionable whether this was the sole reason, inasmuch as in North Carolina the rate of production increase has been lower since the relative decline in feed price than it was in the years immediately preceding such decline. Moreover, in Pennsylvania the persistent decline in production has coincided, so far, with the decline in relative feed price.

In West Virginia, since 1960 , a decline in production has coincided with a decline in relative feed prices, although the major post-war decline in egg production in the state, 1950-57, was concurrent with an apparent increase in relative feed prices. The opposite rrends in egg production for West Virginia and Virginia stand in sharp contrast to the parallel movements in the case of broilers. In all instances, changes in egg prices have been small relative to those in feed prices (Table 17). On balance, there are both prior and empirical bases to conclude that the relative decline in feed prices has been instrumental in increasing egg production in certain states. However, it is clear that this is not the only casual factor, and, therefore, substantial further area-relocation of production can be expected even after stability in feed price relationships among states is attained.

Although changes in recent years have been smaller for egg prices than for feed prices, both, obviously, are important in the longer run. For this reason, some data are presented in Table 18, comparing the composite of changes in prices of feed and eggs with production by contrasting 1963 figures with those for 1947-49. The price paid by farmers for laying mash in Pennsylvania, for example, showed a differential over Minnesota in 1947-49 of 22 cents per hundredweight. By 1963 this had increased to 25 cents. Based on five pounds of feed required to pro duce a dozen eggs this means that the cost of producing a dozen eggs in Pennsylvania increased 15 cents between $1947-49$ and 1963, relative to the cost in Minnesota. For the same period the price received for eggs in Pennsylvania declined 

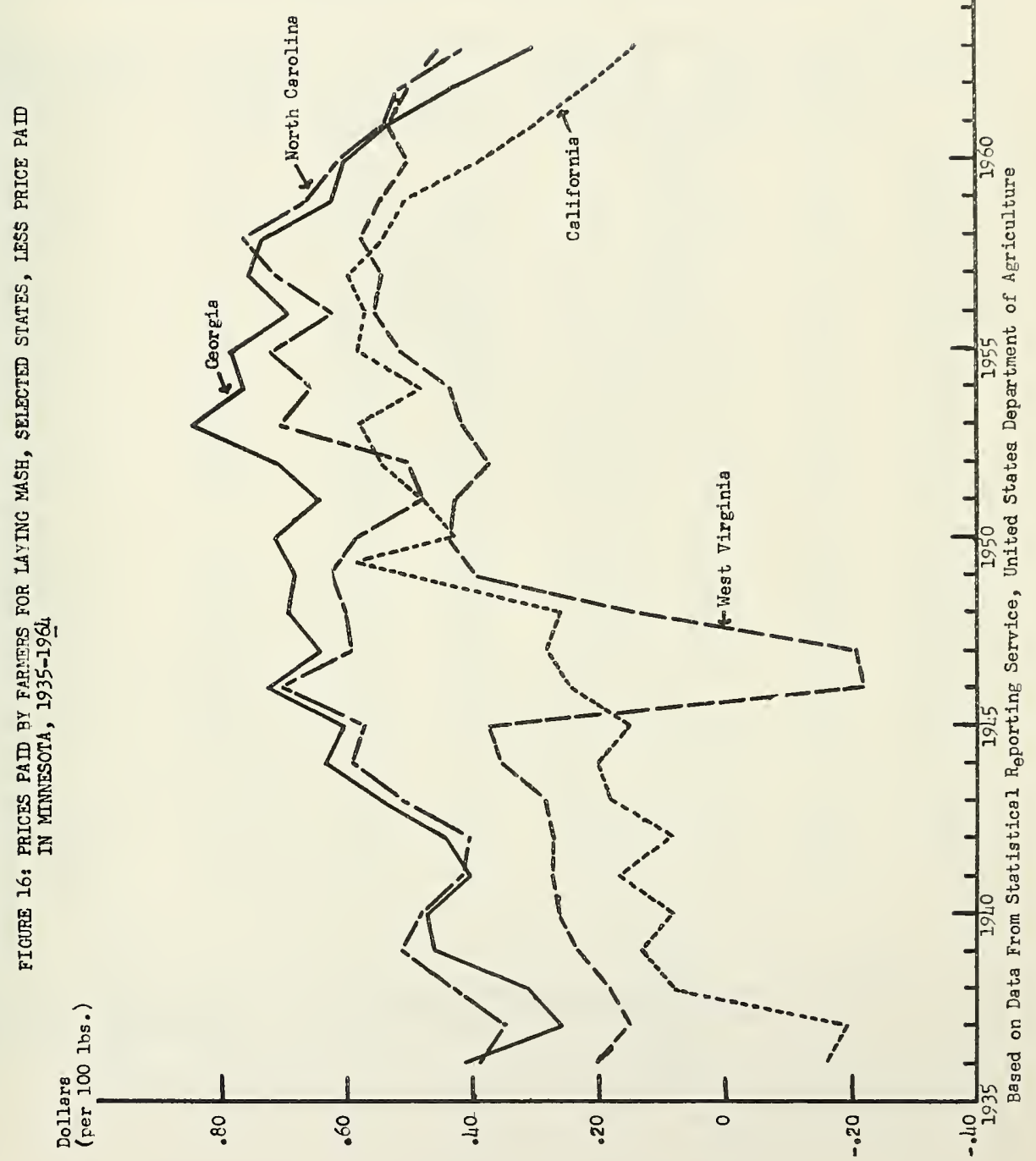
TABLE 16: PRICES PAID BY FARMERS FOR LAYING MASH PER 100 POUNDS, SELECTED STATES, LESS PRICE PAID IN MINNESOTA, 1936-63

\begin{tabular}{|c|c|c|c|c|c|c|c|}
\hline YEAR & PENNA. & IONA & VIRGINIA & W. VA. & N. C. & GEORGIA & CALIFORNIA \\
\hline & Dollars & Dollars & Dollars & Dollars & Dollars & Dollars & Dollars \\
\hline 1936 & .07 & .10 & .16 & .20 & .39 & .41 & -.16 \\
\hline 1937 & .01 & .07 & .12 & .15 & .35 & .26 & -.19 \\
\hline 1938 & .05 & .08 & .24 & .18 & .43 & .31 & .08 \\
\hline 1939 & .16 & .14 & .32 & .23 & .51 & .46 & .13 \\
\hline 1940 & .15 & .08 & .27 & .26 & .48 & .47 & .08 \\
\hline 1941 & .16 & .14 & .24 & .27 & .41 & .40 & .17 \\
\hline 1942 & .17 & .14 & .17 & .27 & .40 & .44 & .08 \\
\hline 1943 & .22 & .08 & .26 & .28 & .51 & .55 & .18 \\
\hline 1944 & .28 & .09 & .34 & .35 & .59 & .63 & .20 \\
\hline 1945 & .25 & .08 & .28 & .37 & .57 & .60 & .15 \\
\hline 1946 & .30 & .12 & .41 & -.22 & .70 & .72 & .24 \\
\hline 1947 & .22 & .21 & .32 & -.21 & .59 & .62 & .28 \\
\hline 1948 & .20 & .23 & .31 & .13 & .60 & .69 & .36 \\
\hline 1949 & .25 & .31 & .34 & .39 & .62 & .68 & .59 \\
\hline 1950 & .28 & .33 & .37 & .43 & .58 & .71 & .43 \\
\hline 1951 & .28 & .32 & .42 & .42 & .48 & .64 & .48 \\
\hline 1952 & .25 & .35 & .37 & .37 & .50 & .70 & .54 \\
\hline 1953 & .28 & .30 & .40 & .41 & .70 & .84 & .58 \\
\hline 1954 & .42 & .46 & .49 & .43 & .65 & .76 & .48 \\
\hline 1955 & .26 & .46 & .44 & .51 & .72 & .78 & .58 \\
\hline 1956 & .31 & .39 & .49 & .55 & .62 & .69 & .57 \\
\hline 1957 & .24 & .44 & .58 & .54 & .71 & .75 & .59 \\
\hline 1958 & .40 & .45 & .63 & .57 & .76 & .73 & .54 \\
\hline 1959 & .34 & .43 & .54 & .54 & .66 & .62 & .50 \\
\hline 1960 & .32 & .43 & .49 & .50 & .61 & .60 & . 38 \\
\hline 1961 & .31 & .48 & .49 & .53 & .53 & .53 & .29 \\
\hline 1962 & .27 & .42 & .49 & .50 & .51 & .42 & .21 \\
\hline 1963 & .25 & .41 & .46 & .45 & .41 & .30 & .14 \\
\hline
\end{tabular}

Differences of unrelghted anmual averages based on dats complled from "Agricultural Prices," Issued monthly by Statistical Reporting Service, U. S. Department of Agriculture. 


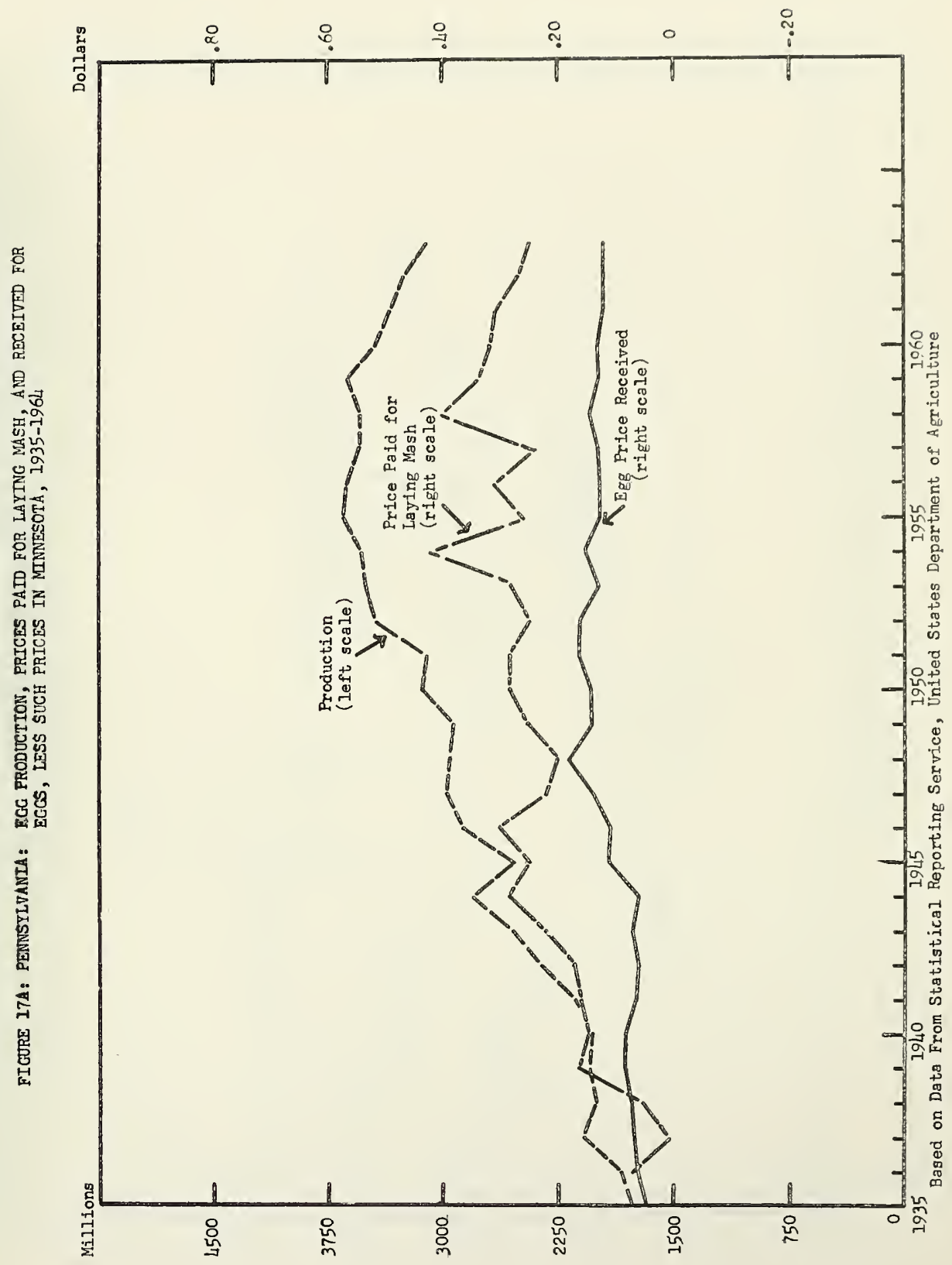




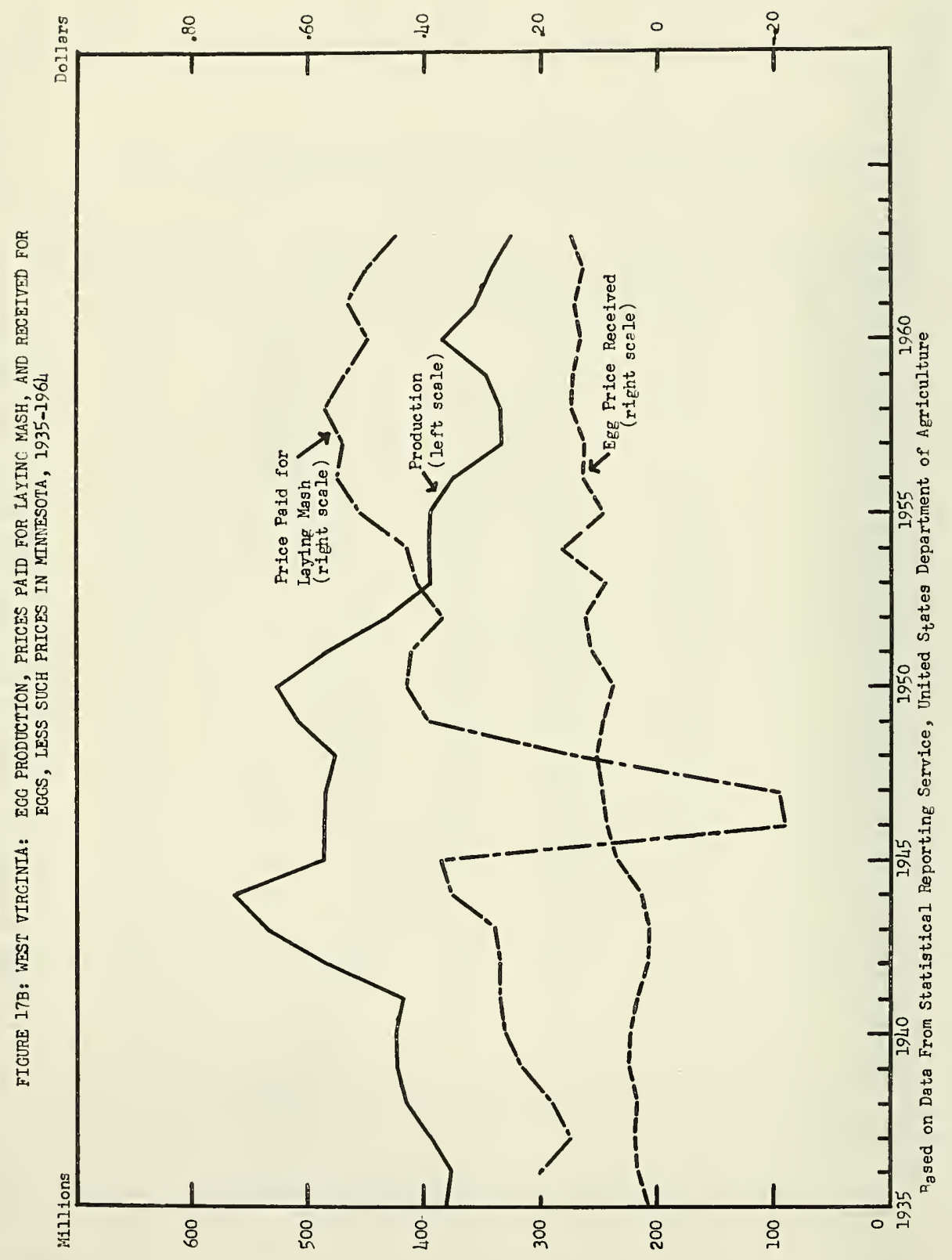




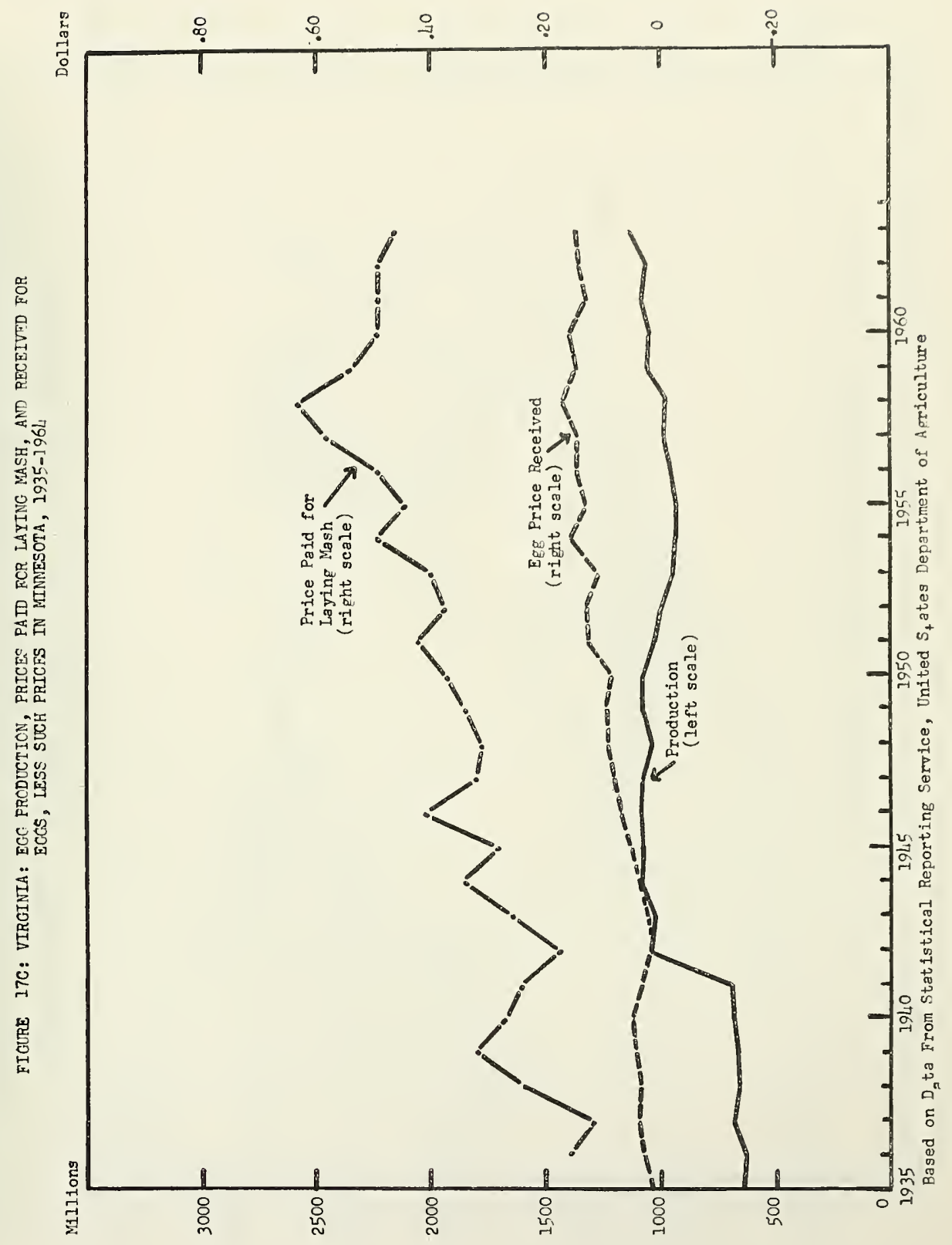




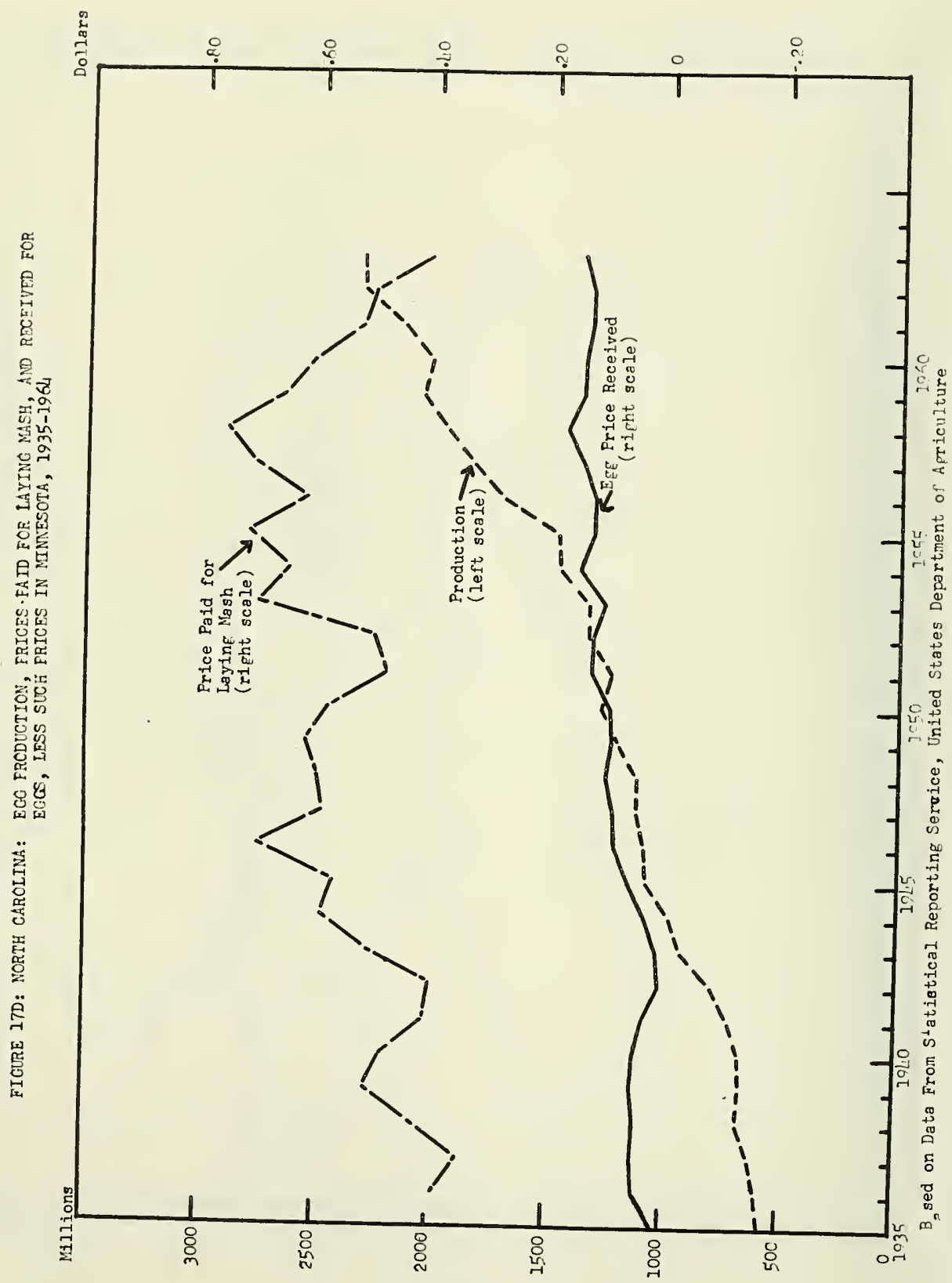




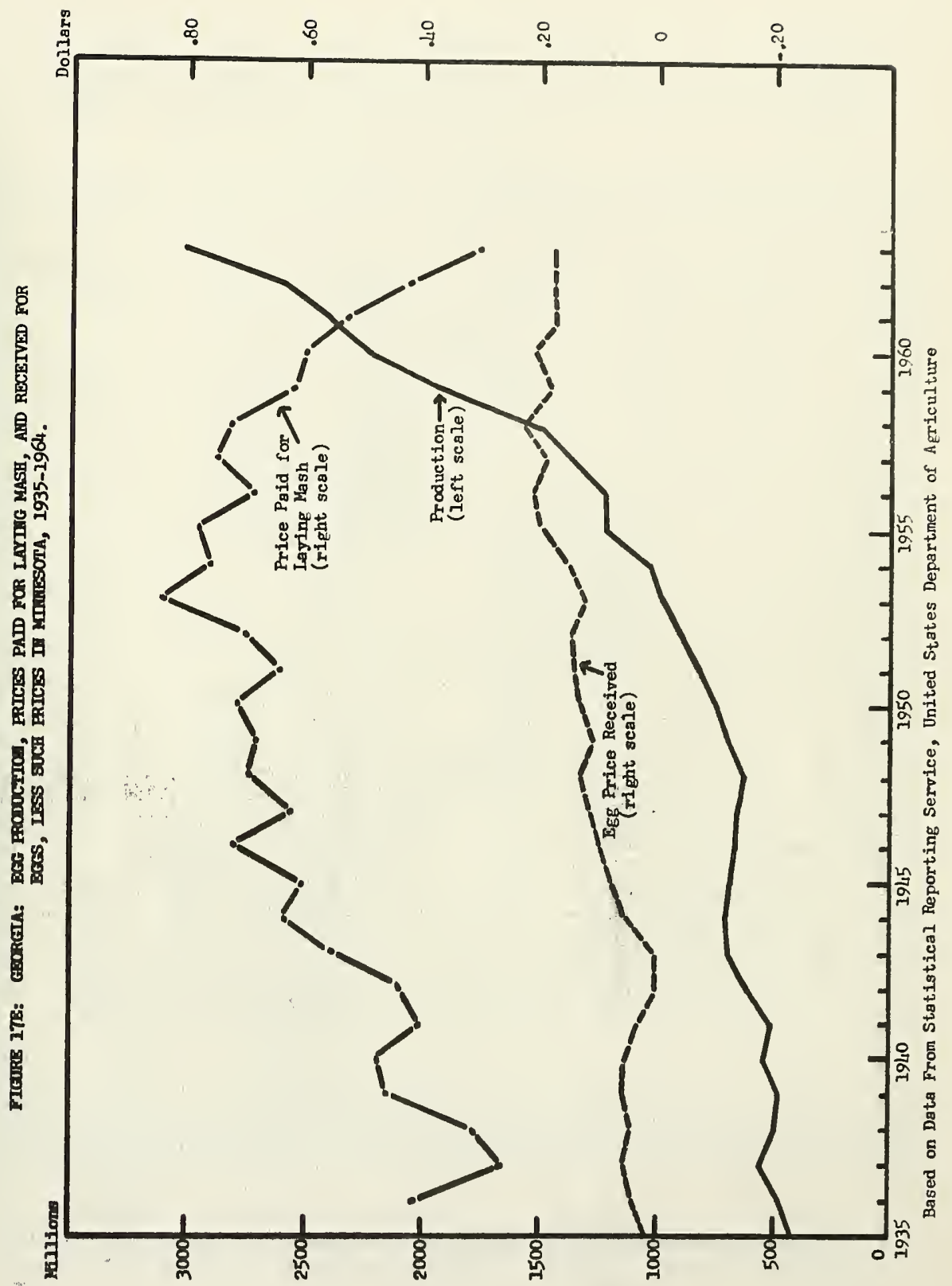




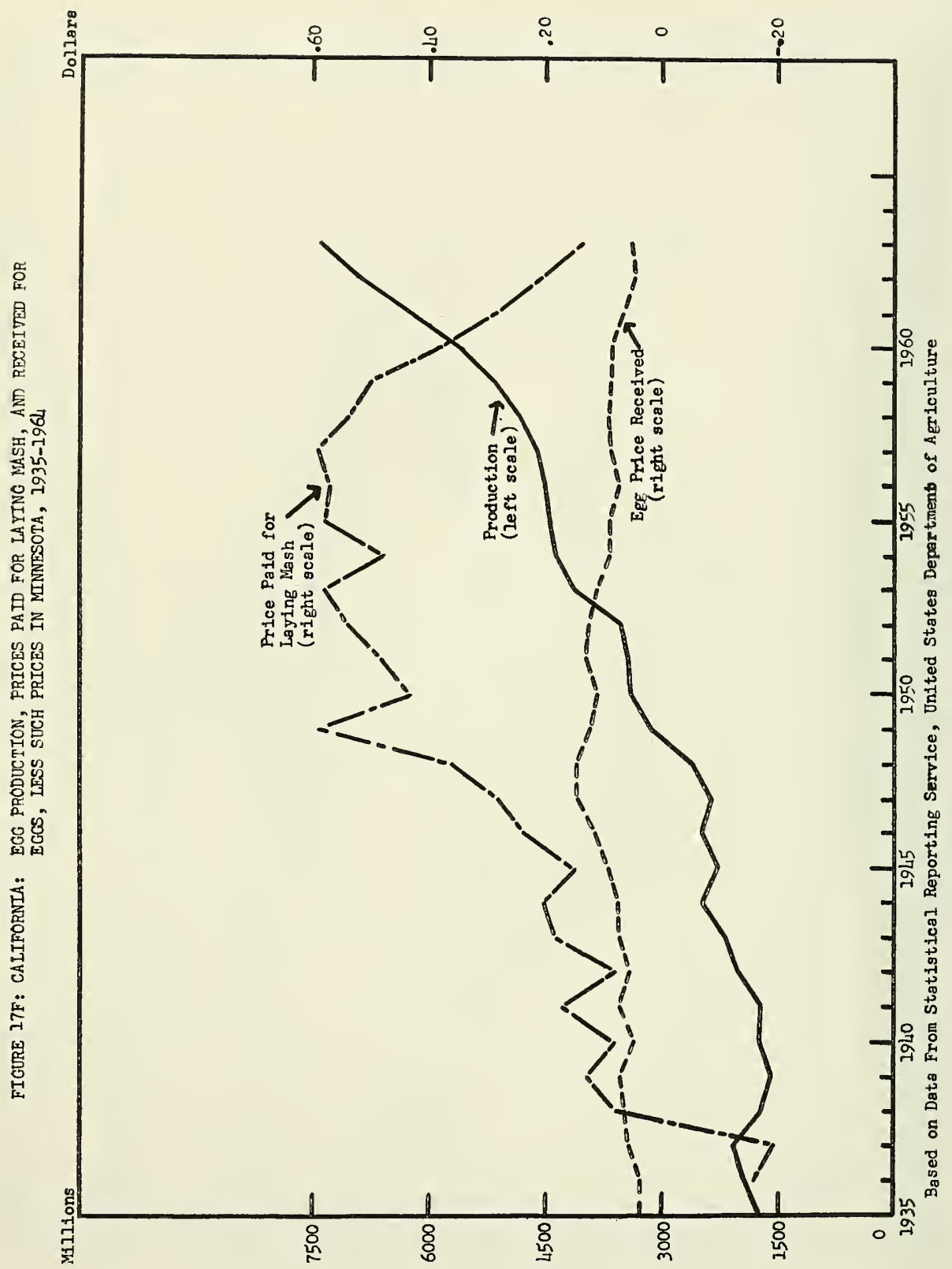


TABLE 17: PRICES RECEIVED BY FARMERS FOR EGGS, PER DOZFN, SELECTED STA'TES, LESS PRICE IN MINNESOTA, 1935-63.

\begin{tabular}{|c|c|c|c|c|c|c|c|}
\hline YEAR & PLNNA. & IOWA & VIRGINIA & WEST VIRGINLA & N. C. & CEORGTA & CABJ. FORIHA \\
\hline & Cents & Cents & Cents & Cents & Cents & Cents & Cent:s \\
\hline 1935 & 5.0 & -.1 & 1.6 & 1.4 & 1.6 & 1.6 & 3.8 \\
\hline 1936 & 6.4 & -.5 & 3.0 & 3.1 & 4.4 & 3.9 & 3.9 \\
\hline 1937 & 6.7 & .1 & 3.4 & 3.9 & 4.5 & 4.8 & 5.7 \\
\hline 1938 & 7.1 & -.4 & 3.1 & 3.6 & 4.4 & 4.3 & 6.5 \\
\hline 1939 & 7.6 & -.6 & 4.1 & 4.5 & 5.3 & 5.0 & 7.4 \\
\hline 1940 & 7.6 & -.6 & 4.4 & 4.3 & 4.9 & 4.8 & 5.3 \\
\hline 1941 & 6.5 & -.3 & 3.1 & 3.2 & 3.5 & 3.0 & 6.0 \\
\hline 1942 & 6.0 & -.3 & 1.6 & 1.8 & .8 & .4 & 5.9 \\
\hline 1943 & 6.8 & -.3 & 2.3 & 1.7 & 1.3 & .6 & 7.2 \\
\hline 1944 & 5.8 & -.4 & 2.7 & 2.2 & 3.7 & 4.4 & 7.13 \\
\hline 1945 & 10.8 & $-1 \cdot 3$ & 5.1 & 6.4 & 6.0 & 7.7 & 9.0 \\
\hline $19: 6$ & 10.9 & -.8 & 6.7 & 8.4 & 8.2 & 9.5 & 11.4 \\
\hline 1547 & 14.0 & -.9 & 8.1 & 9.5 & 3.6 & 11.1 & 14.1 \\
\hline 1948 & 17.7 & -.3 & 8.9 & 10.9 & 10.0 & 12.8 & 14.5 \\
\hline 1949 & 14.3 & -.4 & 9.1 & 9.7 & 9.6 & 11.6 & 12.4 \\
\hline 1950 & 14.2 & -1.0 & 8.2 & 8.9 & 9.8 & 12.9 & 11.3 \\
\hline 1951 & 16.0 & -1.1 & 12.3 & 11.1 & 12.2 & 14.1 & 13.4 \\
\hline 1952 & 15.9 & -2.3 & 12.7 & 12.1 & 12.1 & 14.5 & 12.1 \\
\hline 1953 & 13.4 & -1.7 & 10.6 & 9.0 & 10.2 & 12.9 & 11.6 \\
\hline 1954 & 15.5 & -1.0 & 15.8 & 15.1 & 14.8 & 15.6 & 9.3 \\
\hline 1955 & 13.4 & -.7 & 13.2 & 9.7 & 12.6 & 19.6 & 9.1 \\
\hline 1956 & 13.5 & 0 & 14.6 & 12.7 & 12.3 & 21.0 & 7.7 \\
\hline 1957 & 13.7 & -.2 & 14.1 & 12.4 & 14.5 & 19.4 & 8.6 \\
\hline 1958 & 14.5 & .7 & 16.8 & 14.6 & 17.2 & 22.7 & 9.3 \\
\hline 1959 & 13.2 & .4 & 14.2 & 14.2 & 14.8 & 18.5 & 3.6 \\
\hline 1960 & 13.5 & .6 & 15.9 & 13.7 & 14.6 & 20.8 & 8.2 \\
\hline 1961 & 12.6 & .5 & 12.6 & 14.1 & 13.9 & 17.4 & 6.4 \\
\hline 1962 & 12.5 & 0 & 14.0 & 13.2 & 13.7 & 17.9 & 4.5 \\
\hline 1963 & 12.0 & .6 & 14.4 & 14.4 & 14.7 & 17.4 & 5.6 \\
\hline
\end{tabular}

Differneces of weighted anmual averages as compiled from "Chickens and Eggs: Farm Production, Disposition, Cash Recelpts and Gross Income," issued annually (and revised perlodically) by Statistical Reporting Service, United States Department of Agriculture. 
TABLE 18. PRICES PAID BY FARMERS FOR LAYING ILASH AND RECEIVED FOR EGGS, SELECTED STATES LESS MINNESOTA, 1947-49 AND 1963, WITH COMPARISONS. 1

\begin{tabular}{|c|c|c|c|c|c|c|c|c|}
\hline \multirow[b]{3}{*}{ STATE } & \multicolumn{2}{|c|}{$1947-49$} & \multicolumn{2}{|c|}{1963} & \multicolumn{4}{|c|}{1963 LESS $1947-49$} \\
\hline & LAYING & EGGS & LAYING & EGGS & LAYIN & MUSH & EGGS & INCREASE* \\
\hline & $\begin{array}{l}\text { MASH } \\
\text { PER } \\
\text { CWT. }\end{array}$ & 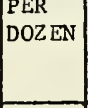 & $\begin{array}{l}\text { MASH } \\
\text { PER } \\
\text { CWT. }\end{array}$ & $\begin{array}{l}\text { PER } \\
\text { DOZ EN }\end{array}$ & $\begin{array}{l}\text { PER } \\
\text { CWT. }\end{array}$ & $\begin{array}{l}\text { EQUIVALENT } \\
\text { PER DOZ EN } \\
\text { EGGS }\end{array}$ & $\begin{array}{l}\text { PLR } \\
\text { DOZEN }\end{array}$ & $\begin{array}{l}\text { RELATIVE TO } \\
\text { MINNESOTA } \\
\text { PER DOZEN } 1\end{array}$ \\
\hline & Cents & Cents & Cents & Cents & Cents & Cents & Cents & Cents \\
\hline Pennsylvania & 22.00 & 15.00 & 25.00 & 12.00 & 3.00 & .15 & -3.00 & -2.85 \\
\hline Virginia & 32.00 & 9.00 & 46.00 & 14.00 & 14.00 & .70 & 5.00 & 4.30 \\
\hline West Virginia 2 & -26.00 & 10.00 & 45.00 & 14.00 & 19.00 & .95 & 4.00 & 3.05 \\
\hline North Carolina & 60.00 & 9.00 & 41.00 & 14.00 & 19.00 & -.95 & 5.00 & 5.95 \\
\hline Georgia & 66.00 & 12.00 & 40.00 & 17.00 & 26.00 & -1.30 & 5.00 & 6.30 \\
\hline California & 41.00 & 14.00 & 14.00 & 6.00 & 27.00 & -1.35 & -8.00 & -6.65 \\
\hline
\end{tabular}

* In combined effect.

1 Increase in price received per dozen eggs less any increase in per dozen cost of feed (change in price per pound of feed multiplied by 5.0 pounds, the approximate conversion rate for 1963) Minnesota prices for laying mash: 1947-49 \$4.29. For Eggs, 1947-49, 39.6 cents, 1963, 25.8 cents.

2 Two-year average to avoid possible aberration from reported price for 1947; three-year average is .10 cents.

Sources:

Farm Production, Disposition, Cash Receipts and Gross Income, Annual or Periodic Issues, Statistical Reporting Service, U. S. Dept. of Agriculture. 
three cents relative to Minnesota. Thus, combining the cost of feed and price of eggs we observe a decrease of 2.85 cents per dozen in Pennsylvania relative to the cost-price situation for Minnesota.

For West Virginia, over this same period, the price recelved for eggs increased four cents relative to Minnesota. The cost of laying mash increased the equivalent of 0.95 cents per dozen, leaving a net change in position of 3.05 cents per dozen. As illustrated in the previous section, however, the production of eggs in both Minnesota and West Virginia is declining. Virginia and North Carolina showed a considerably greater gain in cost-price position relative to Minnesota than did West Virginia, and as illustrated also in the earlier section, production of eggs has been increasing in these states. Iikewise in Georgia where the price of feed has actually declined relative to Minnesota, even more than in North' Carolina, the price received for eggs has increased 5.0 cents per dozen compared with Minnesota. Thus, there was an increase in the net position equivalent to 6.3 cents per dozen between $1947-49$ and 1963.

In view of the large increases discussed in the previous section for California the data shown in the accompanying table are in the nature of sharp departures from the other data in that table. We see, for example, that the price received by farmers for eggs in California declined 8 cents per dozen relative to Minnesota between 1947-49 and 1963. It is true that during the same years the price paid for laying mash declined 27 cents per hundredweight. This, however, is equivalent to only 1.35 cents per dozen of eggs and still leaves a net decrease for the feed cost-price received complex of 6.65 cents for California relative to Minnesota. In other words, the apparent relative "disadvantage" developed over this period for California was about as great as the relative advantage developed for Georgia. 
Yet, production increased almost as much in California in the last several years as it did in Georgia. And, as noted earlier, California is now the leading egg producing state. Demand for eggs within California has grown rapidly in the recent past. But egg production has grown even more rapidly and there is some prospect that substantial out-of-state shipments will be resumed in the near-future, possibly paralleling developments of the late $1920^{\prime} \mathrm{s}$.

These few comparisons emphasize again the need to allow for various unmeasurable and perhaps unidentifiable factors to explain the behavior of egg production among regions. In all these comparisons, moreover, it should be emphasized that the limitations of price data for these purposes may be changing irregularly among states, also. 1

It is noteworthy at this point that the price increase for Georgia relative to either Minnesota or California may reflect something more than an increase in price for a given grade and size of eggs. It is to be remembered that in all these cases the data represent weighted average prices received for eggs over the entire state. This is a price such that if multiplied by the total quantities sold would be equivalent to the number of dollars received by farmers for the eggs. Undoubtedly as farmers in Georgia and other states in that section of the country have increased the scale of operation the quality of eggs has improved greatly and thereby has contributed to the increase in price relative to some of the other states. Use of eggs by hatcheries, of course, has expanded and demand for table eggs probably has increased in the Southeast.

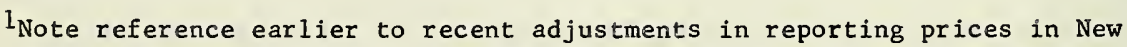
England and California, to reflect more accurately the large volume, low-priced laying feeds . 


\section{MOTIVATIONS FOR INCREASING BROILIR PRODUCTION}

In view of the ever-present tendency for prices received by brofler growers to follow the down-trend in broiler production costs, it is appropriate to consider briefly the possible motivations for the constant tendency to expand broiler outpur, particulariy in view of the current West Virginia situation. No doubt, the usual economic rationale is applicable, i.e., a firm under highly competitive conditions strives to artain a level of production approximately at the point where the marginal cost is equal to the selling price. This rationale can be applied to the non-farm components of the integrated system separately, to the farm sector, or to a combination of the two. However, this does not explain the attraction to newcomers in the field. Uncuestionably, a number of factors influence this, including the estimated or projected financial remuneration as compared with feasible alternatives.

Considering the popular image as to the highly competitive nature of the broiler industry, it may come as some surprise that hourly returns to some broiler growers ranked among the highest of major livestock industries in the U. S. in 1963. For example, the hourly return for "Typical Farms" as reported by the Economic Research Service (27) showed $\$ 1.33$ for LelMarVa, after deducting the current interest rate on all capital supplied by the grower. (Table 19). For 1963, this was the highest for any type of livestock farm except for sheep ranches in the Northern Plains which averaged \$2.07. In both 1960 and 1961, however, broilers in DelMarVa exceeded sheep ranches as well. As calculated for these "typical farms" returns to broiler growers in Maine have been moderately below DelMarVa and those in Georgia only a fraction of DelMarVa. Hourly returns in some types of crop produc- 
tion, however, were much greater than broiler returns even for DelMarVa. Hourly rates, of course, do not determine the level of living for a farm family. This is true for two reasons: (1) the number of hours worked vary considerably among types of farms and (2) the amount of capital required for the different types of farming varies considerably as does the total return from capital that is available for family living. The proportion of that capital owned by the operators varies among types of farms and spendable returns from capital vary for this reason, also.

In the calculations of net income by the Economic Research Service for its "typical farms" a charge for the total amount of capital is made against the net income in determining the hourly rates to the operator and family labor. For broilers, little or no working capital for the broiler grow-out phase itself is included in. the total capital requirements, since most of this is provided by non-farm entities. The returns to the broiler enterprise are merely premised on a going rate of payment per 1,000 birds, recognizing that such payments cover certain physical inputs (with regional variations) by broiler growers as well as their labor. In this case, of course, no charge is made for the capital furnished by the non-farm integrator; no separate, direct credit is made either. Broiler farms generally are on the low end of the range in total capital requirements. This means that less income is atrributed to capital in this accownting process. Also, it means that the business is easier to enter than are most other farming enterprises.

The import of some of these data can be illustrated by a few comparisons. In the fourth column of Table 20 it will be seen, for example, that net farm income during 1963 for DelMarVa broiler farms is estimated to have been $\$ 5,954$. Contrast this with the Grade $A$ dairy farm for eastern Wisconsin which had a net farm income in 1963 of $\$ 5,725$. It happens that the total 
TABLE 19: "TYPICAL" BROILER FARMS OF THREE REGIONS COMPARED INTERNALLY.

\section{Item}

Land in Farm Cropland Harvested Birds started, Per Lot. No. Number Produced Annually No.

Unt

Acres

Acres

3.6

106

13,951

54,790

9,710

38,014

1,900

1,830

210

Hrs.

390

210

Farm Capital, Jan 1. Total

Jand \& Buildings Maohinery \&.: Equipment Crops and Livestock

Total Cash Receipts Broilers

Livestock and Live stock Products Crops

Gross Farm Income

Total Cash Expenditures

Feed Purchases \& Livestock Expense Fertilizer, Lime \& Other Crop Exp. Machinery

Farm Bldgs \& Fences

Hired Labor

Taxes

Other

Net Farm Income

Charge for Capital at

Current Int. Rates

Return Per Hour to

Operator and Family:

No Interest Deducted

Interest Deducted at

Current Rate Applied to

Interest Deducted at Current

Rate Applied to One-Third

of Assets
Dollars

Dollars 24,150

Dollars 17,930

27,860

Dollars

Dollars

Dollars

6,220

21,210

6,590

60

Dollars

$5 \overline{5,645}$

7,068

2,680

Dollars

Dollars

Dollars

5,253

\section{1}

110

4,254

$5,974 \quad 7,557$

Dollars

3,675

3,728

Dollars

- 53

553

Dollars

Do1lars

Dollars

Dollars

Dollars

Dollars

Dollars

$1, \overline{571} \quad 1,944$

966

407

482

323

202

408

129

127

3,196

4,111

Dollars

1,332

1,582

Dollars

1.68

2.25

.98

1.38

1.27

1.85
1,580

110

12,400

8,630

3,020

750

2,012

1,590

239

22

2,490

2,001

336

46

1,138

333

64

38

46

$9 ! 1$

684

.58

2.41

2.69

.55

$\begin{array}{rr}\overline{76} & 5, \overline{372} \\ 7,595 & 10,238\end{array}$

$4,457 \quad 6,966$

36

585

314

$1, \overline{481}$

2,518

2,774

343

171

217

5,954

2,859

963

.14

.97

1.33

$-.11$

.48

1.59

2.15

.34

Data for this table are revisions of those previously published (at time this manuscript was prepared) and were supplied in separate compilations by the Economic Research Service. Comparable data for later periods presumably will be carried in the annual report "Farm Costs and Returns, Commercial Farms by Type, Size and Location" issued by ERS of U.S. Dept. of Agriculture usually released in mid-year. Data for last line and third from last line computed by author as described in text. 
TABLE 20: CAPITAL AND LABOR USED ON SELECTED TYPES OF FARMS AND AVERAGE RETURNS TO OPERATOR AND FAMLLY. 1

\begin{tabular}{|c|c|c|c|c|c|c|c|c|}
\hline & $\begin{array}{c}\text { TOTAL } \\
\text { FARM } \\
\text { CAPITAL }\end{array}$ & $\begin{array}{l}\text { LABOR } \\
\text { OPERATOR } \\
\text { AND }\end{array}$ & USED & $\begin{array}{c}\text { NET } \\
\text { INCOME } \\
\text { (FARM) }\end{array}$ & $\begin{array}{l}\text { RETU } \\
\text { AND } \\
\text { CURR }\end{array}$ & $\begin{array}{l}\text { NS PER H } \\
\text { AMILY LA } \\
\text { NT RATES }\end{array}$ & $\begin{array}{l}\text { DUR TO OF } \\
\text { 3OR, BASE } \\
\end{array}$ & $\begin{array}{l}\text { ERATOR } \\
\text { D ON }\end{array}$ \\
\hline & JAN. 1,1963 & FAMILY & HIRED & 1963 & $1957 \overline{759}$ & 1961 & 1962 & 1963 \\
\hline & DOLLARS & HOURS & HOURS & DOLLARS & DOLLARS & DOLLAR\$ & DOLLARS & DOLLARS \\
\hline \multicolumn{9}{|l|}{ DAIRY FARMS: } \\
\hline $\begin{array}{l}\text { Central Northeast } \\
\text { Eastern Wisconsin }\end{array}$ & 43,400 & $3,76 d$ & 830 & 4,068 & 0.66 & 0.57 & 0.28 & 0.42 \\
\hline Grade A & 67,680 & 4,120 & 510 & 5,725 & 0.69 & 0.82 & 0.65 & 0.49 \\
\hline $\begin{array}{c}\text { Grade B } \\
\text { Western Wisconsin } \\
\text { Grade B }\end{array}$ & $\begin{array}{l}44,800 \\
37,410\end{array}$ & $\begin{array}{l}3,700 \\
4,02 d\end{array}$ & 100 & 3,128 & 0.21 & 0.33 & 0.19 & 0.18 \\
\hline $\begin{array}{l}\text { DAIRY HOG FARMS: } \\
\text { Southeestern MInn. }\end{array}$ & 55,730 & 3,860 & 340 & 4,358 & 0.47 & 0.57 & 0.38 & 0.33 \\
\hline $\begin{array}{l}\text { POULTRY FARMS: } \\
\text { New Jersey, egg }\end{array}$ & & & & & & & & \\
\hline $\begin{array}{l}\quad \text { production } \\
\text { Maine, broilers } \\
\text { DelMarVa, broiler }\end{array}$ & $\begin{array}{l}44,080 \\
31,420 \\
46,860\end{array}$ & $\begin{array}{l}4,170 \\
1,920 \\
2,330\end{array}$ & $\begin{array}{l}910 \\
370 \\
320\end{array}$ & $\begin{array}{l}2,008 \\
3,662 \\
5,954\end{array}$ & $\begin{array}{r}-0.14 \\
0.81 \\
1.28\end{array}$ & $\begin{array}{l}0.55 \\
0.69 \\
1.45\end{array}$ & $\begin{array}{r}-0.03 \\
0.88 \\
1.48\end{array}$ & $\begin{array}{r}-0.13 \\
0.97 \\
1.33\end{array}$ \\
\hline $\begin{array}{l}\text { Georgia, broilers } \\
\text { CORN BELT FARMS: }\end{array}$ & 16,050 & 1,440 & 140 & 806 & 0.18 & -0.02 & -0.03 & -0.11 \\
\hline $\begin{array}{l}\text { Hog Dairy } \\
\text { Hog Fattening, }\end{array}$ & 62,170 & 4,260 & 470 & 5,071 & 0.82 & 0.67 & 0.56 & 0.39 \\
\hline Beef Raising & 58,920 & 3,600 & 260 & 4,130 & 0.50 & 0.28 & 0.21 . & 0.20 \\
\hline Hog-Beef Fattening & 98,920 & 3,980 & 600 & 3,674 & 1.14 & 0.57 & 1.31 & -0.54 \\
\hline Cash Grain & 137,020 & 3,010 & 330 & 14,311 & 0.48 & 0.95 & 1.20 & 2.18 \\
\hline COTTON FARMS: & & & & & & & & \\
\hline $\begin{array}{l}\text { Southern Piedmont } \\
\text { Mississippi Delta }\end{array}$ & 30,750 & 2,450 & $* 2,660$ & 3,037 & 0.39 & 0.40 & 0.30 & 0.44 \\
\hline Small & 15,470 & 2,190 & 820 & 2,666 & 0.39 & 0.50 & 0.53 & 0.80 \\
\hline $\begin{array}{l}\text { TEXAS: } \\
\text { Black Prairie } \\
\text { High Plains (non- }\end{array}$ & 57,330 & 2,310 & 480 & 5,246 & 0.39 & 0.20 & 0.36 & 0.86 \\
\hline $\begin{array}{l}\text { irrigated) } \\
\text { High Plains }\end{array}$ & 84,950 & 1,960 & 2,190 & 10,131 & 2.51 & 5.57 & 1.66 & 2.70 \\
\hline $\begin{array}{l}\text { (1rrigated) } \\
\text { CATTLE RANCHES }\end{array}$ & 139,450 & $2,39 d$ & 3,330 & 17,037 & 3.15 & 5.81 & 3.87 & 3.76 \\
\hline $\begin{array}{l}\text { CATTLE RANCHES } \\
\text { Northern Plains } \\
\text { Intermountain Re- }\end{array}$ & 89,260 & $3,30 d$ & 720 & 7,540 & 0.67 & 0.84 & 1.18 & 1.18 \\
\hline gion & 95,550 & 4,000 & 1,120 & 9,838 & 2.11 & 1.62 & 2.06 & 1.48 \\
\hline Southwest & 179,190 & 2,700 & 1,050 & 5,081 & 0.68 & 0.67 & 0.61 & -0.84 \\
\hline SHEEP RANCHES & & & & & & & & \\
\hline Northern Plains & 100,850 & 3,580 & 3,900 & 12,961 & 1.73 & 0.63 & 1.80 & 2.47 \\
\hline Southwest & 219,460 & 2,700 & 2,710 & 5,926 & 0.61 & 0.31 & -0.28 & -1.14 \\
\hline
\end{tabular}

\footnotetext{
* Cropper, $\$ 890.00$
}

1 All data except those for broller farms were compiled from "Farm Costs and Returns," Africulture Information Bulletin No. 230, Econamic Research Service, U. S. Dept. of Agriculture, revised June, 1964. For broller farms, revised data were obtained by letter from Economic Research Service. 
capital requirements at the beginning of January, 1963, for the DelMarVa broiler farm, column one, (excluding working capital on broilers) was $\$ 46,860$ while for the Grade A dairy farm in Wisconsin it was $\$ 67,680$. (27) At the 1963 interest rate, the total charge for capital on the broiler farm was $\$ 2,859$ while for the Grade A dairy farm in Wisconsin it was $\$ 3,722$. Subtracting these two figures from the net farm income shown in column 4 of Table 20 and dividing the respective remainders by the total hours worked by the operator and family during 1963 in each instance gives the hourly rate indicated in the last column - \$1.33 for the DelMarVa broiler farm and $\$ 0.49$ for the Wisconsin Grade A dafry farm. Now it happens that in 1963 the number of hours worked on DelMarVa broiler farms by operator and family totaled 2,060 compared with 4,120 for the Grade A dairy farm in Wisconsin. A similar calculation for the broilex farm in Maine shows a flgure of $\$ 0.97$ to operator and famlly labor in 1963 based on a net farm income of $\$ 3,662$, a charge for capital of $\$ 1,807$ and the reported number of hours worked during the year at 1,920.

It is important to observe, incidentally, the substantial income attributable to (as opposed to charges for) capital on farms with the higher amounts of total capital. For cartle ranches in the Southwestern United States, for example, the net ranch income in 1962 was $\$ 8,237$. This farm at the beginning of 1962 had capital of $\$ 164,700$. Based on interest rates of that year the total charge for al1 capital involved was $\$ 9,058$. Subtracting this from the net of $\$ 8,237$ left a deficit which, divided by the 2,420 hours worked by operator and family was equivalent to a loss of $\$ 0.34$ per hour. This calculation implicity assumes, in effect, that all capital was borrowed and interest paid on it at the going rate. For purposes of ascertaining the return to labor, as distinguished from capital, such procedure 
has merit. If, on the other hand, such a typical farmer"s equity were equal to half the assets, the interest charge (actwally paid out) would have been $\$ 4,529$. Then the total return to that operator and family for capital as well as labor) would have been equivalent to $\$ 1.50$ per hour. In an analytical sense the second figure is not as valid as the first but it gives a closer approximation to amount of income available for family Ifving. This goes far to help explain why farmers frequently can withstand apparent adversity for prolonged periods. Obviously, and to an increasing extent, the operators of farms with such large capital involvement must be viewed as financial nanagers of a very high order.

The size of enterprise and proportion of equity owned by operators also can be of crueial importance to broller growers. From Table 19 it is to be noted that the typical size of enterprise (in terms of Janvary 1 capitalization) Varies substantially among areas being, respectively, (in 1963) for Maine, DelMarVa, and Georgia, $\$ 31,420, \$ 46,860$ and $\$ 16,050$. In all three areas, the non-farm contracting firms supply the feed, chicks, medicines, and related items, exeept in Georgia where the growex supplies litter and fuel. This makes the broller farms non-comparable with other farms shown in Table 20 but comparisons san be made among the broiler type farms as in Table 19. Differences in capital reflects to a degree the capacity of the growers to enl1st contractual support of the purveyor of feed and chicks, etc. Incomes, accordingly, can be influenced as a result. In these comparisons, however, it is to be recognied that the typical tarm on DelMarVa depicts more of an fndigeneows kind of operation than either of the other two areas by virtue of relatively heavier local production of corn and soybeans. 
No data are available as to the average amount of indebtedness of the different broiler farms. It will be assumed for purposes of this analysis that the typical farm in each of the three broiler areas is in debt to the extent of one-third of assets. As shown in Table 19, the total charge for capital at (then) current interest rates was, in $1963, \$ 1,807, \$ 2,859$, and $\$ 963$, respectively. Subtracting these charges from net income of the enterprise and dividing the remainders by the number of hours worked gives hourly returns for Maine, DelMarVa, and Georgia, respectively, $\$ 0.97, \$ 1.33$ and -\$0.11. If no interest charge were made in approximating family returns (for labor and capital combined) the comparable hourly returns would have been $\$ 2.41, \$ 2.69$, and $\$ 0.55$. But subtracting from net farm income an amount equivalent to interest on one-third capital, as assumed above, and dividing the remainder by the respective number of hours worked, would have yielded hourly returns in 1963 of $\$ 1.59, \$ 2.15$, and $\$ 0.34$, respectively. Similar data for earlier years are shown in Table 21. Even allowing for rather large errors in these calculations, two points particularly stand out in the comparisons: (1) In both Maine and DelMarVa the trends in total and hourly returns (based on indebtedness equal to one-third assets) have been upward, while for Georgia they have been distinctly downward and (2) the level of hourly rates and annual farm income in Maine and DelMarVa, respectively, are several times those in Georgia.

The series for Georgia, to the extent that it is representative of the broiler situation in that state and any other areas similarly situated as contrasted with DelMarVa particularly, raises serious questions as to the stability of any equilibrium now prevailing there. If returns are anywhere near as low as the calculations indicate, there is certain to be shifting to better paying alternatives as soon as labor becomes better educated and 
trained. Such adjustments will take place even if some migration would be involved. Considerations such as these suggest that geographic realignments in broiler production may be far from complete although those in the near future may be less tumultuous than of the recent past.

\section{Ability of Broiler Growers to Accumulate Capital}

Differences among areas currently and in the future in returns to broiler growing families for their labor as well as capital raise serious questions about willingness, and particularly the ability, to maintain or expand physical facilities for producing broilers. The above comparisons of income data raise these questions about Georgia particularly, although, in recent years, erection of new units and other signs of apparent vigorous growth could be widely observed in the main producing areas of that state. In general, however, the newer units being erected in Georgia more nearly resemble the buildings made of wood products on Virginia and West Virginia farms than the masonry, more permanent construction of DelMarVa. In the Shenandoah Valley area of Virginia and adjacent counties of West Virginia the average age of buildings is higher than elsewhere and practically no new construction is taking place, as would be expected in an area of rapidly declining production. Practically all the new construction on DelMarVa is basically of masonry materials and many provide for controlled environment.

An analysis by Burbee and Frick (28) of the New Hampshire Agricultural Experiment Station indicated that the ability of growers to maintain their physical facilities varied with size of enterprise. Based on data for 1957, since which time New Hampshire production has declined more than 50 per cent, they concluded that growers in the 10,000 to 20,000 annual output range probably were unable to accumulate sufficient capital to provide re- 
TABLE 21 - INCOMES ON BROILER TYPE FARMS, THREE MAJOR AREAS $1950-1963^{1}$

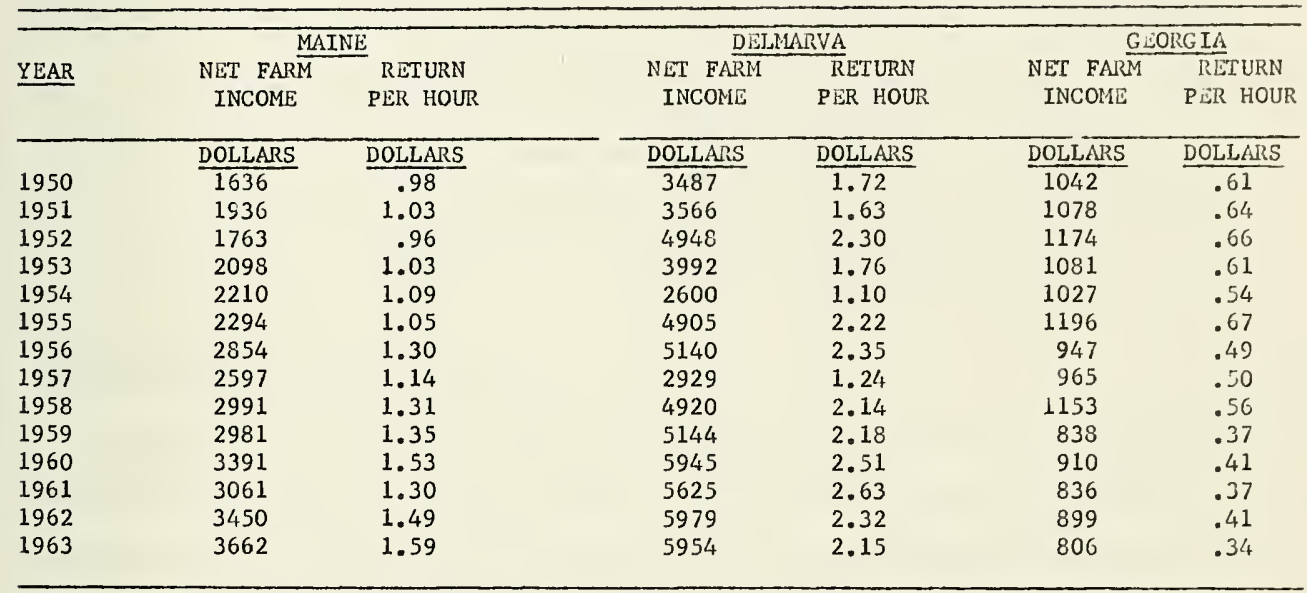

1 Based on data obtained from the Economic Research Service of the U.S. Dept. of Agriculture; at time of preparing manuscript most figures represented revisions of those in released publications. For all three areas, the returns per hour were premised on assumption that indebtedness equalled one-third of assets and returns to owners' equity were imputed to labor. 

placements when existing physical facilities became unusable. At best, units of this size were deemed to be suitable for part-time farming operations since the earnings from alternative occupations could thereby assist in maintaining a reasonable level of family income and permitting some set-aside from the broiler operation for future capital expansion.

Based on data for the same period it was estimated that units in the 35,000-50,000 bird-per-year range would permit sufficient capital accumulating potential to enable the industry to at least perpetuate itself and possibly to expand. This was premised on these capacity units providing a full-time family operation. The above pair of calculations is a manifestation of the very narrow margins under which broiler growers operate, in view of the fact that the costs for buildings are equivalent to less than five per cent of the total cost of producing broilers and to no more than 20 per cent of the cost of non-1abor items other than chicks and feed.

\section{Characteristics of Broiler Growers}

Broiler growing is still being introduced to new areas and to additional people within present producing axeas. Even existing producers are being confronted with more sophisticated production and management techniques. These conditions together with the fact that broiler growing requires less land than production of most other items labeled agricultural products, make the characteristics of potential growers emerge as quite important in evaluating broiler-producing prospects for an area. In a study made in Maine (29) for 1957 and based on a sample of 245 growers, it was revealed that about two-thirds of the broiler raisers and one-half of their wives were farm-reared. Eighty per cent of the growers considered farming to be their major occupation. Sixty-nine per cent were primarily broiler operators. Fifty-six per cent did no off-farm work in the year prior to this study. 
Before beginning their broiler operation, the major occupation of 52 per cent of the respondents was a blue collar one. At the time of the study, 11 per cent were employed primarily as blue collar workers. Forty-seven per cent of the growers were, or had been, members of a labor union.

The growers in Maine tended to have a generally favorable attitude toward contract broiler growing. Forty-one per cent of them said that they favored it over all other occupations. Although economic factors were reported to be the major reason for entry into contract broiler raising, sizeable proportions began contracting broilers because of the opportunities it afforded for: (1) staying on the farm, (2) raising animals, meeting a crisis situation such as retirement, and (4) to gain a sense of independence of self-employment. Nevertheless, overall, just short of fifty per cent of the growers believed that their status at least resembled that of an employee. Eighty-six per cent of the growers thought that the day-to-day operating decisions of the farm were made directly by themselves or jointly with their spouses even though they had rather rigid and frequent supervision by the representatives of their non-farm contracting firm.

On the average, the Maine survey showed that broiler growers were younger ${ }^{l}$ and had a greater number of years of schooling than the average farmer in that state. The level of living of the broiler operators tended to be higher than that of other maine farmers.

${ }^{1}$ An unpublished manuscript by Paul Nesselroad of this station indicates that in West Virginia, also, broiler growers" age is substantially below the average age of farmers in the State. 
Although no one would enter, or continue in, the production of broilers solely for the manure obtained, it apparently happens from time to time that this is the only return from a given brood of birds. Even where it isn ${ }^{\circ} t$ the only return, it might be termed a non-pecuniary reward. Nevertheless, yaluing the nutrients supplied by chicken manure in accordance with a reasonable measure of their productivity, if used properly, a fairly significant return can be established. Whether a return is actually experienced depends upon whether the economic significance is appreclated; and if appreciated, Whether it is economically feasible to realize the economic value. Undoubtedly, for one or the other of these reasons, there are many instances where the manure is viewed as a liability rather than an asset.

Estimates as to the amount of manure obtained per 1,000 brollers produced, as well as the value of such manure per ton, or fer 1,000 birds, varies over a rather wide range. The amounts obtained, of course, can vary among growers due to differences in their basic practices, differences in the type of litter employed, and differences among areas in humidity. In fact, even for a given grower in a particular locality the amount of litter required to keep a given level of dryness can vary considerably through seasons of the year or as weather conditions change. The valve per ton, or per 1,000 birds, on the other hand, will vary considerably depending upon the uses to which the manure can be practically employed, the labor costs involved in the area for handling the material, and the distance that the material must be transported to the point of eventual use. A factor also involved in measurfing its value is the volatile nature of nitrogen contained in the material; under conditions of improper management as much as one-half or more can escape into the atmosphere. 
In the early part of 1963, a single experiment was concluded at the West Virginia Agricultural Experiment Station which was designed to ascertain the value of chicken manure obtained in a broiler producing operation approximately simulating practical conditions experienced by growers in the field. (30) Since the litter itself normally has some fertilizing value even if placed directly on the field, rather than by way of the broiler houses, this particular experiment was conducted to credit the litter component of the total manure with some fertilizer value. This was accomplished by observing and measuring the additions to the litter which resulted from being placed in the broiler house for the period that the brood of broilers was grown. The amounts added were then reduced to a dry basis and the available quantities of the normal components of fertilizer, that is nitrogen, phosphorus, and potash, were evaluated by chemical analysis. The total amount of manure, per se, added from the broiler grow-out operation was equivalent to approximately .295 pound dry weight basis per pound of feed supplied to the broilers. The chemical context showed 3.3 per cent nitrogen, 3.4 per cent phosphoric acid, and 1.7 per cent potash. This is equivalent to commercially handled fertilizer that might be described as a 3-3-2 mixture, a rather low nutrient formula. As is genexally known, the practice in recent years has been to increase the nutrient content of inorganic fertilizers per unit of weight so as to permit more efficient handling and distribution methods.

Using the above basic data and assuming a feed requirement of 2.3 pounds per pound of live broiler produced, we observe that to produce 1,000 broilers weighing 3,500 pounds would require 8,050 pounds of feed. The 8,050 multiplied by the .295 gives a figure of 2,360 pounds of dry weight manure. This 
means in terms of the three major materials of fertilizing properties the 1,000 birds would yield 78 pounds of nitrogen, 79 pounds of phosphoric acid, and 40 pounds of potassium. Based on prices paid by farmers in West Virginia in September 1963 for fertilizing materials, the aggregate value was as follows: nitrogen, 78 pounds at $\$ 0.13$ giving a total value of $\$ 10.14$; phosphorous, 79 pounds at $\$ .094$ giving an aggregate value of $\$ 7.43$; and, the 40 pounds of potash at $\$ .054$ giving an aggregate value of $\$ 2.16$. The combined value of these aggregates is $\$ 19.73$ (per 1,000 birds).

The value, it is to be emphasized, is applicable to the manure as it exists in the house after the removal of the broilers and is separate from any value that may be inherent in the iitter material itself. This value, of course, is in terms of the price paid by farmers for the same fertilizing nutrients contained in inorganic fertilizer mixtures. There is considerable labor involved in getting the manure out of the poultry house and onto the field where it can be used. Undoubredly, this labor and handling cost, particularly in view of the low nutrient content of the material, is substantially above that experienced by providing the same quantity of nutrients in the normal inorganic fertilizers. An unknown quantity, nevertheless, is the value added to the soil by virtue of the humus contained in the chicken manure mixture in contrast to supplying the same nutrients in the inorganic form.

Actual practices in the field with regard to disposition of chicken manure varies over a wide range from one in which the grower may actually pay someone to remove the manure from the houses and haul it away, to the situation where the eventual user of the manure is willing to pay the grower for the manure and move it away at no charge. Many growers, of course, use the manure on their own land. 
Chappell et. al. (13) suggest that the day may come, if it has not already arrived in some areas, where the manure disposal problem will be a controlling factor in determining the density of broiler production per unit of land avallable. Even where it is used for fertilizing purposes, because of the bulky nature of the material there is an upper 1 imit to the distance that the manure can be transported. 


\section{PART III}

A COMPARISON OF SOME INTERNAL CHARACTERISTICS OF CERTAIN STATES PRODUCING BROILERS AND EGGS

As a basis to evaluate the ability of a state, or area, to maintain its progress along with others in the production of any particular commodity it is necessary to know something about the internal characteristics as well as the likely influence of "external" factors discussed in Part I. Also needed are results of dynamic interaction of the effects of external factors discussed in Part II. It is to be recognized that what is internal to one state, or area, is external to others and if economic progress renders a particular phenomenon a disadvantage to another area, that affect is just as real and important as if it were due to any internal factor.

A permanent "fixture" as unchangeable through time as a mountain can nevertheless have changing economic affects as progress occurs. At the production level, for example, so long as plowing was done everywhere with two horses and a single-bottorn walking plow a man could be nearly as effective in an Appalachian field with a steep gtadient as on a flat piece of Iowa 1and. But with the advens of five or six bottom plows and the tractors to pull such rigs the comparison changed sharply. Or, as an example in the marketing field, as long as cattle were driven to market, the marketing cost was not greatly different for a mountainous terrain as compared with level terrain. It may have taken a day or two longer for a given distance in order to avoid greater weight $10 \mathrm{ss}$ but time was relatively cheap so this was a minimum factor. Now with the use of trucks for marketing, and with time far more valuable, the mountain terrain constitutes a larger relative disadvantage. 
Changes in the margin between costs and returns per unit also can be very important. As long as the difference between selling prices and outof-pocket costs were reasonably wide, such as in the early years of the broiler industry or during World War II, a significant relative disadvantage could be tolerated. But now that margins are so narrow a small shift in relative cost or returns can transform an enterprise from one showing a small net remuneration to a clear-cut, long-term red ink operation.

Whereas, most of the analyses employed in Parts I and II were dynamic in nature the procedure employed in this Part will be essentially static, although some references w11l be made to change between census periods. That is, most comparisons will be made among states or among areas within states in terms of certain characteristics as of given time periods. In most cases, comparisons will be made on the basis of those characterlstics of the economy, agriculture, or the broiler and egg industries which could be important in determining the manner and extent of future adjustments to dynamic influences, such as discussed in Part II. Some of the data employed in these comparisons may be helpful in understanding reasons why the Industry has come to be located in particular localitles or counties rather than elsewhere. They may be helpful also in identifying areas destined for further growth (or decline), particularly when supplemented by data from ensuing census takings.

A necessary, but apparently not a sufficient condition for the broiler Industry to locate in a locality is that ample labor - particularly agricultural labor - be available. This is suggested first by the fact that the map of depressed areas of the United States, published by the Area Redevelopment Administration in 1963, showed that of the 70 counties accountIng for two-thirds of the broiler output of the states in which located, 50 
were classified as in over-all depressed conditions. Thus, it is not surprising that using the statistical technique of rank correlation there was a high degree of positive association for the year 1959 between value of broilers sold in counties of West Virginia and the proportion of employed males engaged in agriculture. Similarly for Georgia counties in 1949

there was a high degree of association between the value of broilers sold and the proportion of farmers working off their farms 100 days or more per year. The statistical measure, "rank correlation," was used with a number of other pairs of variables to try to identify either the factors associated with the growing importance of broilers, supposedly as a causal element, or to reflect the influence of expansion in broiler output. A11 these analyses gave non-significant results. For example, there was no relationship shown between the importance of counties in broiler production and recent changes in cotton acreages. If there had been such a relationship, one might conclude that the decline in cotton released resources for broiler production. There is no question, of course, but what the decline in cotton released resources for many other activities. But this was true generally. Choices of the counties for expanding broiler production were based on other criteria and in some cases may have been more or less accidental in natuse. That is, there probably are many areas in the states where broiler production is now important, and perhaps some areas outside those stares, that are just as well suited to broiler production as the areas which have been chosen. It may be surprising that no association was found between broiler production and cattle population. This may be due to the fact that the transition out of cotton was still underway and there is a strong motivation to establish livestock in all areas to use the land resources. Conceivably, in the near future a positive relationship with broiler production will become 
evident because of the value of poultry manure. 1

In the early years of the broiler industry, introduction of broiler growing in an area usually resulted in increased returns to resources employed and meant substantially larger total incomes to the area. It may be significant, however, that there was no relationship between the relative standing in value of broller sales in 1959 and the change in median income between 1949 and 1959 for either Georgia or West Virginia counties. Similarly there was no positive relationship found between the change in median income of the counties, 1949 to 1959, and the change in value of broilers sold. In fact, there was some tendency toward a negative relationship - the larger the increase in income from broilers between 1949 and 1959, the smaller the increase in income for the county as a whole. This may be a manifestation of the downward trend in returns to resources committed to broiler production in early years, even though the volume of broiler production was increased enough to give a rise in the aggregate value of sales despite the decline in prices. The margin per unit between cost and selling price narrowed so much that returns to people and physical resources involved showed relatively little increase from 1949 to 1959. In some cases, no doubt, there were other counties that engaged in other types of economic activity early in the $1950^{\prime} \mathrm{s}$, and whose products of which did not experience price declines similar to broilers. As a result, these counties enjoyed greater income levels at the end of the $50^{\circ} \mathrm{s}$, relatively, than did those counties engaged heavily in the production of broilers.

${ }^{1}$ See page 103 for some analysis of the fertilizer aspects of the broiler industry. 
The particular aspects of the economies discussed in the following paragraphs were chosen because, of the available measures, they seemed logically most appropriate to judge the receptiveness of a locality or area to produce broilers and eggs. On the other hand, a number of series appeared potentially most helpful in appraising the effects of increases in production of broilers and eggs on the economy-at-1arge. As indicated earlier, the inability to obtain statistically significant relationships, so far, should not be construed as absolutely and permanently ruling out their relevance. In many instances the particular phenomenon or characteristic described, may constitute only the necessary condition for the production of broilers or eggs - the additional ingredient to make a sufficient condition may have to come from outside the area. For example, it is conceivable that a dozen or more counties may be equally well suited to broiler production based on all indications - those described in the following paragraphs as well as other relevant considerations such as freight rates for the raw materials in and the finished product out, feed costs, wage rates, prices of baby chicks, etc. But only one of the counties may be chosen by a national distributor, thereby making conditions sufficient for the expansion in broller production in that locality.

With the passage of time the relative importance of these various measures will shift. Judgment on these matters will have to be made as future census data become available to indicate differing rates of economic growth as manifested in the various measures and indexes. Moreover, improvement in statistical concepts and statistical coverage may reveal more helpful indications in future census years. 
The size of population in itself is not a decisive determinant as to whether an area engages in any particular line of economic activity as long as there are enough people to conduct that activity. It is of some interest, nevertheless, to compare the population among major broiler areas and to observe recent changes. It would be appropriate, in a study of a larger context, to also consider other aspects of the populations, such as age distribution, the level of academic attainment, etc. However, this avenue of investigation, particularly on education, as urgently as it is needed, is outside the scope of this study.

of the broiler-producing counties shown in Appendix Table Xx, the total population has decreased only in Arkansas, Alabama, Mississippi, and West Virginia. In both Mississippi and Alabama, however, the population for the states as a whole increased slighely between 1949 and 1959. To a degree, therefore, a slight decline in the population for the important brofler-producing counties is no different from what has been happening generally in the population of agricultural areas in recent decades. The population of the states as a whole shows a decline, therefore, only for Arkansas and West Virginia. Both these states, incidentally, showed a greater reduction in population for the states-at-large than for the broiler counties, but West Virginia showed a larger decline for both the State as a whole and the broiler counties than did any other state.

West Virginia has the lowest population density of any broiler section. In 1959 for the broiler counties of West Virginia there was an average of 22 persons per square mile. The next lowest was Arkansas with 28.5 persons. The highest was Maryland with 84.3 , followed by Maine with 80.0 , and Georgia at 60.0 . 


\section{Employment}

In the broller areas of Arkansas, Alabama, and West Virginia total employment declined from 1949 to 1959. For Mississippi the total employment increased very slightly in the broller counties but a substantial decrease occurred for the state as a whole. Iikewise, state-wide employment decreased for Arkansas and West Virginia. For Alabama, however, there was a slight increase in total employment for the state as a whole despite the decline of about 9 per cent in employment within the important and rapidly growing broiler counties. Each broller producing county for West Virginia listed in the table, showed a decline in the total employment from 1949 to 1959 with the total for the four counties showing a decline of about 15 per cent, the largest decline for any state group of broiler producing counties. In judging the long-run prospects for broiler production in any area, one consideration is the existence currently, or probable existence in the future, of alrernative employment possibilities. One important alternative can be factory employment since this not only gives direct employment but more jobs are brought about in supporting industries as well. In many instances the rates of pay in factory employment even for the same caliber of people as are engaged in broiler production will be somewhat above the level received from the production of broilers. To an increasing extent, of course, factory operations of most kinds are becoming highly automated which increases the skills required of employees and is tending to reduce the number of total positions. In general, however, the existence of major manufacturing industries in an area has a buoyant effect on the wage rates and if it occurs to an increasing extent in a broiler area will tend to lessen the attractiveness of broller production, as judged by a firre deciding where to locate expanded broiler producing facilities. 
Factory employment as a percentage of total employment in the broiler producing states varies widely. The lowest reported figure for 1959 was for the West Virginia broiler area with 15 per cent. Within West Virginia, the range was from 12.4 per cent for Pendleton County to 13.3 per cent for Preston, 14.9 per cent for Grant, and 26.6 per cent for Hardy County. Within all states there were wide ranges, particularly for the states of Alabama and Georgia. In Alabama the range was from 20 per cent for Cullman County to 46 per cent for Clayborne County, an average for the entire state of 25.5. For Georgia the range was from 16 per cent for Coffee County to over 50 per cent for Whitfield County with an average for the broiler counties of 40 per cent. All these data on factory employment, incidentally, are in terms of the jurisdictions in which the employment occurred. In many instances there is the practice of commuting which interferes with the comparisons.

\section{Value Added by Manufacture}

Another manifestation as to the importance of factory production to the economy of an area is "Per Capita Value Added by Manufacture." West Virginia at large, because of the importance of the chemical industry mainly in the west-central part of the State, shows a favorable comparison with other states. The State average for 1959 was $\$ 653$ for West Virgin 1 , which is exceeded slightly by North Carolina at $\$ 677$, Maine at $\$ 659$, Maryland at $\$ 767$, and Delaware at $\$ 941$. The individual counties of West Virginia, important in broiler production, on the other hand, have very little manufacturing. The per capita figure for 1959 for the four broiler producing counties was $\$ 96$. The next lowest figure for the broiler counties of any state 
was $\$ 209$ for Alabana, followed by Mississippi at $\$ 272$, and Arkansas at $\$ 289$. North Carolina counties average $\$ 533$, and Georgia broiler counties $\$ 563$.

The signiflcance of these data, it is to be noted, is somewhat limited by virtue of the fact that in many instances the manufacture includes the processing of poultry which, of course, will show a larger figure for the broiler-producing counties than ff the processing of the broiler output of the county takes place in an adjoining county or adjoining state. It is not readily possible to obtain the data on per capita added in the manufacture of items separately from processed poultry.

\section{Unemployment}

Another indication as to whether an area might be receptive to a larger broiler enterprise is the extent of unemployment which exists. This, however, sannot be used as an indication without considering other relevant factors as well. For example, an area may have a high rate of unemployment but because of other conditions the existing wage or salary structure may discourage the entrance of other industriss such as a broller production enterprise. Morecver, the existence of unemployed people is far from a sufficient condition because a huge amount of capital is needed, as well, in order to start produeing commercial broilers. In 1959, West Virginia had the highest rate of unemployment of any broiler state show in the Appendix Table $x_{x}, 8$ per cent for the broflex counties of West Virginia. The next highest average for broiler counties of a state was for Alabama and Maine at 5.4 per cent, and for Mississippi and Arkansas at 4.2 per cent of the broiler-produeing states listed in the table, the rates of unemployment insreased from 1949 to 1959 in all instances except for Maine. In that state the rate dropped for the state as a whole from 8.7 per cent in 1949 to 6.2 per cent in 1959. For the broller counties of Maine the decline was from 
7.5 per cent in 1949 to 5.4 per cent in 1959. Georgia also showed a reduction in the rate of unemployment for the state as a whole (from 3.4 to 2.4 per cent), although for the broiler producing counties it increased from 3.0 per cent in 1949 to 4.0 per cent in 1959. With the exception of Georgia and Maryland, the percentage of unemployment for the state as a whole was equal to or greater than that for the broller areas of those states in 1959. In 1949 every state except West Virginia had a lower percentage unemployment for the broller counties than for the respective states-at-large.

\section{Median Income}

A first impression might be that the relative level of family income would be one indication of the receptiveness of a locality or people to the introduction of a new economic activity, such as broller production. This might appear particularly appropriate for the broiler industry since much of the capital which growers need is supplied by outside sources. Again it is to be noted that both confirming and rejecting experiences can be observed. It appears that a condition for the introduction of the broiler enterprise in an area is an adequate supply of labor, which probably is receiving below average incomes, but that this is by no means a sufficient condition. The median family income in the West Virginia broiler-producing area in 1959 was lower than that for any other state shown in Appendix Table XX; in 1949 four states were below West Virginia: Alabama, Georgia, Mississippi, and Arkansas.

The states which have experienced the most rapid growth in broiler output over the past ten to fifteen years are states whose broiler areas had very low incomes in 1949. The lowest average for broller areas in that year was Mississippi with $\$ 999$ which compares with $\$ 1,194$ in Alabama and $\$ 1,436$ in Arkansas. West Virginia had an average of $\$ 1,759$. 
The largest increases in median family income occurred in the extreme southern states from 1949 to 1959. The state with the leading increase for the broiler areas concerned was Mississippi which showed a rise of 216 per cent. The next highest increase was Alabama with 145 per cent, followed by Georgia with 138 per cent, and Arkansas with 115 per cent. The gain for West Virginia was 65 per cent, ranging from 48 per cent for Preston County to 92 and 97 per cent, respectively, for Grant and Pendleton counties and 104 per cent for Hardy County.

West Virginia showed a significantly smaller increase in median family income for the broller producing counties than for the state-at-large. Again, the biggest difference was shown for Mississippi with a 216 per cent increase in median income for the broiler producing counties, compared with 140 per cent for the state as a whole. Georgia showed a gain for the broiler producing counties of a 138 per cent compared to 85 per cent for the stateat-large. North Carolina showed a gain of 88 per cent for the broiler producing counties as compared to 87 per cent for the state-at-1arge. The increase for West Virginia, both for the state-at-large and for the broiler counties, was smaller than for any other state.

\section{Proportion of Land in Farms}

Decisions as to whether to promote broiler production in any particular area can be expected to be influenced to some extent by the structure of the area's agricultural industry. Some of the more important aspects of the structure of agriculture in the different broiler areas are shown in Appendix Table XXI. Some of these have not been influential in describing the present geographical pattern of broiler output but they could well become so in the future. One condition for an area to become important in broiler production 
appears to be the predominancy of agriculture. It so happens that in all the states listed in the table, except West Virginia, the acres in farms showed a decrease from 1954 to 1959. For the broiler counties of West Virginia there was an increase of a little over one per cent in the acres farmed in 1959 as compared with 1954. The number of farms in these states, as in all states of the United States, showed a substantial drop from 1954 to 1959. The increase in average size of farms partly offset the decline in numbers except in West Virginia, where the size of farm increased enough to more than offset the decline in number, and as indicated, the acreage involved exceeded that of five years earlier.

The proportion of land engaged in farming activity varied greatly among the states concerned, ranging from 22 per cent in the broiler areas of Maine to a high of 63 per cent for Sussex County, Delaware. All of the southernmost states ranged close to 50 per cent, and for West Virginia, 58.5 per cent. Within West Virginia the range was from 50 per cent in Preston County to 60 per cent for Hardy County, 62 per cent for Grant, and 66 per cent for Pendleton County. Thirty-nine per cent of the land in West Virginia was utilized for agriculture during 1959, the lowest for any state except Maine.

\section{Proportion of People in Farming}

A more appropriate indicator as to the receptiveness of an area for the production of broilers would be the proportion of people engaged in farming. To indicate this, data are presented in Appendix Table XXI showing the number of employed males working in agriculture during 1949 and 1959, respectively. These figures are expressed as a percentage of total employed males in each county during the two census years. As is to be expected, there is a wide range among states in these percentages. For the broiler areas of the states 
concerned the lowest proportion is for Maine at 5 per cent. Within that state the broiler counties ranged from 2.6 per cent up to 19 per cent. In Sussex County, Delaware, the leading single county in the production of broilers in the Uniced States, 20 per cent of enployed maies were engaged in farming, compared with 30 per cent in 1949. For the West Virginia broiler axea 26 per cent of employed nales were engaged in agriculture in 1959 compared with 38 per cent in 1949. For the state-at-1arge, however, only 5.7 per cent were engaged in farming in 1959, less than half the average in 1949. The state-wide figure was lower for West Virginia than in any other state except the 4.4 per cent for Naryland. In Maryland, however, for the broiler counties concerned, 15 per cent of the males were engaged in farming, with a high of 22.5 per cent for Worcester County. Among broiler areas of the states concened, Mississippi showed the highest figure at 35 per cent, followed by Alabame and Arkansas, each at about 25 per cent, and Georgia and North Carolina each at about 15 per cent

Within these states, wile ranges existed. In Georgia, for example, the range was from a lor of about 6 per cent to a high cf about 33 per cent. One county each in Mississippi and lin Axkansas exceeded 50 per cent, and in Alabana one county exceeded 40 per cent. As indicated earlier, using the statistical procedure, rank correlation, it wes established that there vere significant relationships between the proportion of males engaged in agriculture and the production of brollers in individual counties for some of the selected states.

Quite clearly the existence of a high proportion of the males in the agricultural industry is not a suffieient condition for the broiler enterprise to take root and grow. Many other sections of the United States also have a high proportion of employed people engaged in agriculture. In the 
southern states of Alabama, Mississippi, and Arkansas, however, the percentage of people engaged in agriculture is high. Their productivity, as measured by the cash value of their production, is relatively low so that with the minimum of resources which they can accumulate it is possible to equip themselves to produce broilers, given the supply of working capital from ourside sources. For West Virginia, the percentage of males employed in agriculture (within broiler areas) is relatively high. As indicated earlier, the median family income is relatively low, yet broiler production is not increasing. To account for this ironical situation, as compared with some of the southern states, it is necessary to refer to the changes among states discussed in Part II indicating the growing relative disadvantage of West Virginia and some other areas in acquisition costs for the major factors of production.

\section{Size of Farm Enterprise}

One characteristic of the broiler industry or of broiler production at the farm level is that it can and does utilize female labor to a greater extent than is true for most other livestock enterprises. Thus, if the size of the farming enterprise is too small to justify the full-time employment of the man of the family, and alcernative opportunities are available for his employment, it is not uncommon for female members of the family to do a substantial part of the broiler work.

The size of farm enterprises can be measured on a number of different bases and the one employed in Appendix Table XXI, in terms of acres per farm, certainly is not the best. Nevertheless, it is of some interest to note this variation. This measure, incidentally, probably is less meaningful for West Virginia than for most other states because of the roughness of its terrain. The average size of farm in West Virginia in 1959 was 214 acres for the broiler 
counties, with 137.8 for the state-at-large. The next largest average size farm for broiler counties of the states concerned was Arkansas with 147 acres, followed by Maine with 138 acres. The other Southern states had around 100 acres per farm in 1959.

\section{Non-Farm Employment and Incomes of Farmers}

In the broiler areas of Mississippi, Alabama, and North Carolina, 35 per cent of the farmers work off their farms 100 days or more during the year. About 40 per cent in the other states are so employed.

Non-farm employment has become an important source of income to farm people. In 1959, for the broiler areas of the states concerned, the proportion of farmers who received more income from non-farm sources than from their farm produce exceeded 50 per cent in a number of cases. The highest state was Georgia with 55 percent followed closely by Virginia and West Virginia at 53 per cent, and Mississippi and Arkansas at 52 per cent. Delaware was lowest at about one-third.

Quite clearly this tendency to work off farms and obtain more income from non-farm sources would be far more prevalent on non-broiler farms. A characteristic of the broiler industry, especially even for a moderate-sized enterprise, is a large turnover of working capital, so that the total value of produce handled during the year may amount to substantial value even tiough the net return to the farm family may vary from a moderate level to a very low return or possibly no net return at all. It is of some significance, however, that Georgia has the highest percentage of farmers where non-farm income exceeds the farm receipts and at the same time has shown relatively little change in the past ten years in the average size of broiler enterprise. 
Within West Virginia there was a considerable range, from 44 per cent for Hardy county, 47 for Pendleton county, 52 for Grant county, and 64 per cent for Preston county. For the state as a whole, 66 per cent of farmers in 1959 received a greater cash income from non-farm sources than from all farm produce sold.

\section{Age of Farmers}

Age is characteristic of farmers that will help determine their receptiveness to any new farming enterprise. This becomes important because it is known that older people are less likely to adopt new techniques or take on new enterprises, particularly if there is greater financial risk involved, than is true of younger people. Among broiler areas of the states listed, the range in age of farmers was between 50 and 52 years except for Virginia and West Virginia which showed 53.6 and 54.6 , respectively.

\section{Community Efficiency in Broiler Production}

As the broiler industry is becoming more advanced, the so-called external economies become more important in determining the ability of individual areas to compete. These include supplementary enterprises such as offal processing plants, disease diagnostic services, machinery maintenance plants, etc. A measure of achieving such economies is afforded by the degree of the geographical concentration of broiler production. Here we find two measures which are significant. One is the percentage of farms engaged in broiler production in a current or recent year, and secondly, the change in this percentage from 1954 to 1959. We find a very wide range among the broiler producing areas of the individual states. For the broiler sections of the states concerned, the highest percentages are shown for Delaware (47 per cent) and Maryland (38 per cent), Appendix Table XXII. However, some counties in 
Georgia show a much higher participation in broiler production, ranging up to 60 per cent in two counties and exceeding 40 per cent in four others. However, the average for all counties in the state is 29 per cent. For Mississippi and Alabama, the two states showing the most rapid increase in recent years, the percentages stand respectively at 9 and 11 per cent. For Arkansas, one of the older broller producing sections of the United States, the range is from 9 per cent to 25 per cent among the counties, accounting for about two-thirds of that state's output, with all broiler counties showing 19 per cent. For the state of Arkansas as a whole only 4 per cent of the farms are engaged in broiler production. On a state-wide basis participation in broiler production is very low in all states except Delaware and Maryland. In no case does it exceed 4 per cent, except Maine with 6.3 per cent. In 1959, for the West Virginia broiler counties, 20 per cent of the total farms were engaged in broiler production, and for Virginia it was 11 per cent.

Cnly Virginia and West Virginia showed a deciine from 1954 to 1959 in the percentage of farms producing broilers. For Hest Virginia the decline was erom 26 per cent in 1954 to 20 per cent in 1959, while for Jirginia the drop was from 16 per cent to 11 per cent. On the other hand, for Mississippi the increase was from 4.4 per cent in 1954 to 8.8 per cent in 1959 and for Alabama from 3.3 per cent in 1954 to 11 per cent in 1959. North Carolina also showed a significant increase, from 6.3 per cent in 1954 to 10.6 per cent in 1959.

It may be rather surprising that an ar sa as well estoblished and as settled as Sussex County, Delaware should still show an increase in the percentage of farms participating in broiler production. But this county increased from 40 per cent in 1954 to 47 per cent in 1959. The comparison 
among states in this set of percentages probably illustrates as well as any one set of figures that other factors also are important in determining potential for expansion. The contrast, for example, between Mississippi at 4.4 per cent of the farms engaged in broiler production in 1954 and 26.6 per cent for West Virginia in that year is significant in view of the fact that from 1954 to 1959 , Mississippi increased its total number of broilers sold from 22 million head to 62 million head, while West Virginia showed an increase of only 3 million - 12 million in 1954 and 15 million in 1959. Apparently the community facilities needed for an efficiently organized industry is being built in Mississippi and some of the other states in that section of the country. As the expansion occurs at the farm level, equal or greater efficiencies are achieved than is true for some of the older producing sections.

It is to be noted that only in the broiler producing counties of Virginia, West Virginia, Georgia, and Axkansas was there a decline in the number of farms selling broilers between 1954 and 1959. State totals showed slight increases between these two years for Arkansas and Georgia. In West Virginia the number dropped from 1,342 to 871 and for Virginia from 2,049 to 1,135 . All counties in both Virginia and West Virginia showed a decrease in the number of farms from 1954 to 1959.

An important determinant of the income to a farmer engaged in the production of broilers, and therefore an indication of the potential attractiveness of the industry to him, is the feasible scale of operations under present technology. The average number of birds sold per farm for Andrascogin, Maine, and Sussex County, Delaware, increased 1 per cent and 10 per cent, respectively, between 1954 and 1959. In 1954 they showed the highest averages per farm of any county listed in Appendix Table XXII. In the ensuing short span 
of five years, however, phenomenal increases occurred in a number of other states, showing for the broiler sections of those states an increase of two-fold or more in Arkansas, Mississippi, Georgia, North Carolina, West Virginia, and Virginia. (The increase for West Virginia is heavily influenced, of course, by the increase of one firm in Preston County between 1954 and 1959). As a result, by 1959 several councies of other states had higher average sales per farm than was true for Maryland and Delaware.

\section{Density of Broiler Production}

Despite the much greater increase in scale of operations in a number of other states, the density of broiler production, as measured by number of birds sold annually per square mile, for Sussex County, Delaware, and Wiscomico County, Maryland, was exeeded in only one other state in 1959 in Forsythe County, Georgia, which had 73,600 head per square mile compared with between 71,000 and 72,000 head in the two counties of Delaware and Maryland. Among the broiler counties of the states shown, the range was from 5,000 birds per square mile in Maine, to between 6,000 and 7,000 per square mile in West Virginia and Virginia, 11,000 for North Carolina, 13,000 for Alabama, 17,000 for Arkansas, and 23,000 for Mississippi and Georgia. Within West Virginia the range was from 3,400 head per square mile in Preston County, to 7,000 in Pendleton and Grant counties, and 8,000 in Hardy County. The range within Virginia also is rather wide, from 2,000 in Augusta County to 13,000 in Rockingham County.

\section{Value of Broilers Sold}

Because of the substantial decline in prices received by farmers for broilers from 1954 to 1959, a sizeable increase in quantities sold was necessary to maintain the value at the 1954 level. As shown in Appendix Table 
XXII Virginia is the only state which did not increase sales enough between those two years to offset the decline in price. As a result, there was a decline in total value of broilers sold. In West Virginia the rise in the volume sold, due mainly to the increase in Preston County, was enough to offset the decline in price, and there was some increase in the gross value of broilers sold. It is to be noted that the downturn in broiler production began a year or two earlier in Virginia than in West Virginia, and was enough to account for the decline in the value of sales. In fact, three of the seven counties in Virginia sold a smaller number of birds in 1959 than in 1954, although the state total went up from 25 million to 26.6 million.

A useful purpose can be served by comparing the income from broilers in individual localities with the income from the total livestock enterprise or the total agricultural income of the area. The relative importance of the broiler industry as measured by this index varies greatly among states. (Appendix Table XXII). Cash receipts from broilers as a percentage of tọtal receipts from livestock ranged from 21 per cent for the broiler counties of Virginia to 92 per cent for Maryland. A number of counties in North Carolina and other southern states exceeded the 60 per cent levels in 1959. In Delaware and Maryland broiler counties, despite the already relatively high concentration of broiler production in 1954, broilers accounted for a still larger percentage of gross cash receipts in 1959. In Georgia, on the other hand, cash receipts from the sale of broilers in the broiler counties of that state accounted for 78 per cent of gross cash income in 1954, but by 1959 it dropped to 71 per cent. In three counties of that state, in 1954, broilers accounted for 90 per cent or more of the income from livestock products. In all these four instances the cash receipts from broilers increased substantially in 1959 , but there was a greater increase in income from other livestock enterprises. 
For West Virginia the broiler counties in 1959 had an income from broilers amounting to 42 per cent of income from all livestock products, compared to 46 per cent in 1954. All excepe Preston County showed a decrease from 1954 to 1959.

The cash receipts from broilers, relative to total value of farm produce sold, ranged over a still greater spectrum than that relating to livestock only. The low for broiler areas concerned was the west Virginia counties at 17 per cent of cash receipts from all sources; next were North Carolina and Maine with 34 per cent. Among the southern states, Mississippi was highest at 64 per cent. Delaware and Maryland counties showed, respectively, 68 and 70 per cent of total cash receipts. As was true of the previous comparison, receipts from broilers in West Virginia counties declined in all instances from 1954 to 1959, except for Preston County which rose from 10 per cent in 1954 to 30 per cent in 1959.

For the broiler states as a whole, it is of some significance that only for Virginia and West Virginia did the income from broilers, as a percentage of total farm marketings, decline from 1954 to 1959. In a number of the southern states the increase for the state as a whole was greater than for the main counties in terms of 1953 volume. It is to be emphasized that the gross comparison of cash receipts from broilers as compared with other parts of agriculture, such as all livestock, or all agriculture, is of 1 imited and varying significance. In a gross sense such a percentage calculation will indicate the percentage of resources devoted to the enterprise, compared with agriculture as a whole, or with a part of agriculture. However, such calculations do not necessarily indicate the source of net income to the farm operators by enterprises. In a particularly unfavorable year, for example, the gross cash income from sale of broilers may amount to 50 per cent 
or more of the income received by farmers in a county. But the margins may be negligible or even negative so that the contribution to the net income from broilers may be zero or less. The same behavior, of course, might apply to other individual enterprises, particularly those which are subject to wide weather or price uncertainties.

\section{Relationship of Beef Cattle To Broiler Production}

The southeastern part of the United States which has experienced a large increase in broiler production in the last decade, also has shown a substantial increase in the number of beef cattle. The availability of manure from the broiler production enterprise sometimes is reported as a partial explanation for the increase in cattle production. Is there such a relationship?

First, note the change in the importance of the cattle enterprise within these states, Appendix Table XXIII. The proportion of farms which had beef cattle in 1959 ranged over a wide spectrum from 45 per cent in the broiler counties of Georgia to 88 per cent for Arkansas and West Virginia.

It is to be noticed that in Georgia, in 1949, 75 per cent of the farms in broiler counties had beef cattle, while by 1959 this had dropped to 46 per cent. Similarly, for Alabama there was a decline from 80 per cent in 1949 to 70 per cent in 1959. On the other hand, in Mississippi and Arkansas slightly larger proportions of farms had beef cattle in the latter year. West Virginia showed a slight increase, Virginia little change, while Maryland and Delaware both showed a decline. The percentage of farms engaged in beef production, of course, is not a completely reliable indication of the scale of aggregate beef production since this enterprise, too, has been moving toward specialization - larger but fewer herds. 
In Georgia, where the percentage of farms with beef cattle declined so sharply, the number of beef cattle and calves on hand in 1959 was 128,000, compared to 113,000 in 1949 . The relative increase for the state as a whole was even larger. The other southern states showed increases equal to, or larger than, Georgia. In West Virginia, despite a few percentage points increase in proportion of farms with cattle, the absolute number of cattle on farms of the broiler-producing counties showed a gain of only about five per cent. For the state as a whole there was a decrease of 14 per cent.

In an effort to get additional insight as to any cause and effect relationship as between beef cattle numbers and broiler production the statistical technique of rank correlation was employed. This did not show consistently significant results. So, the best that can be reported at this time is that indications are inconclusive so far as statistical evidence is concerned. It seems entirely plausible, however, that the number of cattle and calves on farms in the broiler-producing counties is larger than it would have been in the absence of fertilizer from the broiler-producing enterprise. It could be that areas where broilers are located also happen to be well adapted to beef cattle production. This is true, for West Virginia and the Shenandoah Valley of Virginia, even though the number of beef animals per square mile is higher in a number of other states than it is in West Virginia, indicating that agriculture is more intensive in terms of land used in these other locations.

It is to be generally noted, in any case, that in most states the beef cattle enterprise is still a relatively unimportant source of income. West Virginia shows a higher percentage of total cash receipts coming from beef cattle than any other state listed - 29 per cent for the State as a whole and 18 per cent for the broiler-producing counties. Next in order is 
Virginia at 20 per cent for the state as a whole and 17 per cent for the broiler counties. For Georgla, on the other hand, the leading broilerproducing state in the United States, only four per cent of the income was from beef cattle in broiler counties and for the state as a whole it was 11.5 per cent. In Sussex County, Delaware, beef cattle accounted for only one per cent of gross cash farm receipts. 
APPENDIX A

BACKGROUND ON INSTITUTIONAL AND STRUCTURAL CHANGES

IN TRANSPORTATION INFLUENCING LOCATION OF THE

POULTRY INDUSTRY IN THE UNITED STATES 
Water Transportation Helps Facilitate Growth of Poultry Industry in the Southeast

One innovation which has grown with the broiler industiy in the Southeast, or at least gave it initial impetus in that area, has been the expansion of navigation on the Tennessee River. Plans for this were drawn up in the early $1920^{\circ} \mathrm{s}$. Later, flood control and generation of power were brought in as additional potential users or benefactors of the improved waterway system. $(31,32)$ The latter happened in the late $1920^{\circ} \mathrm{s}$ and early $1930^{\circ} \mathrm{s}$. Actual building of dams and other appurtenances to the waterway system was started in 1933. The Tennessee River has a long history of transportation for local uses. But it was not possible for long distance movement of cargo-carrying vessels because of the numerous falls, low water points, etc.

The first movement of grain on the Tennessee River from the Middlewest to the Southeast occurred in 1939. The total inbound movement for that year was 6,000 tons. In 1943 over 120,000 tons were delivered to the ports of Guntersville, Alabama, and Chattanooga, Tennessee. As soon as a navigable channel and terminal facilities were available in the spring of 1944, grain began to move by barge as far as Knoxville, Tennessee. Total in-movement reached 148,000 tons by $1950 ; 374,000$ tons by 1954 ; and 700,000 tons by 1955. Rapid growth continued in the late $1950^{\circ} \mathrm{s}$ reaching a milion tons in 1957 and 2.2 million tons in $1960 .(33,34)$

During the $1940^{\circ} \mathrm{s}$, movement of wheat was as important or more important than corn. But during the 1950's the volume of corn increased much more rapidly, and by 1960 corn accounted for more than half the inbound movement of grain. Soybeans, a newcomer to the Tennessee River traffic, amounted to 5,000 tons for 1954; 140,000 tons for 1955; and reached about 450,000 tons by 1960 . 
In terms of total tonnage on the Tennessee River, grain is not the most important product. In 1961, this river carried over $41 / 2$ million tons of coal and coke and $21 / 2$ million tons of stone, sand, and gravel, compared with 2.1 million tons of grain. In that year the movement of grain accounted for 23 per cent of the total actual tons hauled. It happens, however, that the distance hauled was much greater for the grain than for the other items so that the ton-mile hauling on grain was more important than any other single item. In 1961 the ton-miles amounted to $800,000,000$ for grain and grain products, out of a total of $1,875,000,000$ ton-miles. Thus, in 1961, grain accounted for 43 per cent of the total ton miles. (35)

Water transportation is potentially available to many other points of the United States, including western Pennsylvania and West Virginia. However, the nucleus of a livestock industry has never been available along the waterway of either of these two states from which a larger industry could develop - it is highly doubtful that a sufficient number of farmers could be induced to produce broilers in the western part of the State under prevailing or prospective cost-price relationships. The poultry industry, and the livestock industry in general, is mostly located in the eastern part of West Virginia. Costly transportation would be involved to move the feed from the river outlets in the northern and western parts of the State over the mountains to where the main livestock industry is presently located. Thus, waterways of the United States are important in appraising the competitive position of West Virginia in the production of broilers and eggs, primarily because of the relative advantage provided, at one time at least, for the southeastern part of the country. 
In the economic development of the United States the railroads, of course, played a prominent role. The only alternative mode of transport available for the use of farmers was driving livestock to market or shipping over limited water transport facilities. In the past few decades or so, technological improvements by railroads apparent1y have not been made as rapidly as they might have been. Except for introducing more powerful locomotives, not much progress was made in the railroad freight business until the last few years. Some recent, more dramatic innovations have been bigger gondola cars, larger flat and box cars, some of which may be opened over the entire side instead of simply the center doorway, and the introduction of the "piggy-back" operations. The shift to diesels occurred in the $1940^{\circ} \mathrm{s}$, but most of the other innovations came in the late $1950^{\circ} \mathrm{s}$ and early $1960^{\prime} s$, apparently ushering in a whole new era in rail transport for the United States. As urban congestion increases, the role of the railroads will be reappraised for transport of people as well as freight. Growth in the two could be complimentary and portend a whole new role for railroad transport, particularly on freight. The potency of this competitive element in the transportation field only began in the early $1960^{\prime} s$ to make itself felt in the freight rate structure, as discussed in the main text.

\section{Highways and Trucking Facilities Gradually Improved}

Within the trucking industry there is nothing in the way of momentous or outstanding developments to abruptly mark one period from another in any physical or technological sense. But the improvement in both highways and the trucking units has been persistent, and with the post-war improvement in highways, particularly with the launching of the 41,000 mile Interstate 
Highway System in the $1950^{\prime} \mathrm{s}$, has had progressively increasing impact on the whole transportation pattern for the United States. Highways have been improved both by making them more suitable for carrying traffic and enabling them to withstand heavier loads so that the trucking industry can expand the capacity of its units. Improved trailers with greater refrigeration capacity and greater cargo capacity have been of particular benefit to the poultry industry. Now, for example, icepacked poultry can be delivered from the central part of the country, particularly Arkansas, or southeastern points to either coast of the United States and to any point in the northern part of the country. The improvement in highways has permitted a reduction in costs, other than time. Areas of the United States competitive with the West Virginia broiler section have shown relative improvement in truck freight transport as a result of the improved highways being built into, or close by, broiler areas. This is readily possible because of the degree to which the production is concentrated in such states as Delaware, the eastern shore of Maryland, parts of Maine, and Arkansas. Improved highways to the Southeast have been significant in taking feed to the Southeast from the Middlewest, as well as dressed poultry to market from that area of the country. Both fruit and vegetable trucks from Florida, for example, to the Midwest, as well as poultry delivery trucks from the Southeast, were enabled to haul feed on the return trip.

\section{Criteria for Establishment of Rates for Freight Transport}

\section{Services Altered in Past Decades}

Given the physical facilities for freight handling, changes in some aspects of which were described above, and the potential labor and managerial forces for the broiler or egg-producing phases, the choice of area in which 
to produce, or to operate by a mobile entity having free choice in the matter will be influenced by: (1) changes among areas in freight rates for given modes of transport, (2) changes in relative amounts of services provided by each of the given modes of transport available, which of course, could change the average rate for all freight inco an area or areas, relative to other areas of the country, (3) changes in freight rates to a given area or areas on raw materials (mainly feed) as compared with the products (dressed broilers or eggs) and (4) changes in efficiency, that is, particularly, the relationship of input to output in poultry production which for given freight rates, in itself, would work toward a shift in location, other relevant ractors remaining unchanged.

Railroad management of the United States has become impressed that a three-fold problem is faced in meeting competition of alternative modes of transport: (1) Devising new techniques which permit a more efficient rendering of the service; (2) obtaining the acceptance by Railroad Brotherhoods of the improved techniques where less employment would result; and (3) obtaining approval of the Interstate Commerce Commission for rates which reflect efficiencies. It might be observed that so far as the public interest is concerned, there has been a fourth factor - the explicit recognition by railroad management that elasticity of demand for their services could be a relevant consideration. The Interstate Commerce Commission is required to adduce its decisions from evidence presented at hearings. So long as the railroads were not cognizant of this important relationship from economic life or, if cognizant did not emphasize it, there perhaps should not be surprise that the criterion did not find its way earlier into the published decisions of the Commission. 
The implementing of national transportation policy with regard to equalization of rates among alternative modes of transport is complicated by the existence of differential tax and subsidy rates. Subsidies in this context may take the form of annual cash outlays or of grants or payments in some past period. Each mode of transport is receiving, or in the past has received, substantial assistance from the Eederal Government. One important grant was that of 1 and to railroads to help expedite economic development of the United States. These grants, of course, it is alleged by the railroads, have been largely offset by property tax structures at the state and local levels which in recent years, with declining volume of freight, have been highly discriminatory. A chronic complaint of those competing with truck lines is that the truck lines are not required to maintain their own roadways or other major facilities comparable to railroad yards, tracks, etc. Barge lines have benefited from heavy expenditures by the Federal Government in past years for the deepening of channels, installation of dams, and assistance in the development of ports, both for inland waterways and for coast-wise systems. The most recent assistance by Federal funds, of course, is in the development of the airline industry, including the establishment of municipal airports.

In its findings (36) issued on July 15, 1963, concerning the case of the Southern Railway freight rates on grain, the Interstate Commerce Commission definitely established that it was not its intention to include public (or government) contributions in computing the remunerative rate for a given mode of transport. This particular decision stems from the assertion that the barge line rates covered only about one-half of the cost of the operation of the barge Iines and related water lines. Quite clearly, if the Interstate Commerce Commission would have allowed such calculations to enter into their 
decision-making in this case a large pandora box would have been opened for consideration of government outlays in 211 lines of transport, and the problem of establishing rates for the different modes of transport, both freight and passengers, would have been made immensely more complicated.

\section{Recent Policy Changes}

Two rather momentous developments in the policy area with broad gage and long term implications for interregional relationships in the production of poultry and eggs have occurred within the past ten years.

In 1958 the United States Supreme Court announced a decision which permitted a broadening of the definition of "exempt" commodities to include dressed poultry. (37) This meant that carriers could haul dressed poultry from processing plants to terminal markets on a strictly negotiated rate basis without any requirement as to publishing such rates. This resulted in a substantial increase in movement of dressed poultry by motor truck. The timing of this major departure from previous practice coincided with the rapid improvement in highways as well as in the vehicles themselves and resulted in substantially more mobile movenent of dressed poultry among alternative markets of the country.

A second major development will have a greater effect on the poultry industry of the United States as to its location, as well as on transportation rates generally. Referred to here is the major break with the past in criteria emphasized in evaluating requests for rate changes by the Interstate Commerce Commission. From the time the Interstate Commerce Commission was established in 1887 until the early $1960^{\circ} \mathrm{s}$, the criteria for judging the reasonableness of rates was primarily the cost consideration as submitted by the carriers. With the advent of rapidly increasing volume of freight trans- 
ported by motor truck, the proportion of the total inter-city freight movement handled by railroads declined to less than 50 per cent by the late 1950 's. (38) With the drop in volume, the increased cost per unit of the remaining volume hauled increased and was in part responsible for the subsequent granting of the additional rate increases such as shown in Figure 9. The rate for transporting corn from mid-Illinois to Moorefield, West Virginia, increased from $\$ 6.70$ per ton at the end of 1946 to $\$ 15.80$ by late 1960. (39) Meanwhile, as will be seen by Figure 9, the volume handled by barge lines and truck lines, was increasing much more rapidly than was the volume hauled by raflroads. (40)

The Southern Railway's request for adjustment in freight rates is noteworthy for several reasons: While not the only product concerned, this case involving grain illustrated the necessity for recognizing the interrelationships in rates among different modes of transport and the need to apply accepted economic principles to arrive at rates to be charged. In contrast to the traditional impression that the demand for railroad freight service was perfectly inelastic, there emerged the recognition that a respectable degree of elasticity probably prevails. Thus, it was explicitly recognized by railroad management that rates cannot be established for any mode of transport without reference to existing rates and volumes for alternative modes of transport. This, of course, was not true at the time the Interstate Commerce Commission was established. At that time the railroad was the only over-land method of transport available and the main objective of the Interstate Commerce Commission was to control what was generally believed to be a highly monopolized situation as to transportation services in given localities. The importance of the recent departure from the past in deriving and justifying rates is made manifest when it is realized that the reductions in 
in rail rates have been as much as 50 to 60 per cent. Thus, in one action the results of eight or ten relatively small increases, stretching over a period of 15 years, in effect, are wiped out. It is to be recognized, however, that the former scale with "in-transit" and other privileges, still prevails thereby giving a dual rate structure.

In the publicity given to the Southern Railway grain case, the general impression apparently has been gained that use of the large scale or jumbo cars was the crucial factor in making the new rates possible. In all likelihood, introduction of these larger scale units has been a factor in lowering the cost of transport. However, also important has been some other innovations in railway rate policy. For example, the new level of rates established by the Southern does not permit in-transit privileges as prevails under the normal rate structure. Secondly, there are greater penalties for the tying-up of cars. In other words, the rate structure is designed to accelerate a quick turn-around of cars and a fuller utilization of equipment. The latter two changes in policies also have been adopted by other railroads with the conventional type of equipment and with such changes in policy, reductions almost as large as those implemented by the Southern system have been adopted. Moreover, substantial rate reductions have been permitted for other railroads shipping other products, such as masonry products or raw material such as coal without an innovation of the stature represented by the jumbo car introduced to help support the grain case. In this latter group of cases, as well as in the Southern Railway grain case it appears that the application of the economic principles previously not employed probably have played a greater role than has been made evident from much of the public discussion of the matter. 
It should be noted that the competitive basis for establishing rates is no different now from what it has been for a long period as far as guide lines to the Interstate Commerce Commission are concerned. In determining whether a particular proposed rate is lawful, the Interstate Cormerce Commission is guided by the following standards (41) which are quite flexible: (1) a rate must be just and reasonable, (2) there must be no unjust discrimination between persons, (3) there must be no "undue or unreasonable preference or advantage to any person, any place, or any particular type of traffic," (4) except in "special cases" a rate for a short haul znay not be greater than a longer haul over the sane zoute. The Interstate Commerce Commission may restrain a carrier from adopting a proposed rate if that rate (1) is not reasonably compensatory; (2) rould constitute a destructive competitive practice; (3) would have the effect of destroying, rather than preserving, the inherent advantages of a competitor; ( 4 ) would seriously disrupt a broad interrelated rate structure, or (5) were judged likely to set off a rate war. The courts have given the Commission the widest possibie latitude in applying these various criterla to a particular case so long as they give due consideration to all the evidence introduced.

It is seen therefore that the competitive element is nothing nem among the guide lines under which the Interstate Commerce Comnission operates. Involved in the Southern Railway grain case, and in other cases like it, there is manifest merely a different degree of emphasis on the competitive aspects as compared with other criteria. This applies both to the agency proposing the revisions, in this case primarily the Southern Railway, as well as to the Interstate Commerce Commission which evaluates the evidence and renders any denying decisions. 
In making, and then announcing, a decision with the potential consequences of that embodied in the Southern Railway grain case, a public body such as the Interstate Commerce Commission must recognize that rate determination is far from an exact science. The departure with the past rate schedule as great as this one, in the view of the Interstate Commerce Commission, requires a constant purview of the developing situation. Thus, in announcing its decision the Interstate Commerce Commission stated that developments within the industry would be followed very closely to ascertain the impact of the proposed rates and that any effective action would be taken that was not precluded by the inequality of competitive opportunity sanctioned by Iaw. Moreover, the Interstate Commerce Commission announced that as a basis for passing judgment on the performance of the new rates, the rail respondents would be required, and directed, to keep car utilization records of their new equipment, including loaded and empty car miles, and number of cars, so that after a sufficient period of actual use, it would be possible to call on the respondents for a more accurate presentation of evidence as to the performance of this new equipment. Such data were to be gathered for the first full twelve-month period following the effective date of the rates concerned. 1

\footnotetext{
${ }^{1}$ Aside from the practical reasons for the Commission's announced policy of such surveillance, in the process they were also conforming to a pattern of procedure suggested by Harter when he stated: "Often without much conscious thought men add piece by piece to their institutions until complexities prevent them from understanding what they are doing. What is more, they can operate their institutions without appreciating their complexities. The rub comes when reformers insist upon tinkering with them. When they do, sometimes unforseen developments may even threaten the continued existence of order and stability. Consequently, prudence requires that changes be made slowly and tentatively." (42)
} 


\section{BIBLIOGRAFHY}

1. Barr, Alfred L., Associate Agricultural Economist, West Virginia University Agricultural Experimenc Station, in private report based on his observations.

2. Black, John D. Introduction to Production Economics, New York: Henry Holt and Company, 1926.

3. Mighe11, R. L. and J. D. Black, Interxegional Competition in Agriculture, Cambridge, Mass., Harvard University Press, 1951.

4. Bressler, $R$. G. as quoted in Interregional Competition Research Methods, The Agricultural Folicy Institute Series 10, North Carolina State of the University of North Carolina, Kichard A. King, ed., 1965 .

5. Waugh, F. V., Demand and Price Analysis, Eccnomic Research Service, United States Department of Agriculture Technical Bulletin No. 1316, Washington, D. C., G.P.O., 1964.

6. Pavlick, A. L., Tcwards Solving the Low-Income Problem of Small Farmers in the Appalachian Area, West Virginia University Agricultura1 Experiment Station Bulletin 499I, Morgancown, West Virginia, 1964.

7. Poh1man, G.G., Land Classification in West Virginia, West Virginia University Agricultural Experiment Station Bulletin 284, 1937.

8. Christensen, M. B., Chief of Construction and Maintenance Division, Office of Engineering and Operations, Bureau of Public kcads, United States Department of Comerce, in letter of August 5, 1963, stated: "While we have no literature for references dealing with this subject, we would estimate that, considering the cost of constructing highways in rolling terrain as typical, the average cost of such construction in flat terrain would range from 20 to 50 per cent below typical, and the average cost of such conscruction in mountainous terrain would range from 55 to 110 per cent above typical. ${ }^{\circ 9}$

9. Bureau of Public Roads, United States Department of Commerce, Quarterly Report on The Federal-Aid Highway Program, BPR 65-10, Washingtor, D. Co, 1965 .

10. Hunter, J.H., Costs of Operating Exempt EOr-Hire Motor Carxiers of Agricultural Commodities, Economic Research Service, United States Department of Agriculture, ERS-109, Washington: G.P.O., 1963. 
11. Bureau of Accounts, Interstate Commerce Commission, Cost of Transporting Freight by $\mathrm{Class} \mathrm{I}$ and $\mathrm{Cl}$ ass II Motor Common Carriers of General Commodities, Rocky Mountain Region - 1959. Statement No.6-60, Washington: G.P.O., 1960 .

12. Saal, C. C., Time and Fuel Consumption in Motor Truck Operation as Affected By Weight and Power of Vehicles and Rise and Fall in Highways, Highway Research Board, Division of Engineering and Industrial Research, National Research Council, Report 9-A, Washington, 1950.

13. Henry, W. R., Joe S. Chappell and James A. Seagraves, Broiler Production Density, Plant Size, Alternative Operating Plans and Total Unit Costs, North Carolina Agricultural Experiment Station Technical Bulletin No.144, Raleigh, North Carolina, 1960 .

14. Phillips, Richard, Analysis of Costs and Benefits to Feed Manufacturers from Financing and Contract Programs in the Midwest, Iowa State Agricultural Experiment Station Special Report No. 30, Ames, Iowa, 1962.

15. Staubes, B. R., Chief Agricultural Price Statistics Branch, Statistical Reporting Service, U.S. Department of Agriculture, Washington, D.C. Letter dated March 19, 1965.

16. Stigler, G. J., Policies for Growth, Proceedings of A Symposium on Economic Growth sponsored by The American Bankers Association, New York. 1963.

17. Lillie, R. J., Twency-five Years of Research - - Better Poultry Rations, Agricultural Research Service, United States Department of Agriculture, 1957.

18. Biennial Report (1960-62) of Commissioner of Agriculture, Stare of Maine, Augusta, Maine, 1962.

19. Christensen, R. P., and R. L. Mighell, Interregional Competition in The Production of Chickens and Eggs. Bureau of Agricultural Economics, United States Department of Agriculture, Technical Bulletin No. 1031. Washington, D.C., G.P.0., 1951 .

20. Judge, G. G., S. K. Searier, and W. F. Henry. Competitive Position of the Connecticut Poultry Industry. No. 1. Economic Interpretations of Interregional Comperition. Connecticut Agricultural Experiment Station Bulletin 309, Storrs, Connecticut, 1954.

21. Bishop, C. E. and W. R. Henry. North Carolina Broilers in Interregional Competition. North Carolina State College, A.E. Information Series No. 56, 1957. 
22. Henry, W. R., "Broiler Froduction Regions of the Future," Journal of Farm Economics (Proceedings Issue), Vo1.39, No. 5, December 1957.

23. Baker, R. L。, "Commercial Egg Production Regions of the Furure," Journal of Farm Economics (Proceedinge Issue), Vol.39, No.5, Decenber 1957.

24. Crop Reporting Board. Agricultural Prices, Statistical Reporting Service, United States Department of Agriculture, Washington, D. C.

25. Rice, $S$. $\mathrm{T}$, Interregional Competition in the Comercial Broiler Industry, Delaware Agricultural Experiment Station Technical Bulletin No. 290, 1951 .

26. D'Armi, Frank, Ray Lloyd and W. T. McAllister. "Cost of Broiler Production" a chapter in DelparVa"s Position in the Broller industry. Published jointly by Stafis of Colleges of Agriculture, Delaware and Maryland, 196I.

27. Economic Research Service, United States Department of Agriculture. Farm Costs and Returns. Commercial Farms by Rype, Size and Location. Agricultural Information Bulletin No. 230, Washington, 1964.

28. Burbee, C. R. and G. E. Frick. Marketing liew England Poultry Capital Accumulation Potencial of Broiler Growers. New Hampshire Agricultural Experiment Station Bulietin 475, 1962.

29. Ploch, L. A. Social and Family Charactexistics of Maine Contract Broiler Growers. Maine Agricultural Experiment Station Bulletin 596, 1960 .

30. Moore, B. W. H. Patrick, J.R. Johnson and H. M. Hyre. Composition and Production of Poultry Manure, West Virginia Agricultural Experiment Station Bulletin 496T. 1964。

31. Tennessee Valley Authority, Racts About TVA Operations, Knoxville, Tennessee, 1962 .

32. Tennessee Valley Authority, Tennessee River History, Knoxville, Tennessee, 1962 .

33. Tennessee Valiey Authority, Transportation of Grain to the Southeast via the Tennessee River, Kroxvi11e, Tennessee, 1947 .

34. Corps of Engineers, Department of the Army, Grain Traffic on the Tennessee River, a special tabulation contained in letter dated November 19, 1962 .

35. Navigation Economics Branch, Tennessee Valley Authority, Tennessee River Freight Traffic, tabular material revised to April 1962. Knoxville, Tennessee. 
36. Interstate Commerce Commission, Investigation and Suspension Docket No. 7656, Grain in Multiple Car Shipments - River Crossings to the South, Washington, D. C. July 15, 1963.

37. Bureau of Motor Carriers, Interstate Commerce Commission, Motor Carrier Portion of the Interstate Commerce Act, Part II, Sec. 203(b) revised to October 1, 1958. Also Commodity Test, incorporated in Ruling (of I.C.C.) No. 107, March 1958. Washington, D.C.

38. Bureau of Railway Economics, Association of American Railroads, Distribution of Intercity Freight Traffic in the United States, a compilation contained in letter dated October 24, 1963.

39. Interstate Commerce Commission, Published Tariffs of individual railroads on file in Library, Washington, D. C.

40. Corson, J. J., Presented as Exhibit No. 4, in Hearings by the Interstate Commerce Commission entitled, "Grain in Multiple Car Shipments River Crossings to the South," for I \& S Docket No.7656, Washington, D. C., January 1962 .

41. Ingerso11, A. C., Jr. An Appraisal of FTC and ICC Price Regulation, an address before the American Transportation Research Forum, Pittsburgh, Pennsylvania, December 27, 1962.

42. Harter, L. G., Jr. "John R. Commons, Conservative or Liberal," Western Economic Journal, Vo1. I, No. 3, Summer, 1963, p. 226. 

APPENDIX TABLE I: NUMBER OF COMMERCIAL BROILERS PRODUCED IN THE UNITED STATES BY REGIONS, 1934-1963.

\begin{tabular}{|c|c|c|c|c|c|c|c|}
\hline YEAR & $\begin{array}{l}\text { NORTH } \\
\text { ATLANTIC }\end{array}$ & $\begin{array}{l}\text { SOUTH } \\
\text { ATLANTIC }\end{array}$ & $\begin{array}{l}\text { EAST } \\
\text { NORTH } \\
\text { CENTRAL }\end{array}$ & $\begin{array}{l}\text { SOUTH } \\
\text { CENTRAL }\end{array}$ & $\begin{array}{l}\text { WEST } \\
\text { NORTH } \\
\text { CENTRAL }\end{array}$ & WEST ERN & $\begin{array}{l}\text { UNITED } \\
\text { STATES }\end{array}$ \\
\hline $\begin{array}{l}1934 \\
1935 \\
1936 \\
1937 \\
1938 \\
1939\end{array}$ & $\begin{array}{r}\text { Thousand } \\
\begin{array}{r}6,360 \\
7,345 \\
8,660 \\
10,360 \\
12,110 \\
14,050\end{array}\end{array}$ & $\begin{array}{l}\text { Thousand } \\
13,200 \\
18,200 \\
23,150 \\
32,100 \\
39,200 \\
50,600\end{array}$ & $\begin{array}{c}\text { Thousand } \\
5,700 \\
5,415 \\
7,365 \\
7,970 \\
9,030 \\
10,650\end{array}$ & $\begin{array}{c}\text { Thousand } \\
\\
5,500 \\
6,650 \\
8,750 \\
10,700 \\
14,150 \\
19,150\end{array}$ & $\begin{array}{l}\text { Thousand } \\
1,700 \\
1,800 \\
1,930 \\
2,070 \\
2,280 \\
4,425\end{array}$ & $\begin{array}{r}\text { Thousand } \\
1,570 \\
2,480 \\
3,300 \\
4,715 \\
5,650 \\
6,755\end{array}$ & $\begin{array}{l}\text { Thousand } \\
\begin{array}{r}34,030 \\
42,890 \\
53,155 \\
67,915 \\
82,420 \\
105,630\end{array}\end{array}$ \\
\hline $\begin{array}{l}1940 \\
1941 \\
1942 \\
1943 \\
1944 \\
1945 \\
1946 \\
1947 \\
1948 \\
1949\end{array}$ & $\begin{array}{r}17,000 \\
20,300 \\
24,600 \\
32,210 \\
29,164 \\
42,903 \\
31,462 \\
29,008 \\
45,883 \\
58,613\end{array}$ & $\begin{array}{r}76,900 \\
107,660 \\
132,550 \\
162,800 \\
157,148 \\
204,769 \\
160,647 \\
170,295 \\
192,310 \\
254,293\end{array}$ & $\begin{array}{l}13,600 \\
17,350 \\
19,310 \\
24,405 \\
21,656 \\
29,739 \\
22,331 \\
22,175 \\
26,297 \\
32,514\end{array}$ & $\begin{array}{l}22,516 \\
30,985 \\
33,835 \\
42,068 \\
36,741 \\
44,690 \\
40,365 \\
38,250 \\
56,926 \\
91,265\end{array}$ & $\begin{array}{r}5,125 \\
5,975 \\
6,725 \\
8,237 \\
7,906 \\
9,827 \\
7,441 \\
6,920 \\
12,016 \\
21,013\end{array}$ & $\begin{array}{r}7,621 \\
9,232 \\
11,167 \\
15,573 \\
21,534 \\
33,644 \\
13,354 \\
16,443 \\
22,353 \\
29,391\end{array}$ & $\begin{array}{l}142,762 \\
191,502 \\
228,187 \\
285,293 \\
274,149 \\
365,572 \\
275,600 \\
283,091 \\
355,785 \\
487,089\end{array}$ \\
\hline $\begin{array}{l}1950 \\
1951 \\
1952 \\
1953 \\
1954 \\
1955 \\
1956 \\
1957 \\
1958 \\
1959\end{array}$ & $\begin{array}{r}79,119 \\
97,186 \\
106,205 \\
123,787 \\
133,096 \\
139,083 \\
167,018 \\
159,806 \\
173,396 \\
163,142\end{array}$ & $\begin{array}{l}298,129 \\
384,724 \\
386,278 \\
405,917 \\
448,556 \\
475,259 \\
581,941 \\
648,630 \\
728,205 \\
727,680\end{array}$ & $\begin{array}{l}52,637 \\
64,942 \\
69,854 \\
73,916 \\
78,973 \\
76,297 \\
88,010 \\
90,001 \\
95,088 \\
86,441\end{array}$ & $\begin{array}{l}123,337 \\
178,569 \\
215,136 \\
237,526 \\
275,958 \\
292,758 \\
386,320 \\
440,917 \\
538,782 \\
617,169\end{array}$ & $\begin{array}{l}25,649 \\
32,413 \\
34,863 \\
37,178 \\
39,974 \\
38,281 \\
43,991 \\
39,582 \\
46,313 \\
52,300\end{array}$ & $\begin{array}{l}52,587 \\
66,767 \\
66,555 \\
68,209 \\
71,241 \\
70,006 \\
78,022 \\
68,592 \\
77,737 \\
83,809\end{array}$ & $\begin{array}{r}631,458 \\
788,601 \\
860,891 \\
946,533 \\
1,047,798 \\
1,091,648 \\
1,345,302 \\
1,447,528 \\
1,659,519 \\
1,730,741\end{array}$ \\
\hline $\begin{array}{l}1960 \\
1961 \\
1962 \\
1963\end{array}$ & $\begin{array}{l}147,057 \\
146,154 \\
138,364 \\
135,525\end{array}$ & $\begin{array}{l}777,869 \\
838,773 \\
868,578 \\
903,187\end{array}$ & $\begin{array}{l}79,472 \\
80,631 \\
66,807 \\
58,071\end{array}$ & $\begin{array}{l}654,975 \\
767,915 \\
803,811 \\
863,011\end{array}$ & $\begin{array}{l}45,957 \\
60,665 \\
55,024 \\
49,226\end{array}$ & $\begin{array}{l}89,636 \\
98,005 \\
92,429 \\
94,409\end{array}$ & $\begin{array}{l}1,794,966 \\
1,992,143 \\
2,025,013 \\
2,194,813\end{array}$ \\
\hline
\end{tabular}

Source:

Chickens and Eggs, Production, Disposition, Cash Recelpts and Gross Income, 1963-64 and earlier issues, Statistical Reporting Service, United States Department of Agriculture. 
APP ENDIX TABLE II: NUMBER OF BROILERS PRODUCED

IN THE U.S., BY REGIONS, 1934-63

(INDEX NUMBERS, 1955.57 = 100)

\begin{tabular}{|c|c|c|c|c|c|c|c|}
\hline YEAR & $\begin{array}{c}\text { NORTH } \\
\text { ATLANTIC }\end{array}$ & $\begin{array}{c}\text { SOUTH } \\
\text { ATLANTIC }\end{array}$ & $\begin{array}{c}\text { EAST } \\
\text { NORTH } \\
\text { CENTRAL }\end{array}$ & $\begin{array}{c}\text { SOUTH } \\
\text { CENTRAL }\end{array}$ & $\begin{array}{c}\text { WEST } \\
\text { NORTH } \\
\text { CENTRAL }\end{array}$ & WESTERN & $\begin{array}{l}\text { UNITED } \\
\text { STATES }\end{array}$ \\
\hline 1934 & 4.1 & 2.3 & 6.7 & 1.5 & 4.2 & 2.2 & 2.6 \\
\hline 1935 & 4.7 & 3.2 & 7.6 & 1.8 & 4.4 & 3.4 & 3.3 \\
\hline 1936 & 5.6 & 4.1 & 8.7 & 2.3 & 4.8 & 4.6 & 4.1 \\
\hline 1937 & 6.7 & 5.6 & 9.4 & 2.9 & 5.1 & 6.5 & 5.2 \\
\hline 1938 & 7.8 & 6.9 & 10.7 & 3.8 & 5.6 & 7.8 & 6.4 \\
\hline 1939 & 9.0 & 8.9 & 12.6 & 5.1 & 10.9 & 9.4 & 8.2 \\
\hline 1940 & 10.9 & 13.5 & 16.0 & 6.0 & 12.6 & 10.6 & 11.0 \\
\hline 1941 & 13.1 & 18.9 & 20.5 & 8.3 & 14.7 & 13.8 & 14.8 \\
\hline 1942 & 15.8 & 23.3 & 22.8 & 9.1 & 16.6 & 15.5 & 17.6 \\
\hline 1943 & 20.7 & 28.6 & 28.8 & 11.3 & 20.3 & 21.6 & 22.0 \\
\hline 1944 & 18.8 & 27.6 . & 25.5 & 9.8 & 19.5 & 29.8 & 21.2 \\
\hline 1945 & 27.6 & 36.0 & 35.1 & 12.0 & 24.2 & 46.6 & 28.2 \\
\hline 1946 & 20.3 & 28.3 & 26.3 & 10.8 & 18.3 & 18.5 & 21.3 \\
\hline 1947 & 18.7 & 29.9 & 26.2 & 10.2 & 17.0 & 22.8 & 21.9 \\
\hline 1948 & 29.5 & 33.8 & 31.0 & 15.2 & 29.6 & 31.0 & 27.5 \\
\hline 1949 & 37.7 & 44.7 & 38.4 & 24.4 & 51.7 & 40.7 & 37.0 \\
\hline 1950 & 50.9 & 52.4 & 62.1 & 33.0 & 63.1 & 72.8 & 48.8 \\
\hline 1951 & 62.6 & 67.7 & 76.6 & 47.8 & 79.8 & 92.5 & 60.9 \\
\hline 1952 & 68.4 & 67.9 & 82.4 & 57.6 & 85.8 & 92.2 & 66.5 \\
\hline 1953 & 79.7 & 71.4 & 87.2 & 63.6 & 91.5 & 94.5 & 73.1 \\
\hline 1954 & 85.7 & 78.9 & 93.2 & 73.9 & 98.4 & 98.7 & 80.9 \\
\hline 1955 & 89.6 & 83.6 & 90.0 & 78.4 & 94.2 & 97.0 & 84.3 \\
\hline 1956 & 107.5 & 102.3 & 103.8 & 103.5 & 108.3 & 108.1 & 103.9 \\
\hline 1957 & 102.9 & 114.1 & 106.2 & 118.1 & 97.4 & 95.0 & 111.8 \\
\hline 1958 & 111.7 & 128.1 & 112.2 & 144.3 & 114.0 & 107.6 & 128.2 \\
\hline 1959 & 105.0 & 128.0 & 102.0 & 165.3 & 128.8 & 116.1 & 133.6 \\
\hline 1960 & 94.7 & 136.8 & 93.8 & 175.4 & 113.1 & 124.1 & 138.6 \\
\hline 1961 & 94.1 & 147.5 & 95.1 & 205.7 & 149.4 & 135.7 & 153.9 \\
\hline 1962 & 89.1 & 152.8 & 78.8 & 215.3 & 135.5 & 128.0 & 156.4 \\
\hline 1963 & 87.3 & 158.4 & 68.5 & 231.2 & 121.2 & 130.7 & 162.6 \\
\hline
\end{tabular}

Source: Calculated from data in Appendix Table I. 


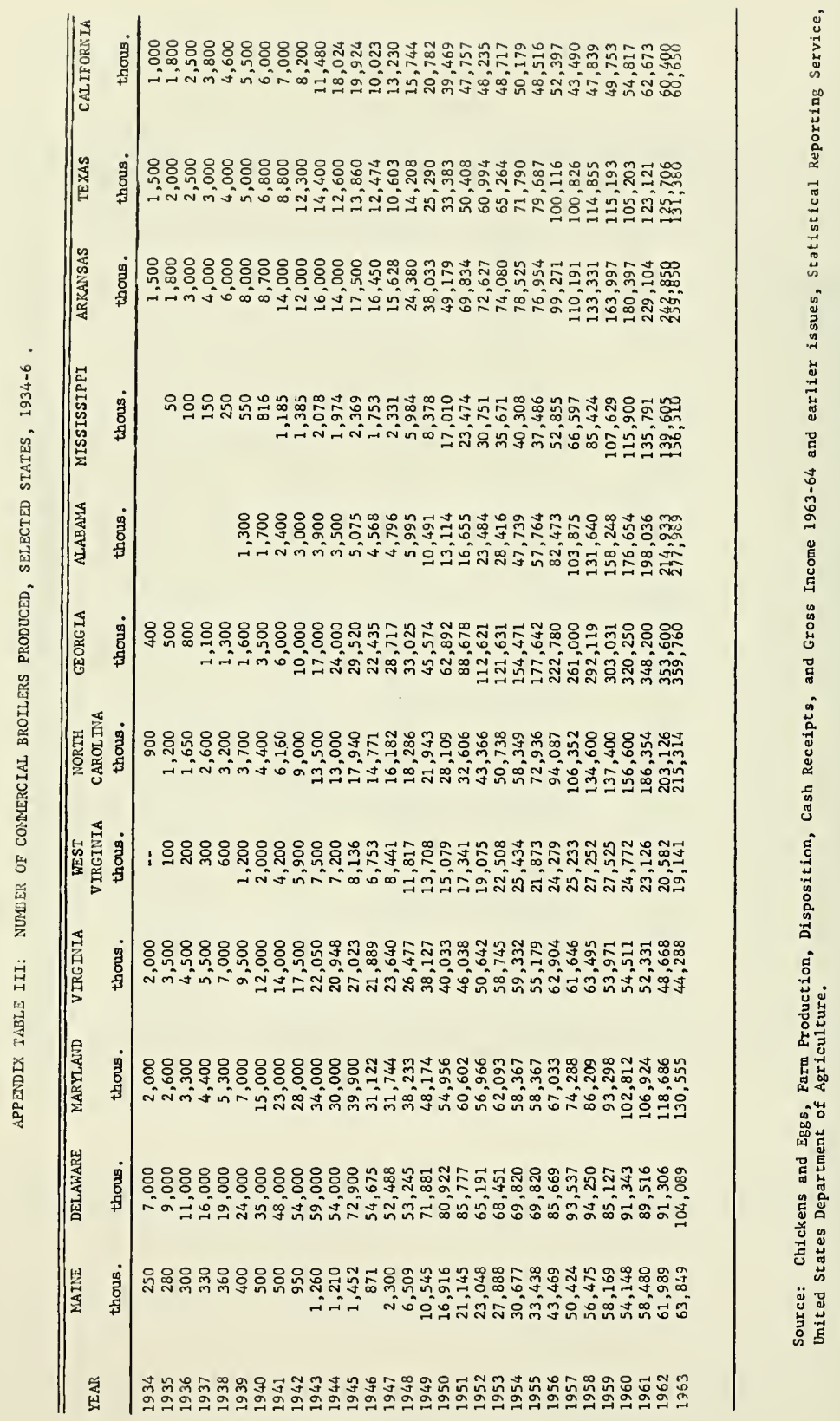




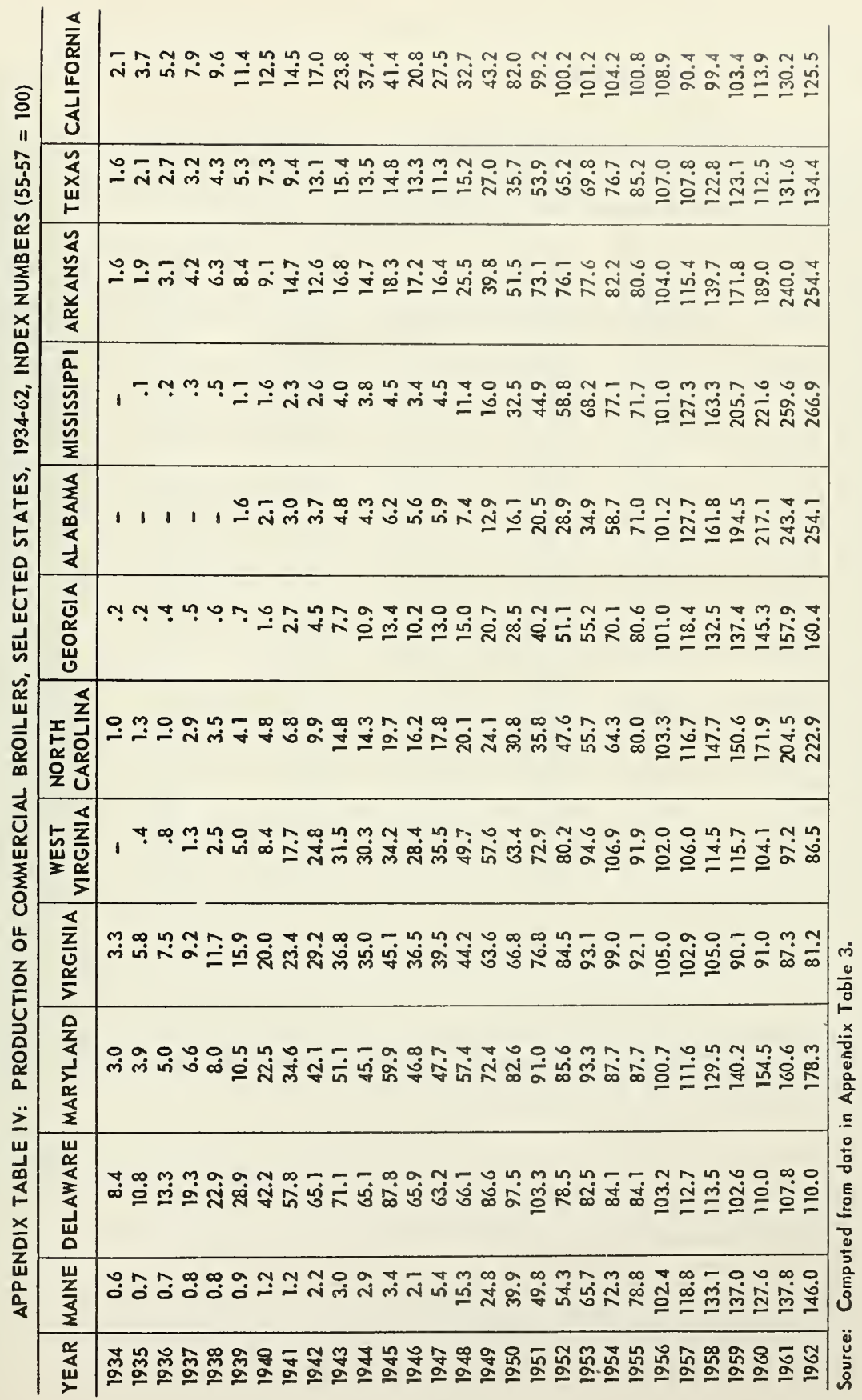


APPENDIX TABLE V: AVERAGE WEIGHT OF BROILERS PRODUCED IN UNITED STATES, BY REGIONS, $1935-63$.

\begin{tabular}{|c|c|c|c|c|c|c|c|}
\hline YEAR & $\begin{array}{l}\text { NORTH } \\
\text { ATLANTIC }\end{array}$ & $\begin{array}{l}\text { SOUTH } \\
\text { ATLANTIC }\end{array}$ & $\begin{array}{l}\text { EAST NO. } \\
\text { CENTRAL }\end{array}$ & $\begin{array}{l}\text { SOUTH } \\
\text { CENTRAL }\end{array}$ & $\begin{array}{l}\text { WEST NO. } \\
\text { CENTRAL }\end{array}$ & WESTERN & $\begin{array}{l}\text { INIT } \\
\text { STAT }\end{array}$ \\
\hline 1935 & 3.0 & 3.0 & 2.8 & 2.5 & 2.7 & 2.9 & 2.9 \\
\hline 1936 & 3.0 & 3.0 & 2.7 & 2.5 & 2.7 & 2.9 & 2.9 \\
\hline 1937 & 3.0 & 3.0 & 2.8 & 2.6 & 2.7 & 2.9 & 2.9 \\
\hline 1938 & 3.1 & 3.0 & 2.8 & 2.7 & 2.8 & 3.0 & 2.9 \\
\hline 1939 & 3.1 & 3.0 & 2.8 & 2.6 & 2.7 & 2.9 & 2.9 \\
\hline 1940 & 3.1 & 3.0 & 2.8 & 2.6 & 2.8 & 2.9 & 2.9 \\
\hline 1941 & 3.1 & 3.0 & 2.8 & 2.7 & 2.9 & 2.9 & 2.9 \\
\hline 1942 & 3.3 & 3.0 & 3.0 & 2.5 & 2.9 & 2.7 & 3.0 \\
\hline 1943 & 3.3 & 2.9 & 3.0 & 2.5 & 2.9 & 2.7 & 2.9 \\
\hline 1944 & 3.3 & 3.0 & 3.0 & 2.5 & 2.8 & 3.0 & 3.0 \\
\hline 1945 & 3.4 & 3.0 & 3.1 & 2.6 & 2.8 & 3.1 & 3.0 \\
\hline 1946 & 3.4 & 3.0 & 3.0 & 2.6 & 3.1 & 3.2 & 3.0 \\
\hline 1947 & 3.4 & 3.0 & 3.1 & 2.7 & 3.1 & 3.1 & 3.0 \\
\hline 1948 & 3.6 & 3.0 & 3.0 & 2.7 & 3.1 & 3.2 & 3.0 \\
\hline 1949 & 3.7 & 3.0 & 3.1 & 2.8 & 3.1 & 3.2 & 3.0 \\
\hline 1950 & 3.9 & 3.0 & 3.1 & 3.0 & 3.0 & 3.3 & 3.1 \\
\hline 1951 & 3.8 & 2.9 & 3.2 & 3.0 & 3.0 & 3.2 & 3.1 \\
\hline 1952 & 3.7 & 3.0 & 3.2 & 3.0 & 3.0 & 3.2 & 3.0 \\
\hline 1953 & 3.7 & 3.0 & 3.2 & 3.0 & 3.0 & 3.2 & 3.0 \\
\hline 1954 & 3.6 & 3.0 & 3.2 & 3.0 & 3.0 & 3.2 & 3.1 \\
\hline 1955 & 3.5 & 3.0 & 3.2 & 2.9 & 3.0 & 3.1 & 3.1 \\
\hline 1956 & 3.6 & 3.2 & 3.3 & 3.0 & 3.1 & 3.3 & 3.2 \\
\hline 1957 & 3.7 & 3.2 & 3.4 & 3.1 & 3.1 & 3.2 & 3.2 \\
\hline 1958 & 3.7 & 3.3 & 3.5 & 3.1 & 3.2 & 3.3 & 3.3 \\
\hline 1959 & 3.7 & 3.3 & 3.4 & 3.2 & 3.3 & 3.4 & 3.3 \\
\hline 1960 & 3.8 & 3.4 & 3.5 & 3.2 & 3.3 & 3.4 & 3.4 \\
\hline 1961 & 3.9 & 3.4 & 3.7 & 3.3 & 3.3 & 3.5 & 3.5 \\
\hline 1962 & 3.9 & 3.4 & 3.5 & 3.3 & 3.5 & 3.6 & 3.4 \\
\hline 1963 & 4.6 & 3.5 & 3.6 & 3.3 & 3.4 & 3.6 & \\
\hline
\end{tabular}

Source:

Calculated from data in "Chickens and Eggs, Production Disposition, Cash Receipts and Gross Income'; 1963-64 and earlier issues. Statistical Reporting Service, U. S. Department of Agriculture. 
APFERDIX TAEDE VI: PRICES RECETVED BY FAPMERS FOR BROILERS, SELECTED GTATES AMT U.3., 1935.69.

\begin{tabular}{|c|c|c|c|c|c|c|c|c|c|c|c|c|c|}
\hline YEAR & MATNE & MARYZAND & DELAWARE & VIRG INIA & $\begin{array}{l}\text { WEST } \\
\text { VIRGINIA }\end{array}$ & $\begin{array}{l}\text { NORTH } \\
\text { CAROLINA }\end{array}$ & GEORGIA & ALABAMA & MISSISSIPPI & ARKANSAS & TERAS & CALIF. & v.s. \\
\hline 1935 & 20.8 & 20.3 . & 20.5 & 21.5 & 20.4 & 18.0 & 18.5 & -- & 20.0 & 18.7 & 18.0 & 20.3 & 20.0 \\
\hline 1936 & 20.2 & 22.2 & 20.9 & 22.0 & 20.5 & 19.0 & 19.0 & - & 19.5 & 21.0 & 18.0 & 18.9 & 20.6 \\
\hline 1937 & 22.3 & 21.3 & 21.9 & 23.5 . & 21.6 & 18.0 & 18.8 & -- & 20.5 & 19.9 & 18.0 & 21.4 & 21.4 \\
\hline 1938 & 18.1 & 18.3 & 19.0 & 20.0 & 18.8 & 17.5 & 18.0 & - & 18.7 & 19.3 & 18.0 & 18.2 & 19.0 \\
\hline 1939 & 16.5 & 16.4 & 16.1 & $18: 2$ & 16.8 & 18.0 & 17.6 & 20.7 & 19.0 & 16.4 & 15.0 & 16.4 & 17.0 \\
\hline 1940 & 17.1 & 16.0 & 16.2 & 18.0 & 17.4 & 17.0 & 17.8 & 21.0 & 19.3 & 18.0 & 18.0 & 17.5 & 17.3 \\
\hline 1941 & 18.9 & 17.6 & 17.6 & 19.5 & 19.0 & 18.0 & 18.5 & 21.2 & 19.5 & 17.8 & 18.0 & 18.3 & 18.4 \\
\hline 1942 & 20.8 & 22.3 & 22.0 & 22.5 & 23.9 & 22.0 & 22.4 & 25.3 & 23.2 & 22.0 & 22.0 & 26.0 & 22.9 \\
\hline 1943 & 28.1 & 28.3 & 28.3 & 29.0 & 28.3 & 28.3 & 28.7 & 31.0 & 28.4 & 28.6 & 26.5 & 30.0 & 28.6 \\
\hline 1944 & 28.1 & 27.6 & 27.6 & 29.5 & 28.4 & 28.2 & 29.5 & 33.8 & 30.4 & 30.0 & 27.2 & 30.0 & 28.8 \\
\hline 1945 & 29.0 & 28.1 & 28.8 & 30.5 & 27.8 & 29.7 & 29.6 & 34.0 & 28.9 & $28.0^{\circ}$ & 29.0 & 30.0 & 29.5 \\
\hline 1946 & 33.5 & 30.1 & 30.3 & 33.5 & 31.5 & 32.3 & 33.3 & 38.0 & 28.7 & 32.0 & 33.0 & 34.0 & 32.7 \\
\hline 1947 & 29.0 & 29.7 & 30.3 & 30.5 & 32.0 & 32.9 & 31.2 & 38.0 & 31.0 & 31.8 & 33.0 & 36.0 & 32.3 \\
\hline 1948 & 35.0 & 34.7 & 35.1 & 35.4 & 35.0 & 34.7 & 33.9 & 36.0 & 32.7 & 35.5 & 38.3 & 38.0 & 36.0 \\
\hline 1949 & 27.3 & 27.0 & 27.2 & 26.9 & 27.0 & 26.9 & 26.8 & 28.3 & 29.1 & 27.5 & 30.0 & 31.0 & 28.2 \\
\hline 1950 & 27.5 & 26.0 & 26.0 & 25.8 & 26.6 & 26.3 & 25.8 & 27.0 & 28.0 & 26.8 & 28.7 & 30.8 & 27.4 \\
\hline 1951 & 27.6 & 27.1 & 27.1 & 27.3 & 28.7 & 27.9 & 27.6 & 29.1 & 29.3 & 27.6 & 30.0 & 30.9 & 28.5 \\
\hline 1952 & 27.0 & 28.2 & 28.2 & 28.0 & 28.5 & 28.4 & 28.1 & 28.8 & 28.0 & 28.2 & 28.9 & 31.2 & 28.8 \\
\hline 1953 & $25.9^{\circ}$ & 26.3 & 26.3 & 26.0 & 26.5 & 26.3 & 26.6 & 27.0 & 26.7 & 26.3 & 27.6 & 29.0 & 27.1 \\
\hline 1954 & 22.5 & 22.6 & 22.6 & 22.5 & 22.9 & 22.4 & 22.0 & 22.8 & 22.2 & 22.0 & 23.3 & 26.2 & 23.1 \\
\hline 1955 & 24.4 & 25.7 & 25.7 & 24.6 & 24.8 & 24.2 & 24.4 & 24.5 & 24.5 & 24.4 & 25.5 & 27.9 & 25.2 \\
\hline 1956 & 19.3 & 19.9 & 19.9 & 19.4 & 19.4 & 18.9 & 18.8 & 18.7 & 18.6 & 18.6 & 19.7 & 22.0 & 19.6 \\
\hline 1957 & 19.5 & 19.4 & 19.4 & 18.5 & 19.1 & 17.9 & 18.0 & 18.0 & 18.3 & 18.2 & 18.9 & 21.6 & 18.9 \\
\hline 1958 & 19.4 & 19.0 & 19.0 & 18.3 & 18.8 & 17.6 & 17.6 & 17.6 & 17.7 & 17.6 & 18.5 & 21.0 & 18.5 \\
\hline 1959 & 17.4 & 17.0 & 17.0 & 16.1 & 16.9 & 15.2 & 15.3 & 15.1 & 15.2 & 15.0 & 15.5 & 18.9 & 16.1 \\
\hline 1960 & 17.7 & 17.6 & 17.6 & 16.7 & 17.1 & 16.0 & 16.2 & 16.2 & 16.2 & 16.3 & 16.7 & 19.0 & 16.9 \\
\hline 1961 & 15.9 & 14.9 & 14.9 & 14.0 & 14.1 & 13.0 & 13.2 & 13.0 & 12.9 & 12.9 & 13.6 & 15.4 & 13.9 \\
\hline 1962 & 17.0 & 16.3 & 16.3 & 15.9 & 16.0 & 14.3 & 14.4 & 14.5 & 14.5 & 14.5 & 15.1 & 17.0 & 15.2 \\
\hline 1963 & 16.5 & 15,6 & 15.6 & 15.2 & 15.4 & 13.6 & 13,8 & 13.9 & 13.9 & 13.7 & 14.4 & 16.8 & 14.5 \\
\hline
\end{tabular}

Source: Chtckens and Eggs (1ncluding broilers) Form Production, D1sposition, Cash Receipts and Cross Incone, 1963-64 and
esrlier 1ssues, Statist1cal Reporting Service, U. S. Dept. of Agriculture. 
APPENDIX TABLE VII: PRICES PAID BY FARMERS FOR BROILER MASH, SELECTED STATES, 1953-64.

\begin{tabular}{lccccccccc}
\hline YEAR & DELAWARE & VIRGINIA & W. VA. CAROLINA & GEORGIA & ARKANSAS & MIINE & ALABAMA & MISSISSIPP \\
\hline 1953 & 5.09 & 5.23 & 5.25 & 5.40 & 5.58 & 5.05 & 5.03 & 5.59 & 5.68 \\
1954 & 5.13 & 5.30 & 5.31 & 5.42 & 5.65 & 4.90 & 5.16 & 5.52 & 5.63 \\
1955 & 4.82 & 4.97 & 5.07 & 5.12 & 5.25 & 4.79 & 4.73 & 5.18 & 5.33 \\
1956 & 4.88 & 4.98 & 5.09 & 5.00 & 5.16 & 4.67 & 4.85 & 5.05 & 5.12 \\
1957 & 4.68 & 4.95 & 4.97 & 4.96 & 5.05 & 4.71 & 4.82 & 4.94 & 4.99 \\
1958 & 4.95 & 5.12 & 5.12 & 5.12 & 5.08 & 4.65 & 4.98 & 5.38 & 5.03 \\
1959 & 4.78 & 4.97 & 5.02 & 4.91 & 4.83 & 4.65 & 4.90 & 4.84 & 4.94 \\
1960 & 4.55 & 4.75 & 4.69 & 4.68 & 4.56 & 4.42 & 4.66 & 4.68 & 4.76 \\
1961 & 4.62 & 4.86 & 4.72 & 4.66 & 4.60 & 4.31 & 4.73 & 4.64 & 4.73 \\
1962 & 4.78 & 4.92 & 4.70 & 4.71 & 4.62 & 4.34 & 4.77 & 4.65 & 4.73 \\
1963 & 4.95 & 5.03 & 4.91 & 4.83 & 4.76 & 4.36 & 4.91 & 4.90 & 4.81 \\
1964 & 4.95 & 5.03 & 4.91 & 4.81 & 4.81 & 4.32 & 4.92 & 4.85 & 4.82
\end{tabular}

\section{Source:}

"Agricultural Prices," issued monthly by Statistical Reporting Service, United States
Department of Agriculture. 


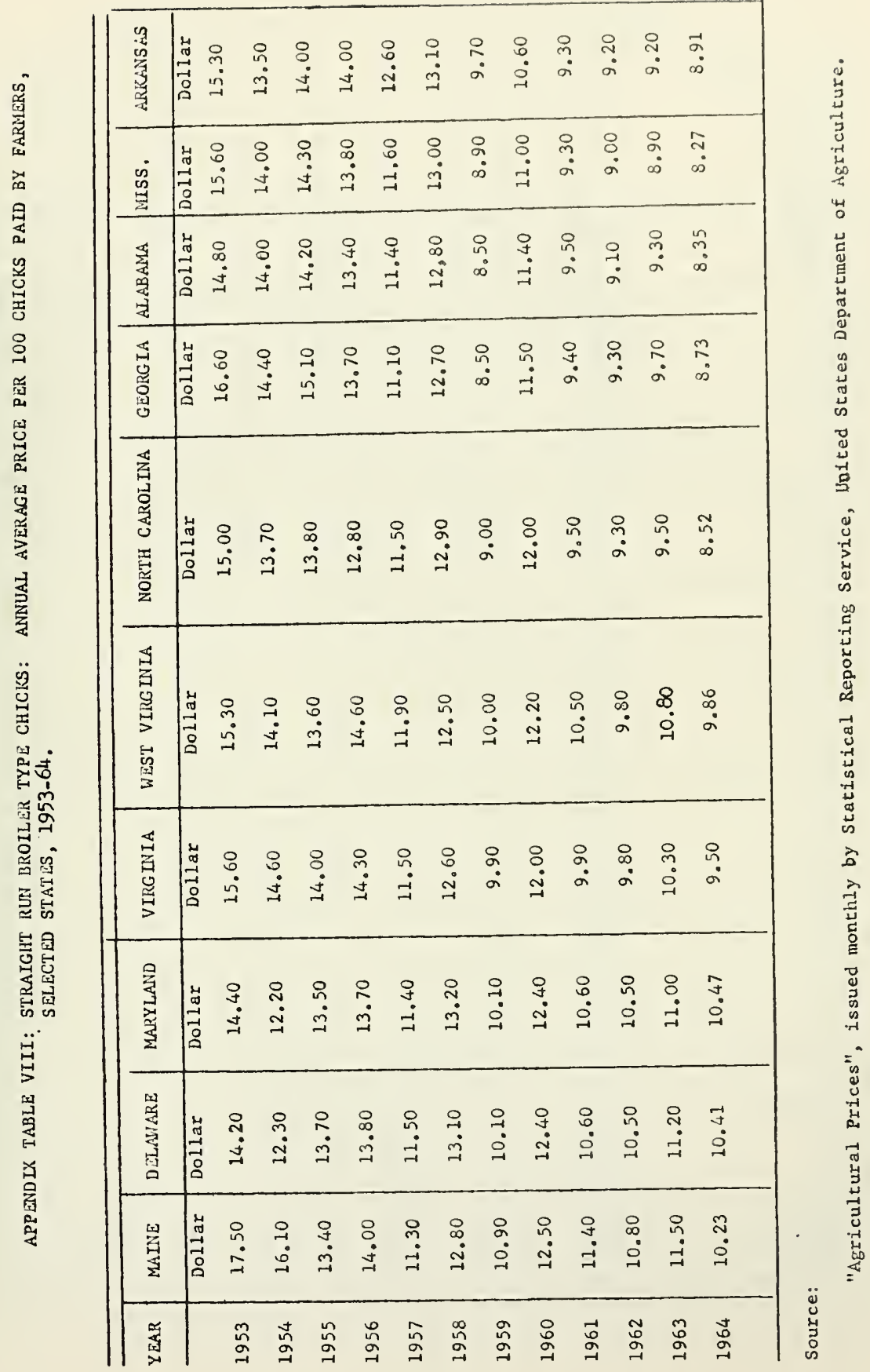


APPENDIX TABLE IX: PRODUCTION OF EGGS IN THE UNITED STATES, AVERAGE PER PERJON, BY STATES, SELECTED YEARS, 1925-63

\begin{tabular}{|c|c|c|c|c|c|c|c|c|c|c|}
\hline STATE & 1925 & 1930 & 1935 & 1940 & 1945 & 1950 & 1955 & 1960 & 1962 & 1963 \\
\hline Maine & 275.3 & 258.8 & 248.8 & 336.9 & 510.0 & 598.2 & 756.0 & 773.9 & 805.8 & 913.4 \\
\hline New Momp shire & 289.8 & 255.4 & 330.6 & 498.0 & 851.9 & 011.7 & 771.6 & 534.4 & 522.2 & 535.9 \\
\hline Vermont & 298.6 & 261.1 & 257.7 & 352.6 & 565.1 & 458.9 & 541.8 & 420.1 & 417.9 & 387.2 \\
\hline Massachusetts & 53.4 & 63.3 & 83.4 & 140.6 & 217.3 & 189.8 & 146.0 & 128.3 & 114.7 & 112.5 \\
\hline Rhode Island & 50.0 & 58.3 & 59.0 & 84.8 & 116.0 & 124.5 & 97.0 & 87.7 & 90.2 & 92.7 \\
\hline Connecticut & 128.2 & 143.2 & 152.5 & 211.4 & 283.8 & 300.7 & 301.1 & 265.9 & 274.9 & 274.9 \\
\hline New York & 129.2 & 116.7 & 114.6 & 129.5 & 173.0 & 141.2 & 132.0 & 110.6 & 102.3 & 102.4 \\
\hline New Jersey & 113.5 & 138.4 & 139.5 & 192.8 & 262.7 & 434.2 & 453.8 & 330.9 & 298.5 & 280.5 \\
\hline Pennsylvanio & 183.3 & 193.3 & 182.2 & 208.4 & 285.7 & 301.8 & 337.9 & 308.1 & 281.6 & 272.6 \\
\hline NORTH ATLANTIC & 139.6 & 140.8 & 140.4 & 175.1 & 244.7 & 255.9 & 261.8 & 223.7 & 208.6 & 205.5 \\
\hline Ohio & 321.3 & 327.7 & 301.0 & 321.8 & 373.8 & 314.5 & 262.3 & 253.5 & 244.1 & 239.4 \\
\hline Indiana & 473.5 & 466.7 & 397.7 & 430.2 & 606.9 & 615.6 & 524.8 & 539.3 & 484.4 & 478.7 \\
\hline Illinois & 263.8 & 265.8 & 221.5 & 244.4 & 365.3 & 341.2 & 328.9 & 237.8 & 225.0 & 199.6 \\
\hline Michigan & 275.2 & 242.0 & 236.7 & 242.1 & 296.3 & 249.2 & 233.2 & 183.5 & 165.9 & 155.9 \\
\hline Wisconsin & 431.4 & 483.7 & 509.8 & 530.4 & 785.2 & 640.2 & 630.4 & 495.1 & 472.4 & 439.3 \\
\hline EAST NORTH CENTRAL & 328.4 & 328.6 & 302.2 & 321.5 & 431.7 & 384.1 & 348.7 & 297.2 & 277.8 & 262.3 \\
\hline Minnesoto & 555.5 & 611.4 & 505.3 & 739.4 & $1,540.0$ & $1,276.1$ & $1,344.7$ & $1,038.9$ & 944.5 & 835.7 \\
\hline lowo & 911.8 & $1,086.1$ & 834.8 & $1,074.1$ & $1,884.7$ & $1,774.9$ & $1,810.4$ & $1,732.9$ & $1,596.0$ & $1,417.3$ \\
\hline Missouri & 658.0 & 673.3 & 463.9 & 547.3 & 824.8 & 703.8 & 505.0 & 393.7 & 400.6 & 342.9 \\
\hline Nort h Dakoto & 648.5 & 602.6 & 403.0 & 568.8 & $1,133.7$ & 839.3 & 890.1 & 657.2 & 660.4 & 608.8 \\
\hline South Dakoto & 878.3 & $1,116.9$ & 626.1 & 928.2 & $1,780.7$ & $1,759.2$ & $1,833.6$ & $2,157.4$ & $2,201.1$ & $1,962.0$ \\
\hline Nebraska & 708.9 & 893.5 & 664.7 & 857.9 & $1,617.7$ & $1,360.3$ & $1,316.2$ & $1,297.0$ & $1,093.7$ & 990.4 \\
\hline Konsas & $1,031.2$ & $1,071.7$ & 842.9 & 828.3 & $1,240.3$ & $1,030.8$ & 828.4 & 614.2 & 498.4 & 436.0 \\
\hline WEST NORTH CENTRAL & 754.2 & 836.4 & 608.6 & 771.6 & $1,361.0$ & $1,186.2$ & $1,117.9$ & 980.1 & 906.2 & 804.2 \\
\hline Delaware & 509.0 & 711.3 & 321.4 & 431.2 & 468.5 & 464.2 & 326.4 & 296.2 & 272.9 & 260.5 \\
\hline Maryl and & 231.4 & 248.8 & 176.4 & 206.1 & 233.8 & 223.1 & 144.6 & 105.2 & 84.6 & 82.1 \\
\hline Virginio & 323.6 & 335.4 & 316.3 & 318.8 & 371.1 & 352.2 & 241.1 & 274.5 & 265.3 & 288.6 \\
\hline West Virginia & 248.0 & 231.4 & 211.8 & 223.4 & 284.5 & 262.2 & 207.7 & 207.7 & 192.9 & 185.0 \\
\hline North Corolino & 220.0 & 171.1 & 167.9 & 188.0 & 301.2 & 314.3 & 341.1 & 445.2 & 487.0 & 488.2 \\
\hline South Corolina & 157.2 & 150.7 & 122.1 & 133.5 & 201.7 & 208.1 & 224.7 & 340.2 & 389.2 & 411.2 \\
\hline Georgi a & 166.5 & 165.3 & 136.4 & 168.0 & 215.8 & 208.9 & 328.5 & 560.4 & 630.0 & 728.0 \\
\hline Florido & 157.4 & 141.4 & 110.4 & 107.0 & 100.2 & 129.0 & 154.8 & 205.8 & 224.4 & 249.8 \\
\hline SOUTH ATL ANTIC & 222.5 & 214.4 & 182.9 & 199.7 & 254.7 & 242.9 & 245.5 & 317.4 & 338.2 & 362.1 \\
\hline Kentucky & 319.4 & 306.9 & 281.3 & 297.0 & 461.7 & 424.1 & 352.9 & 291.9 & 276.8 & 295.0 \\
\hline Tennessee & 340.6 & 312.7 & 265.2 & 238.5 & 379.4 & 313.9 & 280.0 & 268.0 & 255.1 & 249.3 \\
\hline Alobomo & 173.6 & 172.6 & 159.2 & 170.8 & 245.4 & 234.6 & 255.1 & 398.0 & 496.1 & 582.6 \\
\hline Mississippi & 209.9 & 215.4 & 193.6 & 200.8 & 292.3 & 317.7 & 281.7 & 532.5 & 669.9 & 798.7 \\
\hline Arkonsos & 269.9 & 282.4 & 222.2 & 292.1 & 403.5 & 380.9 & 305.8 & 521.0 & 834.9 & 991.4 \\
\hline Louisiana & 130.3 & 134.0 & 105.9 & 119.8 & 160.6 & 144.8 & 123.9 & 156.2 & 153.5 & 147.7 \\
\hline Okl ohamo & 494.1 & 446.1 & 352.9 & 422.8 & 722.4 & 539.9 & 384.3 & 260.7 & 228.8 & 208.7 \\
\hline Texas & 283.9 & 341.4 & 280.6 & 359.2 & 503.1 & 359.7 & 257.3 & 251.4 & 253.3 & 241.6 \\
\hline SOUTH CENTRAL & 281.5 & 288.9 & 242.4 & 277.0 & 409.8 & 337.4 & 270.6 & 301.9 & 336.5 & 359.6 \\
\hline Montona & 405.6 & 408.2 & 310.9 & 353.0 & 519.9 & 414.7 & 361.7 & 300.0 & 279.3 & 275.8 \\
\hline Idaho & 449.5 & 545.9 & 390.9 & 459.8 & 554.2 & 476.4 & 458.6 & 397.9 & 369.6 & 352.0 \\
\hline Wyoming & 310.2 & 362.8 & 236.3 & 300.0 & 368.2 & 345.9 & 247.6 & 170.1 & 156.2 & 172.1 \\
\hline Colorado & 320.9 & 374.0 & 258.8 & 295.6 & 393.4 & 323.9 & 212.3 & 158.3 & 148.9 & 134.6 \\
\hline New Mexico & 202.0 & 224.8 & 187.4 & 194.0 & 229.0 & 180.5 & 141.1 & 140.9 & 153.9 & 157.2 \\
\hline Arizono & 178.1 & 177.4 & 131.3 & 130.3 & 129.6 & 109.8 & 90.3 & 121.4 & 106.0 & 106.5 \\
\hline Utah & 322.4 & 603.1 & 511.4 & 487.3 & 665.0 & 610.6 & 476.2 & 344.1 & 309.2 & 304.2 \\
\hline Nevoda & 282.4 & 358.7 & 260.0 & 247.8 & 234.9 & 166.7 & 83.3 & 41.1 & 35.8 & 29.9 \\
\hline Washington & 471.2 & 628.2 & 477.6 & 473.6 & 369.0 & 293.4 & 314.8 & 365.4 & 350.6 & 344.6 \\
\hline Oregon & 428.1 & 394.4 & 356.6 & 408.8 & 397.6 & 359.0 & 364.5 & 336.3 & 306.3 & 309.4 \\
\hline Colifornio & 307.0 & 392.6 & 284.9 & 253.4 & 230.1 & 325.0 & 334.8 & 358.3 & 407.0 & 421.2 \\
\hline WESTERN & 344.0 & 422.8 & 317.6 & 311.5 & 313.4 & 326.8 & 314.6 & 319.1 & 339.3 & 346.3 \\
\hline
\end{tabular}

Source: Calculated from data in Chickens and Eggs, Farm Production, Disposition, Cash Receipts and Gross Incame 1962-63 and eorlier issues Statistical Reporting Service, United States Department of Agriculture ond Papulation Es. timates, United Stotes Deportment of Commerce Series P-25, October 4, 1963 and earlier issues. 


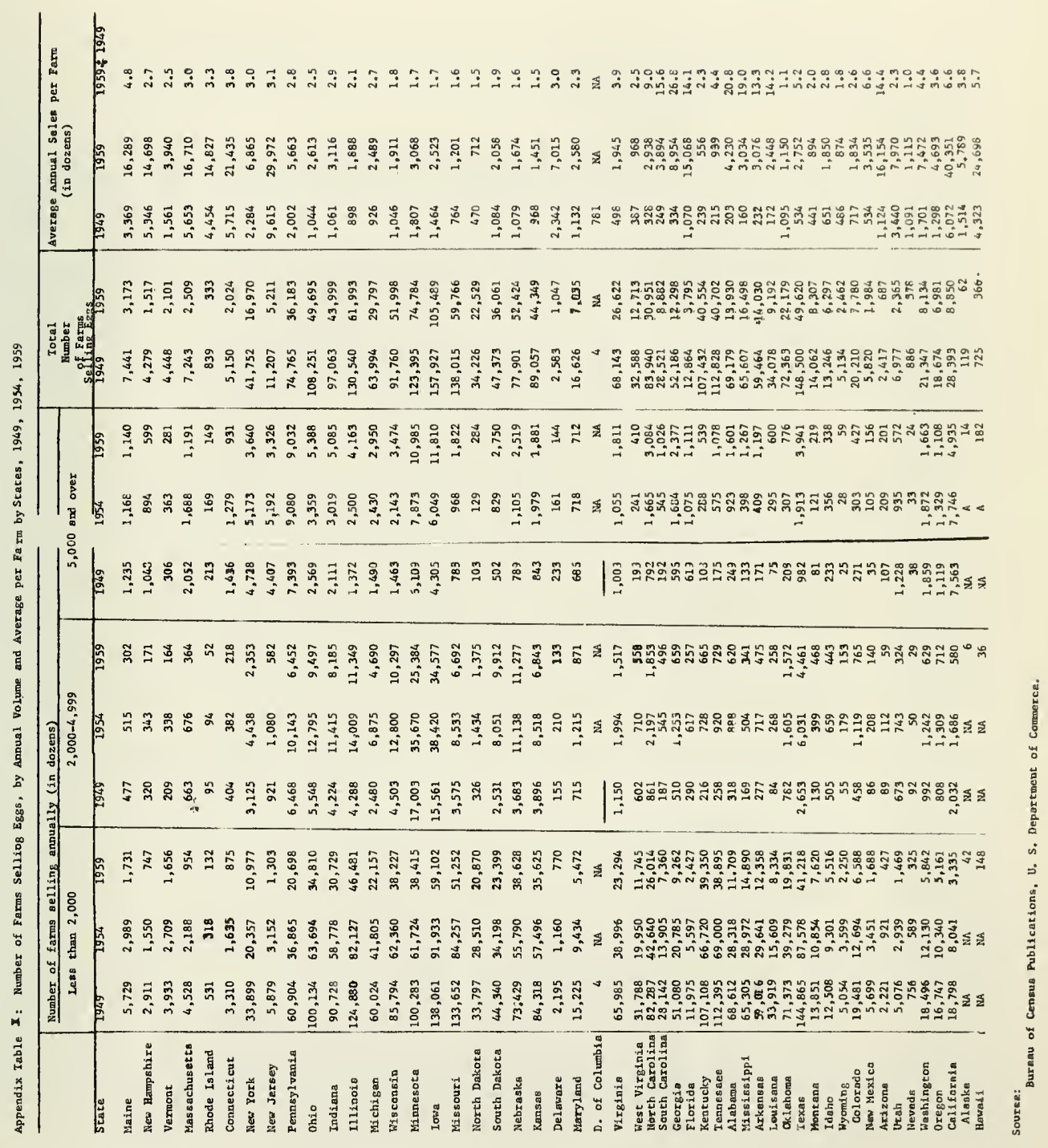


APPRNIX TABLE XI. NUMBER OF FARMS SELI. ING EGGS AND VOLUME PER FARM, BY COUNTIES, WEST VIRGINIA, CENSUS YEAR 1940-1959

\begin{tabular}{|c|c|c|c|c|c|c|c|c|c|c|c|c|c|c|c|}
\hline \multirow[t]{3}{*}{ COUNTIES } & \multicolumn{5}{|c|}{ NUMBER OF FARMS } & \multicolumn{5}{|c|}{ TOTAL YOLUME SOLD } & \multicolumn{5}{|c|}{ AVERAGE VOLUME PER FARM 1} \\
\hline & 1940 & 1945 & 1949 & 1954 & 1959 & 1940 & 1945 & 1949 & 1954 & 1959 & 1940 & 1945 & 1943 & 1954 & 1959 \\
\hline & Number & Number & Number & Number & Number & 1000 & 1000 & 1000 & 1000 & 1000 & Doz. & Doz. & Dor. & Doz. & Doz. \\
\hline Barbour & $\overline{1,692}$ & $\overline{1,687}$ & 922 & 523 & 348 & $\frac{\text { Doz. }}{397}$ & $\frac{\mathrm{Doz} .}{540}$ & $\frac{\mathrm{Doz} .}{270}$ & Doz. & Doz. & & & & & \\
\hline Berkeley & 1,085 & 1,065 & 564 & 486 & 336 & 369 & $\begin{array}{l}540 \\
430\end{array}$ & $\begin{array}{l}270 \\
275\end{array}$ & 200 & 331 & 235 & 320 & 293 & 382 & 951 \\
\hline Boone & 851 & 1,042 & 186 & 224 & 120 & 185 & 239 & $\begin{array}{r}275 \\
39\end{array}$ & 254 & 266 & 340 & 404 & 488 & 523 & 792 \\
\hline Braxton & 2,543 & 2,188 & 1,183 & 595 & 490 & 658 & 736 & $\begin{array}{r}39 \\
384\end{array}$ & 88 & 55 & 217 & 229 & 210 & 393 & 458 \\
\hline Brooke & 316 & 393 & 138 & 84 & 60 & 117 & 106 & $\begin{array}{r}384 \\
79\end{array}$ & 244 & 213 & 268 & 336 & 325 & 410 & 435 \\
\hline Cabe 11 & 1,621 & 1,908 & 595 & 432 & 205 & 400 & 566 & $\begin{array}{r}79 \\
223\end{array}$ & 101 & 72 & 370 & 270 & 572 & 1,202 & 1,200 \\
\hline Calhoun & 1,427 & 1,200 & 620 & 367 & 262 & 342 & 342 & 22.3 & 214 & 306 & 247 & 297 & 375 & 495 & 1,493 \\
\hline Clay & 1,112 & 884 & 237 & 143 & 47 & 218 & 197 & 146 & 116 & 118 & 240 & 285 & 235 & 316 & 450 \\
\hline Doddridge & 1,223 & 929 & 460 & 316 & 66 & 286 & $\begin{array}{l}197 \\
260\end{array}$ & 122 & 110 & 180 & 196 & 223 & 515 & 769 & 3,829 \\
\hline Fayette & 1,804 & 1,952 & 565 & 471 & 108 & 384 & $\begin{array}{l}260 \\
521\end{array}$ & 93 & 82 & 103 & 234 & 280 & 202 & 259 & 1,561 \\
\hline Gilmer & 1,506 & 1,067 & 562 & 381 & 73 & 390 & $\begin{array}{l}521 \\
350\end{array}$ & 170 & 186 & 411 & 213 & 267 & 301 & 395 & 3,806 \\
\hline Grant & 762 & 854 & 415 & 246 & 310 & 274 & $\begin{array}{l}350 \\
361\end{array}$ & 130 & 97 & 215 & 259 & 328 & 231 & 255 & 2,945 \\
\hline Greenbrier & 2,388 & 2,353 & 1,239 & 896 & 248 & 756 & $\begin{array}{l}361 \\
912\end{array}$ & 163 & 118 & 186 & 360 & 423 & 393 & 480 & 600 \\
\hline Hampshire & 1,277 & 1,216 & 645 & 485 & 219 & 546 & $\begin{array}{l}912 \\
675\end{array}$ & 458 & 370 & 636 & 317 & 388 & 370 & 413 & 2,565 \\
\hline Hancock & 245 & 250 & 107 & 87 & 31 & 64 & $\begin{array}{r}675 \\
90\end{array}$ & 351 & 311 & 301 & 428 & 555 & 544 & 641 & 1,374 \\
\hline Hardy & 981 & 1,032 & 656 & 257 & 182 & 442 & $\begin{array}{r}90 \\
954\end{array}$ & 52 & 71 & 49 & 261 & $36 J$ & 477 & 828 & 1,581 \\
\hline Herriaon & 2,228 & 1,990 & 915 & 528 & 363 & $\begin{array}{l}442 \\
666\end{array}$ & $\begin{array}{l}954 \\
635\end{array}$ & 515 & 364 & 573 & 451 & 924 & 785 & 1,416 & 3,148 \\
\hline Jack6on & 2,168 & 1,724 & 1,272 & 742 & 379 & 1,040 & 635 & 400 & 345 & 519 & 299 & 319 & 437 & 653 & 1,430 \\
\hline Jefferaoo & 741 & 839 & 354 & 260 & 170 & $\begin{array}{r}1,040 \\
325\end{array}$ & 967 & 704 & 424 & 202 & 480 & 561 & 553 & 571 & 533 \\
\hline Kanawha & 2,309 & 3,403 & 609 & 378 & 193 & & 512 & 162 & 119 & 111 & 439 & 610 & 458 & 458 & 653 \\
\hline Lewis & 1,532 & 1,332 & 665 & 472 & 309 & $\begin{array}{l}656 \\
418\end{array}$ & 948 & 249 & 169 & 267 & 284 & 279 & 409 & 447 & 1,383 \\
\hline Lincoln & 2,350 & 1,896 & 685 & 242 & 197 & $\begin{array}{l}418 \\
360\end{array}$ & 399 & 269 & 203 & 325 & 273 & 300 & 405 & 430 & 1,052 \\
\hline Logen & 821 & 1.078 & 126 & 47 & 47 & $\begin{array}{l}360 \\
154\end{array}$ & 328 & 98 & 64 & 68 & 153 & 173 & 143 & 264 & 345 \\
\hline McDowe 11 & 1,571 & 1,214 & 139 & 81 & 59 & $\begin{array}{l}154 \\
226\end{array}$ & 298 & 35 & 29 & 22 & 188 & 276 & 278 & 617 & 468 \\
\hline Mation & 1,916 & 2,045 & 690 & 302 & 236 & $\begin{array}{l}226 \\
475\end{array}$ & 258 & 21 & 15 & 38 & 144 & 213 & 151 & 185 & 644 \\
\hline Marahall & 1,507 & 1,244 & 734 & 473 & 291 & $\begin{array}{l}475 \\
494\end{array}$ & 497 & 273 & 141 & 251 & 248 & 243 & 396 & 467 & 1,064 \\
\hline Mason & 1,911 & 1,642 & 932 & 632 & 316 & 494 & 428 & 317 & 268 & 193 & 328 & 344 & 432 & 567 & 663 \\
\hline Mercer & 2,496 & 2,565 & 903 & 618 & $\begin{array}{l}316 \\
369\end{array}$ & 722 & 785 & 406 & 323 & 231 & 378 & 478 & 842 & 511 & 731 \\
\hline Mineral & 824 & 824 & 290 & 208 & $\begin{array}{l}369 \\
100\end{array}$ & 489 & 678 & 164 & 191 & 276 & 196 & 264 & 182 & 309 & 748 \\
\hline Mingo & 1,511 & 1,385 & 127 & $\begin{array}{r}200 \\
97\end{array}$ & $\begin{array}{r}100 \\
58\end{array}$ & 325 & 339 & 119 & 76 & 74 & 394 & 411 & 410 & 365 & 740 \\
\hline Monongalia & 1,504 & 1,847 & 680 & 323 & $\begin{array}{r}58 \\
234\end{array}$ & 200 & 386 & 33 & 29 & 36 & 132 & 279 & 260 & 299 & 621 \\
\hline Monroe & 1,664 & 1,637 & 1,172 & 925 & 234 & 390 & 419 & 225 & 127 & 276 & 259 & 227 & 331 & 393 & 1,179 \\
\hline Morgan & 628 & 558 & 332 & $\begin{array}{l}923 \\
167\end{array}$ & 566 & 630 & 807 & 422 & 309 & 546 & 379 & 493 & 360 & 334 & 965 \\
\hline Nichols & 1,884 & 1,825 & 682 & $\begin{array}{l}167 \\
524\end{array}$ & 117 & 258 & 376 & 357 & 277 & 264 & 411 & 674 & 1,075 & 1,659 & 2,256 \\
\hline Oh 10 & 363 & 507 & 207 & $\begin{array}{l}524 \\
159\end{array}$ & 270 & 529 & 564 & 222 & 213 & 197 & 281 & 309 & 326 & 406 & 730 \\
\hline Pendleton & 1,293 & 1,248 & 805 & $\begin{array}{l}159 \\
556\end{array}$ & 76 & 194 & 248 & 179 & 156 & 122 & 534 & 489 & 865 & 981 & 1,605 \\
\hline Pleasanta & 461 & 494 & 180 & $\begin{array}{r}556 \\
99\end{array}$ & 463 & 507 & 780 & 519 & 418 & 547 & 392 & 625 & 645 & 752 & 1,181 \\
\hline Pocahontas & 1,226 & 1,152 & 569 & $\begin{array}{r}99 \\
422\end{array}$ & 54 & 113 & 154 & 61 & 52 & 34 & 245 & 312 & 339 & 525 & 630 \\
\hline Preston & 2,190 & 2,279 & 1,127 & & 272 & 303 & 319 & 119 & 124 & 135 & 247 & 277 & 209 & 294 & 496 \\
\hline Putnam & 1,482 & 1,420 & 670 & $\begin{array}{l}756 \\
486\end{array}$ & 476 & 835 & 894 & 479 & 481 & 455 & 381 & 392 & 425 & 636 & 956 \\
\hline Raletgh & 2,037 & 1,885 & 648 & & 186 & 477 & 529 & 253 & 202 & 182 & 322 & 373 & 378 & 416 & 978 \\
\hline Randolph & 1,693 & 1,764 & 637 & $\begin{array}{l}420 \\
362\end{array}$ & 260 & 400 & 428 & 147 & 265 & 433 & 196 & 228 & 227 & 631 & I , 665 \\
\hline Ritchle & 1,495 & 1,294 & 667 & $\begin{array}{l}362 \\
449\end{array}$ & 263 & 448 & 433 & 199 & 179 & 160 & 265 & 245 & 312 & 494 & 608 \\
\hline Roane & 1,990 & 1,900 & 1,305 & $\begin{array}{l}449 \\
738\end{array}$ & 195 & 387 & 411 & 158 & 106 & 42 & 259 & 318 & 237 & 236 & 215 \\
\hline Summe $\mathrm{r}_{6}$ & 1,780 & 1,639 & 741 & $\begin{array}{l}738 \\
472\end{array}$ & 374 & 672 & 808 & 600 & 317 & 304 & 338 & 425 & 460 & 430 & 813 \\
\hline Taylor & 874 & 842 & 324 & $\begin{array}{l}472 \\
197\end{array}$ & 321 & 524 & 575 & 259 & 214 & 223 & 294 & 351 & 350 & 453 & 695 \\
\hline Tucker & 649 & 595 & 235 & $\begin{array}{l}197 \\
189\end{array}$ & 164 & 136 & 189 & 74 & 92 & 106 & 156 & 224 & 228 & 467 & 646 \\
\hline Tyler & 1,109 & 718 & 448 & $\begin{array}{l}189 \\
264\end{array}$ & 103 & 179 & 199 & 72 & 61 & 57 & 276 & 334 & 306 & 323 & 553 \\
\hline Upshur & 1,792 & 1,591 & 677 & $\begin{array}{l}264 \\
466\end{array}$ & 160 & 299 & 267 & 139 & 104 & 60 & 270 & 372 & 310 & 394 & 375 \\
\hline & 2,203 & 958 & 071 & 466 & 343 & 469 & 552 & 195 & 160 & 568 & 262 & 347 & 288 & 343 & 1,656 \\
\hline $\begin{array}{l}\text { Wayne } \\
\text { Webster }\end{array}$ & $\begin{array}{l}2,203 \\
1,315\end{array}$ & 1,958 & 754 & 395 & 220 & 603 & 541 & 261 & 253 & 137 & 274 & 276 & 346 & 641 & 623 \\
\hline $\begin{array}{l}\text { Webster } \\
\text { Wetzel }\end{array}$ & $1, \$ 47$ & $\begin{array}{l}1,175 \\
1,258\end{array}$ & 209 & 230 & 86 & 264 & 253 & 103 & 94 & 177 & 201 & & 493 & 409 & $\begin{array}{r}2,058 \\
258\end{array}$ \\
\hline Wetzel & 853 & & 534 & 416 & 132 & 402 & 380 & 178 & 134 & 34 & 278 & 302 & 333 & 322 & 258 \\
\hline $\begin{array}{l}\text { Wirt } \\
\text { Wood }\end{array}$ & 1,795 & $\begin{array}{r}688 \\
1,855\end{array}$ & $\begin{array}{l}416 \\
741\end{array}$ & $\begin{array}{l}175 \\
566\end{array}$ & $\begin{array}{l}118 \\
257\end{array}$ & $\begin{array}{l}341 \\
791\end{array}$ & $\begin{array}{l}329 \\
846\end{array}$ & $\begin{array}{l}209 \\
440\end{array}$ & $\begin{array}{l}136 \\
404\end{array}$ & $\begin{array}{r}60 \\
501\end{array}$ & $\begin{array}{l}400 \\
441\end{array}$ & $\begin{array}{l}478 \\
456\end{array}$ & $\begin{array}{l}502 \\
594\end{array}$ & $\begin{array}{l}777 \\
714\end{array}$ & $\begin{array}{r}508 \\
1,949\end{array}$ \\
\hline Wyoming & 1,385 & 1,335 & 293 & 76 & 153 & 194 & 303 & 33 & 23 & 54 & 140 & 227 & 123 & 303 & 353 \\
\hline
\end{tabular}

Source: Computed from data in Bureau of Census Publications, United States Department of Commerce.

11940 and 1945 baeed on egge produced. 


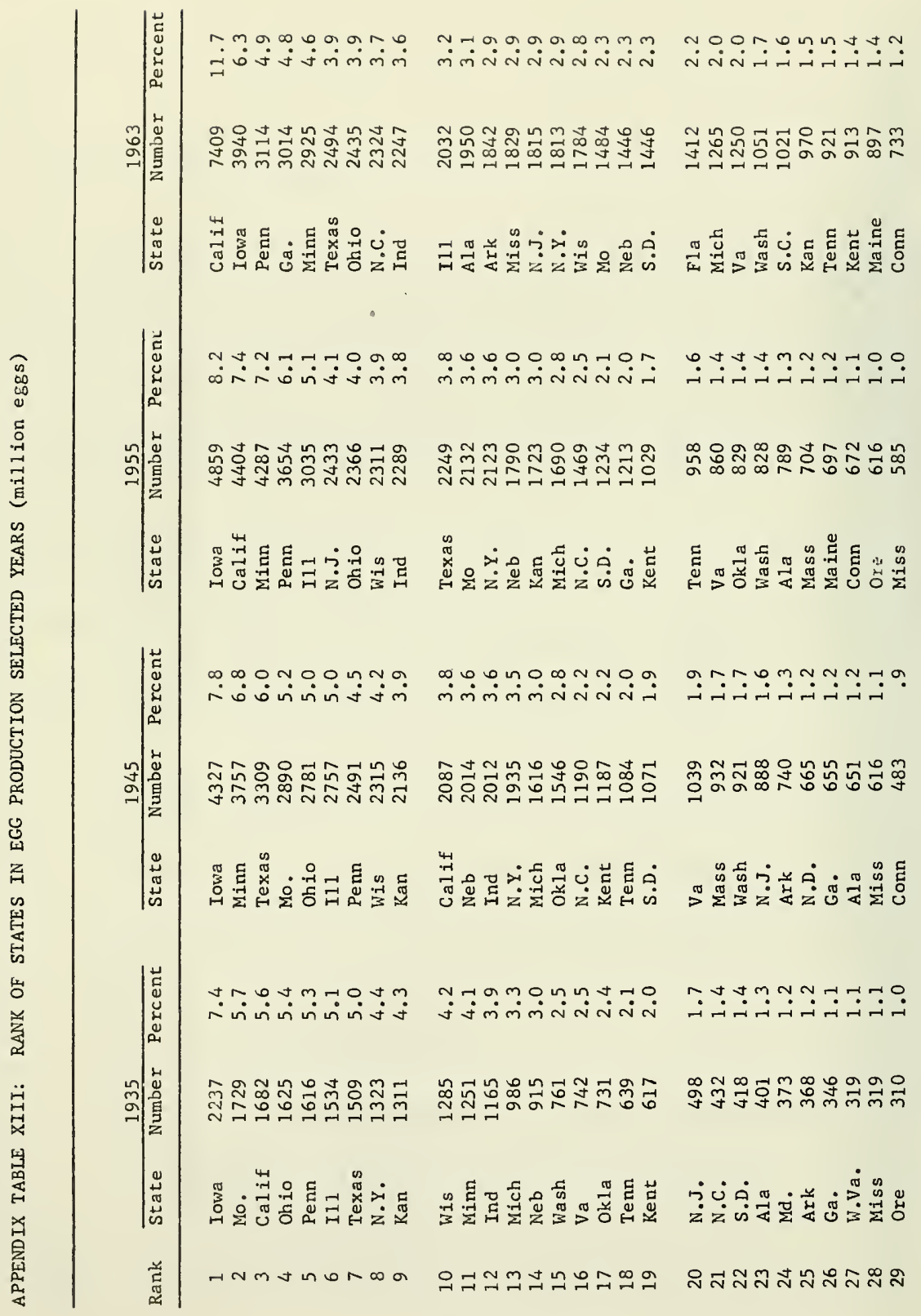




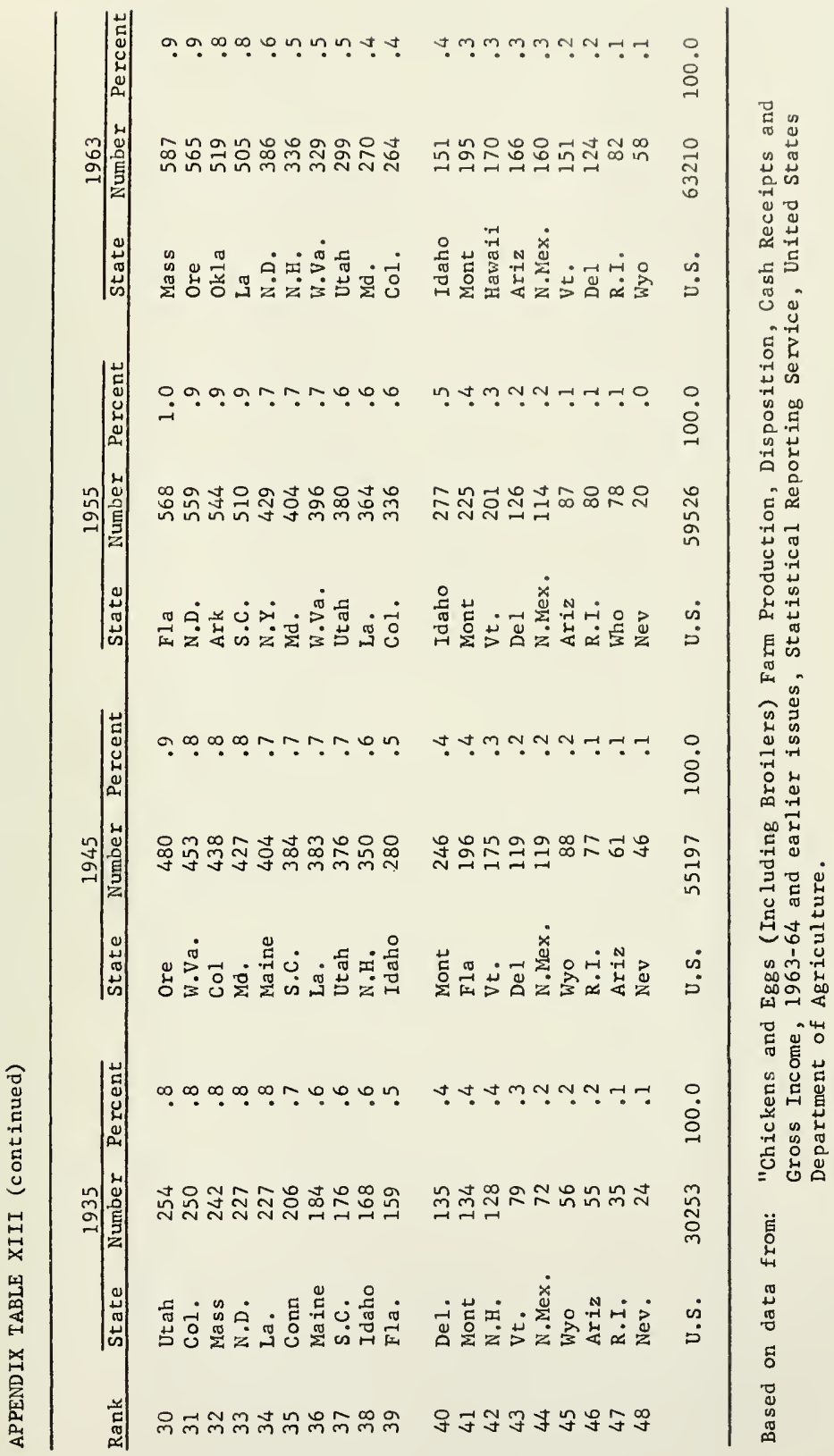


APPENDIX TABLE XIV: PRODUCTINN OF EGGS, SELECTED STATES, $1925-63$.

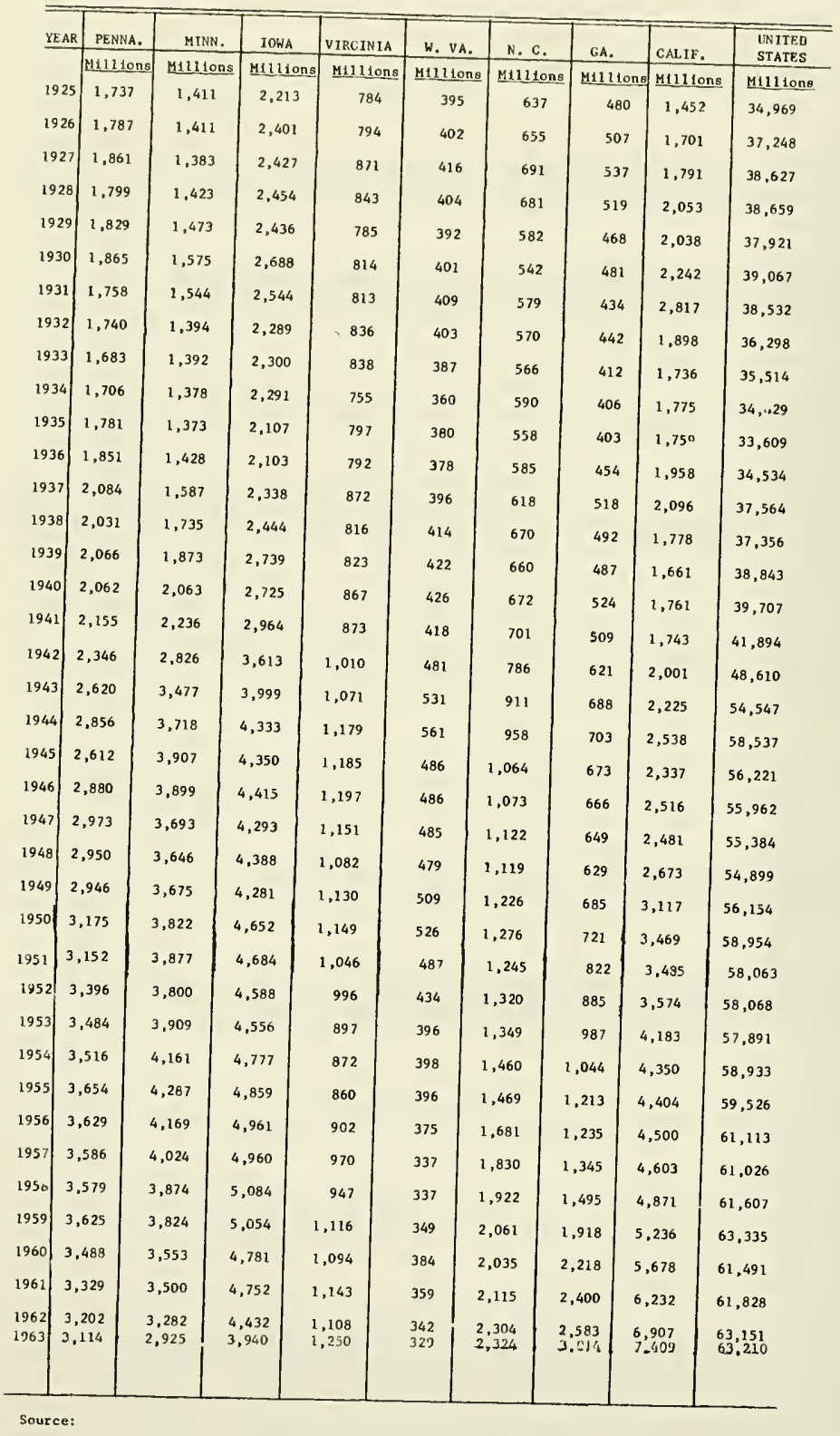

Chickens and Egge, Farm Production, 01sposition, Gash Receipts and Cross Income, 1962-63 snd earlier 1ssues Statistical Reporting Service, U. S. Department of Agriculture. 
APEENDIX TABLE XV: PRODUOTION OF EGGS, SELECTED STATES, AND UNETED STATES, 1925-63, ( INDEX NUMBERS $1955-57=100$ )

\begin{tabular}{|c|c|c|c|c|c|c|c|c|c|}
\hline YEAR & PENNA. & MINN. & 10WA & VIRGINIA & W.VA. & N.C. & $C A$. & CALIF. & $\begin{array}{l}\text { UNITED } \\
\text { STATES }\end{array}$ \\
\hline 1925 & 47.9 & 33.9 & 44.9 & 86.1 & 107.0 & 38.4 & 38.0 & 32.3 & 57.7 \\
\hline 1926 & 49.3 & 33.9 & 48.7 & 87.2 & 108.9 & 39.5 & 40.1 & 37.8 & 61.5 \\
\hline 1927 & 51.4 & 33.2 & 49.3 & 95.6 & 112.7 & 41.6 & 42.5 & 39.8 & 63.8 \\
\hline 1928 & 49.7 & 34.2 & 49.8 & 92.5 & 109.5 & 41.0 & 41.1 & 45.6 & 63.8 \\
\hline 1929 & 50.5 & 35.4 & 49.4 & 82.2 & 106.2 & 35.1 & 37.0 & 45.3 & 62.6 \\
\hline 1930 & 51.5 & 37.9 & 54.6 & 89.4 & 108.7 & 32.7 & 38.1 & 49.8 & 64.5 \\
\hline 1931 & 48.5 & 37.1 & 51.6 & 89.2 & 110.8 & 34.9 & 34.3 & 62.6 & 63.6 \\
\hline 1932 & 48.0 & 33.5 & 46.5 & 91.8 & 109.2 & 34.3 & 35.0 & 42.2 & 59.9 \\
\hline 1933 & 46.5 & 33.5 & 46.7 & 92.0 & 104.9 & 34.1 & 32.6 & 38.6 & 58.6 \\
\hline 1934 & 47.1 & 33.1 & 46.5 & 82.9 & 97.6 & 35.5 & 32.1 & 39.4 & 56.9 \\
\hline 1935 & 49.2 & 33.0 & 42.8 & 87.5 & 103.0 & 33.6 & 31.9 & 39.1 & 55.5 \\
\hline 1936 & 51.1 & 34.3 & 42.7 & 86.9 & 102.4 & 35.2 & 35.9 & 43.5 & 57.0 \\
\hline 1937 & 57.5 & 38.1 & 47.5 & 95.7 & 107.3 & 37.2 & 41.0 & 46.6 & 62.0 \\
\hline 1938 & 56.1 & 41.7 & 49.6 & 89.6 & 112.2 & 40.4 & 38.9 & 39.5 & 61.7 \\
\hline 1939 & 57.0 & 45.0 & 55.6 & 90.3 & 114.4 & 39.8 & 38.5 & 36.9 & 64.1 \\
\hline 1940 & 56.9 & 49.6 & 55.3 & 95.2 & 115.4 & 40.5 & 41.5 & 39.1 & 65.6 \\
\hline 1941 & 59.5 & 53.7 & 60.2 & 95.8 & 113.3 & 42.2 & 40.3 & 38.7 & 69.2 \\
\hline 1942 & 64.8 & 67.9 & .73 .3 & 110.9 & 130.4 & 47.3 & 49.1 & 44.4 & 80.3 \\
\hline 1943 & 72.3 & 83.6 & 81.2 & 117.6 & 143.9 & 54.9 & 54.4 & 49.4 & 90.1 \\
\hline 1944 & 78.8 & 89.4 & 87.9 & 129.4 & 152.0 & 57.7 & 55.6 & 56.4 & 96.7 \\
\hline 1945 & 72.1 & 93.9 & 88.3 & 130.1 & 131.7 & 64.1 & 53.2 & 51.9 & 92.8 \\
\hline 1946 & 79.5 & 93.7 & 89.6 & 131.4 & 131.7 & 64.6 & 52.7 & 55.9 & 92.4 \\
\hline 1947 & 82.1 & 88.8 & 87.1 & 126.3 & 131.4 & 67.6 & 51.3 & 55.1 & 91.5 \\
\hline 1948 & 81.4 & 87.6 & 89.1 & 118.8 & 129.8 & 67.4 & 49.8 & 59.4 & 90.7 \\
\hline 1949 & 81.3 & 88.3 & 86.9 & 124.0 & 137.9 & 73.9 & 54.2 & 69.2 & 92.7 \\
\hline 1950 & 87.6 & 91.9 & 94.4 & 126.1 & 142.5 & 76.9 & 57.0 & 77.1 & 97.4 \\
\hline 1951 & 87.0 & 93.2 & 95.1 & 114.8 & 132.0 & 75.0 & 65.0 & 77.4 & 95.9 \\
\hline 1952 & 93.7 & 91.3 & 93.1 & 109.3 & 117.6 & 79.5 & 70.0 & 79.4 & 95.9 \\
\hline 1953 & 96.2 & 94.0 & 92.5 & 98.5 & 107.3 & 81.3 & 78.1 & 92.9 & 95.6 \\
\hline 1954 & 97.0 & 100.0 & 97.0 & 95.7 & 107.9 & 88.0 & 82.6 & 96.6 & 97.3 \\
\hline 1955 & 100.9 & 103.1 & 98.6 & 94.4 & 107.3 & 88.5 & 96.0 & 97.8 & 98.3 \\
\hline 1956 & 100.2 & 100.2 & 100.7 & 99.0 & 101.6 & 101.3 & 97.7 & 99.9 & 100.9 \\
\hline 1957 & 99.0 & 96.7 & 100.7 & 106.5 & 91.3 & 110.2 & 106.4 & 102.2 & 100.8 \\
\hline 1958 & 98.8 & 93.1 & 103.2 & 104.0 & 91.3 & 115.8 & 118.3 & 108.2 & 101.7 \\
\hline 1959 & 100.1 & 91.9 & 102.6 & 122.5 & 94.6 & 124.2 & 151.7 & 116.3 & 104.6 \\
\hline 1960 & 96.3 & 85.4 & 97.0 & 120.1 & 104.1 & 122.6 & 175.5 & 126.1 & 102.5 \\
\hline 1961 & 91.9 & 84.1 & 96.4 & $: 2 \leq .5$ & 97.3 & 127.4 & 189.9 & 138.4 & 102.1 \\
\hline 1962 & 88.4 & 78.9 & 90.0 & 131.9 & 92.7 & 138.8 & 204.4 & 153.4 & 104.3 \\
\hline 1763 & 86.0 & 70.1 & 79.6 & 150.2 & 83.0 & 141.3 & 240.0 & 164.6 & 104.8 \\
\hline
\end{tabular}


APFENDIX TABLE XVI: PROIUCTION OF EGGS, HY REGIONS, 1925-63.

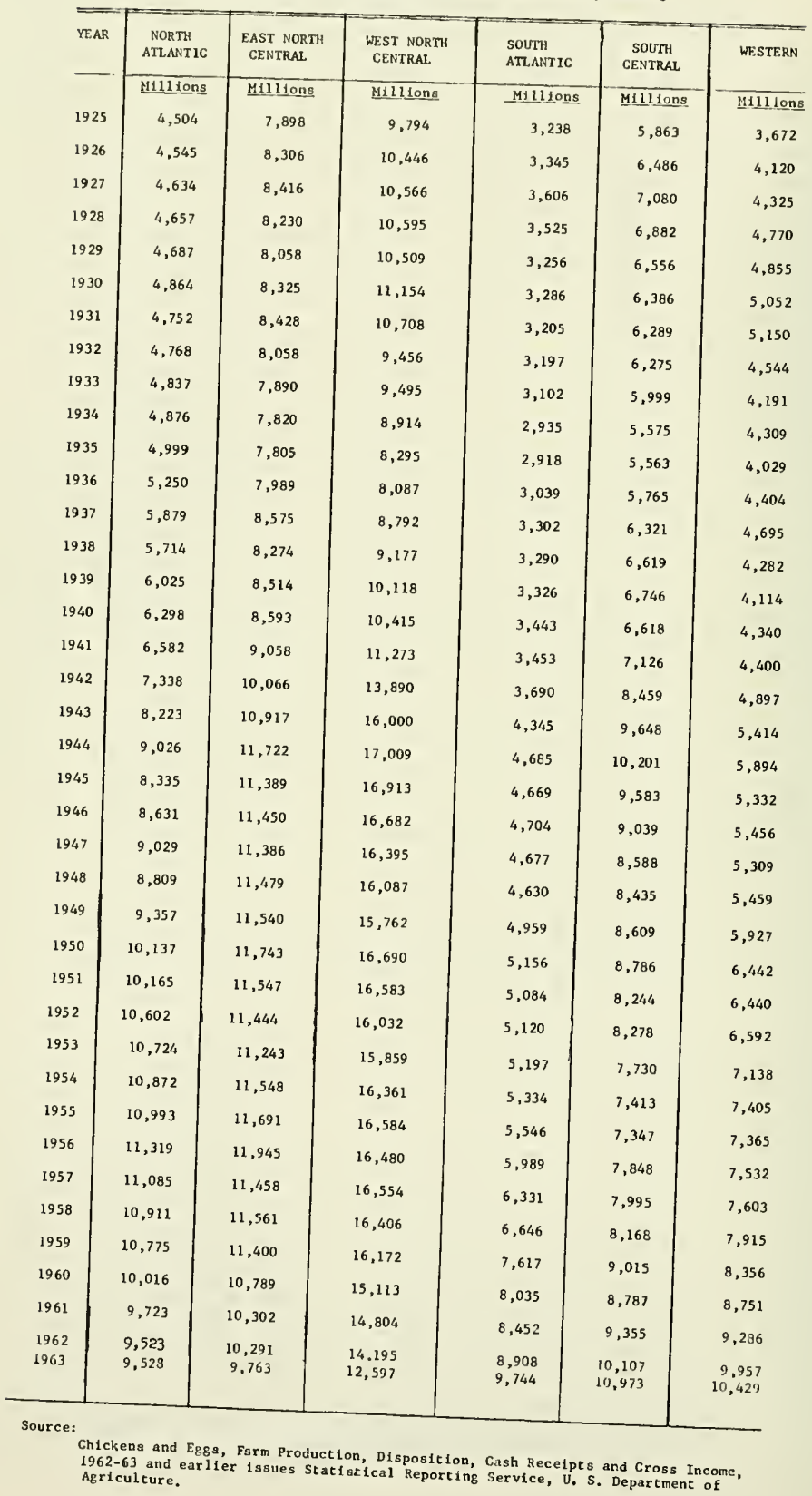




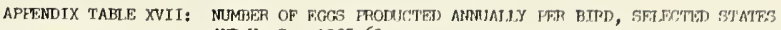
AND U. S. $1925-63$.

\begin{tabular}{|c|c|c|c|c|c|c|c|c|c|}
\hline YEAR_ & PENNA. & MINN. & _ 10WA & va. & W. VA. & $-N_{2} C_{2}$ & ClORGIA & CALIF. & U. S. \\
\hline 1925 & 128 & 110 & 99 & 112 & 121 & 102 & 96 & 134 & 112 \\
\hline 1926 & 129 & 113 & 104 & 119 & 121 & 108 & 106 & 148 & 118 \\
\hline 1927 & 131 & 106 & 104 & 122 & 124 & 107 & 106 & $13 / 4$ & 117 \\
\hline 1928 & 131 & 109 & 107 & 119 & 122 & 107 & 100 & 145 & 119 \\
\hline 1929 & 134 & 114 & 107 & 117 & 126 & 103 & 99 & 137 & 119 \\
\hline 1930 & 135 & 117 & 113 & 1.17 & 124 & 102 & 108 & 145 & 121 \\
\hline 1931 & 136 & 121 & 118 & 124 & 130 & 108 & 103 & 159 & 127 \\
\hline 1932 & 136 & 112 & 105 & 123 & 131 & 103 & 99 & 146 & 121 \\
\hline 1933 & 135 & 108 & 108 & 121 & 126 & 102 & 95 & 142 & 118 \\
\hline 1934 & 135 & 108 & 107 & 115 & 126 & 104 & 99 & 146 & 118 \\
\hline 1935 & 137 & 114 & 108 & 121 & 129 & 101 & 97 & 148 & 122 \\
\hline 1936 & 136 & 112 & 107 & 120 & 127 & 102 & 100 & 149 & 121 \\
\hline 1937 & 148 & 120 & 118 & 132 & 136 & 108 & 104 & 156 & 130 \\
\hline 1938 & 148 & 135 & 126 & 132 & 142 & 119 & 108 & 149 & 135 \\
\hline 1939 & 150 & 133 & 127 & 134 & 143 & 114 & 105 & 153 & $13+$ \\
\hline 1940 & 149 & 135 & 123 & 135 & 142 & 113 & 101 & 156 & 134 \\
\hline 1941 & 156 & 140 & 130 & 140 & 143 & 118 & 104 & 155 & 139 \\
\hline 1942 & 157 & 150 & 139 & 141 & 145 & 120 & 106 & 161 & 142 \\
\hline 1943 & 159 & 153 & 142 & 139 & 147 & 121 & 107 & 153 & 142 \\
\hline 1944 & 164 & 161 & 149 & 141 & 150 & 121 & 1113 & 168 & 148 \\
\hline 1945 & 164 & 166 & 157 & 148 & 154 & 130 & 114 & 163 & 152 \\
\hline 1946 & 172 & 172 & 163 & 155 & 158 & 132 & 115 & 165 & 156 \\
\hline 1947 & 174 & 174 & 165 & 159 & 158 & 138 & 118 & 176 & 160 \\
\hline 1948 & 175 & 178 & 175 & 163 & 161 & 145 & 124 & 181 & 166 \\
\hline 1949 & 177 & 183 & 180 & 168 & 169 & 152 & 134 & 180 & 170 \\
\hline 1950 & 183 & $183^{\prime}$ & 185 & 170 & 170 & $155^{\circ}$ & 139 & 192 & 174 \\
\hline 1951 & 183 & 191 & 189 & 171 & 174 & 156 & 149 & 192 & 177 \\
\hline 1952 & 191 & 192 & 192 & 172 & 175 & 161 & 158 & 197 & 181 \\
\hline 1953 & 195 & 197 & 198 & 175 & 177 & 163 & 173 & 203 & 185 \\
\hline 1954 & 196 & 195 & 201 & 173 & 176 & 175 & 178 & 209 & 188 \\
\hline 1955 & 198 & 201 & 207 & 177 & 175 & 180 & 192 & 211 & 192 \\
\hline 1956 & 202 & 205 & 209 & 182 & 179 & 188 & 196 & 218 & 197 \\
\hline 1957 & 205 & 207 & 212 & 184 & 178 & 197 & 197 & 222 & 199 \\
\hline 1958 & 207 & 212 & 216 & 189 & 178 & 193 & 199 & 225 & 202 \\
\hline 1959 & 211 & 217 & 216 & 201 & 190 & 203 & 206 & 229 & 207 \\
\hline 1960 & 214 & 220 & 220 & 201 & 194 & 206 & 208 & 225 & 209 \\
\hline 1961 & 211 & 221 & 221 & 207 & 199 & 207 & $2 \mathrm{Il}$ & 224 & 210 \\
\hline 1962 & 214 & 223 & 222 & 206 & 206 & 213 & 208 & 224 & 212 \\
\hline 1903 & 213 & 225 & 222 & 210 & 207 & 212 & 208 & 225 & 213 \\
\hline
\end{tabular}

Source:

Chickens and Eggs, Farm Production, Disposition, Cash Receipts and Cross Incone, 1962-63 and earl1er issues Statistical Reporting Service, U. S. Department of
Agriculture. 
APPENDIX TAIBL: XVIII. PRICES PAID BY FARMERS FOR LAYING WLISI PBR 100 POUIDS, SGLECTED STATIS AND U.S., 1935-64

\begin{tabular}{|c|c|c|c|c|c|c|c|c|c|}
\hline YEAR & PENNA. & MINN. & IOWA & VIRGINIA & พ. VA. & N. C. & GA. & CALIF. & บ. 3. \\
\hline & Dollars & Dollars & Dollars & Dollars & Dollars & Dollars & Dollars & Dollars & Dollars \\
\hline 1935 & & & 2.30 & 2.39 & & 2.63 & 2.45 & & 2.32 \\
\hline 1936 & 2.35 & 2.28 & 2.38 & 2.44 & 2.48 & 2.67 & 2.69 & 2.12 & 2.36 \\
\hline 1937 & 2.62 & 2.61 & 2.68 & 2.73 & 2.76 & 2.96 & 2.87 & 2.42 & 2.64 \\
\hline 1938 & 2.10 & 2.05 & 2.13 & 2.29 & 2.23 & 2.48 & 2.36 & 2.13 & 2.12 \\
\hline 1939 & 2.16 & 2.00 & 2.14 & 2.32 & 2.23 & 2.51 & 2.46 & 2.13 & 2.13 \\
\hline 1940 & 2.25 & 2.10 & 2.18 & 2.37 & 2.36 & 2.58 & 2.57 & 2.18 & c. 22 \\
\hline 1941 & 2.44 & 2.28 & 2.42 & 2.52 & 2.55 & 2.69 & 2.68 & 2.45 & 2.40 \\
\hline 1942 & 2.95 & 2.78 & 2.92 & 2.95 & 3.05 & 3.18 & 3.22 & 2.86 & 2.89 \\
\hline 1943 & 3.34 & 3.12 & 3.20 & 3.38 & 3.40 & 3.63 & 3.67 & 3.30 & 3.28 \\
\hline 1944 & 3.70 & 3.42 & 3.51 & 3.76 & 3.77 & 4.01 & 4.05 & 3.62 & 3.61 \\
\hline 1945 & 3.66 & 3.41 & 3.49 & 3.69 & 3.78 & 3.98 & 4.01 & 3.56 & 3.59 \\
\hline 1946 & 4.30 & 4.00 & 4.12 & 4.41 & 3.78 & 4.70 & 4.72 & 4.24 & 4.22 \\
\hline 1947 & 4.89 & 4.67 & 4.88 & 4.99 & 4.46 & 5.26 & 5.29 & 4.95 & 4.87 \\
\hline 1948 & 5.15 & 4.95 & 5.18 & 5.26 & 5.08 & 5.55 & 5.64 & 5.31 & 5.16 \\
\hline 1949 & 4.45 & 4.20 & 4.51 & 4.54 & 4.59 & 4.82 & 4.88 & 4.79 & 4.49 \\
\hline 1950 & 4.53 & 4.25 & 4.58 & 4.62 & 4.68 & 4.83 & 4.96 & 4.68 & 4.53 \\
\hline 1151 & 4.96 & 4.68 & 5.00 & 5.10 & 5.10 & 5.16 & 5.32 & 5.16 & 4.96 \\
\hline 1952 & 5.22 & 4.97 & 5.32 & 5.34 & 5.34 & 5.47 & 5.67 & 5.51 & 5.27 \\
\hline 1933 & 4.82 & 4.54 & 4.84 & 4.94 & 4.95 & 5.24 & 5.38 & 5.12 & 4.88 \\
\hline 1954 & 4.99 & 4.57 & 5.03 & 5.06 & 5.00 & 5.22 & 5.33 & 5.05 & 4.90 \\
\hline 1955 & 4.50 & 4.24 & 4.70 & 4.68 & 4.75 & 4.96 & 5.02 & 4.82 & 4.58 \\
\hline 1956 & 4.46 & 4.15 & 4.54 & 4.64 & 4.70 & 4.77 & 4.84 & 4.72 & 4.48 \\
\hline 1957 & 4.28 & 4.04 & 4.48 & 4.62 & 4.60 & 4.75 & 4.79 & 4.63 & 4.42 \\
\hline 1958 & 4.48 & 4.08 & 4.53 & 4.71 & 4.65 & 4.84 & 4.81 & 4.62 & 4.44 \\
\hline 1959 & 4.45 & 4.11 & 4.54 & 4.65 & 4.65 & 4.77 & 4.73 & 4.61 & 4.44 \\
\hline 1960 & 4.32 & 4.00 & 4,43 & 4.49 & 4.50 & 4.61 & 4.60 & 4.38 & 4.31 \\
\hline 1961 & 4.38 & 4.07 & 4.55 & 4.56 & 4.60 & 4.60 & 4.60 & 4.36 & 4.36 \\
\hline $\begin{array}{l}1962 \\
1963 \\
1964\end{array}$ & $\begin{array}{l}4.42 \\
4.54 \\
4.50\end{array}$ & $\begin{array}{l}4.15 \\
4.29 \\
4.22\end{array}$ & $\begin{array}{l}4.57 \\
4.70 \\
4.69\end{array}$ & $\begin{array}{l}4.54 \\
4.75 \\
4.70\end{array}$ & $\begin{array}{l}4.65 \\
4.74\end{array}$ & $\begin{array}{l}4.66 \\
4.70\end{array}$ & $\begin{array}{l}4.57 \\
4.69\end{array}$ & $\begin{array}{l}4.36 \\
4.43\end{array}$ & $\begin{array}{l}4.39 \\
4.4 .3\end{array}$ \\
\hline & & & 4.69 & 4.70 & 4.73 & 4.68 & 4.70 & 4.43 & 4.39 \\
\hline
\end{tabular}

Source:

"Agricultural Prices", issued monthly by Statistical Reporting Service, United States
Department of Agriculture. 
APEENDIX TABLE XTX, PRICTS RECEIVED BY FAPMITRS FOR EOCS, HTR DOZEN, BELFCTED STATFS, AND UN TTED STATES, $1925-63$.

\begin{tabular}{|c|c|c|c|c|c|c|c|c|c|}
\hline YEAR & PENNA. & MINN. & JoWA & VIRGINIA & W. VA. & N. C. & GA. & CALIF. & UPITED STATYS \\
\hline & Cents & Cents & Cents & Cents & Cent $\theta$ & Cente & Cent 5 & Cent 5 & Cents \\
\hline 1925 & 35.8 & 27.4 & 27.4 & 30.3 & 33.6 & 31.2 & 30.1 & 36.0 & 30.4 \\
\hline 1926 & 34.7 & 26.7 & 26.5 & 29.6 & 32.2 & 31.6 & 31.2 & 31.1 & 28.9 \\
\hline 1927 & 30.9 & 22.7 & 22.3 & 25.9 & 29.0 & 27.7 & 27.7 & 27.2 & 25.1 \\
\hline 1928 & 33.7 & 26.2 & 26.0 & 28.7 & 31.1 & 28.3 & 28.5 & 28.4 & 28.1 \\
\hline 1929 & 35.7 & 26.9 & 26.8 & 30.5 & 31.9 & 31.2 & 31.1 & 32.0 & 29.8 \\
\hline 1930 & 29.2 & 21.0 & 19.7 & 25.1 & 26.6 & 26.4 & 26.0 & 26.6 & 23.7 \\
\hline 1931 & 22.8 & 14.6 & 14.8 & 19.2 & 19.9 & 19.7 & 19.4 & 19.9 & 17.6 \\
\hline 1932 & 18.2 & 11.7 & 11.8 & 14.6 & 14.7 & 15.0 & 15.4 & 17.2 & 14.2 \\
\hline 1933 & 17.6 & 11.5 & 11.1 & 14.8 & 15.0 & 15.3 & 15.3 & 17.2 & 13.8 \\
\hline 1934 & 20.8 & 14.4 & 14.3 & 18.0 & 18.0 & 19.2 & 18.9 & 19.0 & 17.0 \\
\hline 1935 & 26.4 & 21.4 & 21.3 & 23.0 & 22.8 & 23.0 & 23.0 & 25.2 & 23.4 \\
\hline 1936 & 25.7 & $19.3^{\circ}$ & 18.8 & 22.3 & 22.4 & 23.7 & 23.2 & 23.2 & 21.8 \\
\hline 1937 & 24.9 & 18.2 & 18.3 & 21.6 & 22.1 & 22.7 & 23.0 & 23.9 & 21.3 \\
\hline 1938 & 24.5 & 17.4 & 17.0 & 20.5 & 21.0 & 21.8 & 21.7 & 23.9 & 20.3 \\
\hline 1939 & 21.8 & 14.2 & 13.6 & 18.3 & 18.7 & 19.5 & 19.2 & 21.6 & 17.4 \\
\hline 1940 & 22.6 & 15.0 & 14.4 & 19.4 & 19.3 & 19.9 & 19.8 & 20.3 & 18.0 \\
\hline 1941 & 27.4 & 20.9 & 20.6 & 24.0 & 24.2 & 24.4 & 23.9 & 27.8 & 23.5 \\
\hline 1942 & 34.1 & 28.1 & 27.8 & 29.7 & 29.9 & 28.9 & 28.5 & 34.0 & 30.0 \\
\hline 1943 & 41.8 & 35.0 & 34.7 & 37.3 & 36.7 & 36.3 & 36.6 & 42.2 & 37.1 \\
\hline 1944 & 36.0 & 30.2 & 29.8 & 32.9 & 32.4 & 33.9 & 34.6 & 37.6 & 32.5 \\
\hline 1945 & 45.2 & 34.4 & 33.1 & 39.5 & 40.8 & 40.4 & 42.1 & 43.4 & 37.7 \\
\hline 1946 & 44.3 & 33.4 & 32.6 & 40.1 & 41.8 & 41.6 & 42.9 & 44.8 & 37.6 \\
\hline 1947 & 53.4 & 39.4 & 38.5 & 47.5 & 48.9 & 48.0 & 50.5 & 53.5 & 45.3 \\
\hline 1948 & 58.0 & 40.3 & 40.0 & 49.2 & 51.2 & 50.3 & 53.1 & 54.8 & 47.2 \\
\hline 1949 & 53.3 & 39.0 & 38.6 & 48.1 & 48.7 & 48.6 & 50.6 & 51.4 & 45.2 \\
\hline 1950 & 44.4 & 30.2 & 29.2 & 38.4 & 39.1 & 40.0 & 43.1 & 41.5 & 36.3 \\
\hline 1951 & 56.8 & 40.8 & 39.7 & 53.1 & 51,9 & 53.0 & 54.9 & 54.2 & 47.7 \\
\hline 1952 & 50.8 & 34.9 & 32.6 & 47.6 & 47.0 & 47.0 & 49.4 & 47.0 & 41.6 \\
\hline 1953 & 55.0 & 41.6 & 39.9 & 52.2 & 50.6 & 51.8 & 54.5 & 53.2 & 47.7 \\
\hline 1954 & 44.7 & 29.2 & 28.2 & 45.0 & 44.3 & 44.0 & 44.8 & 38.5 & 36.6 \\
\hline 1955 & 46.0 & 32.6 & 31.9 & 45.8 & 42.3 & 45,2 & 52.2 & 41.7 & 39.5 \\
\hline 1956 & 45.4 & 31.9 & 31.9 & 46.5 & 44.6 & 44.2 & 52.9 & 39.6 & 39.3 \\
\hline 1957 & 42.0 & 28.3 & 28.1 & 42.4 & 40.7 & 42.8 & 47.7 & 36.9 & 35.9 \\
\hline 1958 & 44.1 & 29.6 & 30.3 & 46.4 & 44.2 & 46.8 & 52.3 & 38.9 & 38.5 \\
\hline 1959 & 36.1 & 22.9 & 23.3 & 37.1 & 37.1 & 37.7 & 41.4 & 31.5 & 31.4 \\
\hline 1960 & 40.9 & 27.4 & 28.0 & 43.3 & 41.1 & 42.0 & 48.2 & 35.6 & 36.0 \\
\hline 1962 & 39.9 & 27.3 & 27.8 & 39.9 & 41.4 & 41.2 & 44.7 & 33.7 & 33.4 \\
\hline $\begin{array}{l}1962 \\
176^{\circ}\end{array}$ & $\begin{array}{r}38.4 \\
37.8\end{array}$ & $\begin{array}{c}25.9 \\
25.3^{9}\end{array}$ & $\begin{array}{r}25.9 \\
20.4\end{array}$ & $\begin{array}{r}39.9 \\
40.2\end{array}$ & $\frac{39.1}{40.2}$ & $\begin{array}{r}39.6 \\
34.9\end{array}$ & $\begin{array}{r}43.8 \\
43.2\end{array}$ & $\begin{array}{l}30.4 \\
31.4\end{array}$ & $\begin{array}{l}33.7 \\
34.4\end{array}$ \\
\hline
\end{tabular}




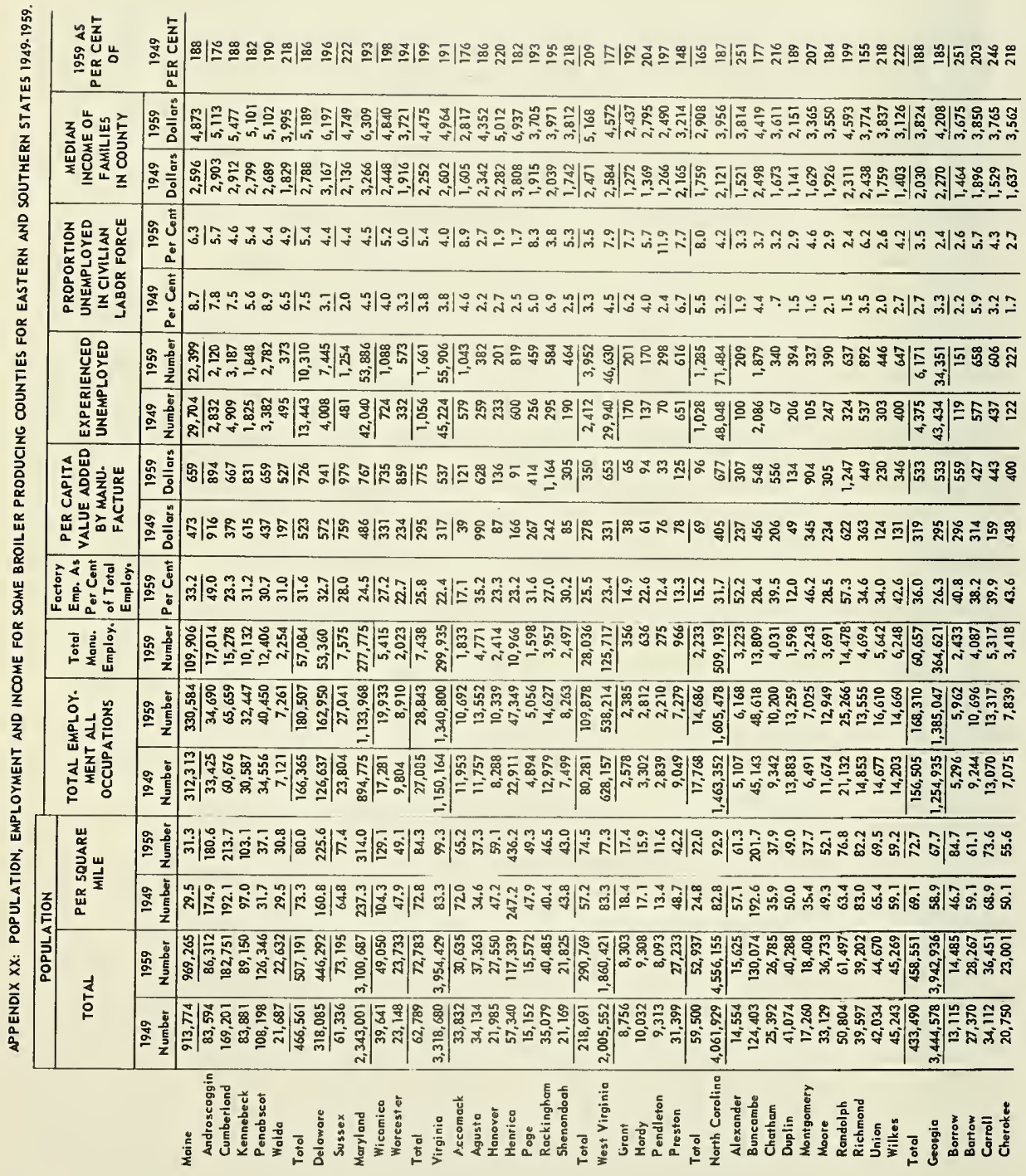




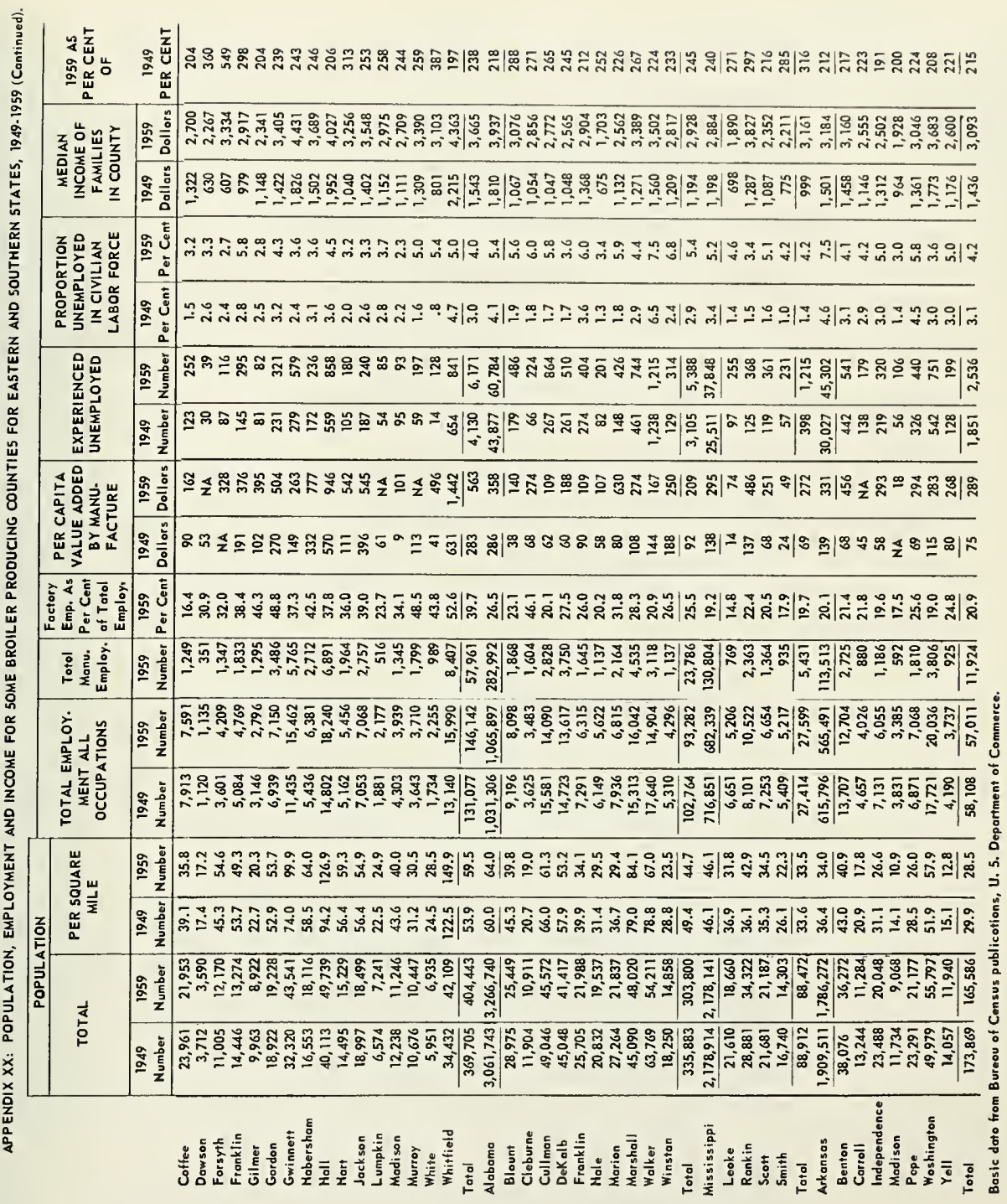




\begin{tabular}{|c|c|c|c|}
\hline & 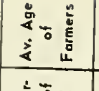 & 高 & 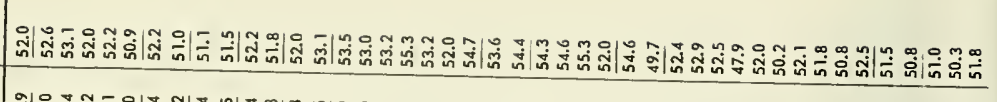 \\
\hline \multirow{2}{*}{ 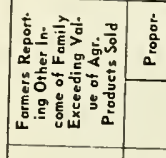 } & 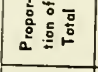 & $\begin{array}{r}50 \\
\vdots \\
\vdots \\
\vdots \\
0\end{array}$ & 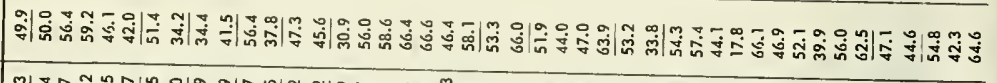 \\
\hline & & 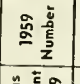 & 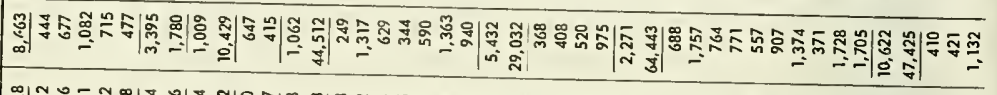 \\
\hline & \multirow{3}{*}{ 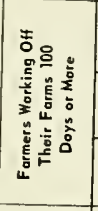 } & $\begin{array}{ll}0 \\
0\end{array}$ & 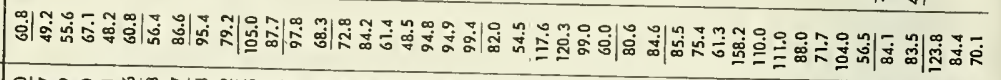 \\
\hline & & 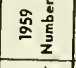 & 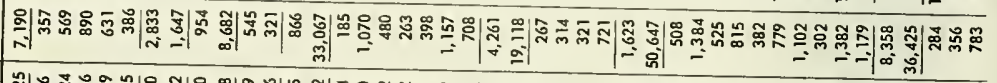 \\
\hline & & 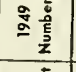 & 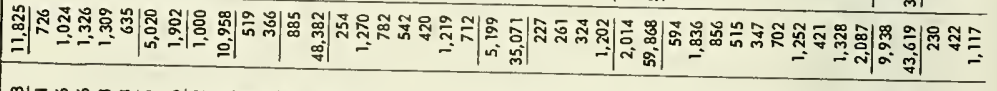 \\
\hline & \multirow{2}{*}{ 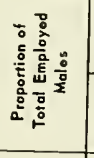 } & 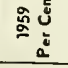 & 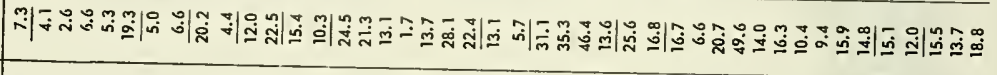 \\
\hline & & 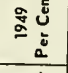 & 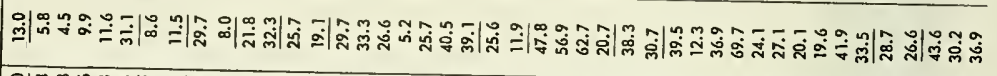 \\
\hline & \multirow{2}{*}{ 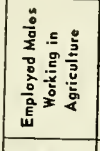 } & 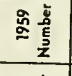 & 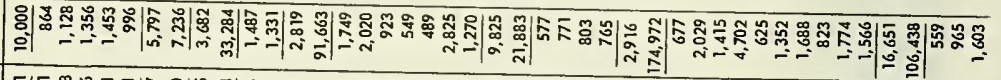 \\
\hline & & 票旁 & 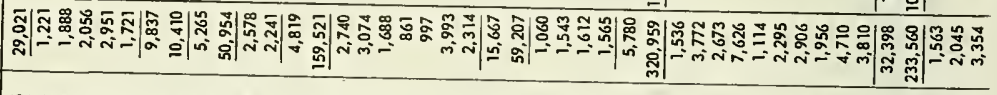 \\
\hline & $\begin{array}{ll}0 \\
0\end{array}$ & $\begin{array}{r}50 \\
05 \\
0 \\
0 \\
0\end{array}$ & 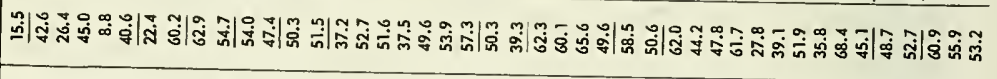 \\
\hline & \multirow{2}{*}{ 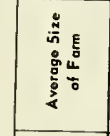 } & 离童 & 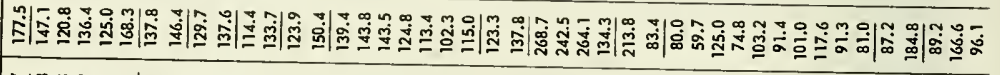 \\
\hline & & 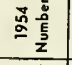 & 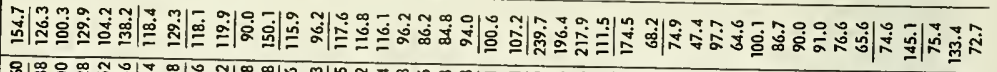 \\
\hline & \multirow{2}{*}{ 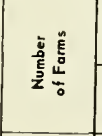 } & 至 & 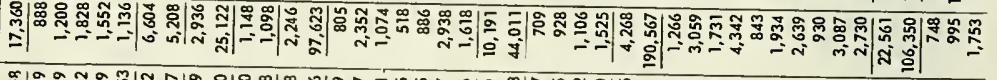 \\
\hline & & 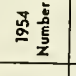 & 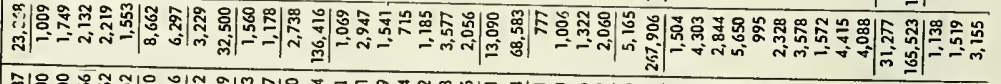 \\
\hline & \multirow{2}{*}{ 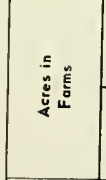 } & 量 & 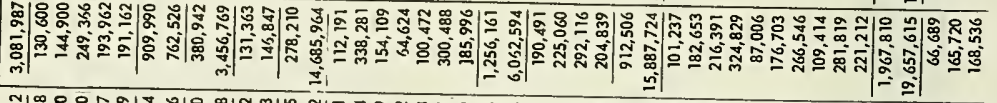 \\
\hline & & 高旁旁 & 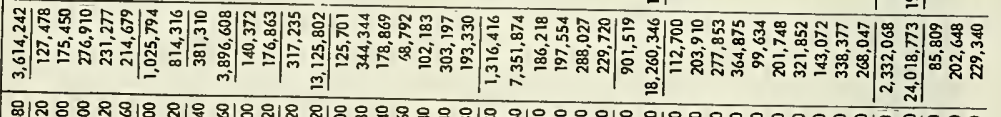 \\
\hline & 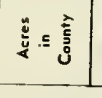 & 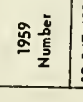 & 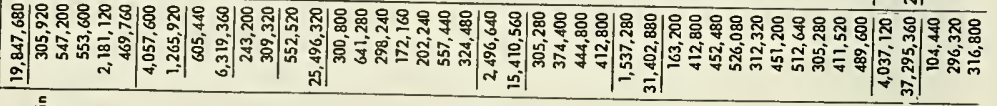 \\
\hline
\end{tabular}




\begin{tabular}{|c|c|c|}
\hline 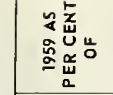 & 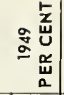 & 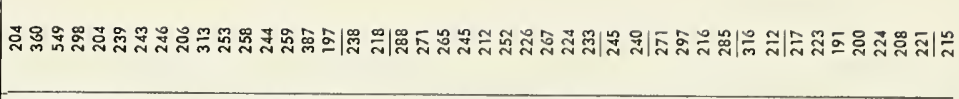 \\
\hline \multirow{2}{*}{ | } & $\mid$ & 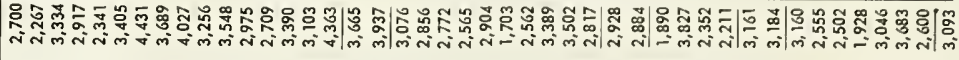 \\
\hline & $\frac{2}{2}$ & 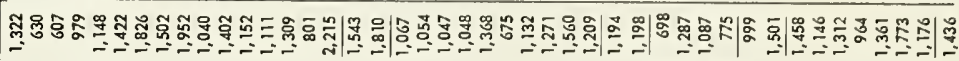 \\
\hline \multirow{2}{*}{ 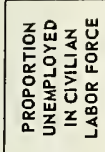 } & 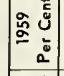 & 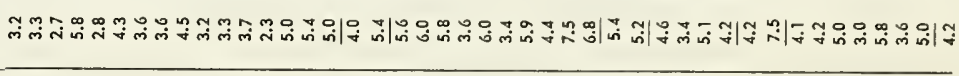 \\
\hline & 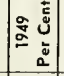 & 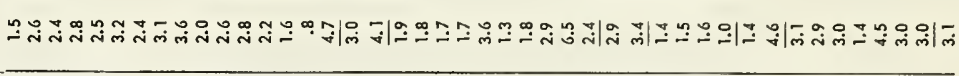 \\
\hline \multirow{2}{*}{ 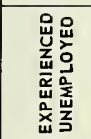 } & 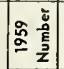 & 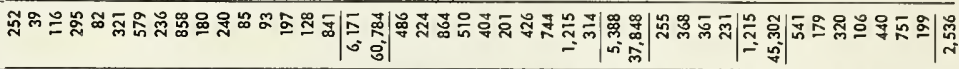 \\
\hline & 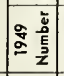 & 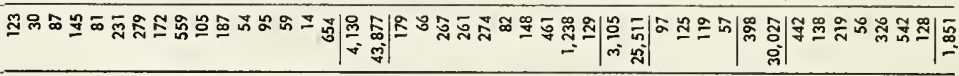 \\
\hline \multirow{2}{*}{ 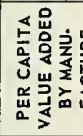 } & 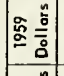 & 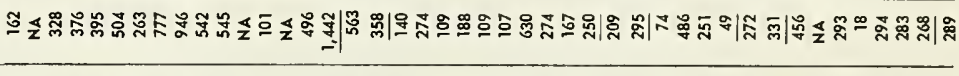 \\
\hline & 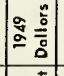 & 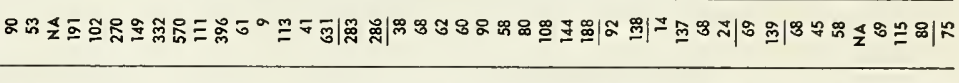 \\
\hline 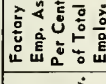 & 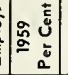 & 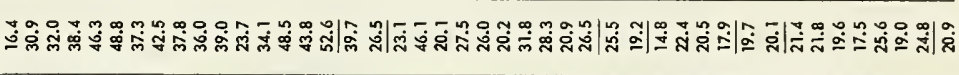 \\
\hline 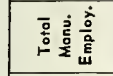 & 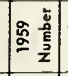 & 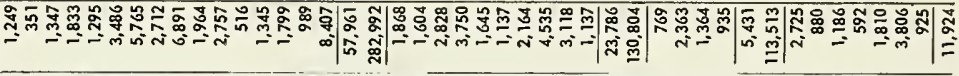 \\
\hline \multirow{2}{*}{ 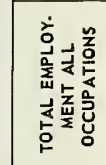 } & 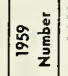 & 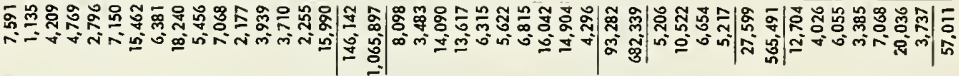 \\
\hline & 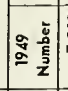 & 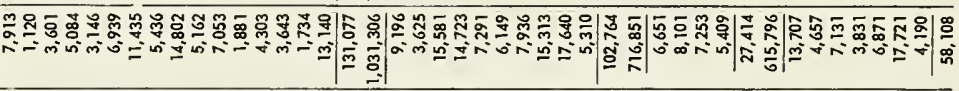 \\
\hline \multirow{2}{*}{ 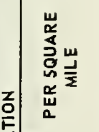 } & 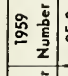 & 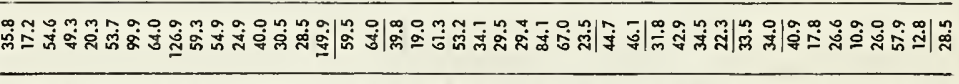 \\
\hline & $\mid$ & 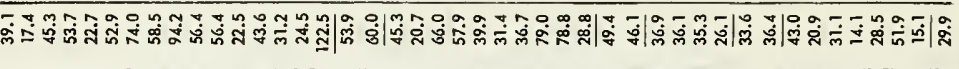 \\
\hline \multirow{2}{*}{5} & 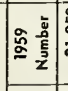 & 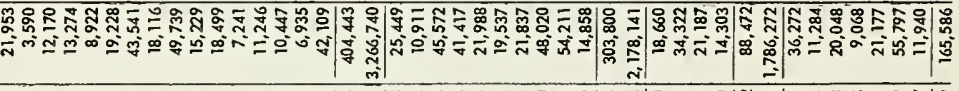 \\
\hline & 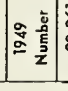 & 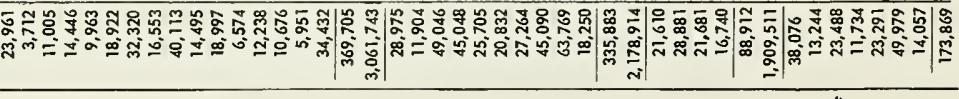 \\
\hline
\end{tabular}




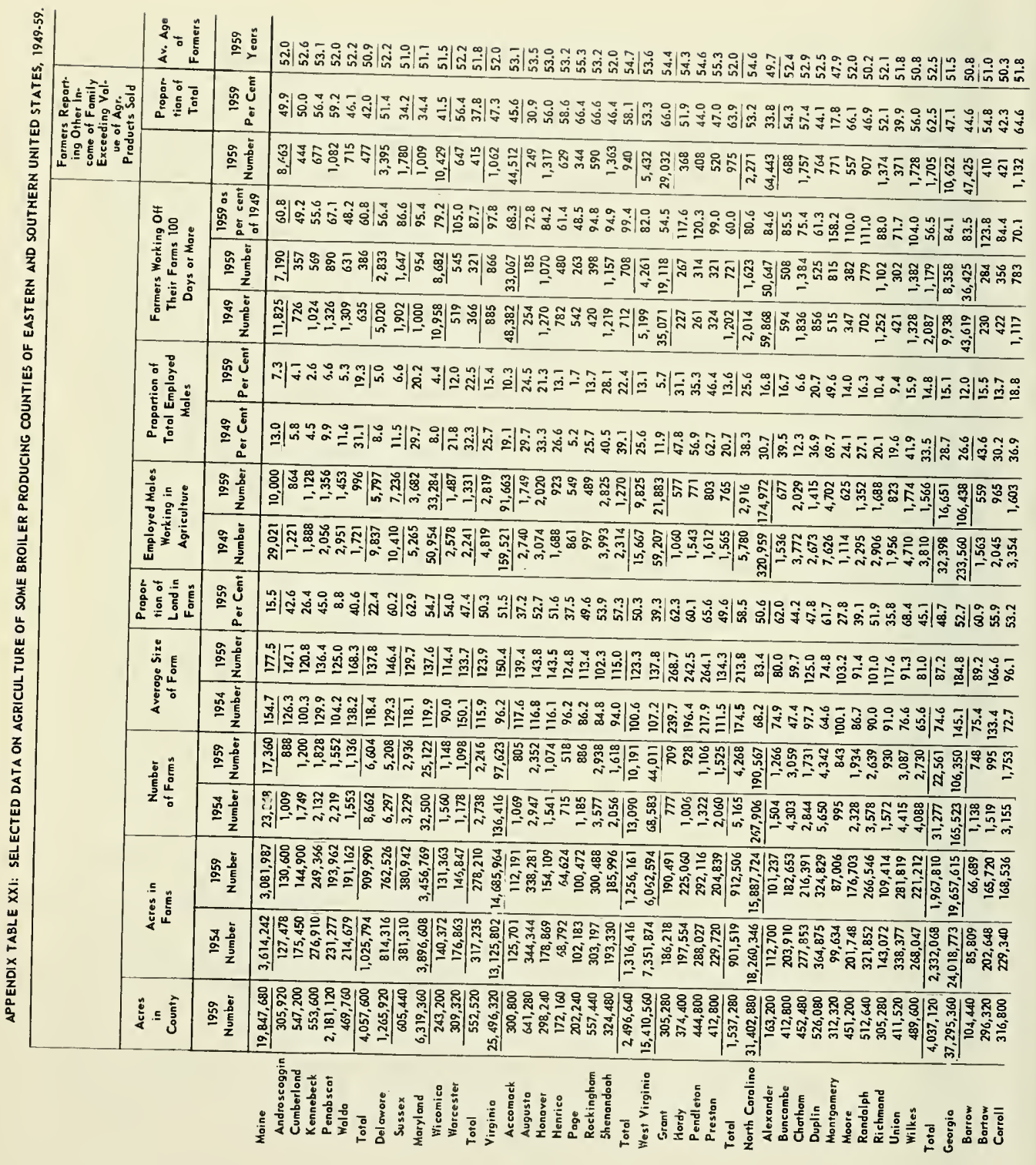




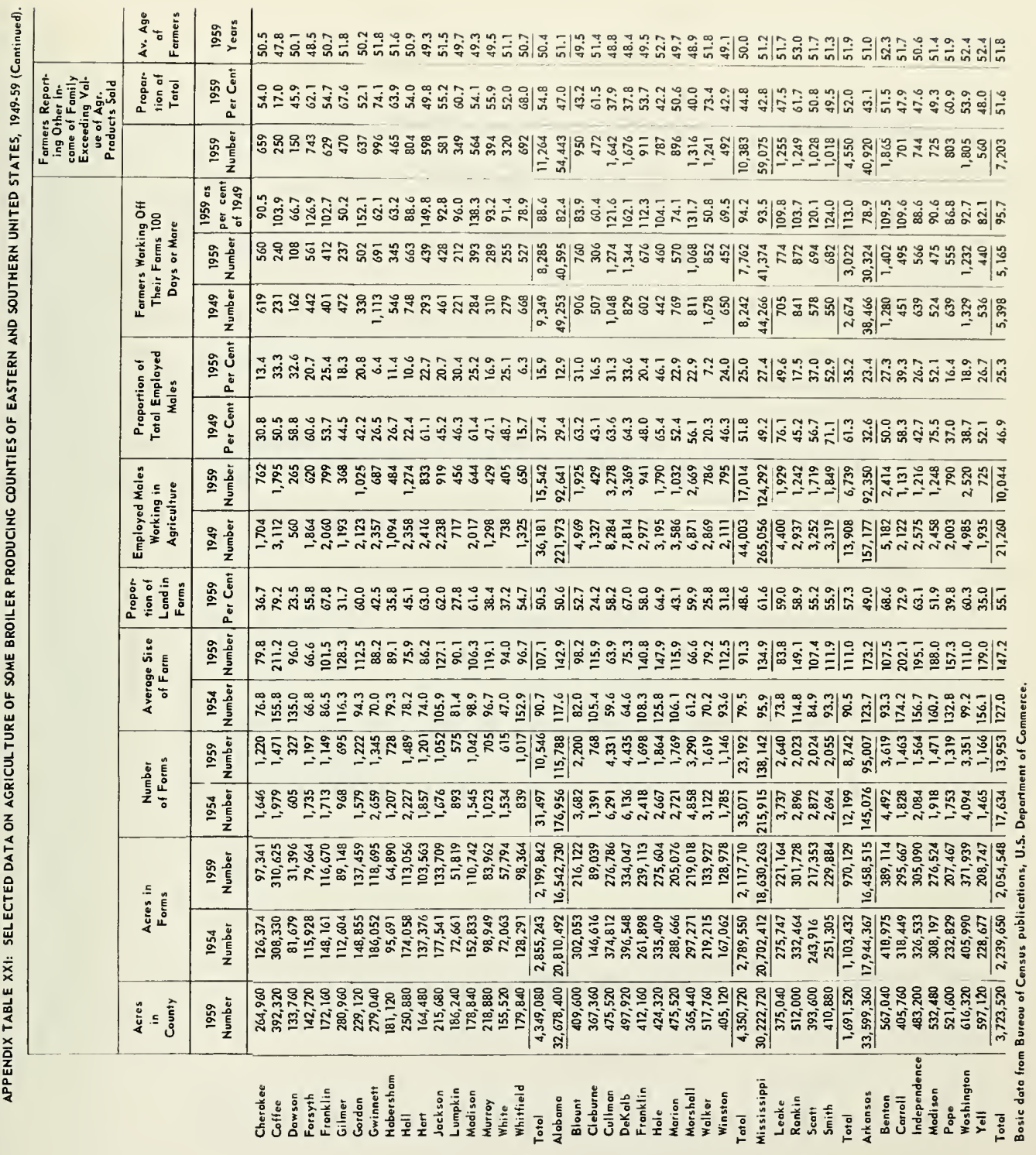




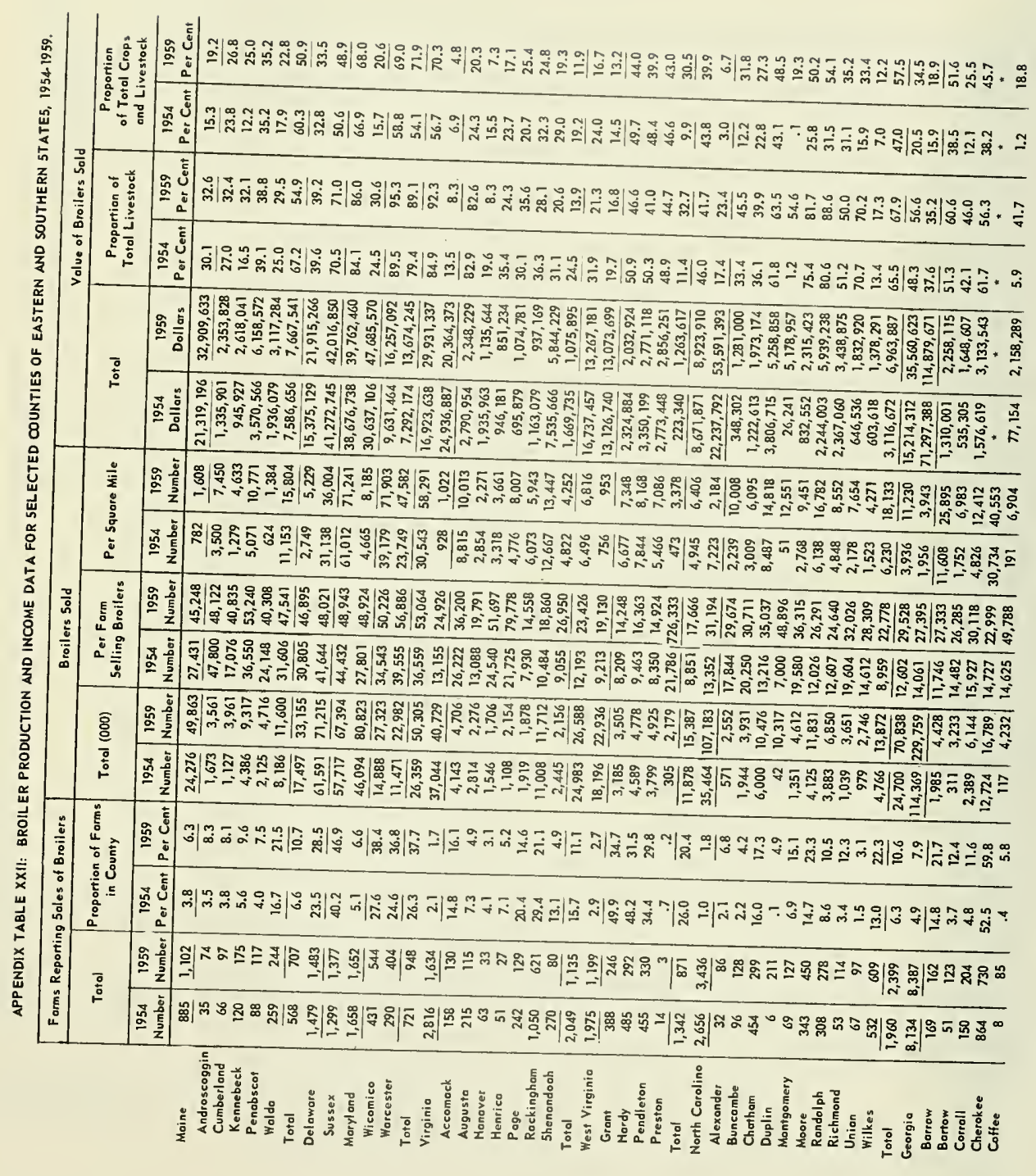




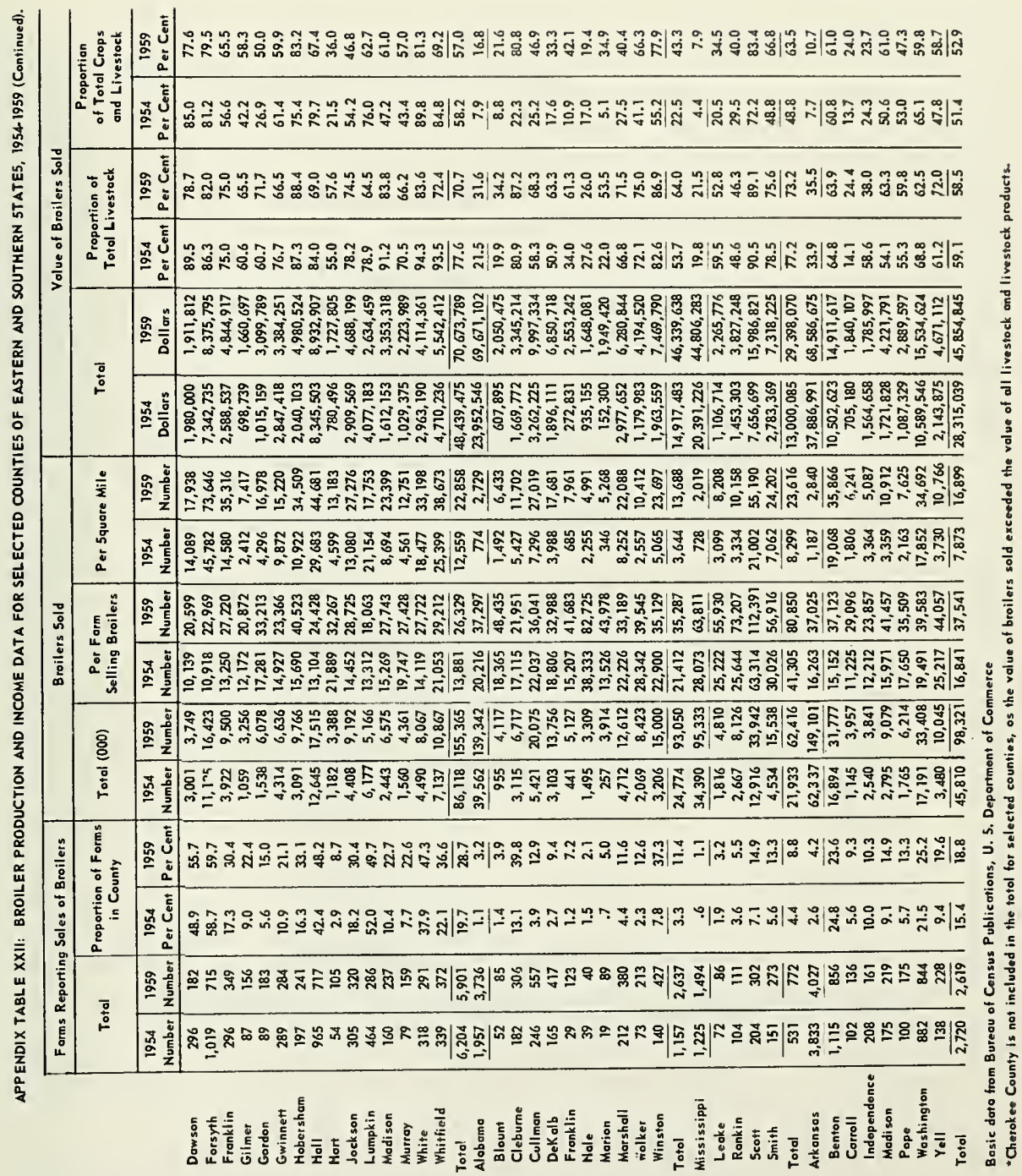




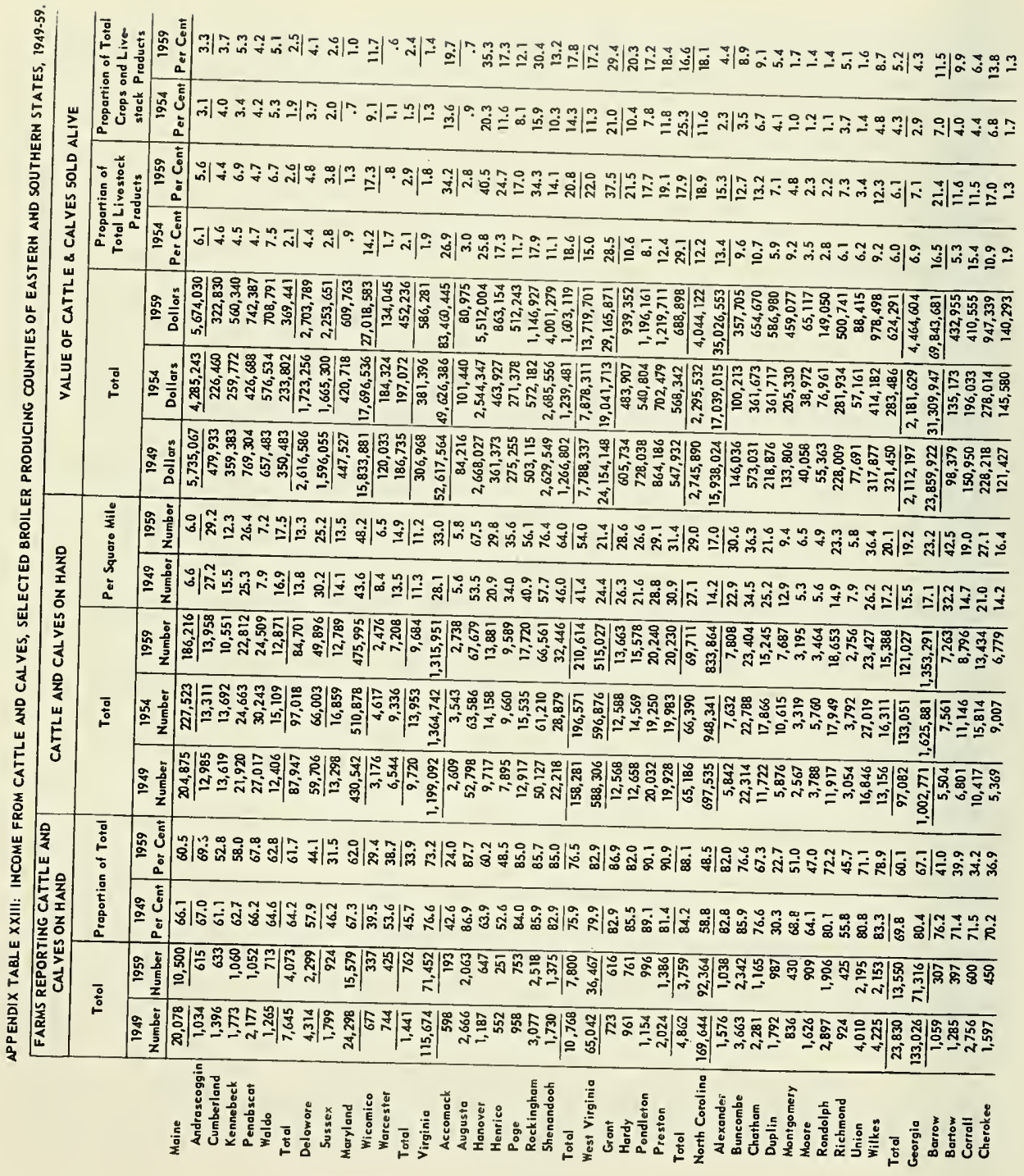




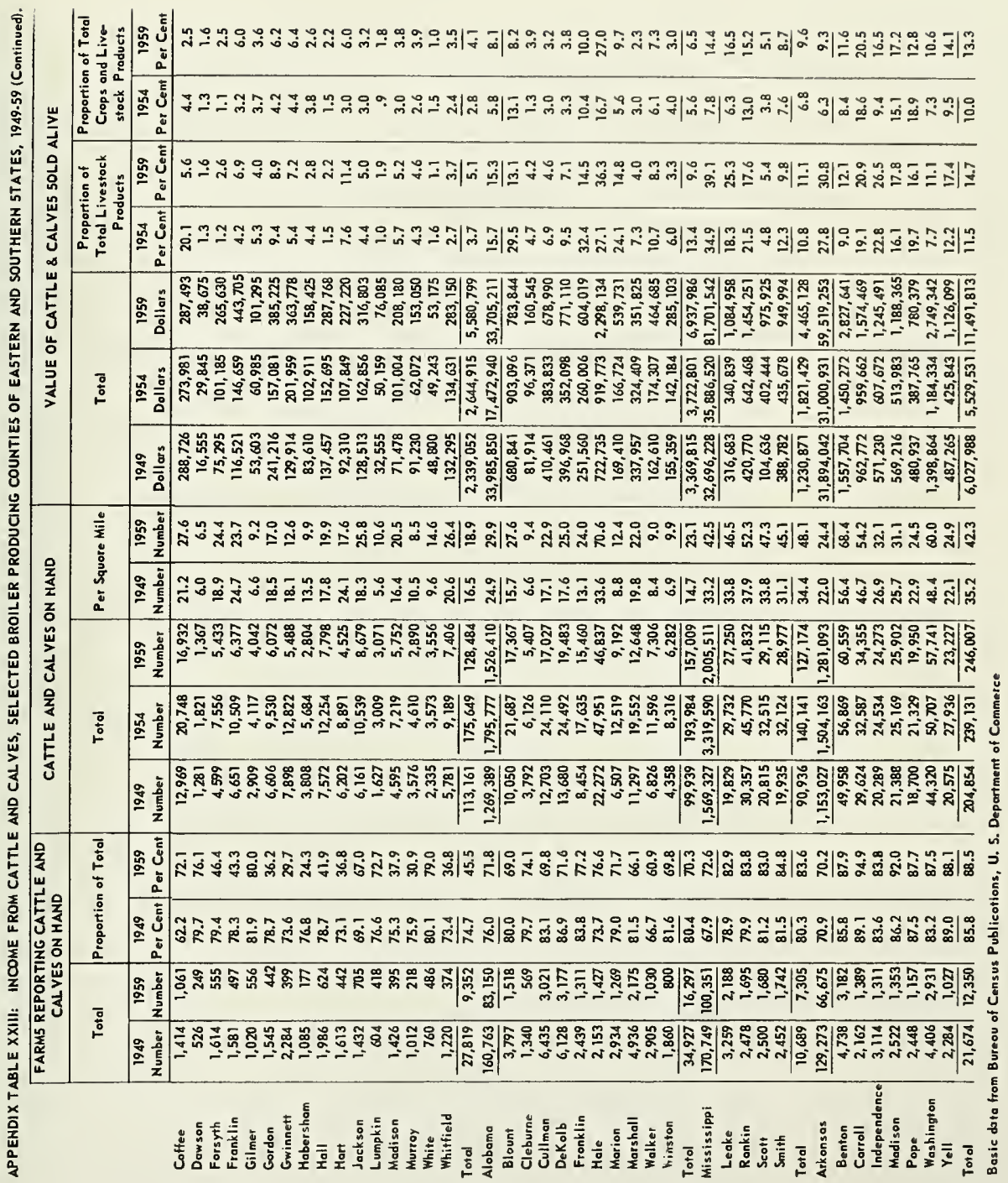




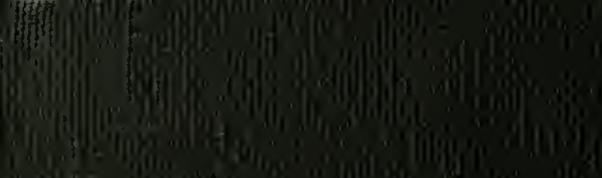

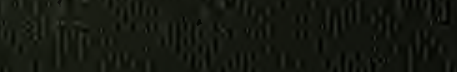

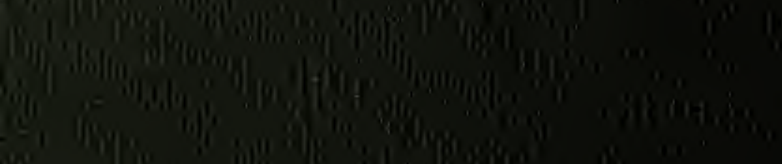

(60.

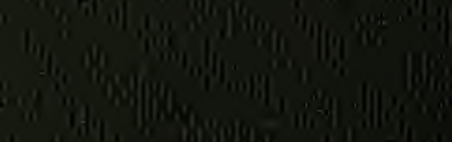

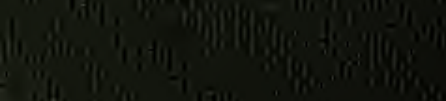

4

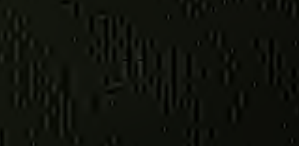

is

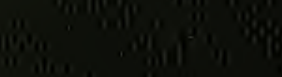

"

$-1$

19

ing

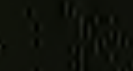

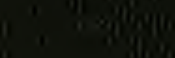

(1) 1979

(3) in 17

FI

(1)

$a^{1}$

antion

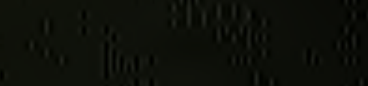

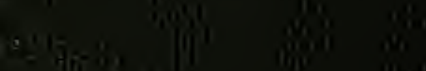

in 8 inl

Sil

, 190

ing

(6)

yon 